\title{
Measuring Sports Class Learning Climates - the development of the Sports Class Environment Scale
}

\author{
Trevor John Dowdell \\ MEdSt BEd DipT(PE) GradDipOHS
}

Submitted in fulfillment of the requirements for the degree of Doctor of Education

Education and Professional Studies (Brisbane, Logan)

Faculty of Education

Griffith University

March 2007 
This work has not previously been submitted for a degree or diploma in any university. To the best of my knowledge and belief, the thesis contains no material previously published or written by another person except where due reference is made in the thesis itself. 


\section{ABSTRACT}

Teaching (in this study, coaching) is a key determinant in learning any sports skill. The coach-athlete relationship is one of the most important influences on athlete's motivation and performance (Mageau \& Vallerand, 2003). One of the key leadership roles the coach has in this relationship is the creation and maintenance of the sports class learning climate. The joint influence of the athlete's motivation and the environmental press (class learning climate) can determine the cognitive, affective, and performance patterns regularly displayed by athletes (Ntoumanis \& Biddle, 1999).

A sports class' learning climate is a set of internal characteristics that has an important role in shaping an athlete's motivational and behavioural pattern (Ames, 1992) and is a key characteristic of class effectiveness. In sports classes, motivational climate is a sub-set of the overall learning climate and is created primarily by the sport class coach. Motivational climate can be described as the participants' relatively persistent collective perceptions of the achievement goal structure of that setting.

Recent studies of motivational climate in sport have provided insight into coaching behaviour and its effect on sports class motivational climate (Ntoumanis \& Biddle, 1999). In spite of the potential value of class learning climate research to the field of sports class behavioural studies, no research has consolidated the fields of classroom learning climate research and sports class motivational climate studies. This study provides a model for the investigation of gymnastics sports class learning climates that involves a consolidation of the dimensions and items of the Perceived Motivational Climate in Sport Questionnaire-2 (Newton, Duda, \& Yin, 2000) and the Classroom Environment Scale (Moos \& Trickett, 1987). The development and validation of a new, unique learning climate scale - the Sports Class Environment Scale (SCES) - constitutes the focus of this research.

The process of developing this consolidated instrument began with the production of an initial scale, and was followed by a review by a panel of experts in coaching and 
independent university researchers in sport and physical education. The SCES draft was then pilot tested with a small group $(n=41)$ of competitive gymnasts to prompt some changes to the scale. Initial field-testing of the SCES occurred with 28 male and 180 female competitive gymnasts from 6 metropolitan and 4 regional competitive gymnastics clubs in Queensland, Australia. Exploratory factor analysis provided a revised SCES with five subscales labeled Task Involvement and Improvement, Ego Involvement and Mistakes, Coach-Athlete Communication, Effort, Order and Organization, and Affiliation. Using the revised SCES subscales as dependent variables, multivariate analyses of variance were conducted to compare club type, gender, and competitive level. In this study, the low training hours and the high training hours gymnastics classes were different in their perceptions of the Ego Involvement of their class climate. Male and female gymnasts were different in their perceptions of Ego Involvement, Affiliation, and Effort, Order and Organization aspects of their class climates. This study demonstrates the potential utility of creating class learning climates high in both Task Involvement and Ego Involvement for competitive gymnastics clubs.

This study breaks new ground, and may lead to novel insights into sports class learning climates. Because class learning climate is easier to manipulate than individual achievement goal dispositions (Whitehead, Andree, \& Lee, 1997) and because perceptions of learning climate account for variance in learning outcomes beyond that attributable to student ability (Fraser, 1994, 1998, 2002), class learning climate is an important variable that should be better understood, described, developed, and manipulated. Effective measurement of sports class learning climates using the SCES may lead to a greater understanding of effective sports classes, and of coach and athlete behaviours in those classes, and provides a first step in monitoring sports class learning climates. 


\section{TABLE of CONTENTS}

LIST of TABLES and FIGURES

pages $x-x i$

ACKNOWLEDGEMENTS

page xii

1.0 INTRODUCTION

pages 1 - 11

1.1 Physical activity, sport and the benefits for children

page 1

1.2 Learning climate defined

page 2

1.3 Motivational climate defined

page 3

$1.4 \quad$ Effective sports classes

page 4

1.5 The gymnastics sports context

page 7

1.6 Measuring learning climate in sports classes

page 8

1.7 Benefits of this study for practice

page 9

1.8 Aim of the study

page 10

1.9 Objectives of the study

page 10

2.0 LITERATURE REVIEW

pages 12 - 48

2.1 Behaviour-Environment perspectives

page 12

2.2 Class learning climate

page 15

2.3 Motivational climate in sport classes and physical

page 16 education classes

2.4 Climate measurement questions

page 19

2.4.1 Distinction between organizational climate and

page 19 class learning climate

2.4.2 Unit of analysis question

page 21

2.4.3 Dimensions of analysis question

page 21

2.5 Assessing classroom learning climate

page 25

2.5.1 Classroom learning climate instruments

page 25 
2.5.2 Validation of the short forms of learning climate scales page 28

2.5.3 Scoring learning climate and motivational climate scales page 29

2.5.4 Classroom learning climate measurement research page 30

2.5.5 Method of instrument development and investigation page 33

2.6 Assessing motivational climate in sport page 34

2.6.1 Sports class motivational climate instruments page 34

2.6.2 The context specific nature of sports class motivational page 39 climate

2.6.3 Sports motivational climate measurement research page 39

2.7 A model for the structure of a sports class learning page 42 climate scale

2.8 The development of a sports class learning environment page 45 scale (SCES)

2.8.1 Summary

page 47

3.0 METHOD

pages $49-58$

3.1 Introduction page 49

3.2 Develop the initial SCES instrument page 50

3.2.1 Create an initial SCES.

Page 50

3.2.2 Review the initial SCES subscales and scoring.

Page 50

3.2.3 Adding PMCSQ-2 subscales to the initial SCES

page 51

3.2.4 Send the first draft SCES for expert review.

page 52

3.2.5 Survey Readability

page 53

3.3 Administer the drafts of the SCES

page 54

3.3.1 Pilot study of the first draft SCES

page 54

3.3.2 Analyze the first draft SCES for internal reliability

page 54 
3.3.3 Administer the second draft SCES to a cohort of page 55 gymnastic classes

3.3.4 Code and rate the second draft SCES survey data page 55

3.4 Test the second draft subscales and modify the SCES page 56

3.4.1 Conduct an exploratory factor analysis and revise page 56 the SCES

3.4.2 Test the SCES subscales for internal reliability and page 56 discriminant validity

3.4.3 The class learning climate of competitive gymnastics page 57 sports classes

3.4.4 Modify the second draft SCES based on findings

page 58

4.0 ANALYSES and RESULTS

pages 59 - 70

4.1 Introduction page 59

4.2 Results from the learning climate survey of competitive page 60 gymnastics sports classes

4.2.1 The participants page 60

4.2.2 Results of the second draft SCES survey page 61

4.3 Results of the factor analysis of the second draft SCES page 64

4.4 Internal reliability and discriminant validity of the page 65 modified SCES

4.5 Club type, competitive level and learning climate page 66

4.6 Gender, competitive level and learning climate page 68

\subsection{DISCUSSION}

pages $71-94$

5.1 Introduction page 71 
5.2 Discussion of findings

page 71

5.2.1 Class learning climate profiles

page 71

5.2.2 Club type and motivational climate

page 73

5.2.3 Gymnast competitive level and motivational climate

page 74

5.2.4 Gymnast gender and motivational climate

page 74

5.2.5 Are achievement goal dimensions orthogonal?

Page 76

5.2.6 Should a task mastery orientation in sports class

page 78 learning climate be always fostered?

5.2.7 Other subscale dimensions in the revised SCES

page 79

\subsection{Contributions of the study}

page 80

5.4 The modified SCES instrument

page 84

5.5 Limitations

page 87

5.6 Directions for future research

page 90

5.7 Recommendations for sports class "Best Practice" page 94

5.7.1 Discover the gymnast's achievement goal disposition page 94

5.7.2 Measure the sports class learning climate page 94

5.7.3 Regularly monitor the actual sports class learning climate page 95

5.7.4 Promote a task-involved learning climate in skill classes page 95

5.7.5 Combine a task-involved class learning climate with a page 96 moderate to high level of ego-involved climate

5.7.6 Dealing with a gymnast's loss of perceived competence page 97

5.7.7 Promote affiliation among class members page 97

5.7.8 Effective coach-gymnast communication is a key page 98 aspect of sports class learning climate

\subsection{Concluding remarks}

page 98 
APPENDIX 1 Class Environment Scale - student actual short form page 104

APPENDIX 2 Perceived Motivational Climate in Sport Questionnaire-2 page 105 APPENDIX 3 Expert coaches \& educators' questionnaire about page 107 the draft SCES

APPENDIX 4 Second draft Sports Class Environment Scale page 109

APPENDIX 5 Gymnastics Queensland permission to conduct page 113 research

APPENDIX 6 Sample club contact seeking expressions of page 114 interest to participate

APPENDIX 7 Formal agreement with participating club page 115 APPENDIX 8 Survey package sent to clubs page 116 APPENDIX 9 Reliability Analysis of draft SCES scale used in pilot study page 121 APPENDIX 10 Second draft SCES subscales Frequency Table page 122 APPENDIX 11 Factor analysis of the second draft SCES scale page 130 APPENDIX 12 Reliability analysis of modified SCES subscales page 133 APPENDIX 13 MANOVA - Club Type (low training hours \& page 138 high training hours) and competitive gymnastics level APPENDIX 14 MANOVA - low training hours clubs and gender page 145 APPENDIX 15 The Sports Class Environment Scale page 156

\section{REFERENCES}

pages $159-168$ 


\section{LIST of TABLES and FIGURES}

\section{Tables}

Table 2.1 Climate dimensions from three types of social environments

page 22

Table 2.2 A description of each of the behavioural subscales in the CES Scale

page 23

Table 2.3 Descriptions of mastery and performance climates in accordance with the TARGET structures

page 24

Table 2.4 Overview of seven class learning climate scales

page 26

Table 2.5. Overview of four physical activity motivational climate scales

page 38

Table 2.6 A description of each of the subscales in the draft SCES

page 47

Table 3.1 Means and standard deviations for all clubs and club type

page 58

Table 4.1. Description of cohort by gender, competitive level, and training hours

page 60

Table 4.2 Means and standard deviations for all clubs and club type

page 61

Table 4.3 Descriptive summary of second draft SCES item scores

page 62

Table 4.4 Descriptive statistics for second draft SCES subscale scores

page 63

Table 4.5 Rotated component matrix arranged in component groups

page 65

Table 4.6

Cronbach's Alphas and Inter-Item correlation means for revised SCES subscales

page 66

Table 4.7 Multivariate tests of club type and competitive level

page 67

Table 4.8 Tests of between-subjects effects of club type and competitive level

page 68

Table 4.9 Ego and Task Involvement subscale mean scores for club types and all clubs

page 69

Table 4.10 Multivariate tests of club type, gender and competitive level

page 69

Table 4.11 Tests of between-subjects effects of club type (low training hours) and gender

page 70

Table 4.12 SCES subscale means scores for club type (low training hours) and gender

page 71

The modified SCES

page 87 


\section{Figures}

$\begin{array}{lll}\text { Figure 1.1 A model of coaching effectiveness } & \text { page } 6\end{array}$

Figure 2.1 An achievement motivation framework for sport $\quad$ page 18

Figure 2.2 A model for the structure of sports class learning page 43 climate

Figure 3.1 Phases and steps in the study $\quad$ page 49

Figure 4.1 Phases and steps in the study $\quad$ page 59

Figure 5.1 Queensland competitive gymnastics club class climate profiles page 73

Figure 5.2 A revised model for the structure of sports class learning page 92 climate 


\section{ACKNOWLEDGEMENTS}

The author gratefully acknowledges the influence, effort and support of several people.

Thank you to the study supervisors, Dr. L. Michaud Tomson and Dr. Michael Davies for their careful editing of the text, patience with the study progress, and for being professional mentors par excellence.

Thank you to Dr. Peter Grimbeek for his significant comments on the study method, and the on-going statistical advice given through out the life of the study.

Recognition of Dr. Jack Genn (University of Queensland) for his early influence in the study of learning environments.

Thank you to Gymnastics Queensland, and in particular the Executive Director Mr. Wayne Hill, for permission to conduct the study within member clubs. A grateful acknowledgement is given to the gymnastic clubs, coaches and gymnasts who participated so willingly in the study.

Finally, to my wife, Laureen Tkacik, who patiently helped with data collation and entry, and contributed much with skillful editing and constant support. 


\section{$1.0 \quad$ INTRODUCTION}

\subsection{Physical activity, sport and the benefits for children}

Recent research revealed poor fundamental motor skill performances among Australian and New Zealand primary school children (Booth, Macaskill, \& McLellan, 1997; Sanders \& Kidman, 1998; Walkley, Holland, Treloar, \& Probyn-Smith, 1993). Despite a reported improvement in fundamental motor skills scores since 1997 (Booth, Okely, Denney-Wilson, Dobbins, \& Yang, 2004) trends of declining fitness and rising proportions of overweight Australian children have been observed (Booth et al., 1997; Tomkinson, Olds, \& Gulbin, 2003), with obesity not only increasing, but also accelerating (Booth, et al., 2004). Moreover, clubs and schools report a decline in organised sport participation since the mid 1990's (Norton, Dollman, Klanarong, \& Robertson, 2001). Hence, the reduction in physical activity, including play and participation in sporting activities, would seem to be having a deleterious effect on the health, fitness and motor skill development of Australian children. With physical activity and sport so important to the growth and development of children, it is critical to provide the best opportunities for the benefits of physical activity to accrue. For these opportunities to be fully utilised, the psychology of the child participant must be considered (Tremayne \& Tremayne, 2004).

There has been considerable research about psychological factors that may influence participation in sport and physical education, and the adaptive and maladaptive behavioural outcomes of this participation (Tremayne \& Tremayne, 2004). These studies fall broadly into two areas, individual factors and environmental factors. Individual factors are learning strategies such as goal setting, self-talk, arousal regulation, imagery, anxiety management, coping skills, and self-monitoring of progress. Environmental factors can include feedback and reinforcement, modelling, coach and parent behaviours, and motivational climate of the setting (task mastery involvement or ego involvement). 
This study focuses on an environmental factor, specifically the learning and motivational climate created by the coach in the class setting. Descriptions of class learning climate and motivational climate follow.

\section{$1.2 \quad$ Learning climate defined}

Often a classroom or sports hall has a motivating atmosphere, one of energy and activity. This perceived "feel about the place" comes not only from persuasive functional and physical cues, but also from the behaviours of goal seeking persons in that environment (Moos, 2002). The first impression can be a lasting and valid assessment of a place or organization. Terms such as "atmosphere", "character", "milieu", or "the emotional climate" are used to label what is perceived about any particular environment. Owen (1991) suggests that this perception about a place that is seemingly so palpable more than just describes the place: it is the place.

In a learning context, climate has been variously described as the atmosphere, environment, ethos, press, or tone of an educational institution (Genn, 1972). The concept of perceived climate essentially describes the tendency (or press) in a situation that impels the efforts of an individual to obtain a particular need or goal, and is referred to as "environmental press". Stern (1964) characterized the environmental press as the external situational counterpart of internalized personality needs. In this context, the climate of a particular setting can be more or less understood as the "personality" of that setting. Climate is to a place as personality is to an individual (Hoy, Tarter, \& Kottkamp, 1991).

The learning climate of a sports class setting is a set of internal characteristics that can distinguish that learning context from another, and is one of many factors that may impact on the students' (hereafter athletes) learning and ultimate performance. Different learning environments evoke different athlete perceptions of their achievement and can subsequently influence athletes' learning (Ames, 1992). However, there are several other influences on an athlete's performance. 
The coach-athlete relationship is one of the most important influences on an athlete's motivation and performance (Mageau \& Vallerand, 2003). One of the key leadership roles the coach has in this relationship is the creation and maintenance of the learning climate. The created class learning climate, along with the socio-cultural context, the athletes' intrinsic motivation, and ability, presses subsequent performance.

For this study, Hoy, Tarter, and Kottkamp's definition of learning climate is adapted.

The sports class learning climate is the relatively persistent quality of the sport training environment that is experienced by a class of participants, affects their behaviour, and is based on their collective (summated) perception of behaviour in that sport class setting (Hoy et al., 1991, p.10).

Whilst the perceived quality of the sport class environment is multi-faceted, a key aspect of the sports class is the motivational climate perceived by the participants.

\subsection{Motivational climate defined}

In their critical review of motivational climate studies in sport and physical education, Ntoumanis and Biddle (1999) stress that climate can influence the perceptions and, therefore, the effort and persistence of individuals in physical activity settings. They suggest that it is the coach that plays a key role in establishing the relevant climate and define motivational climate as, "the perception of the psychological climate" (p.645). Sports class motivational climate has been defined as the environment created by coaches that affects athletes' behaviour and achievement strategies (Boixad'os, Cruz, Torregrosa, \& Valiente, 2004), or perceived situational achievement goal structure (Ames, 1988, 1992, 1995).

For this study, sport class motivational climate is defined as the relatively persistent collective perception held by a class of participants of the achievement goal structure of that 
setting. It can be regarded to be a sub-set of the sports class learning climate and is primarily created by the sport class coach.

The sports class learning climate is not only perceived by athletes, but may be manipulated by coaches for the benefit of the class as a whole. Along with other factors, an appropriate class learning climate is a characteristic of an effective sports class.

\section{$1.4 \quad$ Effective sports classes}

Effective educational classes have some characteristics in common, other than the quality of student outcomes or results. A mix of student aptitudes, effective instruction, and advantageous learning climate are seen as characteristics of effective classrooms (Creemers, 1994). The same applies to effective sports classes.

Effective sports classes also demonstrate particular characteristics such as the use of well-prepared and directed class programs, strong coach control, the primacy of positive changes in student skill performance, and meeting class objectives (Dowdell, 2002a, 2002b, 2002c). By extension, sports classes that produce successful athletes also may have characteristics that separate them from those that do not. Performance success in a sport class setting may be seen in terms of the outcome of an athlete's capabilities and behaviours, and/or the influence of a particular effective coach's training of the talented athlete(s) (Bompa, 1983). Investigations into successful sports performance have evolved over the last century.

Early research (1920s-1960s) into sports settings was heavily dominated by classical behaviourist studies. Stimulus-response studies, personality trait studies, and information processing research dominated in attempts to unravel the successful athletic personality. However, nothing could be further from the truth than to suggest a universally successful athletic personality. Researchers pointed to the myth of individual consistency across various environmental situations, and suggested that research that investigates variations between persons while disregarding environmental effects tends to be rather 
insular (Hunt, 1975). Rushall (1978) suggested that more viable and effective methods of research into behaviour in sport, other than personality trait research, must be developed, while Carron (1980) suggested that the trait approach to personality research in sport was ineffective,

However, it would appear that this consistency of behaviour is a function of the response situation...If we are to understand and predict behaviour in a sport context, we must have greater understanding of the psychological characteristics of the specific response situations in athletic events. (p.43)

Contemporarily, representational psychological studies are in the majority in psychosocial investigations of sport and physical education (Byra \& Karp, 2000). Data from surveys, interviews, and observations are used to understand sports class context and content. This has widened the essentially kinesiological view of physical education research. However, some of these methods (such as the use of survey data from coaching staff) are product-oriented views of physical education and have been de-contextualized. Research into understanding the dynamic of sports classes is necessarily incomplete unless contextual factors are considered (Potrac, Brewer, Jones, Armour, \& Hoff, 2000). Simply put, interactions in sports class settings are relevant to the athletes' performance in that they both reflect the need and the drive to behave in certain ways.

Investigation of the sports class learning climate may reveal much about the interactions that can influence the effectiveness of the sports class. All these interactions occur in a physical context or setting. Such physical settings and the attendant resources therein are secondary determinants of learning. This study adopts the perspective that teaching (in this study, coaching) is the key determinant in any learning. Coaching affects the creation of the learning climate and, in turn, is affected by it (Fraser, 1994). Effective coaching, then, is crucial to the effective sports class. 
In a review of research on coach effectiveness, it was concluded that a coach's leadership style, behaviour, and feedback pattern significantly influence an athlete's performance (Horn, 2002). The nature and strength of these correlates are context specific and cannot be generalized across sports. A proposed model (Horn, 2002) of coaching effectiveness is illustrated in Figure 1.1. The model suggests that a coach's behaviour exerts not only a direct influence on the athlete's performance and behaviour, but also an indirect influence via the athlete's self-perceptions and perceptions of coach behaviour. A coach's influence over an athlete's performance is mediated by both the meanings the athlete attaches to the coach's behaviour and indirectly by the athlete's self-perception (box 5, ellipsis 8, and ellipsis 9). The coach's behaviour is shaped by both the sportspecific social and organizational context (ellipses 1 and 2). The sport specific context and the sports class climate are examples of ellipses 1 and 2. Further, antecedent situational and personal factors (represented by ellipses 1 and 3) also affect the coach's behaviour.

Figure removed, please consult print copy of the thesis held in Griffith University Library

Figure 1.1. A model of coaching effectiveness (Horn, 2002) 
Measuring and understanding the sports class learning climate is important as it impels coaching behaviour and is, in turn, created by the coach's behaviour (Fraser, 1994). The sports specific context influences the attendant learning climate and coachathlete behaviours. The relevant training and competitive demands of the particular sport will drive expectations and goals in that setting. A short description of the competitive gymnastics sports context follows.

\subsection{The gymnastics sports context}

Gymnastics as a human performance activity is as old and venerable as the history of sport. Gymnastics itself has developed over three millennia and carries with it a long and complex tradition of human movement, performance art, and physical education. Competitive gymnastics is the oldest internationally organized sport in the world, dating back to the formation of the Federation of International Gymnastics (FIG) in 1881. Often called the "basic sport" since it derives from the most primary human activity central to all human movement, gymnastics has been a constant feature of all modern Olympic Games since 1896 (Samaranch quoted in Langsley, 1996).

Australian gymnastics consists of a federation of state associations that, in turn, consist of member clubs and technical members. Queensland gymnastics is a reasonably large sport community consisting of more than 135 clubs and over 26,000 registered gymnasts in seven gymnastics sports. Women's Artistic Gymnastics (WAG) is the largest competitive sport of six gymnastics sports (Men's Artistic Gymnastics, Trampoline, Rhythmic Gymnastics, Sports Acrobatics, and Sports Aerobics) organized by Gymnastics Australia.

There are approximately ninety-five WAG gymnastics clubs in Queensland catering to approximately 8,000 female competitive gymnasts. These competitive gymnasts participate in a national program (syllabus) that consists of ten levels (Levels 1-10) of competition in the national stream, and three levels in the international stream. The 
standard of training and performance of the top ten clubs in Queensland is very competitive. Australian WAG teams and gymnasts have held world rankings among the world's top five nations (of the more than 130 nations in the FIG) for over ten years.

Training for competitive gymnastics is demanding. Most WAG gymnasts begin their training at age 6-8 years and continue this sports "career" for up to ten years. Training hours for the junior competitive levels (Levels 3 - 6) range from 12 - 20 hours per week and are made up of four hour training sessions $3-5$ days each week. The number of training hours for the senior competitive level (Levels 7 - 10) range from 18 - 26 hours per week. These comprise 4 - 6 training days of daily four hour sessions, and with several days of double training sessions. Gymnasts in the international stream train twice a day for 5 - 7 hours per day, 6 days per week.

\subsection{Measuring learning climate in sports classes}

Competitive gymnastic sports standards have risen dramatically over the last 30 years. A "user-pays" proviso for participation is a recent and pervasive development that consequently demands positive results for the sports "client" (student and parent). Quality, business-like organization is demanded, and "duty of care" and other legal obligations have come to the forefront of the sport coaching experience in recent years. The importance of sports class climate has increased because the quality of the class outcomes depends greatly on the effectiveness of the sports class. Both gymnasts and parents have expectations of an effective and motivational class. Class climate is an important characteristic of any effective sports class, and the sports class learning climate has a substantial role in shaping an athlete's motivational pattern (Ames, 1992).

In physical education and sport research the assessment of motivational climates has been conducted primarily using questionnaires. In spite of the current growth in motivational climate research in sport and the development of the underlying research methodology, only one study (Goudas \& Biddle, 1994) has attempted to consolidate the 
field of classroom learning climate research and physical education motivational climate studies. Goudas and Biddle (1994) developed the Physical Education Class Climate Scale (PECCS) from a confluence of the Classroom Environment Scale (Moos \& Trickett, 1987) and the Learning and Performance Orientation in Physical Education Classes Questionnaire (LAPOPEQ) (Papaioannou, 1994). However, no study has yet consolidated the fields of classroom learning climate research and sports class motivational climate studies.

The development of a sports class learning climate scale would seem to be a worthwhile research endeavor (Dowdell, 1981). Potential improvements to the current instruments measuring sport class motivational climate by the inclusion of relevant scale items from classroom learning climate scales have not been attempted to date. The ability to measure and monitor sports class learning climate may eventually lead to a greater predictive understanding of effective classes and of coach and athlete behaviour in those classes. It also holds the potential to assist in the monitoring of intervention strategies designed to improve sports class learning climate (Ntoumanis \& Biddle, 1999).

\subsection{Benefits of this study for practice}

Several implications follow from an investigation of the sports class learning climate. While there has been a desire to understand and modify athlete behaviour through isolated behaviour modification, an investigation of the sports class learning climate adds another dimension to the explanation of the variable interaction between the individual, the class, and the situation. The coach is usually placed in the role of creating and maintaining the sports class climate. Expanded interpretations of this role may be found by discerning the common environmental press experienced by athletes and coaches, rather than simply through a representational examination of coaching characteristics. 
Understanding and enhancing motivation is a central concern in the sports context (Roberts, 2001). If the motivational investment of athletes and coaches in sport settings is to be understood, then motivational climate is a critical factor to consider. Perceived motivational climates may influence the effort, persistence, cognition, and emotions of participants in their sports context (Roberts, 1992). Sporting organisations appreciate athletes and coaches with adaptive behaviours such as exerting appropriate effort, valuing, persisting with, and enjoying the task at hand. Such sports participants may be more likely to have a life-long love of sport and physical activity that has personal (including health) benefits for them and for society at large.

Effective research may help to answer some pedagogical questions about how sport class learning climate affects athletes' perceptions of learning, or their performance (Fraser, 2001). In doing so, coach and athlete perceptions of class learning climate can be better understood and compared with each other. If there is a relationship between sports class performance outcomes and the characteristics of its class learning climate, an instrument to measure sports class climate may allow a coach to conveniently assess their class climate and, if desired, change it.

\subsection{Aim of the Study}

The development of a sports class learning and motivational climate scale is unique in research into effective sports classes. This study aimed to develop and validate a new learning climate scale, the Sports Class Environment Scale (SCES), for measuring the learning and motivational climate of competitive gymnastics sports classes.

\subsection{Objectives of the study}

This study meets its aim by achieving the following objectives:

Objective 1: Develop an initial instrument - the Sports Class Environment Scale (SCES) for measuring learning climates in competitive gymnastic sports classes. 
Objective 2: Revise and refine the SCES based on pilot and first cohort responses and analyses.

Objective 3: Contrast the learning climate perceptions of the competitive gymnastics classes.

Objective 4: Construct a modified SCES for future research. 


\subsection{LITERATURE REVIEW}

The development and validation of a new and unique learning climate scale, the Sports Class Environment Scale (SCES) constitutes the major focus of this research. This study is unique in the learning climate research field, as no research has consolidated the classroom learning climate research and sports class motivational climate research. To enable this consolidation of climate measurement domains, a systematic exploration of the relevant literatures was necessary. Consequently, three main bodies of information formed the basis for the literature review: the socio-ecological approach to environmental determinants of behaviour, the historical antecedents of needs-based behaviour and environmental press, and theoretical underpinnings to class learning climate and achievement motivation climate measurement. A review of historically important learning climate and motivational climate instruments, their development, validation, scoring, and application in research informed the method for developing the SCES.

\subsection{Behaviour-Environment perspectives}

Behaviour can be defined at the individual level as an observable and measurable personal act or response (Alberto \& Troutman, 1991). Expanding this definition to describe behaviour as an individual's response to both internal and external stimuli can help to explain the causes of behaviour; however, the interwoven factors of instinctive drives, needs deficiency, social context, and expectations can also be pre-determinants of behaviour.

In the study of human behaviour, positivist experimental paradigms have eventually given way to a mutual acceptance of constructivist research (i.e., interpretative methodology) paradigms in the various fields of psychology. The fields of social and ecological psychology have built on the preceding rationales of biophysical, developmental, behaviourist, and humanist approaches to psychological research. 
Baker's (1968) work in behavioural settings was among the first in ecological psychology. Baker and his colleagues suggested the attributions of behavioural settings were imperfect and proposed a model of behaviour-environment congruence to explain the influence settings have over behaviour.

Moos (1976) and colleagues described the increased interest of human ecologists in the way humans grow and adapt in their settings, and that of psychologists and sociologists in studying and creating environments that maximize human functioning and competency. Moos distinguishes his "social ecological approach" from human ecology by suggesting the impact of the environment on the individual and how the individual adjusts, adapts, and copes with their environment are paramount. The social ecological approach is essentially an applied and humanistic study of the environmental determinants of behaviour and how the given environment can be organized to maximize human functioning and personal growth.

Moos detailed "five conceptions of how the environment works" (1976, p. 29) along a continuum from stressful to stimulating. These conceptions were: 1) from the perspective of evolution and human ecology, that environments can be limiting on the actions of people; 2) from the perspective of social Darwinism, that environments favour people by choosing those with stronger characteristics; 3) that environments motivate and challenge individuals, facilitating individual and social growth in terms of the development of civilizations; 4) from a social ecological approach, that individuals seek information about environments in order to select those with the greatest probability for success; and 5) that individuals seek to increase their control over environments in order to increase individual freedom.

A social ecological approach provides a distinctive "point of entry" to studying the effects of human environments on human behaviour. The antecedents for a social ecological approach to research into behaviour owe much to Kurt Lewin's classic (1936) 
definition of behaviour: $B=F(P . E$.$) . Here, behaviour is seen as a function of the$ congruence of the person $(P)$ and the environment $(E)$.

Lewin's purpose was to conceptualize behaviour as a molar [amalgamated] event, involving an actor and a broad contextual setting, as opposed to what he perceived as the then prevailing trend towards correlating fragmented responses with equally discrete stimuli (Stern, 1964, p.161).

The person and the environment in this model of behaviour are seen as mutually dependent on each other, and an understanding of the individual's behaviour cannot be reached without considering both (Lewin, 1951). In the educational setting, the behaviour (i.e. learning) can be jointly determined by the student $(P)$ and the teacher and the teaching (E) (Hunt, 1975). Hunt concluded that the person-environment interaction is complex and often confusing, and suggested that new conceptions of the personenvironment interaction must be explored.

Walberg (1981) further developed this concept with the formula $L=f(A, T, E)$ where the behaviour of learning $(L)$ is a function of the student's ability $(A)$, the teacher and the teaching $(T)$, and the learning environment $(E)$. Learning environment $(E)$ is presented as distinct from the teacher, the instruction, and the students' competence, and supposes that the learning environment can be adapted to influence the learning outcome. Studies over several years (Fraser 1994, 1998, 2002) have provided evidence that the perceptions of the learning environment may account for a variance in learning outcomes beyond that attributable to background student ability. Ability is generally defined as an inherited, relatively enduring, stable trait of the individual underlying or supporting physical or cognitive skill (Schmidt, 1991). This might suggest a limit to an individual's development via learning. Throughout this study, the term "competence" will be used in place of ability. 
Outcomes such as the development of inquiry skills, self-control, academic selfefficacy, school attendance, exam results and satisfaction with studies are examples that have been related to perceptions of the learning environment (Fraser, 1994). This association has been replicated for a variety of cognitive and affective outcome measures, a variety of classroom environment instruments, and a variety of samples ranging across numerous countries and grade levels (Fraser, 1998). The creation and management of appropriate class learning climates can play a role in student outcomes in that class, and should be considered an important pedagogical tool. Measurement of class learning climate can allow a teacher to monitor the current and preferred learning climates and, if so desired, change the learning climate to maximize student outcomes. Learning climate measurement emerges from the theories related to personality, needs, and environmental press.

\section{$2.2 \quad$ Class learning climate}

Much of the relevant empirical research used to conventionally measure the psychosocial characteristics of a setting is derived from the initial contribution of Murray (1938) who conceptualized the dual process of personal needs and environmental press. Murray suggested that individuals have specific needs (e.g., need for achievement, affiliation, autonomy) and that the strength of these needs characterizes personality. The concept of need represents the significant internal or personal determination of behaviour but, as Murray (1938) has suggested, is incomplete as it leaves out the nature of the environment. Murray used the term "press" to indicate a directional tendency in an object or situation that facilitates or impedes the efforts of an individual to obtain a particular goal (Moos, 1979).

Thus, press becomes the external counterpart of a person's internal needs. It can be seen as the influence that the environment has on behaviour. Murray (1938) further defined press as being either alpha press (the press as perceived by an observer) or beta 
press (a person's private perception of the environmental effect). However, there is the common point at which a single person's private perception (of the beta press) of their world merges with that of others. This mutually shared view of environmental press (called consensual beta press) became the basis for many studies of educational environments. The need-press model has been applied to the construction of an environmental press inventory, the College Characteristic Index (CCl; Pace \& Stern, 1958). Numerous social "climate" inventories that assess student and teacher perceptions of environmental press in the learning context have blossomed from this initial instrument. Among these are independently developed instruments such as the Learning Environment Inventory (LEI; Anderson \& Walberg, 1974) and the Classroom Environmental Scale (CES; Moos \& Trickett, 1974, 1987). Further studies grew from these beginnings and examples of developed instruments at the school and classroom level include the revised Organizational Climate Description Questionnaire for Schools (Hoy et al., 1991), the Individualized Classroom Environment questionnaire (ICEQ; Fraser, 1991) and the What is Happening in this Classroom (WIHIC) questionnaire (Fraser, Fisher, \& McRobbie, 1996).

\subsection{Motivational climates in sport classes and physical education classes}

Studies of motivational climate in physical education and sports settings have their foundation in the social-cognitive concepts of achievement goal theory (Roberts, 1992, 2001). Achievement goal theories are social-cognitive perspectives, since they examine how individuals cognitively and affectively process and develop their views about achievement in various social settings and under a variety of influences (Ntoumanis \& Biddle, 1999).

Achievement goal theory can be said to apply only to persons who have a personal or socially constructed goal in an achievement context, such as sport. This theory attempts to explain why a person strives in their particular achievement context, and argues that the overarching reason is to demonstrate competence (Roberts, 2001). 
An individual's achievement goal disposition reconciles their choice of achievement goals in a particular setting, such as in a sports training class (Ames 1992; Nicholls, 1984, 1992), and is a result of their prior socialization in that context. The individual is "predisposed" to behaviours based around their usual dispositional achievement goal choices. Consequently, to understand the potential influence of different motivational climates, one must first consider the meaning individuals attach to achievement. This requires a brief description about the nature of individuals' achievements of goals.

According to achievement goal theory, self-perceptions of competence (perceived achievement) are influenced by personal goal dispositions and perceived social climate factors in that particular achievement goal setting (Ntoumanis \& Biddle, 1999). The primary goal in achievement contexts, such as sports training and competition, is the demonstration of competence (Nicholls, 1984). Two primary conceptions of competence and, therefore, two types of achievement goals are suggested by Nicholls. When an individual athlete aims to learn, improve, or perfect a skill, then the athlete is using a task oriented conception of competence to achieve task mastery. In the second conception of competence, the athlete performs skills in a direct social comparison with others, or judges their skill capacity solely relative to others. When the focus of attention is on the self, compared to others, the athlete is using an ego oriented conception of competence to achieve ego involved goals.

Significant persons (teacher-coaches and peers) create social climates that affect athletes in achievement settings (Ames, 1988, 1992, 1995). The coaches in the athletes' achievement setting create task involved or ego involved goal structures by their choice of either task oriented or ego oriented conceptions of competence. In this way, the created goal structures produce a motivational climate that makes one or the other conceptions of competence conspicuous. The athlete recognizes that their competency is thus assessed in a task involved or ego involved manner and they develop context-specific goals of 
achievement consistent with the achievement goal structure created in that setting. Effective leadership in competitive sport settings has much to do with creating and maintaining a "climate of success" (Ntoumanis \& Biddle, 1999). Coaches, who have the key leadership role in sports class settings, play a major part in the creation of the learning climate and, in turn, are affected by it (Fraser, 1994).

Roberts (1992) proposed an achievement motivation framework for the sports class. This framework is shown as a flow-chart in Figure 2.1. The overarching motivation for the individual athlete is to demonstrate competence in the particular sport class setting. The athlete begins their achievement behaviour with a disposed conception of achievement goals, either task oriented or ego oriented. This individual conception of achievement goals is reconciled by the athlete's perceived competence and the perceived motivational climate, either task involved or ego involved, experienced in the activity. The athlete's perceived competence is predicted to promote the adoption of adaptive or maladaptive performance behaviours. Adaptive performance behaviours are those that promote the likelihood of achievement success. These behaviours are broadly

\begin{tabular}{|c|c|c|c|c|c|c|c|}
\hline MOTIVATION & \multicolumn{7}{|c|}{ Demonstration of ability (competence) } \\
\hline $\begin{array}{c}\text { Dispositional } \\
\text { ACHIEVEMENT } \\
\text { GOALS }\end{array}$ & \multicolumn{4}{|c|}{ Ego Orientation } & \multicolumn{3}{|c|}{ Task Orientation } \\
\hline $\begin{array}{l}\text { Perceived } \\
\text { MOTIVATIONAL } \\
\text { CLIMATE }\end{array}$ & \multicolumn{2}{|c|}{ Ego Involved } & \multicolumn{2}{|c|}{$\begin{array}{l}\text { Task Mastery } \\
\text { Invqlved }\end{array}$} & Ego Involved & \multicolumn{2}{|c|}{$\begin{array}{l}\text { Task Mastery } \\
\text { Inyolved }\end{array}$} \\
\hline $\begin{array}{c}\text { PERCEIVED } \\
\text { COMPETENCE }\end{array}$ & High & Lc & & $\begin{array}{c}\text { Not } \\
\text { Relevant }\end{array}$ & High & Lqw & $\begin{array}{c}\text { Not } \\
\text { Relevant }\end{array}$ \\
\hline $\begin{array}{l}\text { ACHIEVEMENT } \\
\text { BEHAVIOUR }\end{array}$ & Adaptive & $\begin{array}{r}\mathrm{M} \\
\text { Ada }\end{array}$ & $\begin{array}{l}\text { I- } \\
\text { tive }\end{array}$ & Adaptive & $\begin{array}{c}\text { Adaptive or } \\
\text { Mal- } \\
\text { adaptive }\end{array}$ & $\begin{array}{c}\text { Mal- } \\
\text { Adaptive }\end{array}$ & Adaptive \\
\hline $\begin{array}{l}\text { ACHIEVEMENT } \\
\text { SUCCESS }\end{array}$ & High & Lc & & High & High or Low & Low & High \\
\hline
\end{tabular}

Figure 2.1. An achievement motivation framework for sport (after Roberts, 1992) 
characterized by the athlete exerting effort, valuing the task at hand, persisting with the task, and enjoying the task effort. Maladaptive performance behaviours are those that do not sustain effective strategies for achievement success. Examples might be avoiding challenges, not exerting effort, failing to persist in the face of difficulty, or dropping out if achievement success appears difficult (Roberts, 1992). The terminology of achievement goal research has been varied, and a call for consistency (Duda, 2002) in the shifting uses of achievement dispositions and achievement goals has resulted. Therefore, throughout this study these terms are used as defined in the Glossary.

\subsection{Climate measurement questions}

Before measuring learning climate, several methodological questions should be answered. These questions relate to the level of analysis, the unit of analysis and the dimensions of analysis. The level of analysis refers to the size and type of group climate that will be measured. Two common learning group types are the school level (organizational climate) and classroom level (class climate). The unit of analysis questions asks a decision to be made about the type of environmental press to be assessed. For example, class learning climate could be assessed from a single student perception (beta press), from an average of all student's perceptions (consensual beta press), or from an observer' perception (alpha press). The dimensions of analysis questions involves decisions about the selection of behavioural criteria used in (the design of) the climate assessment instrument.

\subsubsection{Distinction between organizational climate and class learning climate}

In spite of the fields of class level and school level climate measurement having similar antecedents and developments, the measurement of learning climate in these two settings has remained independent. A weak relationship $(r=.48, p<0.05)$ between only two school level and classroom level climate subscales was discovered when examining such environment relationships in Australian secondary schools (Dorman, Fraser, \& 
McRobbie, 1997). This finding suggested that the school environment cannot be assumed to transmit automatically to the classroom, and gives support to the contention that organizational climate and class climate should be studied separately.

The school setting has been recognized as a more distinct and more global setting, obtaining much of its research impetus from studies of organizational climate (Fraser, 1986). On the other hand, class learning climate studies have focused on the perceptions, learning implications, and relationships of the teacher, the student, and the specific classroom. A brief description of the investigations into school level climate and classroom level climate follows.

School level climate studies have variously considered the relationships between teachers and their peers, teachers and heads of departments, and teachers and their school principals and governance. School level climate has usually been measured in terms of the perceptions of principals, teachers, and administrators. The early work in this area was the Organizational Climate Description Questionnaire (OCDQ; Halpin \& Croft, 1963) and the College Characteristics Index (CCl; Stern, 1970). A simplification of Halpin and Croft's early work on organizational climate in schools was the Organizational Climate Description Questionnaire for Schools containing separate scales for both secondary and primary Schools (Hoy, Tarter, \& Kottkamp, 1991). Schools have been, and continue to be, viewed as fields of study of educational administration and organizational climate.

The practice of classroom level climate research has been to use student perceptions, and sometimes teacher perceptions of the consensual environmental press (Fraser \& Rentoul, 1982). This research focus has provided support for the predictive validity of classroom climate perceptions in explaining some student outcomes (Fraser, 1994). Implicit in much of the research on classroom learning environments is the assumption that the environment is relatively stable over the time of the study, so that associations between learning climate and other variables, such as learning outcomes, 
can be studied. The assumption of relatively stable, but not enduring, classroom learning environments can be accepted with some caution as successive class learning climate measurements have been conducted with numerous classes (with the same teacher) over several weeks to several months with little significant differences in climate scores (Fraser, 1986). The study of learning climate at the class level seems particularly relevant, as the class teacher creates much of the learning climate, and it appears that school level climate exerts relatively little influence on classroom level learning climate.

\subsubsection{Unit of analysis question}

In designing class learning climates scales, Fraser (1994) suggests that researchers have had to decide whether their analyses will involve perception ratings from individual students (beta press) or from averaged perception scores of all the students in the class (consensual beta press). Evidence has demonstrated a closer fit of an individual student's actual and preferred learning class climate, as opposed to observer based classroom level climate measures (alpha press), as an important predictor of affective and cognitive achievement (Fraser \& Fisher, 1983; Fraser \& Rentoul, 1982). Moreover, individual student perception of climate scores can be averaged to arrive at a consensual perception of the learning climate. An advantage of this may be that achievement of specific class outcomes (as opposed to individual student outcomes) may be enhanced by changing the whole class learning climate to one that is congruent with the learning climate collectively preferred by that class (Fraser, 1994).

\subsubsection{Dimensions of analysis question}

Moos (1974) described a model for measuring a variety of human environments that provided dimensions of behaviour. A notable feature of Moos' findings (1976) was that the behavioural dimensions emanated from classroom environments, as well as from a variety of social environments including university residences, hospital wards, prisons, military units, family settings, and generalized work places. Using this model, Moos 
proposed that vastly different social environments could be described by a common set of dimensions from three broad categories. These categories are Relationship dimensions, Personal Development dimensions, and System Maintenance and Change dimensions.

Relationship dimensions identify the nature, and describe the intensity of personal relationships within the respective environment. Involvement within the environment, and affiliation-cohesiveness with others in that environment, are units of measurement common to most settings (Moos, 1976). Personal Development dimensions judge the direction and degree to which personal growth and self-enhancement tend to occur in the particular environment. Typical (but not inclusive) units of measurement are independence, task orientation, and competition orientation (Moos, 1976). System Maintenance and Change dimensions are similar across most settings, and measure orderliness, rule clarity, control, and degree of responsiveness to change.

Table 2.1 lists the subscales of these three climate dimensions from three types of social environments (Moos, 1976). Subsequent work demonstrated the enduring quality of these dimensions across family, work, school, health, military, prison, and community social contexts (Moos, 1976, 1979, 2002). Although similar subscales (measures) for each dimension appear in most social environments some are relevant to specific environments.

Table 2.1. Climate dimensions from three types of social environments (Moos, 1976)

\begin{tabular}{|l|l|l|l|}
\hline Type of environment & $\begin{array}{l}\text { Relationship } \\
\text { dimensions }\end{array}$ & $\begin{array}{l}\text { Personal Development } \\
\text { dimensions }\end{array}$ & $\begin{array}{l}\text { System Maintenance } \\
\text { and Change dimensions }\end{array}$ \\
\hline Work setting & $\begin{array}{l}\text { Involvement } \\
\text { Peer cohesion } \\
\text { Staff support }\end{array}$ & $\begin{array}{l}\text { Task Orientation } \\
\text { Competition } \\
\text { Cooperation }\end{array}$ & $\begin{array}{l}\text { Work pressure } \\
\text { Rule clarity } \\
\text { Innovation } \\
\text { Physical comfort }\end{array}$ \\
\hline $\begin{array}{l}\text { High school } \\
\text { classrooms }\end{array}$ & $\begin{array}{l}\text { Involvement } \\
\text { Peer cohesion } \\
\text { Teacher support }\end{array}$ & $\begin{array}{l}\text { Task Orientation } \\
\text { Competition } \\
\text { Cooperation }\end{array}$ & $\begin{array}{l}\text { Order \& Organization } \\
\text { Rule clarity } \\
\text { Teacher control } \\
\text { Innovation }\end{array}$ \\
\hline Military company & $\begin{array}{l}\text { Involvement } \\
\text { Peer cohesion } \\
\text { Officer support }\end{array}$ & Personal status & $\begin{array}{l}\text { Order \& Organization } \\
\text { Rule clarity } \\
\text { Officer control }\end{array}$ \\
& & & \\
\hline
\end{tabular}


Innovation is relevant to educational and workplace settings but as would be expected, not to military settings. Teacher control is specific to educational settings but not workplaces.

The behavioural subscales for educational settings are Involvement, Affiliation, Teacher Support, Task Orientation, Order \& Organization, and Rule Clarity. These are used as subscales in the Classroom Environment Scale (CES; Moos \& Trickett, 1987). The CES is a leading measure of class learning climate in primary and secondary schools. The short form CES subscales are defined, and an example of each subscale items is given in Table 2.2.

Table 2.2. A description of each of the behavioural subscales in the CES Scale (Moos \& Trickett, 1987)

\begin{tabular}{|c|c|c|}
\hline $\begin{array}{l}\text { Subscale } \\
\text { (Dimension) }\end{array}$ & Definition & Example Scale Item \\
\hline $\begin{array}{l}\text { Involvement } \\
\text { (Relationship } \\
\text { Dimension) }\end{array}$ & $\begin{array}{l}\text { Students' attentive interest in } \\
\text { classroom activities }\end{array}$ & $\begin{array}{l}\text { Students put a lot of energy } \\
\text { into what they do here }\end{array}$ \\
\hline $\begin{array}{l}\text { Affiliation } \\
\text { (Relationship } \\
\text { Dimension ) }\end{array}$ & $\begin{array}{l}\text { The levels of friendship } \\
\text { students feel for each other, } \\
\text { helping each other and } \\
\text { enjoying working together. }\end{array}$ & $\begin{array}{l}\text { Students in this class get to } \\
\text { know each other really well. }\end{array}$ \\
\hline $\begin{array}{l}\text { Teacher Support } \\
\text { (Personal } \\
\text { Development } \\
\text { dimension) }\end{array}$ & $\begin{array}{l}\text { The amount of help and } \\
\text { friendship the teacher } \\
\text { manifests toward students }\end{array}$ & $\begin{array}{l}\text { The coach goes out of his/her } \\
\text { way to help students. }\end{array}$ \\
\hline $\begin{array}{l}\text { Task Orientation } \\
\text { (Personal } \\
\text { Development } \\
\text { dimension) }\end{array}$ & $\begin{array}{l}\text { The amount of emphasis on } \\
\text { completing planned activities } \\
\text { and staying on subject matter }\end{array}$ & $\begin{array}{l}\text { This class is more a social time } \\
\text { than a place to learn skills. }\end{array}$ \\
\hline $\begin{array}{l}\text { Order \& } \\
\text { Organization } \\
\text { (System Maintenance } \\
\text { and Change } \\
\text { dimension ) }\end{array}$ & $\begin{array}{l}\text { The emphasis on students } \\
\text { behaving in an orderly and } \\
\text { polite manner, and the overall } \\
\text { organization of class activities }\end{array}$ & This is a well-organized class \\
\hline $\begin{array}{l}\text { Rule clarity } \\
\text { (System Maintenance } \\
\text { and Change } \\
\text { dimension ) }\end{array}$ & $\begin{array}{l}\text { Emphasis on following } \\
\text { consistent rules and knowing } \\
\text { consequences if the rules are } \\
\text { not followed }\end{array}$ & $\begin{array}{l}\text { Rules in this class seem to } \\
\text { change a lot. }\end{array}$ \\
\hline
\end{tabular}


Much of our knowledge of the situational antecedents of achievement goals in physical activity settings stems from the work of Ames $(1984,1992)$ in academic classroom settings. Her models for curriculum work and classroom instruction based on motivational climates have shown specific learning environments evoke different perceptions about participants' achievements and can subsequently influence participants' learning (Ames, 1992). The two broad dimensions or conceptions of achievement, in the field of motivational climate have been described as the task mastery orientation and the ego or performance orientation. Just as Moos' (1976) three dimensions of behaviour were commonly found in most settings, these two dimensions have been generally applied in measures of motivational climate across all sport and physical activity settings (Ntoumanis \& Biddle, 1999).

Drawing on previous research (Epstein, 1989), Ames (1992) described six variables that can help teachers organise classroom instruction and interactions. . Examples of these six teaching variables contrasting a task mastery involved climate and a performance (ego) involved learning climate are provided in Table 2.3.

Table 2.3. Descriptions of mastery and performance climates in accordance with the TARGET structures (Ames, 1992)

\begin{tabular}{|l|l|}
\hline In a Task Mastery involved Climate & In a Performance (Ego) involved Climate \\
\hline Tasks - Challenging and diverse & Tasks - Absence of variety and challenge \\
\hline $\begin{array}{l}\text { Authority - Students are given choices and } \\
\text { leadership roles }\end{array}$ & $\begin{array}{l}\text { Authority - Students do not take part in the } \\
\text { decision-making processes }\end{array}$ \\
\hline $\begin{array}{l}\text { Recognition - Private and based on } \\
\text { individual progress }\end{array}$ & $\begin{array}{l}\text { Recognition - Public and based on social } \\
\text { comparison }\end{array}$ \\
\hline $\begin{array}{l}\text { Grouping - Promotion of cooperative } \\
\text { learning and peer interaction }\end{array}$ & $\begin{array}{l}\text { Grouping - Groups are formed on the basis } \\
\text { of ability }\end{array}$ \\
\hline $\begin{array}{l}\text { Evaluation - Based on mastery of tasks } \\
\text { and on individual improvement }\end{array}$ & $\begin{array}{l}\text { Evaluation - Based on winning or } \\
\text { outperforming others }\end{array}$ \\
\hline $\begin{array}{l}\text { Time - Time requirements are adjusted to } \\
\text { personal capabilities }\end{array}$ & $\begin{array}{l}\text { Time - Time allocated for learning is } \\
\text { uniform to all students }\end{array}$ \\
\hline
\end{tabular}


These variables are Task (design of tasks), Authority (location of decision-making), Recognition (distribution of rewards), Grouping (manner and frequency of grouping), Evaluation (standards for performance), and Time (pace of learning). The first letters of the six variables create the acronym TARGET.

\subsection{Assessing classroom learning climate}

To be able to understand, describe, monitor, and potentially change class learning climate, psychometrically valid instruments have been developed in the areas of classroom learning climate and sports class motivational climate. The next two sections describe some of the historically important learning and motivational climate scales, their development, validation, and scoring.

\subsubsection{Classroom learning climates instruments}

Comprehensive reviews of instruments for assessing perception of classroom environments are reported in Fraser $(1986,1994,2002)$. With so many instruments described in the literature, a historical review of previously developed instruments was conducted. Instruments that reflect dimensions of behaviour measurement based on Moos (1976) classification of human social environment settings were selected.

Table 2.4 shows seven learning environment scales in chronological order, with the scales categorized within each of the three Moos' dimensions. The Classroom Environment Scale (CES), My Class Inventory ( $\mathrm{MCl})$, and What is Happening in this Class (WIHIC) scale are three of the most developmentally representative of classroom learning climate measurements. The CES (Moos \& Trickett, 1974, 1987) evolved from a research program that measured perceptions of environments in many different class settings. The CES is particularly relevant to learning climate research in upper primary \& secondary education classes. The published versions of the scale $(1974,1987)$ contain nine dimension scales with ten (10) true-false items on each scale. The $\mathrm{MCl}$ (Fisher \& Fraser, 1981 ) is a simplified form of an earlier instrument, the Learning Environment Inventory 
Table 2.4. Overview of seven classroom learning climate scales in order of development.

\begin{tabular}{|c|c|c|c|c|c|}
\hline Instrument & $\begin{array}{l}\text { Setting } \\
\text { \& level }\end{array}$ & $\begin{array}{l}\text { Total } \\
\text { Items }\end{array}$ & $\begin{array}{l}\text { Relationship } \\
\text { Dimensions } \\
\text { (classified by } \\
\text { Moos } 1974,1975 \text { ) }\end{array}$ & $\begin{array}{l}\text { Personal } \\
\text { Development } \\
\text { Dimensions } \\
\text { (classified by } \\
\text { Moos 1974, 1975) } \\
\end{array}$ & $\begin{array}{l}\text { System } \\
\text { maintenance \& } \\
\text { change } \\
\text { (classified by } \\
\text { Moos 1974, 1975) }\end{array}$ \\
\hline $\begin{array}{l}\text { Individualized } \\
\text { Classroom } \\
\text { Environment } \\
\text { Questionnaire } \\
\text { (ICEQ) (Rentoul } \\
\text { \& Fraser 1979) }\end{array}$ & $\begin{array}{l}\text { Second- } \\
\text { ary }\end{array}$ & $\begin{array}{l}50 \\
\text { (10 per } \\
\text { subscale) }\end{array}$ & $\begin{array}{l}\text { 1. Personalization } \\
\text { 2. Participation }\end{array}$ & $\begin{array}{l}\text { 3. Independence } \\
\text { 4. Investigation }\end{array}$ & 5. Differentiation \\
\hline $\begin{array}{l}\text { My Class } \\
\text { Inventory } \\
\text { (MCl) } \\
\text { (Fisher \& Fraser } \\
\text { 1981) }\end{array}$ & $\begin{array}{l}\text { Primary } \\
\text { \& Middle } \\
\text { schools }\end{array}$ & $\begin{array}{l}\text { (6-9 per } \\
\text { subscale) }\end{array}$ & $\begin{array}{l}\text { 1. Cohesiveness } \\
\text { 2. Friction } \\
\text { 3. Satisfaction }\end{array}$ & $\begin{array}{ll}\text { 4. } & \text { Difficulty } \\
\text { 5. } & \text { Competitive- } \\
\text { ness }\end{array}$ & \\
\hline $\begin{array}{l}\text { College and } \\
\text { University } \\
\text { Classroom } \\
\text { Environment } \\
\text { Inventory } \\
\text { (CUCEI) } \\
\text { (Fraser \& } \\
\text { Treagust 1986) }\end{array}$ & $\begin{array}{l}\text { Higher } \\
\text { education }\end{array}$ & $\begin{array}{l}49 \\
\text { (7 per } \\
\text { subscale) }\end{array}$ & $\begin{array}{l}\text { 1. Personalization } \\
\text { 2. Involvement } \\
\text { 3. Student } \\
\text { Cohesiveness } \\
\text { 4. Satisfaction }\end{array}$ & $\begin{array}{l}\text { 5.Task } \\
\text { Orientation }\end{array}$ & $\begin{array}{l}\text { 6. Innovation } \\
7 . \\
\text { Individualization }\end{array}$ \\
\hline $\begin{array}{l}\text { Classroom } \\
\text { Environment } \\
\text { Scale (CES) } \\
\text { (Moos \& Trickett } \\
\text { 1974, 1987) }\end{array}$ & $\begin{array}{l}\text { Second- } \\
\text { ary }\end{array}$ & $\begin{array}{l}90 \\
\text { (10 per } \\
\text { subscale) }\end{array}$ & $\begin{array}{ll}\text { 1. Involvement } \\
\text { 2. Affiliation } \\
\text { 3. Teacher } \\
\text { support }\end{array}$ & $\begin{array}{ll}\text { 4. } & \text { Task } \\
\text { Orientation } \\
\text { 5. Competition }\end{array}$ & $\begin{array}{ll}\text { 6. } & \text { Order \& } \\
\text { Organization } \\
\text { 7. } \\
\text { 8ule clarity } \\
\text { 8. } \text { Teacher } \\
\text { control } \\
\text { 9. Innovation }\end{array}$ \\
\hline $\begin{array}{l}\text { Constructivist } \\
\text { Learning } \\
\text { Environment } \\
\text { Survey } \\
\text { (CLES) } \\
\text { (Taylor, Dawson } \\
\text { \& Fraser 1995) }\end{array}$ & $\begin{array}{l}\text { Second- } \\
\text { ary }\end{array}$ & $\begin{array}{l}35 \\
\text { (7 per } \\
\text { subscale) }\end{array}$ & $\begin{array}{l}\text { 1. Uncertainty } \\
\text { 2. Personal } \\
\text { Relevance }\end{array}$ & $\begin{array}{ll}\text { 3. } & \text { Critical Voice } \\
\text { 4. Shared } \\
\text { Control }\end{array}$ & $\begin{array}{l}\text { 5. Student } \\
\text { negotiation }\end{array}$ \\
\hline $\begin{array}{l}\text { What is } \\
\text { happening in } \\
\text { this class } \\
\text { (WIHIC) } \\
\text { (Fraser, Fisher \& } \\
\text { McRobbie 1996) }\end{array}$ & $\begin{array}{l}\text { Second- } \\
\text { ary }\end{array}$ & $\begin{array}{l}56 \\
\text { (8 per } \\
\text { subscale) }\end{array}$ & $\begin{array}{l}\text { 1. Student } \\
\text { Cohesiveness, } \\
\text { 2. Teacher } \\
\text { Support, } \\
\text { 3. Involvement }\end{array}$ & $\begin{array}{ll}\text { 4. Investigation } \\
\text { 5. Task } \\
\text { Orientation } \\
\text { 6. Cooperation }\end{array}$ & 7. Equity \\
\hline $\begin{array}{l}\text { Science } \\
\text { Laboratory } \\
\text { Environment } \\
\text { Inventory } \\
\text { (SLEI) } \\
\text { (Fraser, Giddings } \\
\text {,McRobbie 1995) }\end{array}$ & $\begin{array}{l}\text { Upper } \\
\text { Second- } \\
\text { ary and } \\
\text { Higher } \\
\text { Education }\end{array}$ & $\begin{array}{l}35 \\
\text { (7 per } \\
\text { subscale) }\end{array}$ & $\begin{array}{l}\text { 1. Student } \\
\text { Cohesiveness }\end{array}$ & $\begin{array}{l}\text { 2. Open - } \\
\text { endedness } \\
\text { 3. Integration }\end{array}$ & $\begin{array}{l}\text { 4. Rule Clarity } \\
\text { 5. Material } \\
\text { Environment }\end{array}$ \\
\hline
\end{tabular}


(LEI; Anderson \& Walberg, 1974). The MCl was developed for use in primary school class settings and differs from its predecessors by having only five dimension scales instead of fifteen. Question readability was considered to meet the needs of younger children and the LEl's four-point response format was changed to a yes-no response. The "What Is Happening In this Class" (WIHIC; Fraser et al., 1996) questionnaire combined modified versions of scales from a wide range of existing questionnaires with scales or questions that account for modern educational concerns (e.g., equity and constructivism). The original 90-item nine-scale version was distilled to 54 items across seven scales. This set of items was expanded to 80 items in eight scales of the second version of the WIHIC, and eventually led to a final form of the WIHIC containing seven eight-item scales. This WIHIC scale was validated with a sample of 1,720 eighth-grade science students from 65 classes in 11 USA schools (Rickards, Bull, \& Fisher, 2001).

Many studies have drawn on scales and items in existing questionnaires to develop modified instruments that better suit particular research purposes and research contexts. For example, there are a limited number of class learning climate instruments that are suitable for use at the primary school level. A primary school level questionnaire has been developed based on the WIHIC, that has the four subscales of Cooperation, Teacher Empathy/Equity, Task Orientation, and Involvement (Fraser \& Sinclair, 2001). This instrument, the Elementary and Middle School Inventory of Classroom Environments (ICE) scale, was validated with a sample of 745 students in 43 grade 6 to grade 8 primary school classes in Texas.

More recently, the selection of instrument subscales for the Online Learning Environment Survey (OLES) was based on the subscale's perceived relevance to characteristics of e-learning environments, and Moos' (1974) scheme for classification of the dimensions of any human environment. The OLES drew on the existing scales of the WIHIC questionnaire, the Constructivist Learning Environment Survey (CLES; Taylor, 
Dawson \& Fraser 1995), the Distance Education Learning Environments Survey (DELES; Jegede, Fraser \& Fisher, 1995), and the Technology Rich Outcomes Focused Learning Environment Instrument (TROFLEl; Aldridge, Fraser, Fisher, Trinidad \& Woods, 2003) to measure the specific "on-line" learning climate (Trinidad, Aldridge, \& Fraser, 2005)

Some of these instruments not only have a scale to measure perception of actual classroom learning climate, but also a scale to measure perceptions of students' and teachers' preferred learning climate. Preferred climate scales are developed by changing the wording of a scale item from an actual reference to a preferred reference. For example, the subscale item, "There is a clear set of rules for students to follow" can be altered "There would be a clear set of rules for students to follow" to allow a measure of preferred learning climate. Having actual and preferred scale formats has allowed a greater range of learning climate research questions to be considered. A study of preferred and actual learning climates in an undergraduate social science class showed that a classroom climate more closely approaching the perceived "ideal" facilitated better class involvement, attendance, and appreciation (De Young, 1977). In other ideal versus preferred learning climate research, an investigation of the perceived differences between student-teacher actual and preferred classroom learning climates discovered a divergence requiring in-service attention (Kiley \& Jensen, 1998). An adaptation of the College Characteristics Analysis Scale (Pace, 1964) was used to examine 137 undergraduate students' perceptions of ideal and actual learning environments in their University course. Differences between students' perceptions of actual and ideal learning environments were observed (Genn, 1975).

\subsubsection{Validation of the short forms of the classroom learning climate scales.}

For reasons of test length, ease of test administration, and the belief that the unit of measurement should be the class and not the individual, shorter forms of the $\mathrm{MCl}$ (Fraser \& Fisher, 1983) and the CES (Moos \& Trickett, 1974, 1987) scales were developed. For 
example, the long form of the CES contained 90 items and was reduced to a short form of 24 items divided equally among six of the original nine scales. These learning climate short form scales have been shown to have adequate reliability and validity.

Both the long and short forms of the Individualized Classroom Environment Questionnaire (ICEQ), the $\mathrm{MCl}$ and the CES scales were piloted using more than 100 junior high school classes in Tasmania (Fraser \& Fisher, 1983). A concurrent correlation range $(r=0.78-0.97)$ between the long and short forms of these scales and a defensible internal consistency (alpha reliability coefficient range $=0.56-0.85$ ) for the short form scale items validated the instruments. In addition to the validation procedures described above, the short form test items were screened for face validity and for a balance between the negative and positive scoring directions of the items.

\subsubsection{Scoring learning climate and motivational climate scales}

Learning climate instruments usually consist of two or more subscales, which must be conceptually and quantitatively independent. Each subscale usually will have several items (statements or questions). Subscale item scores can be summed and averaged, however subscale scores cannot be summed to arrive at a total scale climate score.

Scoring of the short forms of classroom environment scales differ (Fraser \& Fisher, 1983). The short form of the CES presents 24 "either-or" questions in four blocks of six questions each. The first, second, third, fourth, fifth, and sixth item questions in each block

of questions measure, respectively, the scale items of Involvement, Affiliation, Teacher support, Task Orientation, Order \& Organization, and Rule Clarity. The responses for each question are scored 3 and 1 respectively for the responses 'Yes' or 'No'. Underlined items or items noted with a $[\mathrm{R}]$ are scored in reverse. Omitted or invalid responses are scored with a 2. A similar scoring method is used for the $\mathrm{MCl}$. The ICEQ scale consists of 25 questions in five blocks of five questions. The first, second, third, fourth, and fifth item questions in each block of questions measure, respectively, the scale items of 
Personalization, Participation, Independence, Investigation, and Differentiation. Questions are scored on a Likert scale of 1,2,3,4, and 5, respectively, for responses of: Almost Never, Seldom, Sometimes, Often, and Very Often. Very similar "scoring" has been used in the scales for measuring motivational climate. In the PMCSQ-1, athletes were asked to think of what it was like playing on their particular team during a season. Their responses are then given on a 5 -point Likert scale $(1=$ strongly agree, through to $5=$ strongly disagree).

\subsubsection{Classroom learning climate measurement research}

A representative overview of the broad types of learning climate studies includes (1) associations between student outcomes and learning climate, (2) use of learning climate dimensions as dependant variables (including the evaluation of educational innovations and investigations of differences between students' and teachers' perceptions of the same classrooms) and (3) investigations of whether students achieve better when in their preferred learning climates, also termed "person-environment" fit (Fraser, 1998). A recent area of research has been cross-national investigations as outlined by Fraser (1991, 1994, 2002).

In investigations of associations between student outcomes and learning climate, research has traditionally focused on the associations between students' cognitive and affective learning outcomes and their perceptions of the psychosocial climate of their classrooms (Fraser \& Fisher, 1982; McRobbie \& Fraser, 1993). Researchers used the Science Laboratory Environment Inventory (SLEI) and other skill and attitude measures to investigate associations between student outcomes and classroom learning climate for high school chemistry students. The nature of the classroom environment accounted for variance in both cognitive and affective outcomes beyond those attributable to general aptitude (McRobbie \& Fraser, 1993). 
Climate dimensions have also been used as dependent variables for the evaluation of educational innovation, comparisons of student and teacher perceptions of class climates, and studies involving other independent variables such as teacher personality, class size or subject matter. For example, classroom environment variables have been shown to differentiate between curricula even when various outcome measures showed negligible differences (Fraser, 1994). The perceptions of 120 students and seven teachers about the learning environment in their inquiry-based computer classrooms were measured using the Computer Laboratory Environment Inventory (CLEI) before and after using a computerized database that had the potential for promoting inquiry skills. The environmental variables of Student Cohesiveness, Open-endedness, Integration, and Technology Adequacy (but not Laboratory Availability) correlated significantly $(p<.01)$ with all attitudinal variables. There was also an increase in Student-perceived investigation and Open-endedness (Maor \& Fraser, 1996).

The CLEI was also used to measure students' perceptions of the computer laboratory class as a learning environment (Newby \& Fisher, 1997). A second instrument called "Attitude towards computers and computing courses" was also administered. It was found that with the exception of Laboratory Availability, all the scales of the CLEI had significant associations with anxiety, enjoyment, usefulness of computers, and usefulness of the course.

In Singapore, classroom environment measures were used as dependent variables in evaluations of computer-assisted learning (Teh \& Fraser, 1994). Six computer assisted learning $(\mathrm{CAL})$ modules in geography were developed by the investigators and evaluated in Singapore schools in terms of impact on achievement, attitudes, and classroom psychosocial environment. A sample of 671 students from the second year of high school were assigned randomly to either a CAL or control group and surveyed with the Geography Classroom Environment Inventory (GCEI). Compared with control students, 
CAL students had significantly higher achievement and attitude scores and perceived their classes as having greater gender equity, investigation, innovation, and resource adequacy.

Person-Environment fit studies involved the use of climate dimension instruments to determine if students achieved better in their preferred learning climate. An early attempt to assess the association between classroom climate and student outcomes ("person-environment fit"), and then use this information in restructuring the class climate to a more 'ideal' situation was reported by De Young (1977). In this study, modifications of a class climate as suggested by a comparison of ideal-real class climates, led to improved class function, student attendance, and course appreciation. The changes occurred in the climate dimensions that the investigators worked to modify.

A recent example of investigating student's perceived and preferred learning environment and then intervening to change the classroom learning climate involved ten middle school teachers and their 43 classes in an urban North Texas school setting (Fraser \& Sinclair, 2001). Perceived and preferred forms of the Inventory of Classroom Environments (ICE), which assessed Cooperation, Teacher Empathy, Involvement and Task Orientation, were administered. The basic method used for changing the classroom environment of each class was adapted from previous research (Fraser \& Fisher, 1986; Yarrow, Millwater \& Fraser, 1997). This process involved: (1) assessing the students' perceived and preferred classroom environments; (2) providing the results to the teachers and assisting them in making action plans to improve their classroom environments; (3) collecting qualitative data from students about the class, activities, and the teacher; (4) holding weekly individual meetings with the teachers concerning class occurrences and specific techniques that could be used in an attempt to change the perceived environment; and (5) reassessing the students' perceived environments. 


\subsubsection{Methods of instrument development and investigation}

Procedures for developing learning climate scales have been described by Fraser, (1986) who suggested a three-step process of a) identification of salient dimensions, b) item writing, and c) field testing and item analysis. Identification of salient dimensions involves assembling a tentative list of relevant individual environmental dimensions across Moos' three broad classifications of social environment dimensions. These individual dimensions will become subscales that need to be conceptually distinct yet, as a grouping, cover all the key dimensions of learning environments. Identification of dimensions is carried out by a combination of review of literature, gathering of opinions of experts and administration of relevant surveys in the area. For example, in developing the CES, Trickett and Moos (1973) sought out descriptions of classroom environments from prior educational research, conducted structured interviews with teachers and students, and observed classroom teaching in several schools.

The second step in the development of a learning climate scale entails writing a set of items (statements or questions for response) intended to measure each individual dimension. Concerted effort must be made to ensure that each item is constructed such that it measures its assigned dimension only, and does not address parts of another dimension. For example, the CES (Moos \& Trickett, 1974) has an individual climate dimension of Teacher Control (under the System Maintenance Dimension). This individual dimension is meant to describe the number or rules and how strictly rules are enforced in the particular setting. An example item measuring this dimension is, "When the teacher makes a rule, she means it". This pool of items would be reviewed by educational experts in the particular setting for opinions on face validity.

The third step of instrument development recognized in the literature involves the administration of the scale items to a sample of classes. A factor analysis follows to test whether or not the items cluster in the theorized dimensions and subscales. The revised 
scales' internal consistency (coefficient of reliability) is measured using Cronbach's alpha, which tests how well a set of scale items (or variables) measures a single, uni-dimensional construct. The revised scales are again administered to another sample of classes to further refine the instrument. This revision process can be repeated many times until the subscale items are confirmed and a final version of the instrument produced.

The preceding review considered a representative number of studies about the development, validation and application of learning climate measurement scales. This research has been progressing for over three decades. The development and application of motivational climate measures is more recent and less numerous and diverse. The key measures of motivational climate in sport are described in the next section.

\subsection{Assessing motivational climate in sport}

\subsubsection{Sports class motivational climate instruments}

A review of studies conducted in the area of sports class motivational climate (Ntoumanis \& Biddle, 1999) indicated that perceptions of a task involved climate are associated with adaptive cognitive and affective athlete behaviours. In contrast, the perception of an ego involved climate is associated with adaptive or maladaptive behaviour patterns dependent on the athlete's level of perceived competence. Studies in physical education class motivational climate (Ntoumanis \& Biddle, 1999) have shown that perceptions of a task involved climate are related to high intrinsic interest and positive attitudes towards lessons, intentions to exercise, and low anxiety. Perceptions of an ego involved climate are unrelated or negatively related to maintaining or raising levels of interest in, and positive attitudes to, physical education. Instruments have been developed for school physical education classes and sports training classes to measure motivational climate. These instruments have proved valid and reliable both in the cultural settings and sport-specific contexts in which they were developed (Ntoumanis \& Biddle, 1999). 
The investigation of student achievement orientations and motivational climate in physical activity settings has resulted in physical education class and sports class settings being the two prime physical activity contexts for investigation. Both settings have class structures and skill learning environments that are accessible. However, these are often seen as separate physical activity settings in terms of voluntary participation, reasons for participation, group homogeneity, variations in physical competence, social meaning attached to the setting, and the social influences that either teachers, coaches, or parents have on the setting (Ntoumanis \& Biddle, 1999).

One of the earliest uses of sports class motivational climate assessment was a survey of 105 male basketball players using the Perceived Motivational Climate in Sport Questionnaire \#1 (PMCSQ-1). The findings suggested that class perceptions of a mastery (task involved) climate were positively associated with reported enjoyment and the belief that effort leads to achievement. Perception of a performance (ego involved) climate was associated with the view that superior ability causes success (Seifriz, Duda, \& Chi, 1992).

Students' perceptions of achievement orientations in physical education classes were also measured via the Learning and Performance Orientations in Physical Education Classes Questionnaire (LAPOPECQ; Papaioannou, 1994). Factor analysis revealed a fivefactor structure under the primary climate dimensions of Learning orientation and Performance (Ego) orientation. Subscale factors were teacher initiated learning, students' learning orientation, students' competitive orientation, students' worry about mistakes, and outcome orientation without effort. Students' intrinsic motivation and positive attitudes toward the lessons were positively associated with the learning-oriented scales and unrelated to ego-oriented scales. Another study surveyed 144 basketball players using the LAPOPECQ and confirmed the instrument's five subscales under the two primary dimensions of learning orientation and performance orientation (Baric, 2001). 
With a view to improving on the original PMCSQ-1 questionnaire, Newton and Duda (1993) surveyed 202 female volleyball and basketball players to investigate the construct and predictive validity of the Perceived Motivational Climate in Sport Questionnaire \#2 (PMCSQ-2). Factor analysis showed that the PMCSQ-2 comprised three task mastery subscales and three competition subscales. Perceptions of mastery climate were positively related to task orientation; perceptions of competitive climate were positively related to ego orientation.

Competitive gymnastics has been the subject of study in the field of motivational climate. A survey of 93 gymnasts and 15 coaches using the PMCSQ-1 and the Task and Ego Orientation in Sport Questionnaire (TEOSQ) examined the relationships between gymnasts' perceptions of their class motivational climate and their goal orientations (Lattimore, 2000). Task orientation and perceptions of a task involved climate were associated with adaptive motivational responses, such as, preference to be challenged, having fun and trying hard. The same pattern of preferring challenging tasks, having fun and trying hard was not as evident with ego orientations. Results suggested that both goal orientations and perceptions of motivational climate play an important role in the adaptive motivational responses of gymnasts.

A further study (Halliburton \& Weiss, 2002) of the motivational climate in gymnastics investigated gymnasts by their competitive level. This investigation surveyed 103 adolescent Level 5-10 female gymnasts using the Sources of Competence Information Scale (SCIS), and the PMCSQ-2. Three questions were considered: do perceptions of motivational climate vary by skill level, do sources of competence information vary by skill level, and are sources of competence information and motivational climate related? The study found that perceptions of motivational climate did not differ across lower to higher competitive levels; however, gymnasts at lower levels used sources of effort rather than competence to judge their achievement. Significant relationships 
emerged between sources of competence and motivational climate. Perceptions of task involved climate were associated with use of self-referenced sources of information. Use of practice performance information as a source of competence was positively related to a task involved climate. Learning and improving skills were also positively related to performance (ego involved) climate.

Following a review of physical activity motivational climate instruments, Ntoumanis and Biddle (1999) suggested that the PMCSQ-2 is the most promising "English-speaking" instrument and should be investigated further. Table 2.5 shows a summary of four historically important sport class and physical education class climate measuring instruments in chronological order with the subscales categorized under the two achievement goal orientations, task and ego orientation (Ntoumanis \& Biddle, 1999).

Of relevance to this study was the suggestion by Ntoumanis and Biddle (1999) that further improvements to physical education and sport motivational climate assessment might be achieved by including items from classroom-specific questionnaires such as the Classroom Environment Scale (Moos \& Trickett, 1987) and the Learning Environment Inventory (Fraser, Anderson \& Walberg, 1982). A broader interpretation of the physical education classroom climate had been attempted by adding two CES subscales (Moos \& Trickett, 1987) to four of the scales of the LAPOPEQ (Papaioannou, 1994). These additional subscales of students' Perceptions of Choice and the students' Perceptions of Teachers' support had been shown to influence student motivation in classrooms. The new scale, the Physical Education Class Climate Scale (PECCS), consisted of 27 items across six subscales. The construct validity of the PECCS was examined though exploratory factor analysis based on a sample of 254 school students in England. The results showed a six-factor solution that included the two new subscales from the CES and the four subscales of the LAPOPECQ. In spite of some changes to scale items 
Table 2.5. Overview of four physical activity class motivational climate scales in order of development (Ntoumanis \& Biddle, 1999).

\begin{tabular}{|c|c|c|c|c|}
\hline Instrument & $\begin{array}{l}\text { Setting } \\
\text { \& sample }\end{array}$ & $\begin{array}{l}\text { Total } \\
\text { Items }\end{array}$ & $\begin{array}{l}\text { Task Involvement } \\
\text { Subscales } \\
\text { (number of items) }\end{array}$ & $\begin{array}{l}\text { Ego Involvement } \\
\text { Subscales } \\
\text { (number of items) }\end{array}$ \\
\hline $\begin{array}{l}\text { The Perceived } \\
\text { Motivational Climate in } \\
\text { Sport Questionnaire \#1 } \\
\text { (PMCSQ-1) } \\
\text { (Seifriz et al., 1992) }\end{array}$ & $\begin{array}{l}105 \text { male } \\
\text { high school } \\
\text { basketball } \\
\text { players - } \\
14-19 y r s\end{array}$ & 21 & 9 items & 12 items \\
\hline $\begin{array}{l}\text { The Perceived } \\
\text { Motivational Climate in } \\
\text { sport Questionnaire \#2 } \\
\text { (PMCSQ-2) } \\
\text { (Newton \& Duda, 1993) }\end{array}$ & $\begin{array}{l}202 \text { female } \\
\text { high school \& } \\
\text { college team } \\
\text { volleyball \& } \\
\text { basketball } \\
\text { players } \\
\text { Mean age = } \\
16.5 y r s\end{array}$ & 33 & $\begin{array}{l}\text { 1.Cooperative } \\
\text { Learning (6) } \\
\text { 2. Effort \& } \\
\text { Improvement (6) } \\
\text { 3. Important Role (5) }\end{array}$ & $\begin{array}{ll}\text { 1. Intra-Team } \\
\text { Member Rivalry } \\
\text { (5) } \\
\text { 2. Unequal } \\
\text { Recognition (6) } \\
\text { 3. Punishment for } \\
\text { Mistakes (5) }\end{array}$ \\
\hline $\begin{array}{l}\text { Learning and } \\
\text { Performance } \\
\text { Orientation in Physical } \\
\text { Education Classes } \\
\text { Questionnaire } \\
\text { (LAPOPEQ) } \\
\text { (Papaioannou, 1994) }\end{array}$ & $\begin{array}{l}2786 \\
\text { students in } \\
\text { high school } \\
\text { PE classes - } \\
\text { 13-16yrs }\end{array}$ & 27 & $\begin{array}{l}\text { 1. Teacher } \\
\text { Initiated } \\
\text { Learning (6) } \\
\text { 2. Student } \\
\text { learning } \\
\text { orientation (7) }\end{array}$ & $\begin{array}{ll}\text { 1. } & \text { Student's } \\
\text { competitive } \\
\text { orientation (5) } \\
\text { 2. Student's worry } \\
\text { about mistakes } \\
\text { (5) } \\
\text { 3. Outcome } \\
\text { orientation } \\
\text { without effort (4) }\end{array}$ \\
\hline $\begin{array}{l}\text { Physical education } \\
\text { Class Climate Scale } \\
\text { (PECCS) } \\
\text { (Goudas \& Biddle, 1994) }\end{array}$ & $\begin{array}{l}254 \text { English } \\
\text { middle } \\
\text { school } \\
\text { children - } \\
13-15 y r s\end{array}$ & 27 & $\begin{array}{ll}\text { 1. } & \text { Perceived } \\
\text { choice (4) } \\
\text { 2. Teacher } \\
\text { Support (3) } \\
\text { 3. Teacher-initiated } \\
\text { learning (6) } \\
\text { 4. Student } \\
\text { learning (6) }\end{array}$ & 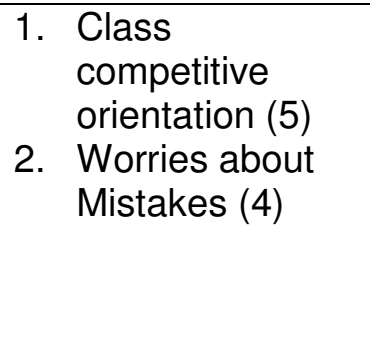 \\
\hline
\end{tabular}

because of factor cross-loading, the six factors loaded on two higher-order factors: 'mastery climate' which consisted of perceived choice, teacher support, teacher-initiated learning and student learning; and 'performance climate' which consisted of class competitive orientation and worries about mistakes (Goudas \& Biddle, 1994). 


\subsubsection{The context specific nature of sports class motivational climate}

Research has shown sports class motivational climate to be context-specific. In a study of the goal-orientations and motivational climate perceptions of two athlete groups (66 Female University Basketball players; 92 Female cross-county athletes) using the Task and Ego Orientation in Sport Questionnaire (TEOSQ) and PMCSQ-1 instruments, cross-country runners perceived their climate as more task involved, while the basketball players saw their sport climate as significantly more ego involved (Paulson, 1999). Task oriented goal scores (TEOSQ) and task involved scores (PMSCQ-1) for the runners were significantly positively correlated $(r=.69, p<.05)$. In contrast, performance oriented goal scores (TEOSQ) and ego involved scores (PMSCQ-1) for the basketball players were positively correlated $(r=.45, p<.05)$. Recognizing that research into class motivational climates should be sport specific, some of the key study areas are briefly reviewed in the following section.

\subsubsection{Sports motivational climate measurement research}

A brief review of achievement goal research in sports and physical activity settings has included (1) the relationship between goal orientations and perceived competence, (2) affective correlates of achievement goal orientations, and (3) the relationships between achievement goal climates, achievement goal orientations, and achievement behaviour (Roberts, 2001).

Research into self-efficacy (a situation-specific form of perceived competence) indicates that perceived competence influences student motivation in physical activity. Students performing a pursuit rotor-tracking task under the belief that competence is an inherent aptitude, gained no self-confidence, and exhibited negative reactions and low interest in the activity as the trial progressed (Jourdan, Bandura, \& Banfield, 1991). Performing the same task under the belief that competence is an acquirable skill led 
students to increased confidence, increased interest, and higher performances across the trial.

Task-involved individuals who have the conception that competence is an acquirable skill tend to express greater confidence, even when starting with lower perceived competence, than individuals who perform the same task in an ego-involving condition (i.e., under the conception that competence is inherent capacity) (Chi, 1993; Hall, 1990). Research has shown that perceived competence does not moderate the positive relationship between Task Involvement and perceptions of success in physical education classes (Vlachopoulas \& Biddle, 1997). Similarly, ego-involved basketball players with low perceived competence had lower success expectations than ego-involved players with higher perceived competence, or task-involved players regardless of their perceived competence (Cury, Biddle, Sarrazin, \& Famose, 1997). The consensus on this line of research is that using task involved conceptions of achievement to judge personal competence strengthens the resilience of the individuals' perceived competence (Roberts, 2001).

Affective variables often used in achievement goal research are anxiety, interest, enjoyment, and satisfaction. One of the key findings in the literature has been the link between achievement goal orientations (either task or ego), task-involved behaviour and enjoyment-interest during participation in physical activity and sports. This has been demonstrated with high school students (Duda, Chi, Newton, Walling, \& Catly, 1995; Duda \& Nicholls, 1992), summer sport camp participants (Nyheim, Kavussanu, Roberts \& Treasure, 1996; Treasure \& Roberts, 1994), and college students (Duda et al., 1995; Kavussanu, \& Roberts, 1996) in a variety of sports. In these studies, ego involvement was either inversely related or unrelated to intrinsic interest, satisfaction, or enjoyment. However, the relationship between ego involvement and enjoyment varies. Athletes with high task involvement, in combination with high or low ego orientation experience greater 
enjoyment than those athletes high in ego ordination and low in task involvement (Goudas, Biddle \& Fox, 1994).

When athletes hold an ego oriented goal dispositions, they view achievement striving as a means to an end; that end being the demonstration of superior competence (Roberts, 2001). For task oriented athletes, task mastery is an end in itself. This contrast is especially true when the two goal perspectives are compared as sources of satisfaction. A consistent pattern of this effect has been demonstrated in research with children and adolescents (Nyheim et al., 1996; Treasure \& Roberts, 1994) and elite athletes (Roberts \& Ommundsen, 1996). Ego oriented athletes mainly gain satisfaction when they demonstrate success in a normative comparison with their peers, or please their coach and parents. On the other hand, task oriented athletes find skill learning, task mastery, and improvement as signs of accomplishment, and thus, sources of satisfaction.

Studies of the relationship between achievement goal orientations, perceived competence, and the attendant achievement behaviours (adaptive or maladaptive) provide meaningful findings for coaches and their conduct of classes (Dweck \& Leggett, 1988; Kavussanu \& Roberts, 1996; Roberts, Treasure, \& Kavussanu, 1997). Adaptive behaviours such as choosing moderately challenging tasks, exerting effort, persistence in the face of obstacles or failure seem to result when an athlete is task oriented or when the athlete is ego oriented and has a high perception of their competence. However, an ego orientation coupled with a perception of low competence is associated with maladaptive behaviours such as choosing easy or very difficult tasks, and lack of effort in the face of difficulty. In a study of the link between achievement goal orientation and task choice among university athletes, athletes high in task orientation reported that they were more likely to choose activities that offer the opportunity to learn, but that were also somewhat challenging (Kavussanu \& Roberts, 1996). Variations in the effort young people exert in physical activity and sport can be attributed in part to the individual differences in 
achievement goal orientations (Cury, et al., 1997; Duda et al., 1995; Kavussanu \& Roberts, 1996; Sarrazin, Roberts, Cury, Biddle, \& Famose, 2002). Research has shown a significant positive relationship between task orientation and reported exerted effort, and a nonsignificant or negative relationship (Duda, et al., 1995; Sarrazin et al., 2002) between ego orientation and exerted effort.

Whether these adaptive behaviours occur because athletes in a task-involved setting adopt adaptive behaviour or because task goal orientations directly lead to these more positive behaviours is unclear. Being task involved in the sport and physical activity setting seems to lead to more appropriate achievement strategies by the athletes, irrespective of the athletes' achievement goal orientation. On the other hand, athletes who are ego-involved and have high-perceived competence can show adaptive achievement behaviours as well, but are vulnerable to decreasing motivation when they perceive their competence deteriorating (Dweck \& Leggett, 1988)

\subsection{A model for the structure of a sports class learning climate scale}

The model for the structure of a sports class learning climate scale (see Figure 2.2) is drawn from the literature reviewed in this chapter. The model is an integration of two environmental measurement concepts and scales. Aspects of the Perceived Motivational Climate in Sport Questionnaire \#2 (Newton \& Duda, 1993) and the Classroom Environment Scale (Moos \& Trickett, 1987) have been combined into a single concept of sports class learning climate. The key parts of the model (coach behaviour, athlete behaviour, class behaviour, and sports class learning climate) are represented by shaded blocks embedded in a social-cultural context. The arrows show the hypothesized relative weight (dashed line) and directionality of the influences of each of these factors upon the other. The relationship of these influences is currently unknown, and would be the basis of structural equation modeling (SEM) in a future study. 
The previous literature review establishes that coaching efficacy directly affects the quality of training an athlete receives. Horn's model (2002) suggests that a coach's behaviour exerts not only a direct influence on the athlete's behaviour and performance, but also an indirect influence via both the athlete's perceptions of the coach's behaviour and of the setting's climate.

This model suggests that sports class learning climate is comprised of six dimensions, two of which are found in a sub-set of the learning climate, the motivational climate. Coaching behaviour is based on personal expectations, personal values and

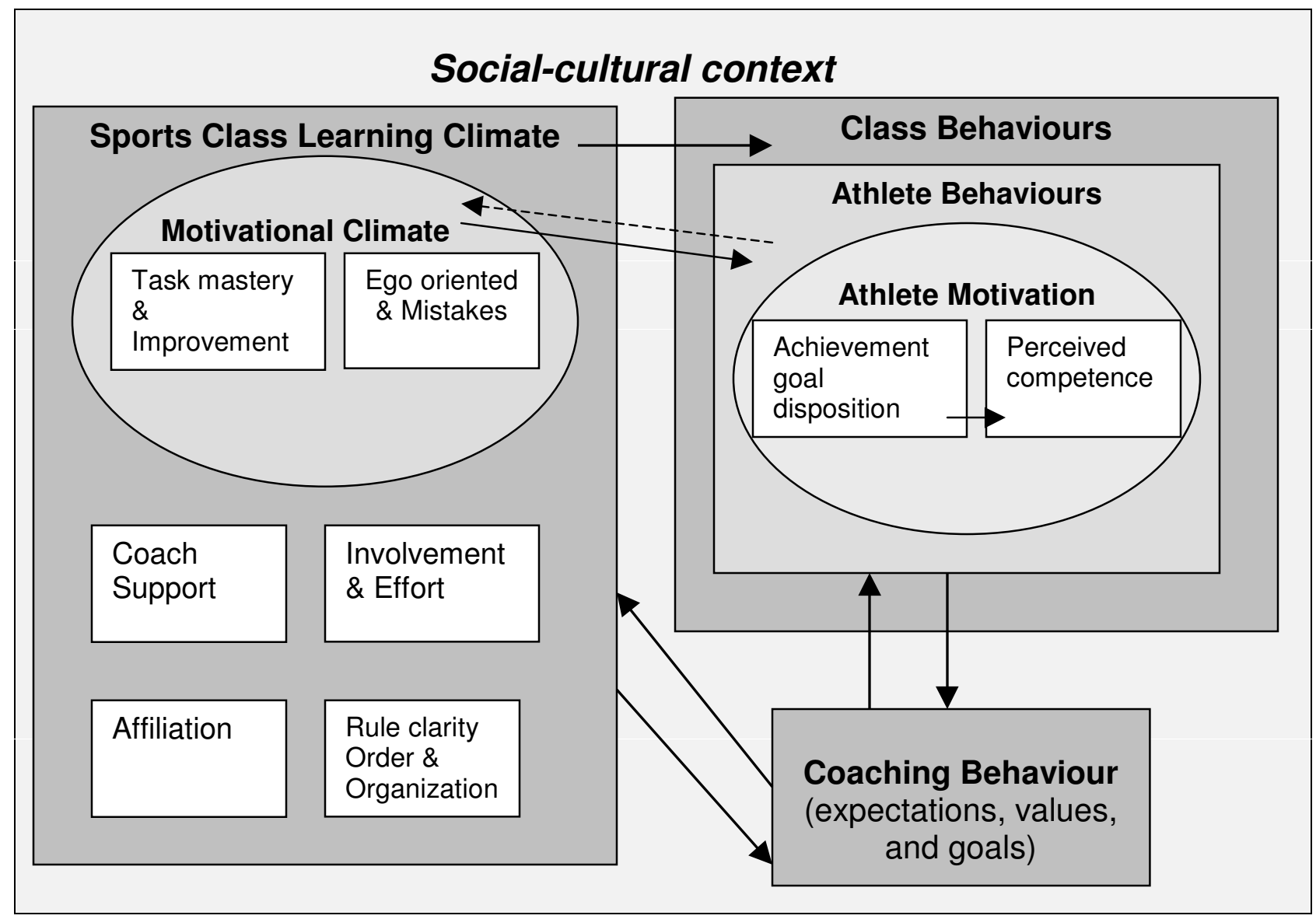

Figure 2.2. A model for the study of sports class specific learning climate goals, and is reflective of the social-cultural context in which it was developed (Horn, 2002). Coaching behaviour directs class behaviour and, in turn, is influenced by perceived class behaviours. Coaching behaviour largely determines learning climate and is 
influenced by the coach's perceptions of the learning climate. Class behaviour is an aggregation of athlete behaviours and is influenced by the learning climate. Athlete motivation has its foundation in personal achievement goal dispositions and perceived competency. Athlete behaviour (adaptive or maladaptive) is a consequence of these personal goal dispositions and the perceived motivational climate experienced in the class learning climate (Horn, 2002). A conceptual argument for this model follows.

From a social-cognitive perspective, how the athlete interprets achievement and how they perceive the sports class climate in which they are training are pivotal to an athlete's motivation. According to achievement goal theory (Nicholls, 1984), selfperceptions of competence are influenced by both personal achievement goal dispositions and experiences with significant others in that particular achievement goal setting.

The primary goal in achievement contexts (such as sports classes) is the demonstration of competence. There are two fundamental conceptions of competence (task oriented or ego oriented conceptions of competence) and, therefore, two types of achievement goals, task involved goals and ego involved goals. The coach creates perceived achievement goal structures usually by choosing either task involved goals or ego involved goals.

In this way, the coach created goal structures engender a motivational climate that makes one or the other conception of competence more conspicuous. The athlete recognizes that their competency is thus assessed from a task-involved or ego-involved perspective and they develop goals of achievement consistent with these conceptions of competence (Nicholls, 1984).

Behaviour (and, by extension, performance) in a sports class setting is multidimensional. Effective coaching and advantageous "environmental press" contribute as various drivers of sports class behaviours. While the dimensions of motivational climate are part of this "environmental press", other dimensions relating to class order, class 
organization, class grouping, time for learning, and efficacious learning (e.g. co-operative learning and mastery learning) are seen as factors in the effective classroom (Creemers, 1994).

This study adopts the perspective that teaching (coaching) is the key determinant in any learning, that teaching affects the creation of the learning climate and, in turn, is affected by it (Fraser, 1994). The learning climate of a sports class setting, which subsumes motivational climate, is a set of internal characteristics that can distinguish one learning context from another and may impact on the athletes' learning and ultimate performance. Different learning environments evoke different perceptions about athletes' achievement, and can subsequently influence athletes' performance. Athlete achievement goal dispositions, perceptions of competency, and perceptions of contextual achievement goals create motivated performance behaviour and, in turn, are affected by the class learning climate as a whole.

Coach-athlete (and, by extension, coach-class) interactions are central to the establishment of the class learning climate. These interactions in sports class settings are relevant to the athletes' performance, and are both reflections of the need and evidence of the drive to behave in certain ways. An investigation of the learning climate of a sports class setting aims to reveal aspects of coach-athlete interactions that may "press" the environment of the sports class.

\subsection{The development of a sports class learning climate scale (SCES)}

It has been suggested (Ntoumanis \& Biddle, 1999) that improvements to the understanding of sport class climate assessment might be achieved by including items from classroom-specific questionnaires such as the Classroom Environment Scale (Moos \& Trickett, 1987). The merging of the three key learning climate dimensions (Relationship dimensions, Personal Development dimensions, and System Maintenance and Change 
dimensions) and the two motivation climate dimensions (Task Involvement and Ego Involvement) may provide a more comprehensive description of the sports class climate.

A "short form" of a climate scale has advantages for the survey of sports classes. This is firstly because of the need for economy of time in testing and marking; secondly due to the expectation that many coaches, or club administrators, may not have access to computer-assisted analysis of the results; and thirdly because the sports class as a whole is the unit of measurement, and not the individual athlete. One of the key uses of a sports class climate scale would be to measure the consensual perception of the learning climate in that class, modify chosen components if desired, and measure again.

The addition of CES scales has been recommended as a methodological improvement when assessing physical activity settings climates and the PMCSQ-2 has been seen as a promising tool in the measurement of sports class climate (Ntoumanis \& Biddle, 1999). Along with the proven construct validity of these two instruments (Newton, Duda, \& Yin, 2000; Fraser \& Fisher, 1983), it is reasonable to suggest the use of both as the basis for the creation of a new sports class learning climate scale - the Sports Class Environment Scale (SCES).

The short form of the CES has six scales in a 24-question survey. These scales are Involvement, Affiliation, Teacher Support, Task Orientation, Competition, and OrderOrganization \& Rule Clarity. The PMCSQ-2 has six scales, with three in each of the two key dimensions of Task Mastery orientation (Cooperative Learning, Role, Effort \& Improvement) and Ego-performance orientation (Punishment, Unequal recognition, and Intra-Team rivalry). Combining these scales at face value results in the construction of a proposed "short form" sports class learning climate scale. Our model shows a combination resulting in six scales for the sports class learning climate. The initial SCES subscales for consideration are Involvement and Effort, Affiliation, Coach Support, Task Involvement and Improvement, Ego Orientation and Mistakes, and Rule Clarity, Order and Organization. 
These scales are described (with example questions) in Table 2.6. A copy of the draft SCES used in initial instrument trials can be found in Appendix 4.

Table 2.6. A description of each of the subscales in the draft SCES.

\begin{tabular}{|l|l|l|}
\hline Dimension Scale & Definition & Example Scale item \\
\hline $\begin{array}{l}\text { Involvement and } \\
\text { Effort }\end{array}$ & $\begin{array}{l}\text { The gymnasts' attentive interest } \\
\text { in class activities and effort in } \\
\text { training. }\end{array}$ & $\begin{array}{l}\text { Q1.Gymnasts in this class put a } \\
\text { lot of energy into what they do } \\
\text { here }\end{array}$ \\
\hline Affiliation & $\begin{array}{l}\text { The friendship gymnasts feel for } \\
\text { each other, helping each other } \\
\text { learn and enjoying working } \\
\text { together. }\end{array}$ & $\begin{array}{l}\text { Q14. Gymnasts in this class are } \\
\text { friendly towards each other. }\end{array}$ \\
\hline $\begin{array}{l}\text { Coach support } \\
\text { Improvement }\end{array}$ & $\begin{array}{l}\text { The amount of help and } \\
\text { encouragement the coach } \\
\text { manifests toward the gymnasts. }\end{array}$ & $\begin{array}{l}\text { Q27. The coach does not go out } \\
\text { of his or her way to help } \\
\text { gymnasts }\end{array}$ \\
\hline $\begin{array}{l}\text { The motivation primarily to } \\
\text { become competent in the tasks at } \\
\text { hand and demonstrate } \\
\text { improvement. }\end{array}$ & $\begin{array}{l}\text { Q16. The main point of this class } \\
\text { is to improve in each practice. } \\
\text { Q28. Doing your best } \\
\text { performance is more important } \\
\text { than winning. }\end{array}$ \\
\hline $\begin{array}{l}\text { Rule Clarity } \\
\text { Ond Order \& }\end{array}$ & $\begin{array}{l}\text { Organization } \\
\text { following consistent rules, } \\
\text { behaving in an orderly manner, } \\
\text { and the overall organization of } \\
\text { the class. }\end{array}$ & $\begin{array}{l}\text { Q18. Rules in this class seem to } \\
\text { change a lot. }\end{array}$ \\
$\begin{array}{l}\text { The motivation to display } \\
\text { appearing incompetent [make } \\
\text { mistakes]) through performance } \\
\text { comparison with others. }\end{array}$ & $\begin{array}{l}\text { Q11. In this class making } \\
\text { mistakes is OK. } \\
\text { Q35. In this class, gymnasts only } \\
\text { feel successful when they win } \\
\text { competitions. }\end{array}$ \\
\hline
\end{tabular}

\subsubsection{Summary}

This study aimed to develop and validate a new learning climate scale - the Sports Class Environment Scale (SCES) for measuring the learning and motivational climate of gymnastics sports classes. The preceding literature places this study into a conceptual framework, and an applied research narrative. The review began with the socio-ecological 
approach to environmental determinants of behaviour, and the concept that environments can be organized to maximize human functioning and personal growth. The historical antecedents of needs-based behaviour and environmental press, and the theoretical underpinnings to class learning climate and achievement motivation climate, were described. Some of the key methodological questions about learning climate measurement, such as the distinction between school level and class level climate, the level of analysis and the dimensions of analysis were broached. A detailed review of assessing class learning climate and physical education and sport motivational climate followed. This literature led to the integration of learning climate and motivational climate measures and the proposed model that describes sports class learning climate. 


\subsection{METHOD}

\subsection{Introduction}

The study sought to develop and validate a new learning climate scale, the Sports Class Environment Scale (SCES), for the measurement of the learning and motivational climate of gymnastics sports classes. In spite of the potential value of class learning climate research to the field of sports class behavioural studies, no research has consolidated the fields of classroom learning climate research and sports class motivational climate studies.

The prior research outlined in the literature review has guided the design of the current research method. The development of the initial survey instrument and the collection and analysis of data was conducted over three phases. These phases are detailed sequentially in Figure 3.1. Each of these phases involved four steps, and the details of each step will be provided.

\begin{tabular}{|cc|}
\hline $\begin{array}{c}\text { Phase 1 } \\
\text { Develop an initial survey } \\
\text { instrument }\end{array}$ \\
\hline 1. Create an initial SCES \\
\hline 2. $\begin{array}{c}\text { Using learning and } \\
\text { motivational climate } \\
\text { research, review the } \\
\text { survey subscales and } \\
\text { scoring }\end{array}$ \\
\hline 3. Combine the CES and \\
PMCSQ-2 to create a \\
first draft scale \\
relevant to competitive \\
gymnastics classes
\end{tabular}

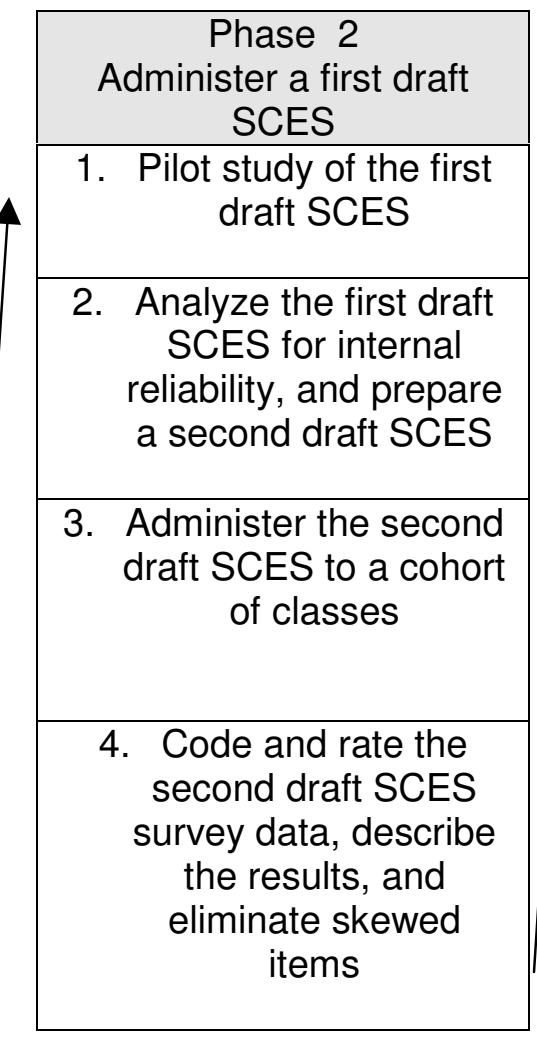

\begin{tabular}{|c|c|}
\hline & $\begin{array}{c}\text { Phase } 3 \\
\text { Test the SCES subscales }\end{array}$ \\
\hline & $\begin{array}{l}\text { 1. Conduct an } \\
\text { Exploratory Factor } \\
\text { Analyses }\end{array}$ \\
\hline & $\begin{array}{l}\text { 2. Develop a revised } \\
\text { second draft SCES } \\
\text { and check internal } \\
\text { reliability and } \\
\text { discriminant validity }\end{array}$ \\
\hline & $\begin{array}{l}\text { 3. Compare competitive } \\
\text { gymnastics sports } \\
\text { classes in terms of } \\
\text { class learning climate }\end{array}$ \\
\hline & $\begin{array}{l}\text { 4. Modify the revised } \\
\text { second draft SCES } \\
\text { based on the findings. } \\
\text { Suggest future } \\
\text { directions for } \\
\text { improvement and } \\
\text { utilization of the SCES }\end{array}$ \\
\hline
\end{tabular}

Figure 3.1 Phases and steps in the study 


\subsection{Develop the initial SCES instrument}

The development of the SCES moved through three phases. Phase one began with an adaptation of the CES (Fraser \& Fisher, 1983) to form the initial SCES. This scale became problematic, and was further developed with subscales and items drawn from motivational climate instruments. This produced a first draft SCES for pilot testing. Revisions after pilot testing developed a second draft scale for initial testing in step 3 of phase two. Factor analysis of the resulting survey data in phase three led to a revision of the second draft SCES.

\subsubsection{Create an initial SCES.}

An initial draft of the SCES was adapted directly from a short form (see Appendix 1) of the CES (Fraser \& Fisher, 1983) with small changes made to the wording of subscale items. For example, "teacher" became" coach, and "student" became "gymnast". The initial SCES consisted of 24 items of the same design and rating system used in the CES. The initial SCES consisted of 24 "either-or" items, with four questions in each for the following subscales: Involvement, Affiliation, Coach Support, Task Involvement, Order, Organization, and Rule Clarity. Each question was scored 3 and 1 respectively for the responses "Yes" or "No". Underlined items or items noted with [R] were scored in reverse. Omitted or invalid responses were scored with a 2. Statisticians highlighted problems with the social desirability of answers when using an "either-or" scoring method. It was advised that issues of response variance and internal reliability would lead to the scale being defective.

\subsubsection{Review the initial SCES subscales and scoring.}

Subsequently, expert reviewers, in the field of sport psychology, called for a review of the initial SCES in light of the literature in achievement motivation in sport. Achievement motivation applies to persons striving to achieve a personal or socially constructed goal in an achievement setting (Roberts, 2001). Sport classes are common examples of 
achievement goal settings. The motivational climate of the sports class has been described under two achievement goal dimensions, Task Involvement and Ego Involvement of the class climate (Roberts, 1992). Learning climate and motivational climate are terms that have rarely overlapped; however, the recommended literature review prompted the use of motivational climate dimensions as potential subscales in the study of sports class learning climates (Ntoumanis \& Biddle, 1999). The use of a Likert rating scale was recommended to help increase subscale reliability.

\subsubsection{Adding PMCSQ-2 subscales to the initial SCES}

All scale items (58 in total) of the PMCSQ-2 scale (Newton \& Duda, 1993) were tabled and considered at face value (See Appendix 2). The PMCSQ-2 subscale of IntraTeam Rivalry addresses issues of competitive rivalry between team-mates in an effort to be selected to compete (game play). Intra-team selections rarely occur in competitive gymnastics, as all gymnasts are given equal opportunity to compete on "game" days. These subscale items were therefore deleted from the potential scale. There was some conceptual overlap between other scale items from the CES and the PMCSQ-2. For example: Involvement (CES) with Effort and Important Role (PMCSQ-2), Task Orientation (CES) with Improvement (PMCSQ-2), Competition (CES) with Cooperation (PMCSQ-2), and Teacher Support (CES) with Unequal Recognition (PMCSQ-2) and Punish for Mistakes (PMCSQ-2). The CES primary dimensions (Relationship, Personal Development, System Maintenance and Change) did not fully capture the Task Involvement and Ego Involvement dimensions that are the foundation of the PMCSQ-2 scale. The PMCSQ-2 did not seem to capture some aspects of effective gymnastics classes (Dowdell, 2002c) such as Affiliation, Coach Support, and Rule clarity, Order and Organization that are subscales in the CES. To accommodate these deficits, a combined scale was created that contained 39 questions theoretically grouped into eight subscales (Involvement and Effort, Affiliation, Coach Support and Recognition, Rule Clarity, Order and Organization, Task Orientation 
and Improvement, and Ego Orientation and Worry about Mistakes). This combined scale is inclusive of Moo's (1976) three social environment dimensions of Relationships, Personal Development, System Maintenance and Change dimensions, and the two primary motivational climate dimensions of Task Involvement and Ego Involvement (Ames, 1992). Changes to relevant terms in the draft SCES subscales were made, for example: "Students" to "Gymnasts" and "on this team" was replaced with "In this class". This draft SCES scale was then subjected to a further two step expert review.

\subsubsection{Send the initial SCES for expert review.}

Before the SCES was administered, it was sent to three objective University researchers and six expert gymnastics coaches for review (see Appendix 3). The gymnastics coaches were all highly experienced practitioners in competitive clubs in metropolitan and regional Queensland and five were tertiary educated in health sciences, human movements or education. The 39 questions were listed randomly and without subscale labels. Each reviewer was initially asked to sort the questions into 6-8 groups and label the group or subscale item. Questions thought to be irrelevant were to be identified and suggestions for other or additional questions were requested. Questions were retained if three or more reviewers grouped them under the same subscale heading. The results grouped 36 questions under eight subscales. The expert coach reviewers used analogous labels for the suggested scales.

These labels were:

- $\quad$ Effort, energy, intensity, work ethic

- $\quad$ Socializing or gymnast relationships

- $\quad$ Organization, structure and class management

- $\quad$ Favouritism, fairness, respect or feeling valued

- $\quad$ Cooperation \& Teamwork 
- How competitive is the class

- Coach-Gymnast communication

- $\quad$ Positive OR negative coach / gymnast behaviours

As well as consideration by University reviewers and expert gymnastics coaches, two upper primary school age gymnasts were interviewed about each question's clarity. These interviews raised concerns about the wording of question 3 ("important" was deleted), question 21 ("the coach is more like a friend than a person in charge" became, "the coach is more like a friend than a teacher") and question 5 ("punished" was deleted and replaced with "picked on"). The first draft of the SCES scale (see Appendix 4) finally contained 36 revised questions under six subscale items shown in the proposed model of sports class learning climate (Figure 2.2). These subscales were Involvement and Effort, Affiliation, Coach Support, Task Orientation and improvement, Ego Orientation and Mistakes, Rule Clarity and Order and Organization.

\subsubsection{Survey Readability}

There was a range of ages (8-18 years) in the cohort surveyed. Ability to be able to read at a level to comprehend the scale items is an important aspect of instrument administration. Survey questions were designed with this in mind, and kept as simple and relevant as possible. The SCES scale readability level was a Flesch-Kincaid Grade level of 5.2 (Johnson, 1998) which equates to Queensland School Grade 4 through 5. To ensure most gymnasts were at this age or above, no Level 2 competitive gymnast survey responses were included in the results, as some of these gymnasts may have been in school grade 3 or lower. Gymnasts in Level 3 and above are typically in school grades 4 through 11. 


\subsection{Administer the drafts of the SCES}

\subsubsection{Pilot study of the first draft SCES}

A cohort of competitive gymnasts from a local competitive clubs was invited to participate in the pilot study. The first draft SCES was administered to 41 gymnasts ( 31 female and 10 male) between the ages of 10 and 16 years. Because no very young children were in the cohort and the nature of the pilot survey posed no risks to the participants, a simplified informed consent (via a single page letter) was gained from the parents, participants, and club directors. A supervisor read the survey completion directions (see Appendix 4), and respondents were given a practice question at the head of the questionnaire to familiarize themselves with using the survey form. Participants completed the survey silently and independently by "ticking" their response under one of the four given responses - a lot like my class, a bit like my class, not much like my class, or not at all like my class. The time required for the respondents to complete the survey was between 15 and 20 minutes. This first draft SCES instrument is intended to measure the sports class learning climate perceptions (the consensual beta press) of all the individuals in the nominated classes. Because of this, the class group was the unit of measurement and the individual scores in the class under study were averaged to arrive at a class climate measurement.

\subsubsection{Analyze the first draft SCES for internal reliability}

Initial data analysis and all other statistical analyses were performed using the Statistical Package for the Social Sciences (SPSS) for Windows Version 13. An alpha level of .05 was used for all statistical tests. The entire scale was checked for internal consistency by analyzing the 41 gymnasts' responses to the 36 items and arriving at a Cronbach's alpha coefficient of .69 (see Appendix 9). Subscale inter-item correlations above .5 were considered for change or removal, as these values of $r$ exceed the tabulated $r$ values for the appropriate degrees of freedom $(d f=41-2)$ (Thomas, Nelson \& 
Silverman, 2005). This occurred with subscale Affiliation question 14 and question $26(r=$ $.68)$, and subscale Ego Orientation questions 17 and $23(r=.63)$. To maintain a similar number of questions in each subscale before initial scale testing, two of the four contentious items were re-written. This was done to remove difficult to understand words (e.g. excel), or to deal with any ambiguity. Affiliation question 26, "In this class, gymnasts help each other to learn and to excel" was reworded to "In this class, gymnasts help each other to learn and to improve". Ego Orientation question 17 changed from "In this class the best gymnasts 'get noticed' by the coach" to 'In this class, only the best gymnasts 'get noticed' by the coach". A second draft SCES was prepared for initial test administration (see Appendix 4).

\subsubsection{Administer the second draft SCES to a cohort of gymnastic classes}

The Queensland Gymnastics Association Inc. is responsible for gymnastics sports in Queensland, and gave permission for this project to be conducted within member clubs (see Appendix 5). A cohort of convenience was selected from the approximately 50 competitive gymnastics clubs in Queensland, with at least two clubs from each of the eight regions of the state being invited to participate. Twenty-nine competitive artistic gymnastics clubs were contacted to participate in the SCES (see Appendix 6). This group of clubs included 11 metropolitan clubs and 18 regional clubs. Thirteen clubs formally agreed to participate (see Appendix 7), representing a potential cohort of 238 female gymnasts and 62 male gymnasts. Of the 13 clubs, 11 clubs were in the top twelve competitive club rankings in the State of Queensland. Each club received a package containing information sheets for parents, gymnasts and coaches, as well as survey forms and survey instructions (see Appendix 8).

\subsubsection{Code and rate the second draft SCES survey data}

The returned surveys were coded for each participant, their gender, their gymnastic level, their club membership, and their club type. Participants' responses to each item 
were scored 1 ('Not at all like my class'), 2 ('Not much like my class'), 3 ('A bit like my class') or 4 ('Very much like my class') with 4 being the 'highest' score and 1 being "lowest”. These scores for each participant's subscale totals were computed to arrive at a final score with a range of 6 up to 24. Each participant's results were entered for each item under a subscale, and a total and average for the set of subscale items were computed. The generated scores for each subscale item were statistically described and presented in frequency tables. Any subscale item (question) that was highly skewed (dominated the total score for that subscale) was identified. Three items of this type were removed from their subscale.

\subsection{Test the second draft subscales, and revise the SCES}

\subsubsection{Conduct an exploratory factor analysis and revise the SCES}

Highly skewed subscale items (Affiliation item Q2, Coach Support item Q9, and Task Mastery item Q10) were removed from their respective subscales, and the resultant items were subjected to an exploratory factor analysis using principal component extraction with Varimax rotation and Kaiser normalization. The appropriateness of the factor analytic model was tested and confirmed using the Kaiser-Meyer-Olkin measure and Bartlett's test of sphericity. The Kaiser-Meyer-Olkin measure of sampling adequacy tests whether the partial correlations among variables are small. Bartlett's test of sphericity tests whether the correlation matrix is an identity matrix, which would indicate that the factor model is inappropriate. Taken together, these tests provide a minimum standard that should be passed before a factor analysis should be conducted. A revised second draft SCES using identified components was formed.

\subsubsection{Test the SCES subscales for internal reliability and discriminant validity}

Each of the identified subscales in the second draft SCES were assessed for internal consistency and discriminant validity by analyzing the participant's responses to 
the given items using Cronbach's alpha coefficient and inter-item correlation. A Cronbach's Alpha coefficient of greater than 0.7 was considered very satisfactory, while a coefficient of 0.5 or greater (for subscales with less than 10 items) was considered adequate (Pallant, 2004). Further small changes to the wording of scale items occurred through expert University researcher review, and the revised SCES was prepared for future testing. Interitem correlation coefficients of approximately 0.3 supported the discriminatory value of the subscales.

\subsubsection{The class learning climate of competitive gymnastics sports classes}

The competitive WAG clubs in Queensland differ not only in their competitive level, but also in their training regimes. One key characteristic of the higher ranked gymnastics clubs is the hours of training undertaken by their junior and senior gymnasts. Many of the higher ranked clubs are characterized by their competitive gymnasts training a greater number of average hours per week than other ranked clubs. Most gymnasts in the competitive clubs above ranking four in the state train $14-22$ hours per week. Competitive gymnasts in the competitive clubs below ranking number four train 9 - 18 hours per week. The clubs in the study cohort were grouped under one of two types, "low training hours" and "high training hours" based on their weekly number of training hours in comparison with the average number of training hours for all clubs. Clubs designated "low training hours" had weekly training hours lower than the "All Clubs" mean training hours, while clubs in the "high training hours" group had weekly training hours that exceeded the "All clubs" training hours average. The means and standard deviations for all clubs, low training hour clubs, and high training hours are shown in Table 3.1.

The survey data from the second draft SCES subscales were used as dependant variables in a multiple regression analysis (MANOVA) to compare the two clubs types (low training hours and high training hours) in the cohort. Using the general linear model, a test of the null hypotheses (to a significance level $p<.05$ ) was conducted to discern if a 
relationship existed between the independent variables (in this case, club type, gender and gymnastics level) and the means of the dependent variables (the SCES subscales). This process was achieved in two steps, because the first club type (high training hours) consisted of one gender only - female gymnasts. The first MANOVA examined the effect of club type on the SCES subscales, while the second MANOVA tested the effect of gender and gymnastics level of the "low training hours" clubs.

Table 3.1 Means and standard deviations for all clubs, and club types

\begin{tabular}{|c|c|c|c|}
\cline { 2 - 4 } \multicolumn{1}{c|}{} & All Clubs & $\begin{array}{c}\text { Low training hours } \\
\text { clubs }\end{array}$ & $\begin{array}{c}\text { High training hours } \\
\text { clubs }\end{array}$ \\
\hline $\begin{array}{c}\text { Mean of training } \\
\text { hours for Level 3-5 } \\
\text { gymnasts }\end{array}$ & $\begin{array}{c}12.6 \\
(1.84)\end{array}$ & $\begin{array}{c}11.7 \\
(1.25)\end{array}$ & 14.7 \\
(Standard Deviation) & & $1.15)$ \\
\hline Mean of training & 17.7 & 16.1 & 21.2 \\
hours for Level 6-10 & $(2.94)$ & $(2.04)$ & $(0.3)$ \\
gymnasts & & & \\
(Standard Deviation) & & & \\
\hline
\end{tabular}

\subsubsection{Modify the second draft SCES based on the findings}

The second draft SCES subscale dimensions were considered in the light of the exploratory factor analysis. With a discrete loading of factors, sufficient evidence of independent dimensionality was assumed. It was considered that the structure of the second draft SCES might vary. For example, the structure modeled in Figure 2.2 might be approximated. The model suggests that all learning climate factors are discrete, but with two subscales (task and ego orientations) being part of a sub-set of the learning climate. However, it was deemed possible that one or more climate dimensions might result, and that motivational climate might be a super-ordinate (instead of subordinate) aspect of the sports class learning climate. It was also possible that any resultant learning climate dimensions and any resultant motivational climate dimensions were not concomitant measures of sports class learning climate. 


\subsection{ANALYSES and RESULTS}

\subsection{Introduction}

The development of the initial survey instrument and the collection and analysis of data were conducted over three phases as previously outlined in Figure 3.1. These phases are displayed again Figure 4.1 with the addition of bolding from Phase 2, step 4. This chapter presents the analyses and results of the study Phase 2 (step 4) to the end of Phase 3.

\begin{tabular}{|cc|}
\hline $\begin{array}{c}\text { Phase 1 } \\
\text { Develop an initial survey } \\
\text { instrument }\end{array}$ \\
\hline 1. Create an initial SCES \\
\hline 2. $\begin{array}{c}\text { Using learning and } \\
\text { motivational climate } \\
\text { research, review the } \\
\text { survey subscales and } \\
\text { scoring }\end{array}$ \\
$\begin{array}{c}\text { Combine the CES and } \\
\text { PMCSQ-2 to create a } \\
\text { first draft scale } \\
\text { relevant to competitive } \\
\text { gymnastics classes }\end{array}$ \\
\hline 4. Send the first draft \\
SCES for expert \\
review
\end{tabular}

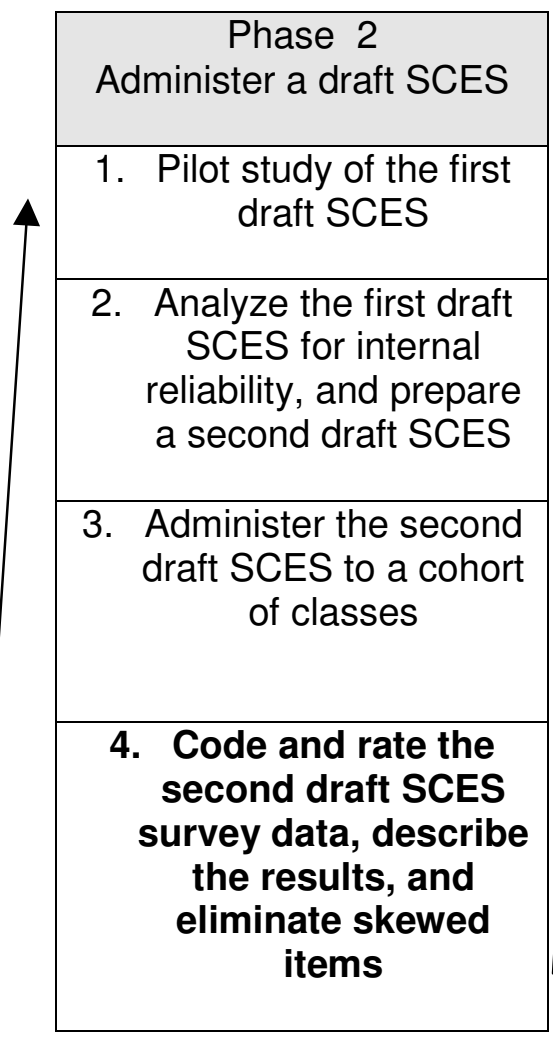

\begin{tabular}{|c|}
\hline Phase 3 \\
Test the SCES subscales \\
\hline $\begin{array}{c}\text { 1. Conduct an } \\
\text { Exploratory Factor } \\
\text { Analyses }\end{array}$ \\
\hline $\begin{array}{c}\text { 2. Develop a revised } \\
\text { second draft SCES and } \\
\text { check internal } \\
\text { reliability and } \\
\text { discriminant validity }\end{array}$ \\
\hline $\begin{array}{c}\text { Compare competitive } \\
\text { gymnastics sports } \\
\text { classes in terms of } \\
\text { class learning climate }\end{array}$ \\
\hline $\begin{array}{c}\text { Modify the revised } \\
\text { second draft SCES } \\
\text { based on the findings. } \\
\text { Suggest future } \\
\text { directions for } \\
\text { improvement and } \\
\text { utilization of the SCES }\end{array}$ \\
\hline
\end{tabular}

Figure 4.1. Phases and steps in the study

Firstly, the responses to the second draft SCES from participants in each club will be summarized, and the collected data statistically described. Secondly, reasons for the exclusion of some SCES subscale items are explained and the results of the subsequent principal component factor analysis reported. A revised second draft SCES evolved from this exploratory factor analysis, and is presented at the end of the chapter. Thirdly, the Cronbach's Alpha coefficients and the average inter-item correlation for each subscale of the revised second draft SCES were analyzed and reported. Finally, using the revised 
second draft SCES subscales as dependent variables, multivariate analyses of variance were conducted to compare classes on club type, gender and level.

\subsection{Results from the learning climate survey of competitive gymnastics sports classes}

\subsubsection{The Participants}

Thirteen competitive gymnastics clubs (by membership address) returned completed SCES surveys. However, two of these clubs have a common competitive class and were considered as one club for the purposes of the data analysis. Of the " 12 " clubs with reportable data, two clubs returned a very small number of completed surveys $(n=4$ and $n=7$ respectively) most of which were by non-competitive Level 2 gymnasts. Consequently, their club results were removed from the study.

The final cohort consisted of 208 gymnasts (180 females and 28 males competing in National Levels 3 -10) from 10 clubs. Nine of the remaining 10 clubs were ranked in the top ten competitive clubs in the state, however, clubs in this group differ in the amount of gymnastics training participated in per week and in the gender of their gymnasts. A description of the gymnasts by gender, competitive level and training hours per week for all clubs and club types (low and high training hours) is shown in Table 4.1

Table 4.1. Description of cohort by gender, competitive level and training hours

\begin{tabular}{|c|c|c|c|c|c|c|}
\cline { 2 - 7 } \multicolumn{1}{c|}{} & $\begin{array}{c}\text { Male } \\
\text { Gymnasts }\end{array}$ & $\begin{array}{c}\text { Female } \\
\text { Gymnasts }\end{array}$ & $\begin{array}{c}\text { Level 3-6 } \\
\text { (Junior } \\
\text { gymnasts) }\end{array}$ & $\begin{array}{c}\text { Level 7-10 } \\
\text { (Senior } \\
\text { gymnasts }\end{array}$ & $\begin{array}{c}\text { Training } \\
\text { Hours / wk } \\
\text { Level 3-6 }\end{array}$ & $\begin{array}{c}\text { Training } \\
\text { Hours / wk } \\
\text { Level 7-10 }\end{array}$ \\
\hline $\begin{array}{c}\text { All clubs } \\
(\mathrm{n}=10)\end{array}$ & 28 & 180 & 150 & 58 & $9-18$ & $12-21.5$ \\
\hline $\begin{array}{c}\text { Low training } \\
\text { hours Clubs } \\
(\mathrm{n}=7)\end{array}$ & 28 & 130 & 121 & 37 & $9-12$ & $12-18$ \\
\hline $\begin{array}{c}\text { High training } \\
\text { hours clubs } \\
(\mathrm{n}=3)\end{array}$ & 0 & 50 & 29 & 21 & $14-18$ & $20-21.5$ \\
\hline
\end{tabular}


The top three ranked clubs (of the top 4 gymnastics clubs in the state) were also clubs with higher weekly training hours (average of $14.7-21.2$ hours) for many of their exclusively female competitive gymnasts. This grouping is shown in Table 3.1 and repeated in Table 4.2. Three of the low training hours clubs had male competitive gymnastic classes that responded to the SCES survey.

Table 4.2. Means and standard deviations for all clubs, and club types

\begin{tabular}{|c|c|c|c|}
\cline { 2 - 4 } \multicolumn{1}{c|}{} & All Clubs & $\begin{array}{c}\text { Low training hours } \\
\text { Clubs }\end{array}$ & $\begin{array}{c}\text { High training hours } \\
\text { clubs }\end{array}$ \\
\hline $\begin{array}{c}\text { Mean of training } \\
\text { hours for Level 3-5 } \\
\text { gymnasts }\end{array}$ & $\begin{array}{c}12.6 \\
(1.84)\end{array}$ & $\begin{array}{c}11.7 \\
(1.25)\end{array}$ & 14.7 \\
(Standard Deviation) & & & $(1.15)$ \\
\hline Mean of training & 17.7 & 16.1 & 21.2 \\
hours for Level 6-10 & $(2.94)$ & $(2.04)$ & $(0.3)$ \\
gymnasts & & & \\
(Standard Deviation) & & & \\
\hline
\end{tabular}

Because of the unequal distribution of males among the cohort of clubs, two separate MANOVAs were conducted. To limit the effect of gender, the first MANOVA tests the effect of club type (Low training hours clubs versus High training hours clubs) as measured by the SCES subscales. The second MANOVA tests the effect of gender and gymnastics level in the lower training hours clubs that include male and female gymnasts.

\subsubsection{Results of the second draft SCES survey}

Descriptive statistics for the SCES items are shown in Table 4.3. Of the 36 items in the draft SCES, three were excluded from further analysis as they were highly skewed (skewness scores $> \pm 3.0$ ) and accounted for approximately $90 \%$ of the total score response of that subscale. Affiliation item Q2 (85.7\%, -3.0), Coach Support item Q9 (87.4\%, -3.47) and Task Orientation item Q10 (91.3\%, -4.45) were deleted from their respective subscales. All item mean scores for the climate subscales of Involvement, Affiliation, Coach Support, Task Orientation, and Order, Organization and Rule Clarity were very near or above 3 ( $A$ bit like my class or Very much like my class), with the exception of Coach Support item Q.21 ( $\mathrm{M}=2.52, \mathrm{SD}=0.98)$. 
Table 4.3. Descriptive summary of second draft SCES item scores $(n=208)$

\begin{tabular}{|c|c|c|c|}
\hline Subscale Items (question) & Mean & SD & $\begin{array}{l}\text { Skew } \\
\text { ness }\end{array}$ \\
\hline InvQ1 Gymnasts in this class put a lot of energy into what they do here & 3.41 & 0.61 & -.64 \\
\hline InvQ7 Gymnasts day-dream in this class & 2.94 & 0.80 & -.24 \\
\hline $\begin{array}{l}\text { InvQ13 Gymnasts often get bored and check how soon their class } \\
\text { Finishes }\end{array}$ & 2.94 & 0.91 & -.35 \\
\hline $\begin{array}{l}\text { InvQ19 This class is more a time to catch up with friends than a place to } \\
\text { Learn skills }\end{array}$ & 3.48 & 0.72 & -1.32 \\
\hline InvQ25 Gymnasts in this class pay attention to what coach is saying & 3.39 & 0.67 & -.86 \\
\hline InvQ31 Gymnasts do a lot of work in this class & 3.50 & 0.64 & -1.17 \\
\hline AffQ2 Gymnasts in this class don't get to know each other & 3.75 & 0.69 & -3.0 \\
\hline $\begin{array}{l}\text { AffQ8 Gymnasts in this class aren't very interested in getting to know } \\
\text { each other }\end{array}$ & 3.74 & 0.61 & -2.70 \\
\hline AffQ14 Gymnasts in this class are friendly towards each other & 3.72 & 0.49 & -1.51 \\
\hline AffQ20 In this class gymnasts do not support each other & 3.71 & 0.64 & -2.53 \\
\hline AffQ26 In this class, gymnasts help each other to learn \& to imp & 3.49 & 0.64 & -1.08 \\
\hline $\begin{array}{l}\text { AffQ32 In this class, each gymnast feels as if they are an important team } \\
\text { member }\end{array}$ & 3.45 & 0.75 & -1.37 \\
\hline $\begin{array}{l}\text { CSQ3 If gymnasts want to talk about something the coach will find time } \\
\text { to do it }\end{array}$ & 3.07 & 0.89 & -.72 \\
\hline ach is not interested in the progres & 3.79 & 0.60 & -3.47 \\
\hline $\begin{array}{l}\text { CSQ15 In this class the coach encourages gymnasts to help each other } \\
\text { learn }\end{array}$ & 3.55 & 0.66 & -1.3 \\
\hline CSQ21 The coach & 2.52 & 0.98 & 0.73 \\
\hline CSQ27 The & 3.29 & 0.93 & -1.14 \\
\hline ts who try hard get praised & 3.34 & 0.88 & -1.33 \\
\hline TOQ4 In this class, the coach wants us to try new ski & 3.67 & 0.56 & -1.84 \\
\hline TOQ10 Practicing skills is important in this class & 3.89 & 0.36 & -4.45 \\
\hline TOQ1 & 3.74 & 0.44 & -1.11 \\
\hline TOQ22 In this cla & 3.72 & 0.60 & -1.3 \\
\hline TOQ28 Doing yc & 3.70 & 0.67 & -2.4 \\
\hline $\begin{array}{l}\text { s, the coach makes sure gymnasts improve on skills } \\
\text { good at }\end{array}$ & 3.70 & 0.49 & -1.38 \\
\hline sts get picked on when they make a mistake & 1.89 & 1.01 & .72 \\
\hline EOQ11 In this cla & 1.85 & 0.84 & .72 \\
\hline only the best gymnasts 'get I & 1.86 & 0.96 & .79 \\
\hline EOQ23 In this class, the coach favours some gymnasts more than others & 1.94 & 1.0 & .68 \\
\hline EOQ29 In this class the focus is on perfect performance & 2.74 & 0.96 & -.41 \\
\hline $\begin{array}{l}\text { EOQ35 The ONLY time gymnasts feel good about themselves is when } \\
\text { they win competitions }\end{array}$ & 1.77 & 0.81 & .75 \\
\hline ORCQ6 This is a disorganized class & 3.55 & 0.77 & -1.84 \\
\hline ORCQ12 In this class gymnasts know what the general rules are & 3.63 & 0.59 & -1.53 \\
\hline ORCQ18 Rules in this class seem to change a lot & 3.31 & 0.79 & -.92 \\
\hline ORCQ24 Gymnasts "muck-around" a lot in this class & 2.91 & 0.83 & -.39 \\
\hline ORCQ30 The coach explains what will happen if a gymnast breaks a & 3.19 & 0.91 & -.94 \\
\hline ORCQ36 The coach explains what the class rules are & 3.35 & 0.79 & -.90 \\
\hline
\end{tabular}

Key: deleted item 
This result might have because the item statement was seen as ambiguous. All the mean scores for the Ego Orientation subscale were below 2 (Not much like my class or Not at all like my class) except Item Q29 ("In this class the focus is on perfect performance"). A possible reason for this is that most gymnastics classes might perceive striving for perfection as a positive learning climate characteristic and therefore score this item higher than the other Ego Orientation items. The frequency tables for second draft SCES subscale items are shown in Appendix 10.

Descriptive statistics for subscale scores are shown in Table 4.4. Subscale mean scores are above 19 (out of a possible 24) in the Involvement and Effort, Affiliation, Coach Support, Task Orientation and Improvement, and Rule Clarity, Order and Organization subscales.

Table 4.4. Descriptive statistics for second draft SCES subscale scores

\begin{tabular}{|c|c|c|c|c|c|}
\hline $\begin{array}{c}\text { Descriptive } \\
\text { Statistics }\end{array}$ & Mean score & $\begin{array}{c}\text { Standard } \\
\text { Deviation }\end{array}$ & $\begin{array}{c}\text { Minimum } \\
\text { score }\end{array}$ & $\begin{array}{c}\text { Maximum } \\
\text { score }\end{array}$ & Skewness \\
\hline Involvement & 19.62 & 2.62 & 9 & 24 & 0.44 \\
\hline Affiliation & 21.88 & 2.31 & 14 & 24 & -0.22 \\
\hline $\begin{array}{c}\text { Coach } \\
\text { Support }\end{array}$ & 19.58 & 2.35 & 11 & 24 & -0.85 \\
\hline $\begin{array}{c}\text { Task } \\
\text { Mastery }\end{array}$ & 22.43 & 1.71 & 17 & 24 & -0.13 \\
\hline $\begin{array}{c}\text { Ego } \\
\text { Orientation } \\
\text { Rule Clarity, } \\
\text { Order and } \\
\text { Organisation }\end{array}$ & 12.09 & 3.47 & 6 & 22.5 & 1.40 \\
\hline
\end{tabular}

The mean scores for the Task Involvement and Ego Orientation subscales are 22.4 and 12.1 respectively. These are the highest and lowest of the subscale mean scores. This is reflective of gymnasts in this cohort perceiving their class task involvement as a bit like my class - very much like my class, while they perceive their class ego involvement as not much like my class - not at all like my class. This may be indicative of high levels of 
task involvement in many of these competitive club classes, while at the same time these classes have inversely lower levels of perceived ego involvement. A primarily task involved class climate can "press" gymnasts to exhibit adaptive behaviours, and can promote performance success (Roberts, 1992). However, the largest range of scores is for the class climate Ego Orientation subscale, $6.00-22.50$ and this range of mean scores is further reflected in the largest standard deviation $(S D=3.47)$ of all subscale mean scores. It may be that the perceived ego involvement in many of the classes is not inversely related to a high task involvement, and that several clubs may have very different perceived ego involvement in their classes. The results of the MANOVA used to test the effect of club type (Low training hours clubs versus High training hours clubs) and competitive level on climate as measured by the SCES subscales should shed light on this important sports class climate issue.

\subsection{Results of the exploratory factor analysis of the second draft SCES}

The remaining number of draft SCES subscale items $(n=33)$ was subjected to an exploratory factor analysis using principal component extraction with Varimax rotation and Kaiser normalization to determine the interrelationships among different items. Factors with eigenvalues greater than 1 , coefficients at 0.4 or greater, and that explained $50 \%$ or more of the variance were considered. The appropriateness of the factor model was assessed by the Kaiser-Meyer-Olkin measure of sampling adequacy, which was 0.81 and by Bartlett's test of sphericity with a significance level $p<.01$. Both these results indicated the suitability of scale data for factor analysis. The full results of this analysis are reported in Appendix 11. A summary of these results in grouped components is shown in Table 4.5.

The majority of scale items $(n=19)$ loaded on five main factors with two items each in factors 6, 7, 8 and 9, and one item in factor 10. Items loading in factors 6, 7, 8, 9 and 10 were too few to form a meaningful or usable subscale and were eliminated. The remaining grouped items represented some of the proposed subscales in the SCES model. 
Table 4.5. Rotated component matrix arranged in component groups

\begin{tabular}{|c|c|c|c|c|c|}
\hline \multirow[b]{2}{*}{ Source Item } & \multicolumn{5}{|c|}{ Component } \\
\hline & $\begin{array}{c}\text { Ego } \\
\text { Involvement \& } \\
\text { Mistakes }\end{array}$ & $\begin{array}{l}\text { Effort, Order } \\
\text { Organization }\end{array}$ & $\begin{array}{c}\text { Task } \\
\text { Involvement } \\
\text { Improvement }\end{array}$ & $\begin{array}{l}\text { Coach-athlete } \\
\text { Communication }\end{array}$ & Affiliation \\
\hline Ego Orientation Q17 & -.729 & -.163 & -.029 & -.005 & -.093 \\
\hline Ego Orientation Q23 & -.710 & -.165 & -.079 & -.136 & -.173 \\
\hline Ego Orientation Q5 & -.608 & .022 & -.063 & -.077 & .156 \\
\hline Ego Orientation Q35 & -.544 & -.316 & -.062 & .111 & -.105 \\
\hline Order-RuleClarity Q18 & .474 & .111 & .062 & .151 & .348 \\
\hline Order-RuleClarity Q24 & .173 & .774 & .231 & .038 & .119 \\
\hline Involvement Q7 & .102 & .690 & .178 & .104 & .106 \\
\hline Involvement Q13 & .360 & .520 & -.071 & .050 & .010 \\
\hline Order-RuleClarity Q6 &. .043 & .422 & -.016 & -.094 & .191 \\
\hline Involvement Q31 & .001 & .164 & .759 & .061 & -.080 \\
\hline Involvement Q1 & .071 & .259 & .657 & .122 & .093 \\
\hline Affiliation Q14 & .312 & .145 & .507 & -.112 & .299 \\
\hline Task Mastery Q22 & .204 & -.096 & .434 & .025 & .180 \\
\hline Order-RuleClarity Q30 & .054 & .110 & .090 & .783 & -.076 \\
\hline Order-RuleClarity Q36 & .048 & -.003 & .129 & .774 & .063 \\
\hline Coach Support Q33 & .032 & .066 & -.095 & .477 & .231 \\
\hline Affiliation Q8 & .021 & .095 & .020 & .124 & .766 \\
\hline Affiliation Q20 & .210 & .210 & .093 & -.115 & .648 \\
\hline Affiliation Q26 & -.002 & .108 & .365 & .145 & .422 \\
\hline
\end{tabular}

Extraction Method: Principal Component Analysis.

Rotation Method: Varimax with Kaiser Normalization. 
The loading of Ego Orientation items under the first component strengthens the case for this independent subscale. However, the proposed subscales of "Coach Support" and "Rule Clarity and Order \& Organization" did not form. Some of the items from these "departed" subscales loaded into a new subscale subsequently labeled "Coach-Athlete Communication". The new subscale of "Task Involvement and Improvement" was a mix of items from the initial subscales of Task Mastery, Involvement, and Rule Clarity, Order and Organization. The new subscale of "Effort, Order and Organization" is made up of items from the second draft SCES subscales of Involvement and Task Mastery. The "Affiliation" subscale component presented with only three items, but is clearly forming as an independent subscale.

The revised second draft SCES was increased to 20 items across five subscales, titled Task Involvement and Improvement, Ego Involvement and Mistakes, Coach-Athlete Communication, Effort, Order and Organization, and Affiliation.

\subsection{Internal reliability and discriminant validity of the modified SCES}

The Cronbach's Alpha coefficients and the average inter-item correlation of the modified SCES subscales are shown in Table 4.6, and fully reported in Appendix 12.

Table 4.6. Cronbach's Alphas and Inter-Item correlation means for modified SCES subscales

\begin{tabular}{|c|c|c|c|c|c|}
\hline $\begin{array}{c}\text { Climate } \\
\text { Scales }\end{array}$ & $\begin{array}{c}\text { Ego } \\
\text { Involvement } \\
\text { and Mistakes }\end{array}$ & $\begin{array}{c}\text { Effort, Order \& } \\
\text { Organization }\end{array}$ & $\begin{array}{c}\text { Task } \\
\text { Involvement \& } \\
\text { Improvement }\end{array}$ & $\begin{array}{c}\text { Coach-Athlete } \\
\text { Communication }\end{array}$ & Affiliation \\
\hline $\begin{array}{c}\text { Cronbach's } \\
\text { Alpha }\end{array}$ & 0.71 & 0.63 & 0.50 & 0.56 & 0.63 \\
\hline $\begin{array}{c}\text { Inter-Item } \\
\text { Correlations } \\
\text { Means }\end{array}$ & 0.38 & 0.29 & 0.20 & 0.24 & 0.29 \\
\hline
\end{tabular}


Ideally, the Cronbach's Alpha coefficient for a scale (with more than 10 items) should be .7 or above, however for scales with less than 10 items, a coefficient greater than .5 can suffice (Pallant, 2004). Each of the new subscales has Cronbach's Alphas at or above .5. Considering that the revised subscales have four items each, the resultant coefficients are supportive of the revised SCES internal reliability. Inter-item correlation means were at 0.38 or below (range $0.2-0.38$ ) and reflect that items for each subscale, while weakly related to the others, differentiate its climate dimension.

\subsection{Club type, competitive level and learning climate}

MANOVA was used to test the effect of club type (Low training hours clubs versus High training hours clubs) and competitive level on climate as measured by the SCES and its subscales. The complete MANOVA results are shown in Appendix 13. The summary results (see Table 4.7) show only a significant main effect for club type $(p<.01)$.

Table 4.7. Multivariate tests of club type and gymnastics level

\begin{tabular}{|c|c|c|c|c|}
\hline Effect & $F$ & Hypothesis df & Error df & $\begin{array}{c}\text { Sig. } \\
\left({ }^{*} p<.05\right)\left(^{* *} p<.01\right)\end{array}$ \\
\hline $\begin{array}{c}\text { Club type } \\
\text { (Low training hours }- \\
\text { High training hours) }\end{array}$ & $6.617(\mathrm{a})$ & 5.000 & 200.000 & $.00^{* *}$ \\
\hline Competitive Level & $1.817(\mathrm{a})$ & 5.000 & 200.000 & .11 \\
\hline Club type * Level & $1.691(\mathrm{a})$ & 5.000 & 200.000 & .14 \\
\hline
\end{tabular}

Tests of between subject effects are summarised in Table 4.8 and indicate that there was significant difference between club types only on the climate subscale of Ego Involvement $(p<.01)$. 
Table 4.8. Tests of between-subjects effects club type and competitive level

\begin{tabular}{|c|c|c|c|c|c|}
\hline Source & $\begin{array}{c}\text { Dependent } \\
\text { Variable Mean }\end{array}$ & $\mathrm{df}$ & $\begin{array}{l}\text { Mean } \\
\text { Square }\end{array}$ & $\mathrm{F}$ & $\begin{array}{l}\text { Sig. } \\
\left({ }^{*} p<.05\right)\left({ }^{* *} p<.01\right)\end{array}$ \\
\hline \multirow{5}{*}{$\begin{array}{c}\text { Club type } \\
\text { (low training hours } \\
\text { - high training } \\
\text { hours) }\end{array}$} & Task Involvement & 1 & .007 & .051 & .82 \\
\hline & Ego Involvement & 1 & 6.257 & 17.573 & $.00^{* *}$ \\
\hline & Communication & 1 & .011 & .031 & .86 \\
\hline & Effort, Order \& Org. & 1 & .088 & .315 & .56 \\
\hline & Affiliation & 1 & .332 & 1.972 & .16 \\
\hline \multirow{5}{*}{$\begin{array}{l}\text { Competitive Level } \\
\text { (Level 3-5 and } \\
\text { Level 6-10) }\end{array}$} & Task Involvement & 1 & .134 & .973 & .33 \\
\hline & Ego Involvement & 1 & 1.137 & 3.192 & .08 \\
\hline & Communication & 1 & .513 & 1.465 & .23 \\
\hline & Effort, Order \& Org. & 1 & .001 & .005 & .94 \\
\hline & Affiliation & 1 & .058 & .347 & .56 \\
\hline \multirow[t]{5}{*}{ Club type * Level } & Task Involvement & 1 & .099 & .715 & .40 \\
\hline & Ego Involvement & 1 & .867 & 2.436 & .12 \\
\hline & Communication & 1 & .323 & .921 & .34 \\
\hline & Effort, Order \& Org. & 1 & .720 & 2.583 & .11 \\
\hline & Affiliation & 1 & .007 & .041 & .84 \\
\hline
\end{tabular}

The subscale means for each club type and all clubs (shown in Table 4.9) indicate the direction of these effects. The SCES subscale climate dimension of Ego Involvement identified and separated competitive gymnastics club types. The clubs with high training hours had a higher overall mean Ego Involvement score than the low training hours clubs. Club 3, club 8, club 7, and club 2 had the highest Ego Involvement scores respectively. 
Table 4.9. Ego and Task Involvement subscale mean scores for club types and all clubs

\begin{tabular}{|c|c|c|c|c|c|c|c|c|c|}
\hline \multicolumn{10}{|c|}{ Club Type } \\
\hline \multirow{2}{*}{\multicolumn{3}{|c|}{$\begin{array}{c}\text { High Training hours } \\
\text { Ego Involvement-all clubs } \\
\text { mean score }=2.21 \\
\end{array}$}} & \multirow{2}{*}{\multicolumn{7}{|c|}{$\begin{array}{c}\text { Low Training hours } \\
\text { Ego Involvement-all clubs } \\
\text { mean score }=1.76\end{array}$}} \\
\hline & & & & & & & & & \\
\hline Club 3 & Club 8 & Club 10 & Club 1 & Club 2 & Club 4 & Club 5 & Club 6 & Club 7 & Club 9 \\
\hline 2.76 & 2.13 & 1.76 & 1.44 & 1.80 & 1.65 & 1.44 & 1.73 & 1.81 & 1.89 \\
\hline \multicolumn{3}{|c|}{$\begin{array}{c}\text { Task Involvement-all clubs } \\
\text { mean score }=3.61\end{array}$} & \multicolumn{7}{|c|}{$\begin{array}{c}\text { Task Involvement }- \text { all clubs } \\
\text { mean score }=3.60\end{array}$} \\
\hline Club 3 & Club 8 & Club 10 & Club 1 & Club 2 & Club 4 & Club 5 & Club 6 & Club 7 & Club 9 \\
\hline 3.53 & 3.56 & 3.85 & 3.58 & 3.69 & 3.71 & 3.93 & 3.69 & 3.51 & 3.45 \\
\hline
\end{tabular}

\subsection{Gender, competitive level and learning climate}

The second MANOVA tested the effect of gender and gymnastics levels in the low training hours clubs that include male and female gymnasts. The complete MANOVA results are shown in Appendix 14. The summarized results (Table 4.10) show significant main effects for club type $(p<.01)$ and gender $(p<.01)$.

Table 4.10. Multivariate tests of club type, gender and competitive level

\begin{tabular}{|c|c|c|c|c|}
\hline Effect & F & Hypothesis df & Error df & $\begin{array}{c}\text { Sig. } \\
\left({ }^{*} p<.05\right)\left({ }^{* *} p<.01\right)\end{array}$ \\
\hline Low Hours Clubs & $6.621(\mathrm{a})$ & 5.000 & 198.000 & $.00^{* *}$ \\
\hline Gender & $8.182(\mathrm{a})$ & 5.000 & 198.000 & $.00^{* *}$ \\
\hline Competitive Level & $1.522(\mathrm{a})$ & 5.000 & 198.000 & .18 \\
\hline Low Hrs Clubs * Level & $1.006(\mathrm{a})$ & 5.000 & 198.000 & .42 \\
\hline Gender * Level & $2.123(\mathrm{a})$ & 5.000 & 198.000 & .06 \\
\hline
\end{tabular}


Tests of between subject effects are summarised in Table 4.11 and indicate that there was significant difference between club types on the climate subscale of Ego Involvement $(p<.01)$. There are significant effects for gender on Task Involvement $(p=$ $.00)$, Ego Involvement $(p=.00)$, Effort, Order and Organisation $(p=.00)$, and Affiliation ( $p$ $=.00$ ).

Table 4.11 Tests of between-subjects effects of club type (low hours clubs) and gender

\begin{tabular}{|c|c|c|c|c|c|}
\hline Source & $\begin{array}{c}\text { Dependent } \\
\text { Variable Means }\end{array}$ & $\mathrm{df}$ & $\begin{array}{c}\text { Mean } \\
\text { Square }\end{array}$ & $\mathrm{F}$ & $\begin{array}{c}\text { Sig. } \\
\left.\left({ }^{*} \mathrm{p}<.05\right) \text { (** }^{*}<.01\right)\end{array}$ \\
\hline & Task Involvement & 1 & .069 & .531 & .47 \\
\hline & Ego Involvement & 1 & 8.863 & 26.288 & $.00^{* *}$ \\
\hline & Communication & 1 & .044 & .124 & .72 \\
\hline & Effort, Order \& Org. & 1 & .191 & .780 & .38 \\
\hline Gender & Affiliation & 1 & .012 & .078 & .78 \\
\hline & Task Involvement & 1 & 1.821 & 14.051 & $.00^{* *}$ \\
\hline & Ego Involvement & 1 & 4.516 & 13.394 & $.00^{* *}$ \\
\hline & Communication & 1 & .150 & .426 & .52 \\
\hline & Effort, Order \& Org. & 1 & 7.161 & 29.199 & $.00^{* *}$ \\
\hline & Affiliation & 1 & 2.942 & 18.989 & $.00^{* *}$ \\
\hline
\end{tabular}

The SCES subscale means for each club type and by gender indicate the direction of these effects. The SCES subscale means scores for club type and gender in the low training hours cohort are displayed in Table 4.12. The means for males were lower than for females on Task Involvement, Effort, Order and Organisation, and Affiliation, but higher on Ego Involvement. 
Table 4.12 SCES subscale means scores for club type (low hours clubs) and gender

\begin{tabular}{|c|c|c|c|c|c|}
\cline { 2 - 6 } \multicolumn{1}{c|}{ Source } & $\begin{array}{c}\text { Task } \\
\text { Involvement }\end{array}$ & $\begin{array}{c}\text { Ego } \\
\text { Involvement }\end{array}$ & $\begin{array}{c}\text { Coach- } \\
\text { athlete } \\
\text { communicate }\end{array}$ & $\begin{array}{c}\text { Effort, Order } \\
\text { Organisation }\end{array}$ & Affiliation \\
$\begin{array}{c}\text { Male } \\
\text { gymnasts }\end{array}$ & 3.34 & 2.15 & 3.26 & 2.61 & 3.30 \\
\hline $\begin{array}{c}\text { Female } \\
\text { gymnasts }\end{array}$ & 3.64 & 1.92 & 3.33 & 3.20 & 3.72 \\
\hline \hline $\begin{array}{c}\text { High hours } \\
\text { Clubs }\end{array}$ & 3.61 & 2.21 & 3.31 & 3.16 & 3.73 \\
\hline $\begin{array}{c}\text { Low hours } \\
\text { Clubs }\end{array}$ & 3.60 & 1.76 & 3.30 & 3.11 & 3.63 \\
\hline
\end{tabular}




\subsection{DISCUSSION}

\subsection{Introduction}

The discussion of the study findings considers the use learning climate profiles of the surveyed clubs before addressing the second draft SCES survey results in relation to the effects of club class type, gender, and competitive level as measured by the SCES subscales. Four key issues central to the development of class learning climate scales are presented as contributions to the study of sports class learning climates. To enable future tests of the SCES, the modified SCES instrument is tabled and explained. The limitations of the study are recognized and the methods used to minimize their effect are outlined. Finally, recommendations for further research are presented.

\subsection{Discussion of findings}

The discussion of findings moves from the broad results found in the learning climate profiles of the clubs surveyed using the second draft SCES, to the specific tests about club class type, gender, and gymnastics level as measured by the modified draft SCES subscales. The differences in Task Involvement and Ego Involvement highlighted in the findings are considered at length from context specific characteristics and the motivational climate literature.

\subsubsection{Class learning climate profiles}

As would be expected, differences in class climate were found across different clubs. Figure 5.1 shows the average class climate subscale score, as measured by the second draft of the SCES, for classes in each of the 10 clubs. Using the second draft version of the SCES, the results are illustrative only for the purpose of visually displaying learning class climate across all the competitive classes in each club. This graphical approach is a valuable tool for coaches, and can give the target class and their coach timely information about the learning climate of their class as perceived by participants in that class. An example of the graphical display of class learning climate profiles is shown 
In Figure 5.1 Only student actual climate perceptions are shown, but student preferred climate perceptions could also be displayed in the same graph to show differences for a particular class.

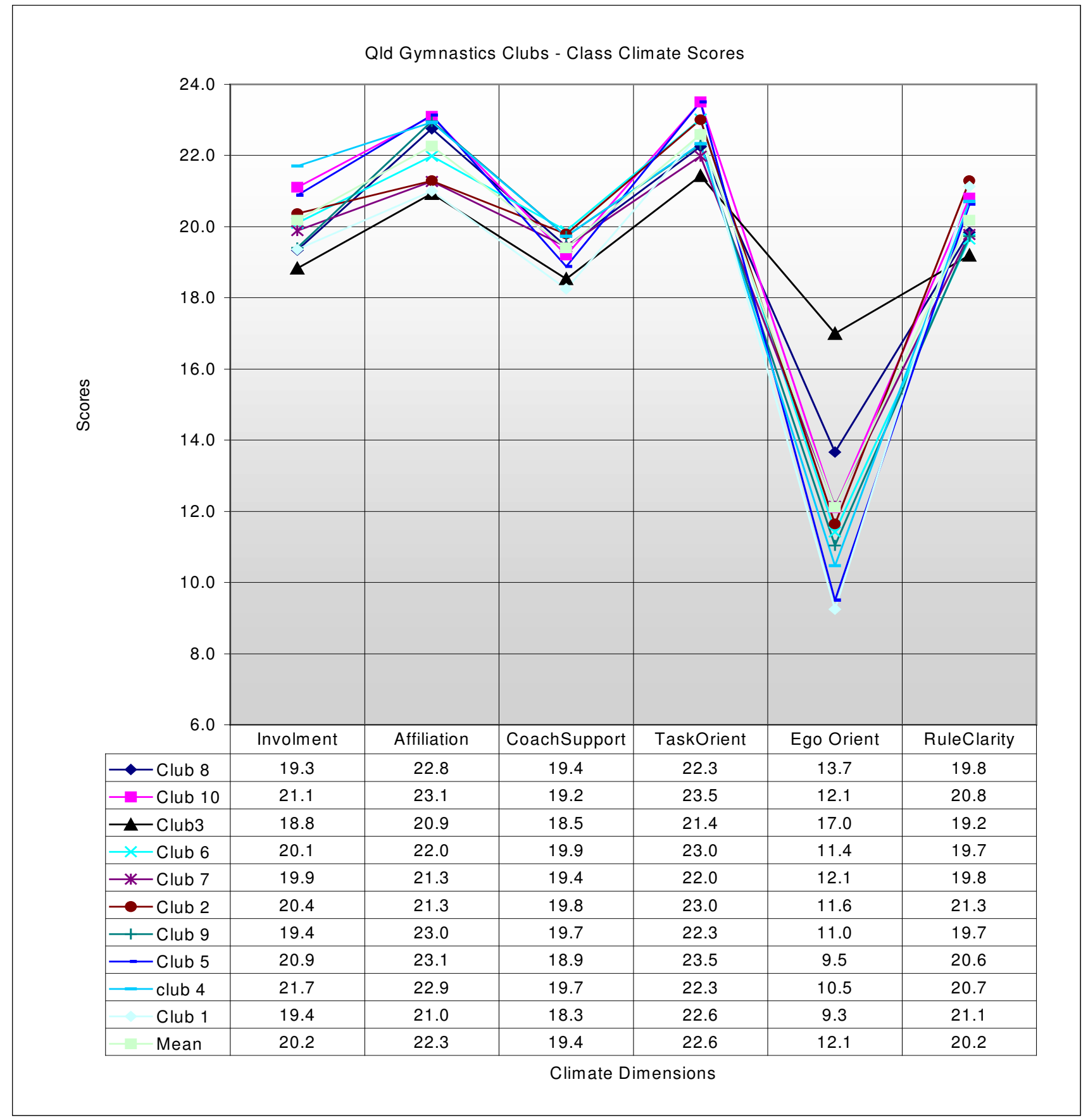

Figure 5.1. Queensland competitive gymnastics club class climate profiles 
While not measured in this study, coaches actual and preferred class climate perceptions could also be monitored and provide a contrast worthy of comparison and intervention. Graphical displays of sports class climate perceptions could be useful in intervention studies, and readily indicate learning class climate at pre-test and post test.

Some practical attempts at improving learning class climates have been made and discussed previously (Fraser, 1991, 1994, 1998). In most intervention studies, the raw mean class climate subscale scores are displayed graphically (as in Figure 5.1) for teacher interpretation. Differences in raw scores have been expressed (Fraser \& Sinclair, 2001) but the relative weight of each score is unknown. Differences in learning climate are assessed, as has occurred in this study, by statistical comparison of differences in mean subscales scores for the whole class.

An illustration of using the SCES in providing a club profile would be to compare the individual club's mean on a particular scale with the Grand Mean of all clubs. For example, the Grand Mean for the Ego Orientation subscale was 12.1. Clubs with a mean above 12.1 on the Ego Orientation subscale, such as Clubs 3 and 8, would be considered to have more Ego-Oriented climates. In the case of the Task Orientation subscale, the Grand Mean is 22.6. Clubs with a mean below 22.6, such as Clubs 3, 4, 7, 8 and 9 would be considered to have less Task Oriented climates. Caution would need to be applied in this second instance, however, because the range of club means is so small on the Task Orientation subscale that the difference between clubs may well be insignificant if a Pooled Standard Deviation statistic were calculated. Nevertheless, this untested approach to class climate subscale average scores suggests that the SCES scale may potentially show differences in sports class climates.

\subsubsection{Club type and motivational climate}

The differences between SCES responses on the subscales of Ego Orientation are related to club type. Classroom learning climate scales have been used to measure 
differences (achieving versus creative classes) in academic classes, in measuring the difference between actual class climate and preferred class climate, and measuring the effects of interventions to change the class learning climate (Fraser, 1994). It is possible that the SCES can be used to monitor and evaluate difference in sports classes.

In this study, the modified SCES identified significant differences between perceptions of class climate in the competitive gymnastics club types (high training hours versus low training hours). The high training hours clubs had a combination of a high task involved climate score $($ mean $=3.61)$ and a moderate to high ego involved climate score (mean $=2.21)$ at the same time. Two of the clubs from the lower training hours group also demonstrated this characteristic. This may be due to the fact that these clubs, like the high training hours clubs, employ professional teachers and/or tertiary educated coach practitioners.

\subsubsection{Gymnast competitive level and motivational climate}

Perceptions of gymnastic class learning climate did not differ between the junior competitive levels (Levels 3-6) and the senior competitive levels (Levels 7-10) in the gymnastics clubs surveyed. This finding is consistent with Halliburton and Weiss (2002), who found that the perceptions of class motivational climate did not differ across the U.S.A. competitive gymnastic levels.

\subsubsection{Gymnast gender and motivational climate}

This study indicated that the perceptions of the motivational climate in gymnastics classes as measured by Task Mastery, Ego Orientation, Effort, Order and Organisation, and Affiliation are gender-related. The finding that male gymnasts perceived their class climate to be less task involved and more ego involved than did female gymnasts agrees with the findings of sport climate surveys with University-aged tennis players (Kavussanu \& Roberts, 1996) and with a mixed group of adolescent-aged athletes (White, Duda, \& Hart, 1992). 
Competitive artistic gymnastics is primarily based on learning complex skills that are then performed sequentially in an individual routine to achieve a competitive result. Therefore, it might be expected that all gymnasts, irrespective of gender, would perceive their training class climates as more task (skill) involved and less ego involved. In this study, this was not the case. The gender differences in task involvement and ego involvement found in these gymnastics classes may reflect a gender-biased view of effort and outcome. It may be that "winning" with less (task) effort is more often seen as a viable characteristic by a successful male athlete, while effort through task mastery itself is more often seen as worthwhile by the female gymnasts. As both boys and girls mature in their conceptions of perceived competence and achievement behaviour, they develop a differentiated view of effort and competence (Fry \& Duda, 1997; Roberts, 2001). When this development threshold is reached, at approximately 11-13 years of age, children can distinguish between effort and competence, can differentiate luck or chance from skilldependant tasks, and can comprehend that task difficulty can relate to a person's competence (Fry \& Duda, 1997; Nicholls, 1984). In testing the predictive validity of the Parent Initiated Motivational Climate Questionnaire-2 (PIMCQ-2), some support was offered for the relationship of ego involvement and success without effort (White, 1996). Perceptions of a success without effort climate emphasised by parents were significantly correlated with ego orientation, whereas perceptions of a learning/enjoyment climate were significantly associated with Task Involvement. Whether there is a gender characteristic to this differentiated view of goal orientations in sport settings has yet to be investigated.

The inverse relationship of task involved versus ego involved climate perception scores between the males and the females in these gymnastics classes tends to support the proposition that achievement goal dimensions are orthogonal (Duda \& Whitehead, 1998; Roberts, 1992). Unfortunately, the small number of male gymnasts in the club cohort makes these findings unconvincing. There may be an actual difference between the 
intended teaching climate and class learning behaviours in male gymnastics classes, or there may be other personal or social aspects (for example, personal goal dispositions in boys) that account for possible differences. Of interest is the question about achievement goal dispositions of the male and female gymnasts that predispose them to a particular achievement goal perception and behaviour. Further tests of the SCES along with measures of personal goal dispositions, such as the Task and Ego Orientation in Sport Questionnaire (TEOSQ) (Duda, 1989), used on much larger numbers of male versus female gymnasts may shed light on gender differences in perceptions of sports class learning climate.

\subsubsection{Are achievement goal dimensions orthogonal?}

The sport and exercise literature supports the contention that personally held achievement goal dispositions and the concomitant achievement goals, predicated in a given class situation, are orthogonal in nature (Duda \& Whitehead, 1998; Roberts, 1992). An orthogonal relationship is necessary for the two achievement goal dispositions (Task Mastery orientation and Ego orientation) and the perceived achievement goal climates (Task involvement and Ego involvement) to be independent of each other. Then an athlete can be high or low in each or both goal orientations at the same time (Roberts, 2001). There is some evidence that elite level athletes seem to function better when a high task mastery orientation and/or a high ego goal orientation are tempered with a high task involved class climate. An elite group of Norwegian winter athletes with high scores on both the ego and task orientations emphasized the importance of the coach in creating climate, and a preference for supportive and caring climates (Pensgaard \& Roberts, 2002). That the climate is important, even with elite athletes, is significant because the climate is easier to manipulate than the individual achievement goal dispositions (Whitehead, Andree, \& Lee, 1997). In a study of the goal orientations and perceived motivational climates of 147 university age athletes in southern England, perceptions of a task involved 
climate were found to be more likely linked with a task mastery orientation, whereas perceptions of a ego involved climate were related to an ego goal orientation (Ntoumanis \& Biddle, 1998). Conversely, in a study of the relationship between achievement goal orientations and perceived motivational climate, there was little support for a "compatibility hypothesis" (that task oriented students were more benefited by task involved climates); however the stability of goal orientations was undermined by incompatible climates (Papaioannou, Marsh, \& Theodorakis, 2004). It may be that athletes with both high task mastery orientation and high ego goal orientation are the most motivated in any perceived class climate, but will do best in a task involved climate if their competence is threatened (Duda, 2001).

Based on the raw score means as shown in Table 4.9, two of the high training hours competitive gymnastics club classes had a significant combination of positive responses to task involved climate perceptions and positive responses to ego involved climate perceptions at the same time. The positive combination of task involved climate perceptions and ego involved climate perceptions may be because high levels of exact performance pervade both skill learning (task mastery) and skill performance (competition) in artistic gymnastics. Even the judging of competition performances is based on individual merit, and a score is not arrived at by comparison with another performer. These factors may require the gymnasts to measure their personal competence on the preparation to perform, as well as the performance outcome - the score. Theoretically, gymnasts may relate positively, through adaptive training behaviours, to both high levels of task involved class climates and moderate-high levels of ego involved class climates. The combination of high levels of task involved class climate and moderate-high levels of ego involved class climate has been reported in one previous study of Level 5-10 competitive female gymnasts in the USA club system (Halliburton \& Weiss, 2002). However, this mix of perceived class climates may also be due to these higher ranked competitive club 
gymnasts having stronger ego oriented goal dispositions. The achievement goal dispositions of the gymnast were not the focus of this study and not measured, but the above implications are deserving of further investigation.

\subsubsection{Should a task involvement in sports class learning climate be always fostered?}

One of the underlying premises of this situational perspective of sports classes is that the nature of an athlete's previous experiences and the way they interpret these experiences influences the degree to which they perceive a task involved class climate and/or ego involved class climate as salient (Roberts, 2001). The establishment of a class motivational climate is important as well, as it has an impact on the athlete's personal assessments of goal behaviour, and this can influence consequential training behaviour and performance success. This premise has been summarized previously in Figure 2.1. Even if it is conceptually possible for an athlete to be simultaneously task and ego involved in practice, an athlete will tend to act from one achievement goal or the other. This occurs as a moment-to-moment balance between these two achievement goals. An athlete chooses to be task or ego involved based on their personal goal disposition and their reading of the criteria of achievement success in that context (Roberts, 2001). The issue, however, is not whether an athlete should be task involved or ego involved, but rather, when is it more appropriate to be task involved or ego involved.

For competitive athletes, especially competing at the higher levels in a sport, being ego involved is unavoidable. Moreover, this may be motivationally appropriate for the successful achievement. An athlete may be highly ego involved when competing, but more often task involved when training. However, time and context are not the only variables here. The original premise in Figure 2.1 shows the influence of the person's perceived competence and the perception of the climate as leading to a choice of achievement goal behaviour. For example, if an athlete has a perceived high competence about the sport 
task at hand, then either of the two motivational climates is consistent with higher motivation and adaptive behaviours. But, if an ego-oriented athlete suddenly finds himself or herself lower in perceived relative competence (e.g. following injury, illness, aging or changed competitive levels) irrespective of the motivational climate, then motivation is likely to suffer and maladaptive training behaviours may eventuate. Such an athlete who is disposed to being ego-oriented and is having doubts about perceived competence is best supported by a class learning climate that is task involved (Chie-der, Chen, Hung-yu, \& Likang, 2003; Reinboth \& Duda, 2004; Roberts, 2001).

All things being equal, most researchers in physical activity and sport suggest that when one is learning physical skills, a task mastery climate and being task involved (as opposed to ego involved) is motivationally conducive to learning (Roberts, 2001). This may result in greater intrinsic motivation for the athlete, and encourage adaptive behaviours by the athlete while in their sports class.

\subsubsection{Other subscale dimensions in the modified SCES}

The revised second draft SCES is a smaller scale with five climate subscales. These subscale climate dimensions are Task Involvement and Improvement, Ego Involvement and Mistakes, Coach-Athlete Communication, Effort, Order and Organization, and Affiliation. The motivational climate dimensions of Task Involvement and Improvement and Ego Involvement and Mistakes have a foundation in sports-based research about achievement motivation. Examples are the relationships between achievement goal orientations and perceived ability, between affective correlates of achievement goal orientations, and between achievement goal climates, achievement goal orientations and achievement behaviour. This research has been summarized previously. Knowledge of sports class learning climate has been limited to conjecture about academic class learning climate scales, effective teaching models, and only one study that considered the development of a physical education class learning climate scale (Goudas \& Biddle, 1998). 
Goudas and Biddle (1998) attempted to conceptualize classroom climate more broadly by adding two factors from the CES classroom learning climate instrument (Moos \& Trickett, 1987) to the LAPOPECQ (Papaioannou, 1994) scale that examines motivational climate in middle school and high school physical education classes. These researchers arrived at the Physical Education Class Climate Scale (PECCS), comprised of two superordinate dimensions (Mastery and Performance). Suggestions of construct validity issues with the PECCS in its present form have prompted calls for further validation of this scale (Ntoumanis \& Biddle, 1999).

Most of the current classroom learning climate scales include subordinate dimensions based on the three enduring social environment dimensions of Relationships, Personal Development, and System Maintenance and Change (Moos, 1976). For example, the WIHIC scale (Fraser, Fisher, \& McRobbie, 1996) and the CES (Moos \& Trickett, 1974, 1987) have very similar subordinate dimensions reflecting Affiliation, Teacher support and Involvement (Relationship dimension), Task Involvement and competition/cooperation (Personal Development dimension) and Teacher control, Order and Organization, Innovation and Equity (System Maintenance and Change dimension).

The modified SCES scale has shown a five-factor solution to the measurement of sports class learning climate reflecting an integration of student perceptions of motivational climate and the key relational, student developmental, and control dimensions of classroom learning climates. As shown by the unfinished development of the PECCS, the final development of a valid sports class environment scale would require several instrument tests across different sport settings. In this process, the four key issues highlighted at the start of the discussion should guide these investigations.

\subsection{Contributions of the study}

Central to this study has been the integration of two areas of climate study, classroom learning climates and sports motivational climate, to form a sports class 
learning climate scale. The conceptual foundations of Moos $(1974,1979)$ in human environments, and Murray (1938) in needs-press theory led to the study of learning environments centred on the academic classroom, the school organization, and other social organizations. The study of achievement motivation in sport and physical activity was a relatively recent development (Roberts, 1992, 2001), emerging from the socialcognitive approach to the study of achievement goals in the classroom (Ames, 1984; Nicholls, 1984).

The integration of these two climate study areas arose from a review of motivational climate studies in sport and physical activity (Ntoumanis \& Biddle, 1999). Furthermore, there have been calls from learning environments scholars to have crosspollination with other lines of inquiry (Johnson, 2002). This type of integration was applied only once before in the development of a physical education class learning climate scale, the PECCS (Goudas \& Biddle, 1994). The development of the SCES in this study is an initial step in attempting to measure this synergy of classroom learning climate and achievement goals in sports settings.

The development of the SCES, as reported in this study, indicates that the integration of classroom learning climate measurement and sports motivational climate measurement is not only plausible, but also possible. While further testing of the revised SCES is required, the capacity of the scale to identify and describe sports class learning climate, and to show differences between sports classes is evident from this study.

Throughout this study, an implicit rather than an explicit working definition of class learning climate was assumed. The absence of an explicit conceptual definition is the first key issue arising from this study. A clear, but implicit definition of class learning climate was proposed in early attempts at integrating learning environments. This study proposed a definition of sports class learning climate as, "the relatively persistent quality of the sports class environment that is experienced by the participants, is based on their 
collective (summated) perception of behaviour in that sport class setting, and that affects their behaviour". Achievement motivation was seen as a sub-set of the class learning climate, and is represented as two dimensions of behaviour, Task Mastery orientations and Ego orientations. A future model of sports class learning climate could begin with the four environmental behavioural dimensions of Relationships, Personal Development, System Maintenance and Change, and Achievement Goal Motivation. The modified SCES subscales of Task Involvement and Improvement, Ego Involvement and Mistakes, CoachAthlete Communication, Effort, Order and Organization, and Affiliation were representative of these broad dimensions, but are not yet sufficiently authenticated.

The second issue to highlight is the yet undefined links of proposed learning climate concepts to class operations, and / or class curriculum. In time, this might become problematic if the area of investigation is viewed as irrelevant at a practical coaching level. While the use of the TARGET structure (Ames, 1992) that describes six variables that can help teachers organise classroom instruction and interactions is an example of this link between concept and practice, similar links in the sports class are currently lacking. A deeper understanding of conceptual relationships in learning climates and achievement settings, such as found in the sports class, will evolve from tighter links between theoretical definitions and coaching practices.

The third issue involves the selection of the dependant variables in investigations about climate subscale relationships. For example, using learning climate subscales as the dependent variables allows the measurement of the effect of independent variables such as specific curriculum choices, specific instructional interventions (e.g. student grouping), classroom-level variables (e.g. grade level, class size), instructional techniques (e.g. use of individualized instruction) and student variables (e.g., age, gender, socioeconomic status). Similarly, effects of modifying learning or motivational climates have been explored with the classroom and student outcomes as the dependent variables. Examples of class 
outcomes include exam results and student grades, while a wide variety of student centred variables such as anxiety, learning skills, attitudes, goal dispositions, enjoyment, and school attendance have been used (Fraser, 1994). There may, in particular cases, be intervening variables that further add to understanding of the mechanism of the relationship between the dependant variable (being measured) and the independent variable (being manipulated). In the area of motivational climate, it might be that perceived competence has an effect on the relationship between goal orientations and perceptions of class climate. The learning climate in sports classes is a new area of study and the future selection of variables will be important to the quality, depth, and timeliness in furthering our understanding of this topic.

The fourth issue relates to broad methodological approaches. Investigators cannot escape the question of the validity of conceptualizing learning environments through the idiosyncratic veil of perceptions (Genn, 1972; Johnson 2002). Michell (1997b) highlighted this concern about "quantifying the unquantifiable" through attributing psychological perceptions that are usually described nominally or ordinally as having the characteristics of interval or ratio scales, and then being objectively analyzed as such. Learning climate research has admitted this concern and applied conventional quantitative methods. The development of quantifiable survey methods with ranked "perceptions" as representational data of the athlete-situation interaction needs to be reconsidered. A possible combination of methods might now be timely and may go a long way to providing a more comprehensive and enlightened understanding of learning climate (Johnson \& Onwuegbuzie, 2004). The current study's approach began with a theory or model, and a study method was chosen to investigate this model. Expert reflection on instrument dimensions, subscales and items, and the exploration and discovery of scale components through factor analysis have been outlined. An inverse approach is provided by grounded theory methodology with which investigators begin with the study of the phenomena and 
allow the theory to emerge from the data (Strauss \& Corbin, 1998). An approach where constructivist methods support and confirm findings from current positivist approaches or vice versa can strengthen the study of learning environments. The use of mixed methodologies can also constrain the limitations of data collection and investigator moderators such as personal bias (Cooke, 1999). In recent years, some progress has been made towards combining quantitative and qualitative methods within the same study in research on classroom learning environments (Fraser \& Tobin, 1991; Tobin \& Fraser, 1998). Student-teacher-expert interviews, observations, field records, and video records have been used to collect data to compliment and contrast quantitative data collected from surveys. Currently, applied qualitative methods are useful in discerning overt behaviours and to compliment concurrent quantitative methods. The potential benefit of more "grounded" techniques, such as conversational analysis, concept mapping, and repertory grid cluster analysis, is in their promise of eliciting tacit concepts and perceptions about class learning environments. Such implicit knowledge is difficult, if not impossible, to discover with the more common representational qualitative methods.

\subsection{The modified SCES instrument}

Following factor analysis the second draft SCES scale was reduced to 19 items across five subscales. The SCES subscale climate dimensions were labeled Task Involvement and Improvement, Ego Involvement and Mistakes, Coach-Athlete Communication, Effort, Order and Organization, and Affiliation and were different to those in the original model shown in Figure 2.2.

The Coach Support subscale was not supported as a factor and a new subscale combining effort, class order, and class organization coalesced. The original items of coach support may have been subsumed under the Task Involvement dimension and the Effort, Order and Organization dimensions. Sport, and gymnastics in particular, are settings of rated performance and achievement. Achievement motivation played a 
significant role in these settings, and it would be expected that the orthogonal climate subscales of Task Involvement and Ego Involvement would factor. The subscale of Affiliation loaded three items only $(p=.766, .648, .422)$, but qualified as a climate dimension as it is a key reason that children participate in competitive gymnastics. Being with and making friends, developing physical fitness and learning and improving skills ranked as the top three reasons for children's' participation in gymnastics (Wald, 2003) Coach-athlete Communication seemed to be a new subscale that attempted to measure clear and affirming communication with the gymnast. Coach-athlete Communication was identified from the factor analysis as a class climate set separate to Task Involvement, Ego Involvement and Affiliation. Coach-athlete communication is about performance feedback and inter-personal communication, and can be a specific part of effective sports class behaviour (Dowdell, 2002c). The new subscale of Coach-Athlete Communication will require further validation in future tests of the SCES. The modified scale is shown in Table 5.1 with revised items listed under each subscale. The modified SCES instrument and administrative instruction are included in Appendix 15.

While the factor analysis loading of scale items was acknowledged, changes to subscale items were warranted. Affiliation item Q.14 ("gymnasts in this class are friendly toward each other") had loaded in the Task Involvement subscale, but did not have face validity in this subscale. This item was moved to the new Affiliation subscale. The original item Q.18 ("In this class rules seem to change a lot”) from the initial Order, Organization and Rule Clarity subscale has no face validity in the Ego Orientation subscale and was moved to the new Effort, Order and Organization subscale. Finally, to increase the number of subscale items to four, an item that measures task mastery was added to the new Task Involvement and Improvement subscale. The item "Doing your personal best performance is more important than winning" is a revision of item Q. 28 from the first draft SCES Task Mastery and Improvement subscale. 
The scale format is structured to limit the effects of survey administration errors, such as central tendency errors, the halo effect and proximity error. The subscale questions are scattered to every sixth place, have no numbering or labelling of subscales, and some questions are stated in the negative and thus rated in the reverse to other questions.

Table 5.1. The modified SCES scale

\begin{tabular}{|c|c|c|c|c|}
\hline $\begin{array}{l}\text { Dimension 1 } \\
\text { Task } \\
\text { Involvement } \\
\text { \& Improvement }\end{array}$ & $\begin{array}{l}\text { Dimension } 2 \\
\text { Ego Involvement } \\
\text { \& Mistakes }\end{array}$ & $\begin{array}{l}\text { Dimension } 3 \\
\text { Coach-Athlete } \\
\text { Communication }\end{array}$ & $\begin{array}{l}\text { Dimension } 4 \\
\text { Effort, Order \& } \\
\text { Organization }\end{array}$ & $\begin{array}{l}\text { Dimension } 5 \\
\text { Affiliation }\end{array}$ \\
\hline $\begin{array}{l}\text { 1. Gymnasts in } \\
\text { this class put a } \\
\text { lot of energy into } \\
\text { what they do } \\
\text { here }\end{array}$ & $\begin{array}{l}\text { 2. In this class, } \\
\text { gymnasts get } \\
\text { picked on when } \\
\text { they make a } \\
\text { mistake }\end{array}$ & $\begin{array}{l}\text { 3. The coach } \\
\text { explains what } \\
\text { will happen if a } \\
\text { gymnast breaks } \\
\text { a rule }\end{array}$ & $\begin{array}{l}\text { 4. Gymnasts } \\
\text { day-dream in } \\
\text { this class }\end{array}$ & $\begin{array}{l}\text { 5. Gymnasts in } \\
\text { this class are } \\
\text { very interested } \\
\text { in getting to } \\
\text { know other }\end{array}$ \\
\hline $\begin{array}{l}\text { 6. In this class } \\
\text { we try to } \\
\text { improve those } \\
\text { things we don't } \\
\text { do well }\end{array}$ & $\begin{array}{l}\text { 7. In this class, } \\
\text { only the best } \\
\text { gymnasts get } \\
\text { noticed' by the } \\
\text { coach. }\end{array}$ & $\begin{array}{l}\text { 8. Rules in this } \\
\text { class seem to } \\
\text { change a lot. }\end{array}$ & $\begin{array}{l}\text { 9. Gymnasts } \\
\text { often get bored } \\
\text { and check how } \\
\text { soon their class } \\
\text { finishes }\end{array}$ & $\begin{array}{l}\text { 10. Gymnasts in } \\
\text { this class are } \\
\text { friendly towards } \\
\text { each other }\end{array}$ \\
\hline $\begin{array}{l}\text { 11. Gymnasts } \\
\text { do a lot of work } \\
\text { in this class }\end{array}$ & $\begin{array}{l}\text { 12. In this class, } \\
\text { the coach } \\
\text { favours some } \\
\text { gymnasts more } \\
\text { than others }\end{array}$ & $\begin{array}{l}\text { 13. Gymnasts } \\
\text { who try hard get } \\
\text { praised }\end{array}$ & $\begin{array}{l}\text { 14. Gymnasts } \\
\text { "muck-around" a } \\
\text { lot in this class }\end{array}$ & $\begin{array}{l}15 . \text { In this class } \\
\text { gymnasts do not } \\
\text { support each } \\
\text { other }\end{array}$ \\
\hline $\begin{array}{l}\text { 16. Doing your } \\
\text { personal best } \\
\text { performance is } \\
\text { more important } \\
\text { than winning. }\end{array}$ & $\begin{array}{l}\text { 17. The ONLY } \\
\text { time gymnasts } \\
\text { feel good about } \\
\text { themselves is } \\
\text { when they win } \\
\text { competitions }\end{array}$ & $\begin{array}{l}\text { 18. The coach } \\
\text { explains what } \\
\text { the class rules } \\
\text { are. }\end{array}$ & $\begin{array}{l}\text { 19. This is an } \\
\text { organized class }\end{array}$ & $\begin{array}{l}\text { 20. In this class, } \\
\text { gymnasts help } \\
\text { each other to } \\
\text { learn \& to } \\
\text { improve }\end{array}$ \\
\hline
\end{tabular}

A more expansive Likert rating scale (of six responses) is used to help increase subscale reliability (Polger \& Thomas, 1995; Thomas, Nelson \& Silverman, 2005). It is understood that if using negatively worded items, care should be taken to avoid conceptual asymmetry between items and their scales. A conceptually complex double negative statement has a 
greater likelihood of being interpreted inconsistently than do items that are positively worded.

This modified SCES has been checked for internal reliability and inter-item correlation (see Table 4.6). Each of the new subscales has Cronbach's Alphas at or above .5. Considering that the revised subscales have four items each, the resultant coefficients were supportive of the revised SCES internal reliability. Inter-item correlation means were at .38 or below (range $0.2-0.38$ ) and reflect that each subscale, while weakly related to the others, differentiates its climate dimension.

\subsection{Limitations}

This study of sports class learning climate is not without inherent limitations. Problems of design of instrument scales, validation of scale items, selection of class type, use of particular sport contexts, and selection of survey cohort were recognized and methods were employed to minimize their impact on this study.

\subsubsection{Measurement of psycho-social scales}

There is some criticism of socio-psychological measurement (Michell, 1997b). Conventionally, researchers have hypothesized that some "qualitative" psychological "attributes" are measurable. For example, psychological perceptions that are usually described nominally or ordinally are treated as having the characteristics of interval or ratio scales (Michell, 1997a). For example, in order to justifiably quantify and validate the Classroom Environment Scale (CES) instruments, authors of the short and long forms of the CES (Fraser \& Fisher, 1983; Moos \& Trickett, 1974) describe methods that score students' and teachers' perceptions against an interval scale, in this case raw scores of 1 , 2, or 3. A final total dimension score (interval ranking) is summed and is used as the basis for validity correlation and to compare multiple classrooms.

The validation of the CES protocols depends on calculation of correlation coefficients. Correlation coefficients describe covariance and require variables that have a 
ratio (or at least interval) level of measurement (Neuman, 1997). A test for quantifiable psychological investigation is to ensure that hypothesized "attributes" are measurable (Michell, 1997a). At face value, climate scale validation methods are conventionally applied. However, the use of psychosocial scales that measure attitudes and perceptions, while conventionally appropriate, should be cautiously interpreted and applied.

\subsubsection{Use of a particular sport and sport context.}

It is recognized that a specific sport is the context of this study. The previous findings of a survey of the goal orientations and perceptions of motivational climate of female basketball players and cross-country runners found goal-orientations and motivational climate perceptions were also sport specific (Paulson, 1999). While many sports class contexts may have similar learning climate dimensions the commonality of these class learning climate dimensions cannot be assumed. It is possible that sports class climate may be sport specific, and that the measurement of these may lead to a multiplicity of learning climate instruments.

This study draws its sample of athletes only from competitive artistic gymnastics (male and female) in the State of Queensland, Australia. The training settings for these gymnasts are clubs, as opposed to sports schools or governmental High Performance Centres. The consequent findings and implications are relevant to these particular sport club contexts.

\subsubsection{A convenience sample is used.}

This study surveyed gymnasts from Queensland competitive gymnastics clubs. A convenience sample was selected from the approximately 50 competitive gymnastics clubs in Queensland. Of these clubs, at least two clubs from each of the eight regions of the state were invited to participate. It is recognized that while a sample of competitive clubs was used, the findings derived from this sample can not be generalized to the remaining clubs. There was a large disparity between genders among the cohort of club 
classes and participants. This far greater representation of female gymnasts $(n=180)$ over male gymnasts $(n=28)$ is a limitation, especially in the consideration of the effects of gender perceptions of climate. In Australia however, female competitive gymnasts outnumber male competitive gymnasts by approximately $5: 1$, making balanced survey groups by gender difficult to achieve.

\subsubsection{Halo error and Proximity error}

Halo effect in this type of survey can produce errors in measurement. For example, when the gymnast gives similar responses to survey items because of a tendency to overgeneralise, or give unduly favourable or unfavorable ratings based on the gymnast's impression of survey dimensions. Proximity errors in the survey can occur when similar responses are given to items that are close together. The actual location of item on page might compel the subject to assign similar ratings to proximal responses. Halo and proximity error sources are classified under research administration related errors and can be accounted for by survey design strategies (Thomas, Nelson, \& Silverman, 2005). In this study, the proximity error was minimised by scattering of the subscale items (questions) to every sixth place, and by having no numbering or labelling of scales. The potential halo errors were minimised by having one or two questions in each scale stated in the negative and thus scored in the reverse to other questions.

\subsubsection{Impression management errors}

Impression management error has been defined as those behaviours individuals employ to protect their self-images, and influence the way they are perceived by significant others (Wayne \& Liden, 1995). Impression management errors are considered most often in management performance ratings where a supervisor's impression of a subordinate may cloud performance ratings. In the use of learning climate scales, it is the gymnasts' favourable or unfavourable impression of the survey supervisor (or coach) that has potential to cause measurement error. 
To minimize impression management errors it was recommended that the class coaches not conduct the survey, or be physically present while the survey was conducted. An independent supervisor should formally read directions for the survey from a prepared document (see Appendix 15 - Student Actual Short form directions). Furthermore, to avoid an uncommitted response to the survey statements, a six point Likert-type scale was used with a mix of positives and negative responses.

\subsection{Directions for future research}

The development of the SCES has led to a revision of the structure of sports class learning climate originally presented in Figure 2.2. The earlier sports class climate model indicated six subscales within two dimensions of behaviour. The modified model arises from the extracted components of the second draft SCES. The modified model shown in Figure 5.2 contains five independent climate subscales, in place of the six climate subscales in the original model. Significant changes have occurred in all the dimensions of environmental perception, with the removal of the Coach Support subscale, the inclusion of a Coach-Communication subscale, and the coalescing of Involvement and Effort with Order and Organization into a single subscale of Effort, Order and Organization. The names of the Personal Development and Motivational dimensions subscales (Task Mastery and Ego Orientation) were changed to Task Involvement and Ego Involvement to better reflect their perceived achievement goal actions.

The modified SCES needs to be re-tested with a cohort of gymnastic clubs and gymnasts, to check scale reliability and test for construct validity. A larger cohort of more than 300 athletes and with a stronger representation of male gymnasts would enhance further investigation. Before a SCES re-trial, further consideration of each subscale dimensions and the number of subscale items by expert academics and sport coach practitioners is warranted. The number of subscale items might be increased from the 
current four items in the modified SCES subscales to five or six, thereby providing additional opportunity for variability.

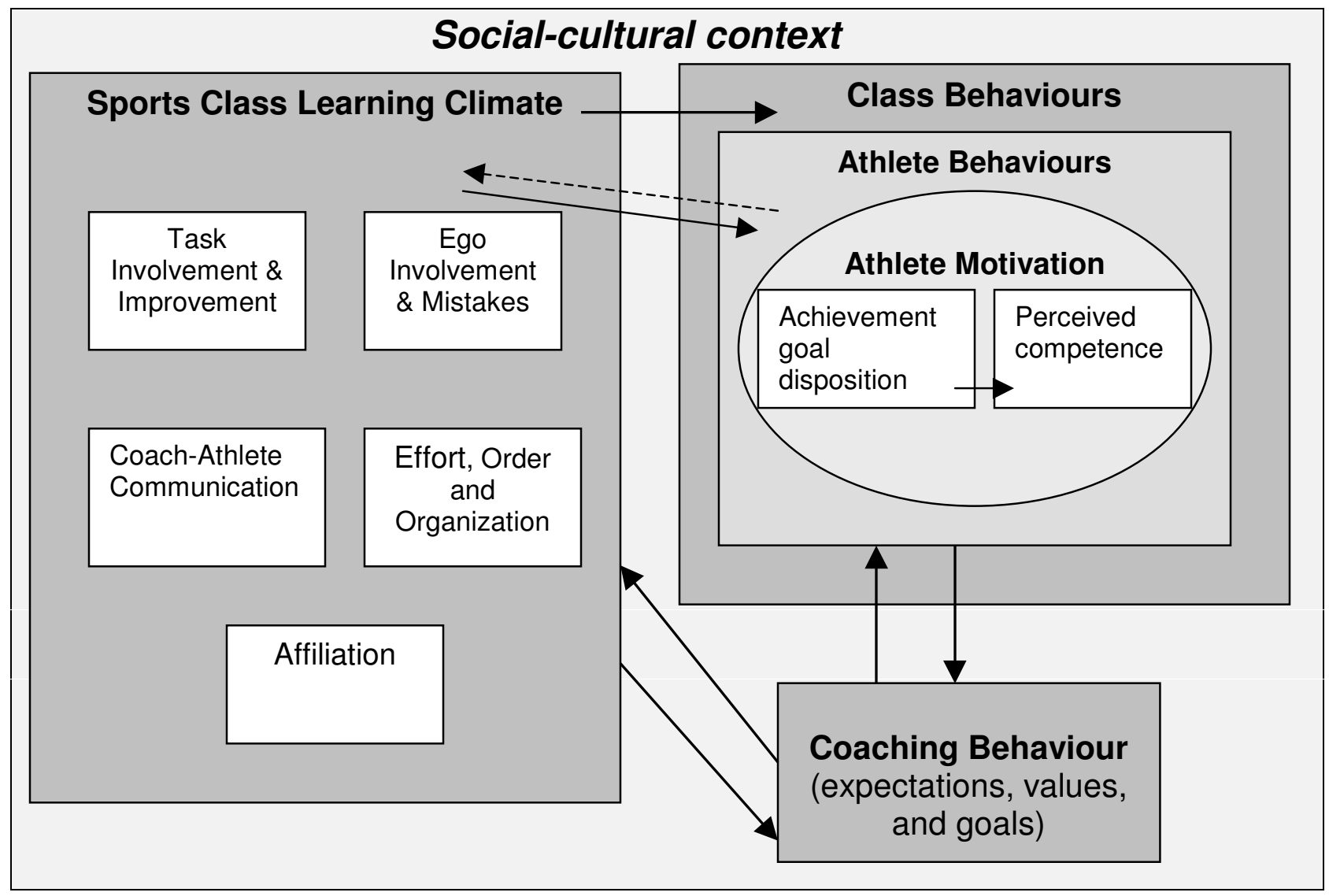

Figure 5.2. A revised model for the study of sports class specific learning climate

Application of the SCES to other sport class settings would increase the instrument's practical utility, however its validity as a general sport class climate instrument has yet to be established. With the next administration of the SCES survey, a corresponding qualitative investigation is recommended to assist with the assessment of construct validity of the dimensions and subscales. Direct observation using a behaviour checklist derived from the SCES as well as interviews with a sample of gymnasts and coaches from each club is suggested. 
While this study investigated the effects of gender and competitive level on sports class climate perceptions, further and broader investigations are needed. Pending large enough samples, investigation of athletes in each competition level is recommended, as well as by age. Additional research of this kind may provide rich information that might be used to educate coaches and athletes about the developmental aspects of child and adolescent athlete's learning and achievement motivation. Of interest is the question about achievement goal dispositions of the male and female gymnasts that predispose them to a particular achievement goal perception and behaviour. Further tests of the SCES along with measures of personal achievement goal dispositions on much larger numbers of male versus female gymnasts may shed light on gender differences in perceptions of sports class learning climate.

Few interventions have been conducted in physical activity climate research (Ntoumanis \& Biddle, 1999). Two physical activity motivational climate intervention studies were found in the literature (Solmon, 1996: Theeboom, De Knop, \& Weiss, 1995), and both were of short duration, at one week and three weeks respectively. The common characteristic of these studies were that the authors adapted and manipulated the TARGET structures that provide framework for researchers and coaches to organise a wide range of motivational strategies that are consistent with a task mastery oriented climate (Ames, 1992). Findings from both intervention studies indicated that a task involved motivational climate might offer more positive experiences for children as they learn new sport skills. Learning climate intervention study is a highly pragmatic use of a valid learning climate instrument and might provide coaching professionals with useful information for monitoring and structuring the best achievement environments for their setting.

Finally, to achieve an understanding of the weight and relationships of climate subscales in the SCES, structural equation modeling (SEM) possibly using LISREL VI or 
AMOS is recommended, particularly if a larger more representative sample of athletes can be obtained across various sports class settings.

\subsection{Recommendations for sports class "Best Practice"}

The study's findings suggest a number of plausible recommendations that coaches may implement in their sports (gymnastics) class. These strategies may support the intrinsic motivation of participating gymnasts, as well as promote gymnast's adaptive behaviours while training. The following eight recommendations arise from the findings related to the sports class learning climate sub-scales of Task Involvement and Improvement, Ego Involvement and Mistakes, Affiliation, and Coach-Athlete Communication.

\subsubsection{Discover the gymnast's achievement goal disposition}

A gymnast's achievement goal disposition predisposes them to a particular goal perception and attendant training behaviours. Knowing the achievement goal disposition of each class member may better help the coach to discretely set the sports class learning climate by managing the balance of task-involved settings and ego-involved settings. Knowledge of the gymnast's achievement goal disposition may enable coaches to match their personal communication to their gymnast's achievement goal orientation. Furthermore, such knowledge might allow coaches to match gymnasts in like-goal orientation groups and in doing so, better support affiliation.

Initially a coach could informally ask each gymnast about their task and competitive goal orientations to intuit knowledge about each gymnast's achievement goal disposition. A coach could then, if desired, confirm the pre-dominate achievement goal disposition of each of their gymnasts by survey using the Task and Ego Orientation in Sport Questionnaire (Duda, 1989).

\subsubsection{Measure the sports class learning climate}


Using the SCES to measure the learning climate perceptions of participants in each sports class can provide learning climate information necessary to affect learning climate change. For example, measuring pre-season and post season sports class learning climate perceptions of class gymnasts can provide comparisons and contrasts that may assist in learning climate interventions in preparation for the competition season. Measuring the actual and preferred learning climate perceptions of both gymnasts and coaches can lead to useful comparisons of learning climate perceptions among coaches, between coaches and gymnasts, between coach's actual and preferred learning climate, and between gymnast's actual and preferred learning climate. These contrasts can be the base-line measurements for interventions when, and where, necessary.

\subsubsection{Regularly monitor the actual sports class learning climate}

A regular seasonal or six-monthly measurement can provide a timely "snap shot" of the current sports class learning climate. Coaches should graphically record this learning climate picture and use this regular monitoring cycle to measure learning climate interventions (as mentioned in 5.7.2), and to market changes.

\subsubsection{Generally, promote a task-involved learning climate in skill classes}

Coaches should promote a task-involved class learning climate when teaching gymnastics skills so as to support the intrinsic motivation of participating gymnasts, as well as promote each gymnast's adaptive behaviours while training. This can involve many strategies which may be best applied in combination.

Coaches should provide a task-involved model placing skill learning, skill mastery and skill improvement at the centre of the sports class activity. Coaches should direct gymnasts to be task-involved by; pre-planning class skill learning and related task activities, task goal-setting with gymnasts at the beginning of class, task supervision by skill assignment, recording task assignment repetitions, providing immediate recognition of skill learning or task improvement (e.g. gymnasts rings a bell to designate skill learnt), and 
providing permanent but up-dated visual symbols of skill learning and improvement in the class setting (e.g. new skill list for each gymnast, skill "clubs", skill "stamps or sticker" rewards etc.). Finally, coaches need to promote task-involvement through personal communication with each gymnast. This will be described in 5.7 .8 below.

Coaches should group their gymnasts in like developmental (maturation) stages, but as importantly, in like skill learning (task development) groups. Progression through classes should be based mainly on skill mastery, while also considering competition results.

\subsubsection{Combine a high task-involved class learning climate with a moderate to high level of ego-involved climate}

Theoretically, a coach may promote adaptive training behaviours in their class gymnasts by ensuring both a high task involved class learning climate and a moderate to high level of ego-involved class climate. This may be achieved through applying taskinvolved strategies listed in 5.7.4 and the use of the following ego-involved strategies.

The coach should conspicuously recognize high level or "winning" competitive scores, but not in direct relative comparison with other class members. Firstly, this can be done by recognizing local, regional, state or national champions by photograph, banner, and plaque or honours board. Secondly, gymnasts can be recognized by various means (newsletters, visual lists, special colour ribbons, recognition pins etc.) for reaching threshold scores or performances (9.0 average or apparatus score, personal bests, top 10 places etc.). Thirdly, coaches can introduce competitive performance experience (and normative assessment) gradually beginning with in-class assessments, then smaller local competitive events, and then experience at state or national competitions. Fourthly, coaches can build confidence in competitive public performances by having class-mates act as spectators or judges for each other as competitive routines are performed "under competitive conditions". This important strategy can be further developed through the 
training season, by inviting parents to act as spectators, and most importantly, having guest judges attend trial competitions during training to provide comparative assessments.

\subsubsection{Support a gymnast experiencing a loss of perceived competence}

Occasionally due to injury, illness, time-off training, aging or changing competitive level, an ego-oriented competitive gymnast may experience a drop in perceived relative performance competence and a resulting loss of intrinsic motivation. In these cases, a coach could best support their gymnast with a class learning climate that is task-involved.

\subsubsection{Promote affiliation among class members}

Many competitive gymnasts are children or young adolescents. A key reason for children and young persons' participation in competitive gymnastics is to be with, and to make, friends. Coaches may implement a variety of strategies to promote affiliation (friendship and a sense of belonging) in their classes.

Some of these strategies are: to create and use a team or class motto, slogan, cheer, uniform adaptation (Hite \& Arnold, 2007); to organize class warm-up so that each gymnast can lead an exercise (given a selected list of exercise activities); include social events such as sleepovers, easter egg hunts, dance and games nights, and tourist visits while away at competitive events within the annual gymnastic events calendar; and to create a standing list of birthdays and have all class gymnast sign birthday cards for each class-mates occasion. All these activities and strategies foster belongingness and greater interactions between class members, thus strengthening friendships.

\subsubsection{Effectively communicate with the gymnast during skill training}

Effective coach-athlete communication is an important part of the sports class learning climate that can promote adaptive learning behaviours in the class gymnasts. Much of the communication between coach and athlete occurs non-verbally through bodylanguage and the use and meaning of symbols, however the following paragraphs deal only with verbal communication as it may relate to the sports class climate. 
Coaches should provide gymnasts with the rationale for class rules and methods of organization. If gymnasts understand the reasons behind rules and limitations in class activities they will tend to acknowledge the rules as more meaningful and commit to them (Hite \& Arnold, 2007).

Communication with the gymnast about skill training should be task focused and encouraging. Coaches should tell the gymnast "what to do, not what not to do". That is to say, on giving performance feedback to the gymnast, a coach should encouragingly comment on effort, and then tell the gymnast what to change in the performance or what to do next. For example, "that was a powerful effort, now try kicking harder on the upswing...". There may be little to be gained from informing a gymnast of what was poor or incorrect about their performance. There is also may be little value in the regular prompting to "do it again" with little or no expectations. Engaging in encouraging, task-focused and rules-based inter-personal communication with the gymnast can enhance motivation, enable autonomy and support the young athlete's independence in a secure class setting.

\subsection{Concluding remarks}

Different sports class learning climates evoke different perceptions in athletes about achievement, and subsequently can influence athletes' learning (Ames, 1992). The learning climate of a sports class setting is the relatively persistent quality of the sports training environment that is experienced by class participants and is based on their collective perception of behaviour in that sport class setting. One of the key leadership roles the coach has is the creation and maintenance of the class learning climate. The created class learning climate, along with athletes' intrinsic and self-determined influences "press" subsequent performance and anticipated learning.

Central to this study is the contention that improvements to the understanding of sport class motivational climate assessment might be achieved by including items from classroom-specific questionnaires such as the Classroom Environment Scale (Moos \& 
Trickett, 1987). The merging of the three key learning climate dimensions (Relationships, Personal Development, and System Maintenance and Change) and the two motivational climate dimensions (Task Involvement and Ego Involvement) may provide a more comprehensive description of the sports class climate. This study aimed to develop and validate a new learning climate scale - the Sports Class Environment Scale (SCES). It has provided the missing framework for integration of class learning climate measures and sports class motivational climate instruments. More specifically, this study has demonstrated the ability to distinctly profile the climate of sports classes and, by extension, club learning climates.

In this study, the low training hours and the high training hours gymnastics classes were different in their perceptions of the Ego Involvement of their class climate. Male and female gymnasts were different in their perceptions of Ego Involvement, Affiliation, and Effort, Order and Organization aspects of their class climates. This study demonstrates the potential utility of creating class learning climates high in both Task Involvement and Ego Involvement for competitive gymnastics clubs.

If there is a relationship between sports class performance/competitive outcomes and the characteristics of the attendant class learning climate, a sports class climate scale may allow a coach to easily assess the learning climate of their class and, if desired, change this learning climate. This study also suggests the potential for investigation of the linkage between sports class learning climate and class performance/competitive outcomes.

This study breaks new ground, and may lead to novel insights into sports class learning climates. Class learning climate is a critical pedagogical variable that should be understood, described, developed and manipulated by coaches because perceptions of the learning climate may account for variance in learning outcomes beyond that attributable to student ability (Fraser 1994, 1998, 2002). Moreover, learning climate is 
significant because the class learning climate is easier to manipulate than the individual student's achievement goal dispositions (Whitehead, Andree, \& Lee, 1997). Achievement of specific class outcomes may be enhanced by changing the whole class learning climate to one that is congruent with the learning climate collectively preferred by that class (Fraser, 1994). The modified SCES is a first step in this important pedagogical process. 


\section{GLOSSARY OF TERMS}

Ability is an inherited, relatively enduring, stable trait of the individual underlying or supporting physical or cognitive skill (Schmidt, 1991).

Achievement is the attainment of a personally or socially valued goal in a physical activity context (Roberts, 2001).

Achievement Behaviours are those behaviours witnessed when participants try harder, concentrate more, persist longer, pay greater attention, perform better, choose to practice longer, join or drop out of physical activity (Roberts, 2001).

Achievement Dispositions are the habitual psychological states of goal achievement, which develop with age and experience. These dispositions are Task Mastery Orientation and Ego Orientation.

Achievement Goals are patterns of behaviour that enable demonstration of competence. These patterns of behaviour may be Task Involved or Ego Involved.

Actual Learning Class Climate is measures of the participant's experienced perceptions of a setting's learning climate.

Alpha Press is the actual environmental press as far as it can be determined by an observer (Murray, 1938).

Behaviour is an observable and measurable act or response of an individual (Alberto \& Troutman, 1991).

Beta Press is a person's interpretation of the environment based upon their private perception of that environment (Murray, 1938).

Effective Sports Classes are well prepared and directed class programs, have strong coach control, achieve positive changes in student skill performance, and meet class objectives (Dowdell, 2002a). 
Ego Involvement is a pattern of behaviour where the goal of action is to demonstrate ability relative to others, to out perform others, and where the demonstration of competence is other-referenced.

Ego Orientation is the habitual psychological state of goal achievement where competence is normative and referenced to the ability of others.

Environmental Press is the externalized situational counterpart to the internalized personality needs.

Learning is a modification of behaviour because of experience or maturation (Alberto \& Troutman, 1991).

Learning climate is the relatively enduring phenomenological quality of the educational environment that is experienced by participants, affects their learning, and is based on their collective perception of behaviour in that setting. This term used interchangeably with educational press or environmental press.

Motivation is an individual's social-cognitive process that energizes, directs regulates achievement behaviour in physical activity.

Motivational climate is a sub-set of the setting's learning climate. It can be considered as the relatively persistent perception that participants have of the setting's achievement goal structure.

Needs are a complex set of organizational tendencies that give unity and direction to a person's behaviour (Stern, 1970).

Preferred learning class climate are measures of the participant's fancied perceptions of a setting's learning climate.

Press refers to the phenomenological world of the individual; includes conditions that represent impediments and aids to a need (Stern, 1970). 
Representational psychological studies are studies based on the theory of perception that holds that since external objects are perceived through the mediation of the human mind, they can never be perceived directly as they are, but only as illustrations of the "real" object.

Skill learning is a set of internal processes associated with practice or experience leading to a relatively permanent change in performance (Schmidt, 1991).

Task Mastery Orientation is the habitual psychological state of goal achievement where competence is dependent on the subjective assessment of task mastery.

Task involvement is a pattern of behaviour where the goal of action is to develop task mastery, task improvement, or task learning, and where the demonstration of competence is self-referenced. 
APPENDIX 1 - Class Environment Scale - Student short form (Fraser \& Fisher, 1983).

\section{DIRECTIONS}

This questionnaire contains statements about practices that generally take place in your class. You will be asked how well each statement describes what your class is actually like. There are no "right" or "wrong" answers. Your opinion is what is wanted. Think about how well each statement describes what your actual class is like. Draw a circle around:

TRUE if it is TRUE or MOSTLY TRUE that the practice actually takes place. FALSE if it is FALSE or MOSTLY FALSE that the practice actually takes place.

Be sure to give an answer for all questions. If you change your mind about an answer, just cross it out and circle another. Some statements in this questionnaire are similar to other statements. Don't worry about this. Simply give your opinion about all statements.

CLASS:

Date:

\begin{tabular}{|c|c|c|c|c|c|}
\hline $\begin{array}{l}\text { Remember YOU are describing } \\
\text { YOUR actual class } \\
\text { Questions }\end{array}$ & $\begin{array}{l}\text { Circle } \\
\text { your } \\
\text { answer }\end{array}$ & & $\begin{array}{l}\text { Remember YOU are describing } \\
\text { YOUR actual class } \\
\text { Questions }\end{array}$ & $\begin{array}{l}\text { Circle } \\
\text { your } \\
\text { answer }\end{array}$ & \\
\hline $\begin{array}{l}\text { 1. Students put a lot of energy } \\
\text { into what they do here }\end{array}$ & $\begin{array}{l}\text { True or } \\
\text { False }\end{array}$ & & $\begin{array}{l}\text { 13. Students are often checking } \\
\text { how soon their class finishes }\end{array}$ & $\begin{array}{l}\text { True or } \\
\text { False }\end{array}$ & $\mathrm{R}$ \\
\hline $\begin{array}{l}\text { 2. Students in this class get to } \\
\text { know each other really well. }\end{array}$ & $\begin{array}{l}\text { True or } \\
\text { False }\end{array}$ & & $\begin{array}{l}\text { 14. A lot of friendships have been } \\
\text { made in this class. }\end{array}$ & $\begin{array}{l}\text { True or } \\
\text { False }\end{array}$ & \\
\hline $\begin{array}{l}\text { 3. If students want to talk about } \\
\text { something, the teacher will find } \\
\text { time to do it. }\end{array}$ & $\begin{array}{l}\text { True or } \\
\text { False }\end{array}$ & & $\begin{array}{l}\text { 15. The teacher is more like a } \\
\text { friend than an authority. }\end{array}$ & $\begin{array}{l}\text { True or } \\
\text { False }\end{array}$ & \\
\hline $\begin{array}{l}\text { 4. We often spend more time } \\
\text { discussing outside activities than } \\
\text { class activities }\end{array}$ & $\begin{array}{l}\text { True or } \\
\text { False }\end{array}$ & $\mathrm{R}$ & $\begin{array}{l}\text { 16. Students don't do much work } \\
\text { in this class. }\end{array}$ & $\begin{array}{l}\text { True or } \\
\text { False }\end{array}$ & $\mathrm{R}$ \\
\hline 5. This is a well-organized class & $\begin{array}{l}\text { True or } \\
\text { False }\end{array}$ & & $\begin{array}{l}\text { 17. Students fool around a lot in } \\
\text { this class. }\end{array}$ & $\begin{array}{l}\text { True or } \\
\text { False }\end{array}$ & $\mathrm{R}$ \\
\hline $\begin{array}{l}\text { 6. Generally, there is a clear set } \\
\text { of rules for students to follow }\end{array}$ & $\begin{array}{l}\text { True or } \\
\text { False }\end{array}$ & & $\begin{array}{l}\text { 18. The teacher explains what } \\
\text { will happen if a student breaks a } \\
\text { rule. }\end{array}$ & $\begin{array}{l}\text { True or } \\
\text { False }\end{array}$ & \\
\hline $\begin{array}{l}\text { 7. Students day-dream a lot in } \\
\text { this class }\end{array}$ & $\begin{array}{l}\text { True or } \\
\text { False }\end{array}$ & 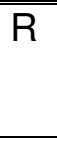 & $\begin{array}{l}\text { 19. Most students in this class } \\
\text { really pay attention to what the } \\
\text { teacher is saying. }\end{array}$ & $\begin{array}{l}\text { True or } \\
\text { False }\end{array}$ & \\
\hline $\begin{array}{l}\text { 8. Students in this class aren't } \\
\text { very interested in getting to know } \\
\text { other students }\end{array}$ & $\begin{array}{l}\text { True or } \\
\text { False }\end{array}$ & $\mathrm{R}$ & $\begin{array}{l}20 . \text { It's easy to get a group of } \\
\text { students together for a task in this } \\
\text { class }\end{array}$ & $\begin{array}{l}\text { True or } \\
\text { False }\end{array}$ & \\
\hline $\begin{array}{l}\text { 9. The teacher takes a personal } \\
\text { interest in students }\end{array}$ & $\begin{array}{l}\text { True or } \\
\text { False }\end{array}$ & & $\begin{array}{l}\text { 21. The teacher goes out of his or } \\
\text { her way to help students. }\end{array}$ & $\begin{array}{l}\text { True or } \\
\text { False }\end{array}$ & \\
\hline $\begin{array}{l}\text { 10. Getting a certain amount of } \\
\text { work done is very important in } \\
\text { this class. }\end{array}$ & $\begin{array}{l}\text { True or } \\
\text { False }\end{array}$ & & $\begin{array}{l}\text { 22. This class is more a social } \\
\text { time than a place to learn. }\end{array}$ & $\begin{array}{l}\text { True or } \\
\text { False }\end{array}$ & $\mathrm{R}$ \\
\hline $\begin{array}{l}\text { 11. Students are almost always } \\
\text { quiet in this class. }\end{array}$ & \begin{tabular}{|l|} 
True or \\
False
\end{tabular} & & 23. This class is very often noisy. & $\begin{array}{l}\text { True or } \\
\text { False }\end{array}$ & $\mathrm{R}$ \\
\hline $\begin{array}{l}\text { 12. Rules in this class seem to } \\
\text { change a lot. }\end{array}$ & $\begin{array}{l}\text { True or } \\
\text { False } \\
\end{array}$ & $\mathrm{R}$ & $\begin{array}{l}24 . \text { The teacher explains what the } \\
\text { rules are. }\end{array}$ & $\begin{array}{l}\text { True or } \\
\text { False }\end{array}$ & \\
\hline
\end{tabular}


APPENDIX 2 - Perceived Motivational Climate in Sport Questionnaire-2 (Newton et al., 2000).

Directions: Please think about how it has felt to play on your team throughout this season. What is it usually like on your team? Read the following statements carefully and respond to each in terms of how you view the typical atmosphere on your team. Perceptions naturally vary from person to person, so be certain to take your time and answer as honestly as possible. Circle the number that best represents how you feel.

Note: Each item is responded to on a 5-point Likert-type scale ( $1=$ strongly disagree; 5 = strongly agree).

1. On this team, the coach wants us to try new skills.

2. On this team, the coach gets mad when a player makes a mistake.

3. On this team, the coach gives most of his or her attention to the stars.

4. On this team, each player contributes in some important way.

5. On this team, the coach believes that all of us are crucial to the success of the team.

6. On this team, the coach praises players only when they outplay team-mates.

7. On this team, the coach thinks only the starters contribute to the success of the team.

8. On this team, players feel good when they try their best.

9. On this team, players are taken out of a game for mistakes.

10. On this team, players at all skill levels have an important role on the team.

11. On this team, players help each other learn.

12. On this team, players are encouraged to outplay the other players.

13. On this team, the coach has his or her own favourites.

14. On this team, the coach makes sure players improve on skills they're not good at.

15. On this team, the coach yells at players for messing up.

16. On this team, players feel successful when they improve.

17. On this team, only the players with the best 'stats' get praise.

18. On this team, players are punished when they make a mistake.

19. On this team, each player has an important role.

20. On this team, trying hard is rewarded.

21. On this team, the coach encourages players to help each other.

22. On this team, the coach makes it clear who he or she thinks are the best players.

23. On this team, players are 'psyched' when they do better than their team-mates in a game.

24. On this team, if you want to play in a game you must be one of the best players. 
25. On this team, the coach emphasizes always trying your best.

26. On this team, only the top players 'get noticed' by the coach.

27. On this team, players are afraid to make mistakes.

28. On this team, players are encouraged to work on their weaknesses.

29. On this team, the coach favours some players more than others.

30. On this team, the focus is to improve each game/practice.

31. On this team, the players really 'work together' as a team.

32. On this team, each player feels as if they are an important team member.

33. On this team, the players help each other to get better and excel.

Perceived Motivational Climate in Sport Questionnaire-2 (subscales)

\begin{tabular}{|c|c|c|c|c|c|}
\hline \multicolumn{3}{|c|}{ Task Mastery } & \multicolumn{3}{|c|}{ Performance Orientation } \\
\hline $\begin{array}{l}\text { Cooperative } \\
\text { Learning } \\
\text { On this team... }\end{array}$ & $\begin{array}{l}\text { Effort \& } \\
\text { Improvement } \\
\text { On this team... }\end{array}$ & $\begin{array}{l}\text { Important } \\
\text { Role } \\
\text { On this team.. }\end{array}$ & $\begin{array}{l}\text { Unequal } \\
\text { Recognition } \\
\text { On this team.. }\end{array}$ & $\begin{array}{l}\text { Intra-Team } \\
\text { Rivalry } \\
\text { On this team.... }\end{array}$ & $\begin{array}{l}\text { Punishment } \\
\text { for mistakes } \\
\text { On this team.. }\end{array}$ \\
\hline $\begin{array}{l}\text { Q1. the coach } \\
\text { wants us to try } \\
\text { new skills. }\end{array}$ & $\begin{array}{l}\text { Q14. the coach } \\
\text { makes sure } \\
\text { players } \\
\text { improve on } \\
\text { skills they're } \\
\text { not good at. }\end{array}$ & $\begin{array}{l}\text { Q4.all players } \\
\text { contribute in } \\
\text { some } \\
\text { important way }\end{array}$ & $\begin{array}{l}\text { Q3. the coach } \\
\text { gives most of } \\
\text { his or her } \\
\text { attention to the } \\
\text { stars. }\end{array}$ & $\begin{array}{l}\text { Q6. the coach } \\
\text { praises players } \\
\text { only when they } \\
\text { outplay team- } \\
\text { mates. }\end{array}$ & $\begin{array}{l}\text { Q2. the coach } \\
\text { gets mad when } \\
\text { a player makes } \\
\text { a mistake. }\end{array}$ \\
\hline $\begin{array}{l}\text { Q8. players } \\
\text { feel good when } \\
\text { they try their } \\
\text { best. }\end{array}$ & $\begin{array}{l}\text { Q16. players } \\
\text { feel successful } \\
\text { when they } \\
\text { improve. }\end{array}$ & $\begin{array}{l}\text { Q5. the coach } \\
\text { believes that } \\
\text { all of us are } \\
\text { crucial to the } \\
\text { success of the } \\
\text { team. }\end{array}$ & $\begin{array}{l}\text { Q13. the coach } \\
\text { has his or her } \\
\text { own favourites. }\end{array}$ & $\begin{array}{l}\text { Q7. the coach } \\
\text { thinks only the } \\
\text { starters } \\
\text { contribute to } \\
\text { the success of } \\
\text { the team. }\end{array}$ & $\begin{array}{l}\text { Q9. players are } \\
\text { taken out of a } \\
\text { game for } \\
\text { mistakes. }\end{array}$ \\
\hline $\begin{array}{l}\text { Q11. players } \\
\text { help each } \\
\text { other learn. }\end{array}$ & $\begin{array}{l}\text { Q20. trying } \\
\text { hard is } \\
\text { rewarded. }\end{array}$ & $\begin{array}{l}\text { Q10. players at } \\
\text { all skill levels } \\
\text { have an } \\
\text { important role } \\
\text { on the team. }\end{array}$ & $\begin{array}{l}\text { Q17. only the } \\
\text { players with } \\
\text { the best 'stats' } \\
\text { get praise. }\end{array}$ & $\begin{array}{l}\text { Q12. players } \\
\text { are } \\
\text { encouraged to } \\
\text { outplay the } \\
\text { other players. }\end{array}$ & $\begin{array}{l}\text { Q15. the coach } \\
\text { yells at players } \\
\text { for messing up. }\end{array}$ \\
\hline $\begin{array}{l}\text { Q21. the coach } \\
\text { encourages } \\
\text { players to help } \\
\text { each other. }\end{array}$ & $\begin{array}{l}\text { Q25. the coach } \\
\text { emphasizes } \\
\text { always trying } \\
\text { your best. }\end{array}$ & $\begin{array}{l}\text { Q19. each } \\
\text { player has an } \\
\text { important role. }\end{array}$ & $\begin{array}{l}\text { Q22. the coach } \\
\text { makes it clear } \\
\text { who he or she } \\
\text { thinks are the } \\
\text { best players. }\end{array}$ & $\begin{array}{l}\text { Q23. players } \\
\text { are 'psyched' } \\
\text { when they do } \\
\text { better than } \\
\text { their team- } \\
\text { mates in game }\end{array}$ & $\begin{array}{l}\text { Q18. players } \\
\text { are punished } \\
\text { when they } \\
\text { make a } \\
\text { mistake. }\end{array}$ \\
\hline $\begin{array}{l}\text { Q31. the } \\
\text { players really } \\
\text { 'work together' } \\
\text { as a team. }\end{array}$ & $\begin{array}{l}\text { Q28. players } \\
\text { are } \\
\text { encouraged to } \\
\text { work on their } \\
\text { weaknesses. }\end{array}$ & $\begin{array}{l}\text { Q32. each } \\
\text { player feels as } \\
\text { if they are an } \\
\text { important team } \\
\text { member. }\end{array}$ & $\begin{array}{l}\text { Q26. only the } \\
\text { top players } \\
\text { 'get noticed' by } \\
\text { the coach. }\end{array}$ & $\begin{array}{l}\text { Q24. if you } \\
\text { want to play in } \\
\text { a game you } \\
\text { must be one of } \\
\text { the best } \\
\text { players. }\end{array}$ & $\begin{array}{l}\text { Q27. players } \\
\text { are afraid to } \\
\text { make } \\
\text { mistakes. }\end{array}$ \\
\hline $\begin{array}{l}\text { Q33. the } \\
\text { players help } \\
\text { each other to } \\
\text { get better and } \\
\text { excel. }\end{array}$ & $\begin{array}{l}\text { Q30. the focus } \\
\text { is to improve } \\
\text { each game / } \\
\text { practice. }\end{array}$ & & $\begin{array}{l}\text { Q29. the coach } \\
\text { favours some } \\
\text { players more } \\
\text { than others. }\end{array}$ & & \\
\hline
\end{tabular}


APPENDIX 3 - Expert gymnastics coaches \& educators questionnaire about SCES

\section{Sports Class Environment Scale - Questionnaire Design exercise \#1}

A team of researchers at Griffith University is preparing a questionnaire that will measure the motivational and learning climate in competitive gymnastics classes. This questionnaire can become a useful tool for clubs or schools in measuring AND changing their competitive gymnastics class motivational climate.

We need help from expert gymnastics coaches \& educators, like you, to design the Questionnaire.

Following is a list of potential questions for this future Sports Class Environment Scale (SCES).

Would you be able to assist in this development by reviewing the list of questions, and:

- Sorting the questions into groups - consider 6-8 groups.

This step should take no more than 30 minutes. Simply enter (copy \& paste) the question \& question number into columns in attached table. You may label the columns if you wish. If you feel a question is not relevant - then cross that question out (strikethrough), and make a comment below the actual question as to why.

- Are these questions are appropriate for the age of the gymnasts (male \& female - 9$18 y r s)$ ?

- Can you think of a different or better phrasing for the questions?

- Can you suggest other questions?

Please feel free to add your suggestions to the attached table or in the space following the list of questions.

1. Gymnasts in this class put a lot of energy into what they do here

2. Gymnasts in this class get to know each other well

3. If gymnasts want to talk about something important, the coach will find time to do it

4. This is a well-organized class

5. There is a clear set of rules for gymnasts to follow

6. In this class, gymnasts help each other learn \& excel

7. In this class, each player contributes in some important way.

8. In this class, the coach wants us to try new skills.

9. In this class, the coach gets mad when a player makes a mistake.

10. Gymnasts day-dream in this class

11. Gymnasts in this class aren't very interested in getting to know other. 
12. The coach takes an interest in the progress of the gymnasts.

13. Getting a certain amount of training done is important in this class

14. Rules in this class seem to change a lot

15. In this class, the coach encourages gymnasts to help each other.

16. In this class, the coach believes that all of us are crucial to the success of the class

17. In this class, the coach has his or her own favourites.

18. Gymnasts often get bored and check how soon their class finishes

19. Gymnasts in this class are friendly towards each other.

20. The coach is more like a friend than the person in charge

21. Gymnasts don't do much work in this class

22. Gymnasts "play up" a lot in this class

23. The coach explains what will happen if a gymnast breaks a rule

24. In this class, the gymnasts really 'work together' as a team.

25. In this class, the coach makes sure gymnasts improve on skills they're not good at.

26. Gymnasts in this class pay attention to what coach is saying

27. The coach goes our of his or her way to help gymnasts

28. This class is more a social time than a place to learn skills

29. The coach explains what the class rules are

30. In this class, gymnasts feel successful when they improve.

31. In this class, each player feels as if they are an important team member

32. In this class, trying hard is rewarded.

33. In this class, gymnasts are punished when they make a mistake.

34. In this class, the coach emphasizes always trying your best.

35. In this class, gymnasts are afraid to make mistakes.

36. In this class, only the top gymnasts 'get noticed' by the coach.

37. In this class, gymnasts are encouraged to work on their weaknesses

38. In this class, the coach favours some gymnasts more than others

39. In this class, the focus is to improve in each practice

\section{End of questions}

Your Notes: 
APPENDIX 4 - second draft Sports Class Environment Scale - Student actual short form

\section{DIRECTIONS}

1. Sit the students in a private (uninterrupted) and comfortable area where they can complete the survey forms. Have them sit separately, so that they may complete the forms privately and in silence.

2. Read the following direction to the students:

This survey has questions about things that generally take place in your gymnastics class. You will be asked how well each statement describes what your class is actually like. There are no "right" or "wrong" answers. It's not a test - it's just what you think - your opinion.

We have some statements here, and I'm going to explain how to answer each of these. There is a sample statement at the top of the survey page. (see below). l'll read this out aloud and you follow along with me. Think about how well the statement describes what your actual gymnastics class is like. Place a tick in one box.

For each statement you will only check one box. Sometimes this box will be on one side of the page, and other times it might be on the other side of the page.

\begin{tabular}{|c|c|c|c|c|c|}
\hline & $\begin{array}{c}\text { Very } \\
\text { Much like } \\
\text { my class }\end{array}$ & $\begin{array}{l}\text { A bit like } \\
\text { my class }\end{array}$ & QUESTION & $\begin{array}{c}\text { Not much } \\
\text { like my } \\
\text { class }\end{array}$ & $\begin{array}{c}\text { Not at all } \\
\text { like my } \\
\text { class }\end{array}$ \\
\hline \# & & & $\begin{array}{c}\text { Gymnasts often arrive early for } \\
\text { class }\end{array}$ & & \\
\hline
\end{tabular}

Be sure to give an answer for all questions. If you change your mind about an answer, just cross it out and check another. Some statements in this survey are similar to other statements. Don't worry about this. Simply give your opinion about all statements.

Your responses will be coded and confidential, and will never be seen by your coaches or any one else at your club. DO NOT write your name on the questionnaire

When you finish your survey form, place it back in the small envelope and SEAL the envelope.

3. Give each student an open envelope (with a questionnaire form and pen/pencil inside)

4. Give all students up to 20 mins to complete the questionnaire

5. Collect all envelopes and check that they are sealed. Place then in the large envelope and seal carefully.

Thanks for your help. 


\section{SPORTS CLASS ENVIRONMENT SCALE -Student actual short form}

CLASS:

DATE:

DIRECTIONS: This is a survey that asks questions about things that take place in your gymnastics class. You are being asked how well each statement describes what your class is actually like. It is not a test. There are no right or wrong answers. Think about how well each statement describes what your actual gymnastics class is like and put a tick underneath that box. If you change your mind, just cross it out and tick another. Your answers will be coded and private and will never be seen by your coaches or anyone else at your club.

\begin{tabular}{|c|c|c|c|c|c|}
\hline & $\begin{array}{l}\text { Very } \\
\text { Much like } \\
\text { my class }\end{array}$ & $\begin{array}{l}\text { A bit like } \\
\text { my class }\end{array}$ & QUESTION & $\begin{array}{l}\text { Not much } \\
\text { like my } \\
\text { class }\end{array}$ & $\begin{array}{l}\text { Not at all } \\
\text { like my } \\
\text { class }\end{array}$ \\
\hline Ex. & & & $\begin{array}{l}\text { Gymnasts often arrive early for } \\
\text { class }\end{array}$ & & \\
\hline 1 & & & $\begin{array}{l}\text { Gymnasts in this class put a lot of } \\
\text { energy into what they do here }\end{array}$ & & \\
\hline$\underline{2}$ & & & $\begin{array}{l}\text { Gymnasts in this class don't get to } \\
\text { know each other. }\end{array}$ & & \\
\hline 3 & & & $\begin{array}{l}\text { If gymnasts want to talk about } \\
\text { something, the coach will find time } \\
\text { to do it }\end{array}$ & & \\
\hline 4 & & & $\begin{array}{l}\text { In this class, the coach wants us to } \\
\text { try new skills. }\end{array}$ & & \\
\hline 5 & & & $\begin{array}{l}\text { In this class, gymnasts get picked } \\
\text { on when they make a mistake }\end{array}$ & & \\
\hline$\underline{6}$ & & & This is a disorganised class & & \\
\hline$\underline{7}$ & & & Gymnasts day-dream in this class & & \\
\hline$\underline{8}$ & & & $\begin{array}{l}\text { Gymnasts in this class aren't very } \\
\text { interested in getting to know other. }\end{array}$ & & \\
\hline$\underline{9}$ & & & $\begin{array}{l}\text { The coach is not interested in the } \\
\text { progress of the gymnasts. }\end{array}$ & & \\
\hline 10 & & & $\begin{array}{l}\text { Practicing skills is important in this } \\
\text { class }\end{array}$ & & \\
\hline$\underline{11}$ & & & $\begin{array}{l}\text { In this class making mistakes is } \\
\text { OK. }\end{array}$ & & \\
\hline 12 & & & $\begin{array}{l}\text { In this class gymnasts know what } \\
\text { the general rules are. }\end{array}$ & & \\
\hline$\underline{13}$ & & & $\begin{array}{l}\text { Gymnasts often get bored and } \\
\text { check how soon their class finishes }\end{array}$ & & \\
\hline 14 & & & $\begin{array}{l}\text { Gymnasts in this class are friendly } \\
\text { towards each other. }\end{array}$ & & \\
\hline 15 & & & $\begin{array}{l}\text { In this class, the coach encourages } \\
\text { gymnasts to help each other to } \\
\text { learn. }\end{array}$ & & \\
\hline 16 & & & $\begin{array}{l}\text { The main point of this class is to } \\
\text { improve in each practice. }\end{array}$ & & \\
\hline
\end{tabular}




\begin{tabular}{|c|c|c|c|c|c|}
\hline & $\begin{array}{l}\text { Very } \\
\text { Much like } \\
\text { my class }\end{array}$ & $\begin{array}{l}\text { A bit like } \\
\text { my class }\end{array}$ & QUESTION & $\begin{array}{l}\text { Not much } \\
\text { like my } \\
\text { class }\end{array}$ & $\begin{array}{l}\text { Not at all } \\
\text { like my } \\
\text { class }\end{array}$ \\
\hline 17 & & & $\begin{array}{l}\text { In this class, only the best gymnasts } \\
\text { 'get noticed' by the coach. }\end{array}$ & & \\
\hline$\underline{18}$ & & & $\begin{array}{l}\text { In this class rules seem to change a } \\
\text { lot }\end{array}$ & & \\
\hline$\underline{19}$ & & & $\begin{array}{l}\text { This class is more a time to catch up } \\
\text { with friends than a place to learn } \\
\text { skills }\end{array}$ & & \\
\hline$\underline{20}$ & & & $\begin{array}{l}\text { In this class gymnasts do not support } \\
\text { each other }\end{array}$ & & \\
\hline$\underline{21}$ & & & $\begin{array}{l}\text { The coach is more like a friend than } \\
\text { a teacher }\end{array}$ & & \\
\hline 22 & & & $\begin{array}{l}\text { In this class we try to improve those } \\
\text { things we don't do well }\end{array}$ & & \\
\hline 23 & & & $\begin{array}{l}\text { In this class, the coach favours some } \\
\text { gymnasts more than others }\end{array}$ & & \\
\hline 24 & & & $\begin{array}{l}\text { Gymnasts "muck-around" a lot in this } \\
\text { class }\end{array}$ & & \\
\hline 25 & & & $\begin{array}{l}\text { Gymnasts in this class pay attention } \\
\text { to what the coach is saying }\end{array}$ & & \\
\hline 26 & & & $\begin{array}{l}\text { In this class, gymnasts help each } \\
\text { other to learn \& to improve }\end{array}$ & & \\
\hline 27 & & & $\begin{array}{l}\text { The coach does not go out of his or } \\
\text { her way to help gymnasts }\end{array}$ & & \\
\hline 28 & & & $\begin{array}{l}\text { Doing your best performance is more } \\
\text { important than winning. }\end{array}$ & & \\
\hline 29 & & & $\begin{array}{l}\text { In this class the focus is on perfect } \\
\text { performance. }\end{array}$ & & \\
\hline 30 & & & $\begin{array}{l}\text { The coach explains what will happen } \\
\text { if a gymnast breaks a rule }\end{array}$ & & \\
\hline 31 & & & $\begin{array}{l}\text { Gymnasts do a lot of work in this } \\
\text { class }\end{array}$ & & \\
\hline 32 & & & $\begin{array}{l}\text { In this class, each gymnast feels as if } \\
\text { they are an important team member }\end{array}$ & & \\
\hline 33 & & & Gymnasts who try hard get praised & & \\
\hline 34 & & & $\begin{array}{l}\text { In this class, the coach makes sure } \\
\text { gymnasts improve on skills they're } \\
\text { not good at. }\end{array}$ & & \\
\hline 35 & & & $\begin{array}{l}\text { In this class, gymnasts only feel } \\
\text { successful when they win } \\
\text { competitions. }\end{array}$ & & \\
\hline 36 & & & $\begin{array}{l}\text { The coach explains what the class } \\
\text { rules are }\end{array}$ & & \\
\hline \multicolumn{6}{|c|}{$\begin{array}{l}\text { Research Use Only: I }=\ldots \mathrm{A}=\ldots \mathrm{TS}=\ldots \mathrm{TM}=\_\mathrm{EO}=\ldots \mathrm{OR}= \\
\text { Flesch Reading Ease }=76.1 \text { Flesch-Kincaid Grade Level }=5.2 \text { (Readabilitywww.timetabler.com/reading.html) }\end{array}$} \\
\hline
\end{tabular}



APPENDIX 5 - Gymnastics Queensland permission to conduct research

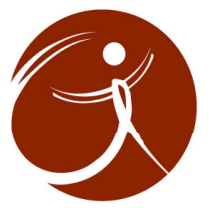

Gymnastics

\section{June 2006}

Mr Trevor Dowdell

School of Curriculum, Teaching and Learning

Griffith University

MT GRAVATT CAMPUS QLD 4122

\section{Dear Trevor}

Further to your request dated 29 May 2006, we hereby give our permission to you to conduct research into learning and motivational climate in member MAG/WAG clubs throughout Queensland.

I would also welcome the opportunity to discuss your research findings with you upon their conclusion.

Please do not hesitate to contact me should you require any further assistance.

With kindest regards

Yours sincerely

Gymnastics Queensland

Wayne Hill

Executive Director 
APPENDIX 6 - Sample club contact seeking expressions of interest to participate

\section{แU Griffith}

August, 2006

TO: Queensland Gymnastics Clubs

FROM: Trevor Dowdell - School of Curriculum, Teaching and Learning, Griffith University, Mt Gravatt Campus, Brisbane

\section{RE: your Club's participation in the Sport Class Climate Scale Project}

My name is Trevor Dowdell and I am conducting research through Griffith University to develop measuring scales of effective learning and motivation in sports classes. I am a long-time gymnastics coach and Life Member of Queensland Gymnastics, and have a strong interest in research that serves and improves the great work being done in Queensland gymnastics clubs.

I am seeking the involvement of your club to assist in gathering information from classes of competitive gymnasts (WAG and MAG) held at your club.

As the learning and motivational climates in competitive gymnastics are unknown, this project will help in this understanding and allow clubs and coaches to use this knowledge to their advantage. Your club can specifically \& confidentially receive some useful information about the current learning and motivational climates of your competitive classes.

Gymnasts \& their coach in one or more class of each competitive discipline (MAG and WAG only) will be required to complete a 36 -item questionnaire. This takes about 20 mins time. This questionnaire contains statements about practices that could take place in that class. Clubs and participants (coaches \& gymnast) will not be identified at any point in this project and all information will be and remain confidential. The outcomes of the project will be provided in summary form only to your club. These summary findings will be very informative, but in no way will negatively impact your club, coaches or gymnasts.

Steps in this process are:

1. Please indicate if your club will participate by signing the attached agreement and post (enclosed envelope) or reply e-mail by Monday $21^{\text {st }}$ August 2006.

2. Your club will then be sent a project package - containing - Parent Consent forms, Survey forms, and return post envelopes. Attached is an information sheet and example ParentGymnast consent form.

3. Your club hands out information forms and consent forms to parents of the nominated competitive class. Nominate a specific day and time to complete the survey.

4. Using the survey instructions - have each gymnast in the nominated competitive class complete the survey and seal their answers in the given envelope.

5. Place all returned consent forms AND survey envelopes (completed or not) in post-paid return mail envelope and post to $\mathrm{T}$. Dowdell.

Participation in this project is voluntary, however the benefit to your gymnastics clubs in particular and the gymnastics community in general will be worth the effort.

Thanking you in anticipation of your assistance with this research project.

Kind regards,

Trevor Dowdell 
APPENDIX 7 - Formal agreement with participating clubs

\section{《U Griffith}

Sport Class Climate Scale Project

Gymnastics Club AGREEMENT

$\mathrm{I}$, of (name of club)

give my approval to Trevor Dowdell of Griffith University to conduct an anonymous questionnaire survey among our club competitive gymnastics members \& coaches for his Doctoral research on "Measuring Sports Class Learning Climates - the development of the Sports Class Environment Scale" in 2006.

I have read and understood the information sheet provided a copy of which I have retained.

I understand that the participation of my Club members in this survey is voluntary.

I understand that I can contact the Manager, Research Ethics, at Griffith University Human Research Ethics Committee on 38755585 (or rsearch-ethics@griffith.edu.au) if I have any concerns about the ethical conduct of the project.

Possible number of competitive gymnast / coaches participating in the survey:

WAG: Level $3 \_$Number

MAG: Level 3 Number

Level 4 Number

Level 4 Number

Level 5 Number Level 5 Number Level 6-10 Number Level 6-10 Number

Club e-mail contact.

Club Official (state position)

Signed

Date 
APPENDIX 8 - Survey package to participating clubs - information and consent forms

\section{《U GNiffith}

\section{September, 2006}

TO:

FROM: Trevor Dowdell - School of Curriculum, Teaching and Learning, Griffith University, Mt Gravatt Campus, Brisbane

\section{RE: Survey package for your Club's participation in the Sport Class Climate Scale Project}

Thank you for joining Griffith University in conducting surveys of your competitive gymnastics members \& coaches that will allow the development of the "Sports Class Environment Scale".

Your WAG / MAG Gymnasts and their coach (as nominated in your club agreement form) are required to complete a 36 -item questionnaire. This takes about $15-20$ mins to do. This questionnaire contains statements about practices that could take place in that class. Clubs and participants (coaches \& gymnast) will not be identified at any point in this project and all information will be and remain confidential. The outcomes of the project will be provided in summary form only to your club. These summary findings will be very informative, but in no way will negatively impact your club, coaches or gymnasts.

Steps in this process are:

1. Please find a project package containing - Parent Consent forms (information cover sheet \& consent forms behind), coded Survey forms, and return post envelopes.

2. Your Club nominated WAG gymnasts and MAG gymnasts.

1. Hands out information forms and consent forms to parents of the nominated gymnasts. Request that the consent forms be returned on or before the survey day.

2. Nominate a specific day and time to complete the survey. If possible, this should be the same day and time for all competitive class members.

3. On the day of the survey follow the instruction sheet. Have each nominated gymnast in the competitive class complete the survey and seal their form in the given envelope.

4. Coaches should read their own survey instructions, complete their survey and seal their form in the given envelope.

5. Place all returned consent forms AND survey envelopes (completed or not) in post-paid return mail envelope and post to $T$. Dowdell. Please complete this survey and return all forms before Monday $\mathbf{2 3}^{\text {rd }}$ October 2006. This allows time to complete the survey either before or after the September school holidays.

Participation in this project is voluntary, however the benefit to your gymnastics clubs in particular and the gymnastics community in general will be worth the effort.

Thanking you again for your participation in this research project.

Kind regards,

Trevor Dowdell

Measuring Sports Class Learning Climates: the development of the SCES 


\section{Sport Class Climate Scale Project Information Sheet}

To prospective participants and Parents,

This undertaking is a Griffith University research project to develop measuring scales for more effective learning in sports classes.

This informed consent package is in two sections: the information section and the consent form. The information section should provide all the information that coach participants; gymnast participants and their parents require when making an informed decision about participation in this research project.

Please retain this section of the document for future reference or should you wish to contact either the researcher(s) or the University regarding the conduct of the research.

\section{Who is conducting the Research?}

Chief Investigator(s):

Supervisor's Name: L. Michaud Tomson, Ph.D.- Lecturer, Health and Physical Education School: School of Curriculum, Teaching and Learning, Griffith University, Mt Gravatt Campus, Brisbane

$\begin{array}{lllll}\text { Contact details: } & \text { (07) } & 3875-6892 & \text { (phone) } & \text { (07) } 3875-5991\end{array}$

$(\mathrm{FAX})$

Student Researcher's Name: Trevor Dowdell MEdSt, BEd, DipT GradDipOHS

School: $\quad$ School of Curriculum, Teaching and Learning, Griffith University, Mt Gravatt Campus, Brisbane

Contact details: $\quad$ (m) 0414-622982, e-mail: dowdell@myoffice.net.au

\section{Why is the research being conducted?}

The development of a sports-class learning climate scale is an undeveloped area of research into effective sports classes. This project aims to develop and validate a new learning climate scale - the Sports Class Environment Scale (SCES). The research project is a key aspect of doctoral research leading to the development of a sports class learning climate scale.

\section{The expected benefits of the research}

This would be the first time such a scale is developed for sports classes and will allow the ability to measure and monitor sports class learning and motivational climate. This may eventually lead to a greater predictive understanding of effective sports classes and of coach and athlete behaviour in those classes.

\section{What you will be asked to do}

Participants will be required to complete a 36 item questionnaire. This questionnaire contains statements about practices that could take place in your sports class. You will be asked how well each statement describes what your class is actually like. 


\section{Your confidentiality}

Participants will not be identified on their questionnaire, and all information will be and remain confidential. Participant's individual responses collected from the questionnaire will be coded, will not be identifiable and will not be given to any persons in your club (ie. coaches, administrators' etc.) The outcomes of the project will be provided in summary form only to the participant's sports clubs.

\section{Your participation is voluntary}

Participation in this project is voluntary and refusal to participate will involve no penalty or loss of benefits to which the participant (club, coach or gymnasts) might otherwise be entitled, and that the participant may discontinue participation at any time without penalty or without providing an explanation.

\section{Questions / further information}

Potential participants (coaches and gymnasts) and/or their Parents can contact members of the research team (listed above) on their given e-mails or 'phone contacts for additional information about the project.

\section{The ethical conduct of this research}

Griffith University conducts research in accordance with the National Statement on Ethical Conduct in Research Involving Humans. If potential participants have any concerns or complaints about the ethical conduct of the research project they should contact the Manager, Research Ethics on 38755585 or research-ethics@griffith.edu.au.

\section{Feedback to you}

The nature of the collected information does not make it appropriate to report the findings back to participants (coaches and gymnasts). The outcomes of the project will be provided in summary form only to the participant's sports clubs.

\section{Privacy Statement}

The conduct of this research involves the collection and use of personal perceptions. The data collated form this study is confidential and will not be disclosed to third parties without your consent, except to meet government, legal or other regulatory authority requirements. A de-identified copy of this data may be used for other research purposes. However, your anonymity will at all times be safeguarded. For further information consult the University's Privacy Plan at www.griffith.edu.au/ua/aa/vc/pp or telephone (07) 38755585.

Thank you for your assistance with this research project. 


\section{Sport Class Climate Scale Project Consent Form - for Gymnasts}

The second section of this consent package is the consent form. It is to be signed by the participant gymnast's parents / guardian after they have read the information sheet and had any questions answered that may have arisen. The consent form is to be retained by the researcher(s).

\section{Research Team}

Supervisor's Name: L. Michaud Tomson, Ph.D.- Lecturer, Health and Physical Education School: School of Curriculum, Teaching and Learning, Griffith University, Mt Gravatt Campus, Brisbane

Contact details:

$3875-6892$

(phone)

$3875-5991$

$(\mathrm{FAX})$

Student Researcher's Name: Trevor Dowdell MEdSt, BEd, DipT GradDipOHS

School: School of Curriculum, Teaching and Learning, Griffith University, Mt Gravatt Campus, Brisbane

Contact details: $\quad$ (m) 0414-622982, e-mail: dowdell@myoffice.net.au

By signing below, I confirm that I have read and understood the information package and in particular have noted that:

- I understand that the gymnast's involvement in this research will include completion of a 36-item questionnaire.

- I have had any questions answered to my satisfaction;

- I understand that there will be no direct benefit from participation in this research;

- I understand that participation in this research is voluntary and that refusal to participate will involve no penalty or loss of benefits to which the participants might otherwise be entitled;

- I understand that the participant may discontinue participation at any time without penalty or without providing an explanation;

- I understand that if I have any additional questions I can contact the research team;

- I understand that I can contact the Manager, Research Ethics, at Griffith University Human Research Ethics Committee on 38755585 (or research-ethics@griffith.edu.au) if I have any concerns about the ethical conduct of the project; and

- I agree to my child's participation in the project.

\section{Name}

(Parent / Guardian)

\section{Signature}

\section{Date}




\section{Sport Class Climate Scale Project Consent Form - for Coaches}

The second section of this consent package is the consent form. It is to be signed by the participant coach after they have read the information sheet and had any questions answered that may have arisen. The consent form is to be retained by the researcher(s).

\section{Research Team}

Supervisor's Name: L. Michaud Tomson, Ph.D.- Lecturer, Health and Physical Education School: School of Curriculum, Teaching and Learning, Griffith University, Mt Gravatt Campus, Brisbane

Contact details:

3875-6892 (phone)

(07) 3875-5991

$(\mathrm{FAX})$

Student Researcher's Name: Trevor Dowdell MEdSt, BEd, DipT GradDipOHS

School: School of Curriculum, Teaching and Learning, Griffith University, Mt Gravatt Campus, Brisbane

Contact details: $\quad$ (m) 0414-622982, e-mail: dowdell@myoffice.net.au

By signing below, I confirm that I have read and understood the information package and in particular have noted that:

- I understand that the coach's involvement in this research will include completion of a 36 item questionnaire.

- I have had any questions answered to my satisfaction;

- I understand that there will be no direct benefit from participation in this research;

- I understand that participation in this research is voluntary and that refusal to participate will involve no penalty or loss of benefits to which the participants might otherwise be entitled;

- I understand that the participant may discontinue participation at any time without penalty or without providing an explanation;

- I understand that if I have any additional questions I can contact the research team;

- I understand that I can contact the Manager, Research Ethics, at Griffith University Human Research Ethics Committee on 38755585 (or research-ethics@griffith.edu.au) if I have any concerns about the ethical conduct of the project; and

- I agree to my participation in the project.

\section{Name}

(Coach)

\section{Signature}

\section{Date}


APPENDIX 9 - Reliability Analysis of initial SCES scale used in pilot study

Reliability Statistics

\begin{tabular}{|l|l|l|}
\hline & $\begin{array}{l}\text { Cronbach's } \\
\text { Alpha Based } \\
\text { on }\end{array}$ & \\
Oronbach's & $\begin{array}{l}\text { Standardized } \\
\text { Ilpha }\end{array}$ & N of Items \\
\hline .609 & .685 & 36 \\
\hline
\end{tabular}

Item-Total Statistics

\begin{tabular}{|c|c|c|c|c|c|}
\hline & $\begin{array}{l}\text { Scale Mean if } \\
\text { Item Deleted }\end{array}$ & $\begin{array}{l}\text { Scale } \\
\text { Variance if } \\
\text { Item Deleted }\end{array}$ & $\begin{array}{l}\text { Corrected } \\
\text { Item-Total } \\
\text { Correlation }\end{array}$ & $\begin{array}{l}\text { Squared } \\
\text { Multiple } \\
\text { Correlation }\end{array}$ & $\begin{array}{l}\text { Cronbach's } \\
\text { Alpha if Item } \\
\text { Deleted } \\
\end{array}$ \\
\hline InvQ1 & 108.10 & 58.381 & .307 & . & .593 \\
\hline InvQ7 & 108.55 & 53.668 & .505 & . & .565 \\
\hline InvQ13 & 108.29 & 56.941 & .199 & . & .598 \\
\hline InvQ19 & 108.31 & 56.658 & .317 & . & .587 \\
\hline InvQ25 & 108.02 & 55.926 & .520 & . & .576 \\
\hline InvQ31 & 108.02 & 56.316 & .398 & . & .582 \\
\hline AffQ2 & 107.90 & 61.649 & -.087 & . & .631 \\
\hline AffQ8 & 107.55 & 60.351 & .051 & . & .610 \\
\hline AffQ14 & 107.69 & 55.195 & .574 & . & .571 \\
\hline AffQ20 & 107.86 & 59.735 & .062 & . & .611 \\
\hline AffQ26 & 107.83 & 54.581 & .575 & . & .567 \\
\hline AffQ32 & 108.07 & 55.726 & .402 & . & .579 \\
\hline CSQ3 & 108.69 & 55.341 & .366 & . & .580 \\
\hline CSQ9 & 107.50 & 60.500 & .040 & . & .611 \\
\hline CSQ15 & 107.57 & 57.080 & .392 & . & .585 \\
\hline CSQ21 & 108.79 & 67.831 & -.406 & . & .670 \\
\hline CSQ27 & 108.05 & 57.217 & .218 & . & .596 \\
\hline CSQ33 & 108.10 & 54.527 & .453 & . & .572 \\
\hline TOQ4 & 107.55 & 60.742 & .043 & . & .609 \\
\hline TOQ10 & 107.40 & 59.954 & .216 & . & .602 \\
\hline TOQ16 & 107.62 & 56.242 & .418 & . & .581 \\
\hline TOQ22 & 107.71 & 57.477 & .280 & . & .592 \\
\hline TOQ28 & 107.88 & 57.717 & .251 & . & .594 \\
\hline TOQ34 & 107.74 & 55.613 & .446 & . & .577 \\
\hline EOQ5 & 109.43 & 64.348 & -.261 & . & .642 \\
\hline EOQ11 & 109.48 & 63.816 & -.234 & . & .637 \\
\hline EOQ17 & 109.21 & 61.977 & -.107 & . & .635 \\
\hline EOQ23 & 108.93 & 62.556 & -.138 & . & .638 \\
\hline EOQ29 & 108.38 & 61.071 & -.035 & . & .620 \\
\hline EOQ35 & 109.40 & 64.539 & -.299 & . & .640 \\
\hline ORCQ6 & 107.98 & 57.975 & .226 & . & .596 \\
\hline ORCQ12 & 107.60 & 57.564 & .364 & . & .588 \\
\hline ORCQ18 & 107.90 & 60.283 & .015 & . & .616 \\
\hline ORCQ24 & 108.55 & 58.010 & .218 & . & .597 \\
\hline ORCQ30 & 107.95 & 57.022 & .289 & . & .590 \\
\hline ORCQ36 & 107.74 & 56.637 & .374 & & .584 \\
\hline
\end{tabular}


APPENDIX 10 - Second draft SCES subscales Frequency Tables

InvQ1

\begin{tabular}{|rr|r|r|r|r|}
\hline & & & & & $\begin{array}{c}\text { Cumulative } \\
\text { Percent }\end{array}$ \\
\hline Valid & 1.00 & 2 & 1.0 & 1.0 & 1.0 \\
& 2.00 & 11 & 5.3 & 5.3 & 6.3 \\
& Frequency & Percent & Valid Percent \\
& 98 & 47.1 & 47.1 & 53.4 \\
& 4.00 & 97 & 46.6 & 46.6 & 100.0 \\
& Total & 208 & 100.0 & 100.0 & \\
\hline
\end{tabular}

InvQ7

\begin{tabular}{|rr|r|r|r|r|}
\hline & & & & & $\begin{array}{c}\text { Cumulative } \\
\text { Percent }\end{array}$ \\
\hline Valid & 1.00 & 6 & 2.9 & 2.9 & 2.9 \\
& 2.00 & 56 & 26.9 & 26.9 & 29.8 \\
& Frequency & Percent & Valid Percent & 73.6 \\
& 4.00 & 91 & 43.8 & 43.8 & 100.0 \\
& Total & 208 & 26.4 & 26.4 & \\
\hline
\end{tabular}

InvQ13

\begin{tabular}{|rr|r|r|r|r|}
\hline & & & & & Cumulative \\
& & Frequency & Percent & Valid Percent & Percent \\
\hline Valid & 1.00 & 12 & 5.8 & 5.8 & 5.8 \\
& 2.00 & 56 & 26.9 & 26.9 & 32.7 \\
& 7.00 & 71 & 34.1 & 34.1 & 66.8 \\
& 4.00 & 69 & 33.2 & 33.2 & 100.0 \\
& Total & 208 & 100.0 & 100.0 & \\
\hline
\end{tabular}

InvQ19

\begin{tabular}{|rr|r|r|r|r|}
\hline & & & & Cumulative \\
& & Frequency & Percent & Valid Percent & \multicolumn{2}{|c|}{ Percent } \\
\hline Valid & 1.00 & 4 & 1.9 & 1.9 & 1.9 \\
& 2.00 & 16 & 7.7 & 7.7 & 9.6 \\
& 64 & 30.8 & 30.8 & 40.4 \\
& 4.00 & 124 & 59.6 & 59.6 & 100.0 \\
& Total & 208 & 100.0 & 100.0 & \\
\hline
\end{tabular}

InvQ25

\begin{tabular}{|rr|r|r|r|r|}
\hline & & & & & Cumulative \\
& & Frequency & Percent & Valid Percent & \multicolumn{1}{|c|}{ Percent } \\
\hline Valid & 1.00 & 2 & 1.0 & 1.0 & 1.0 \\
& 2.00 & 15 & 7.2 & 7.2 & 8.2 \\
& 89 & 42.8 & 42.8 & 51.0 \\
& 4.00 & 102 & 49.0 & 49.0 & 100.0 \\
& Total & 208 & 100.0 & 100.0 & \\
\hline
\end{tabular}


InvQ31

\begin{tabular}{|rr|r|r|r|r|}
\hline & & & & & Cumulative \\
& & Frequency & Percent & Valid Percent & Percent \\
\hline Valid & 1.00 & 2 & 1.0 & 1.0 & 1.0 \\
& 2.00 & 11 & 5.3 & 5.3 & 6.3 \\
& 7.00 & 74 & 35.6 & 35.6 & 41.8 \\
& 4.00 & 121 & 58.2 & 58.2 & 100.0 \\
& Total & 208 & 100.0 & 100.0 & \\
\hline
\end{tabular}

AffQ2

\begin{tabular}{|rr|r|r|r|r|}
\hline & & & & & $\begin{array}{c}\text { Cumulative } \\
\text { Percent }\end{array}$ \\
\hline Valid & 1.00 & 8 & 3.8 & 3.8 & 3.8 \\
& 2.00 & 7 & 3.4 & 3.4 & 7.2 \\
& Frequency & Percent & Valid Percent & 14.4 \\
& 4.00 & 15 & 7.2 & 7.2 & 100.0 \\
& 4.00 & 178 & 85.6 & 85.6 & \\
\hline & Total & 208 & 100.0 & 100.0 & \\
\hline
\end{tabular}

AffQ8

\begin{tabular}{|rr|r|r|r|r|}
\hline & & & & & $\begin{array}{c}\text { Cumulative } \\
\text { Percent }\end{array}$ \\
\hline Valid & 1.00 & 4 & 1.9 & 1.9 & 1.9 \\
& 2.00 & 5 & 2.4 & 2.4 & 4.3 \\
& Frequency & Percent & Valid Percent & 19.2 \\
& 4.00 & 31 & 14.9 & 14.9 & 100.0 \\
& 4.00 & 168 & 80.8 & 80.8 & \\
\hline & Total & 208 & 100.0 & 100.0 & \\
\hline
\end{tabular}

AffQ14

\begin{tabular}{|rl|r|r|r|r|}
\hline & & & & & $\begin{array}{c}\text { Cumulative } \\
\text { Percent }\end{array}$ \\
\hline Valid & 2.00 & 4 & 1.9 & 1.9 & 1.9 \\
& 3.00 & 48 & 23.1 & 23.1 & 25.0 \\
& 4.00 & 156 & 75.0 & 75.0 & 100.0 \\
& Total & 208 & 100.0 & 100.0 & \\
\hline
\end{tabular}

AffQ20

\begin{tabular}{|rr|r|r|r|r|}
\hline & & & & & Cumulative \\
& & Frequency & Percent & Valid Percent & Percent \\
\hline Valid & 1.00 & 5 & 2.4 & 2.4 & 2.4 \\
& 2.00 & 6 & 2.9 & 2.9 & 5.3 \\
& 3.00 & 34 & 16.3 & 16.3 & 21.6 \\
& 4.00 & 163 & 78.4 & 78.4 & 100.0 \\
& Total & 208 & 100.0 & 100.0 & \\
\hline
\end{tabular}


AffQ26

\begin{tabular}{|rr|r|r|r|r|}
\hline & & & & & Cumulative \\
& & Frequency & Percent & Valid Percent & Percent \\
\hline Valid & 1.00 & 2 & 1.0 & 1.0 & 1.0 \\
& 2.00 & 10 & 4.8 & 4.8 & 5.8 \\
& 8100 & 38.9 & 38.9 & 44.7 \\
& 4.00 & 115 & 55.3 & 55.3 & 100.0 \\
& Total & 208 & 100.0 & 100.0 & \\
\hline
\end{tabular}

AffQ32

\begin{tabular}{|rr|r|r|r|r|}
\hline & & & & & $\begin{array}{c}\text { Cumulative } \\
\text { Percent }\end{array}$ \\
\hline Valid & 1.00 & 6 & 2.9 & 2.9 & 2.9 \\
& 2.00 & 15 & 7.2 & 7.2 & 10.1 \\
& Frequency & Percent & Valid Percent & 42.3 \\
& 4.00 & 67 & 32.2 & 32.2 & 100.0 \\
& Total & 208 & 120.0 & 57.7 & \\
\hline
\end{tabular}

CSQ3

\begin{tabular}{|rr|r|r|r|r|}
\hline & & & & & Cumulative \\
& & Frequency & Percent & Valid Percent & \multicolumn{1}{c|}{ Percent } \\
\hline Valid & 1.00 & 14 & 6.7 & 6.7 & 6.7 \\
& 2.00 & 33 & 15.9 & 15.9 & 22.6 \\
& 3.00 & 86 & 41.3 & 41.3 & 63.9 \\
& 4.00 & 75 & 36.1 & 36.1 & 100.0 \\
& Total & 208 & 100.0 & 100.0 & \\
\hline
\end{tabular}

CSQ9

\begin{tabular}{|rr|r|r|r|r|}
\hline & & & & & Cumulative \\
& & Frequency & Percent & Valid Percent & Percent \\
\hline Valid & 1.00 & 6 & 2.9 & 2.9 & 2.9 \\
& 2.00 & 3 & 1.4 & 1.4 & 4.3 \\
& 18 & 8.7 & 8.7 & 13.0 \\
& 4.00 & 181 & 87.0 & 87.0 & 100.0 \\
& 4.00 & 208 & 100.0 & 100.0 & \\
\hline & Total & & &
\end{tabular}

CSQ15

\begin{tabular}{|rr|r|r|r|r|}
\hline & & & & & \multicolumn{2}{c|}{$\begin{array}{c}\text { Cumulative } \\
\text { Percent }\end{array}$} \\
\hline Valid & 1.00 & 1 & .5 & .5 & .5 \\
& 2.00 & 16 & 7.7 & 7.7 & 8.2 \\
& & Vrequency & Percent & Valid Percent & 35.6 \\
& 5.00 & 134 & 27.4 & 27.4 & 100.0 \\
& Total & 208 & 100.0 & 64.4 & \\
\hline
\end{tabular}


CSQ21

\begin{tabular}{|rr|r|r|r|r|}
\hline & & Frequency & Percent & Valid Percent & $\begin{array}{c}\text { Cumulative } \\
\text { Percent }\end{array}$ \\
\hline Valid & 1.00 & 31 & 14.9 & 14.9 & 14.9 \\
& 2.00 & 77 & 37.0 & 37.0 & 51.9 \\
& 3.00 & 57 & 27.4 & 27.4 & 79.3 \\
& 4.00 & 43 & 20.7 & 20.7 & 100.0 \\
& Total & 208 & 100.0 & 100.0 & \\
\hline
\end{tabular}

\section{CSQ27}

\begin{tabular}{|rr|r|r|r|r|}
\hline & & & & & $\begin{array}{c}\text { Cumulative } \\
\text { Percent }\end{array}$ \\
\hline Valid & 1.00 & 14 & 6.7 & 6.7 & 6.7 \\
& 2.00 & 25 & 12.0 & 12.0 & 18.8 \\
& Frequency & Percent & Valid Percent & 43.3 \\
& 4.00 & 51 & 24.5 & 24.5 & 100.0 \\
& 118 & 56.7 & 56.7 & \\
\hline
\end{tabular}

CSQ33

\begin{tabular}{|c|c|c|c|c|c|}
\hline & & Frequency & Percent & Valid Percent & $\begin{array}{c}\text { Cumulative } \\
\text { Percent }\end{array}$ \\
\hline \multirow[t]{5}{*}{ Valid } & 1.00 & 14 & 6.7 & 6.7 & 6.7 \\
\hline & 2.00 & 14 & 6.7 & 6.7 & 13.5 \\
\hline & 3.00 & 64 & 30.8 & 30.8 & 44.2 \\
\hline & 4.00 & 116 & 55.8 & 55.8 & 100.0 \\
\hline & Total & 208 & 100.0 & 100.0 & \\
\hline
\end{tabular}

TOQ4

\begin{tabular}{|rr|r|r|r|r|}
\hline & & & & \multicolumn{2}{c|}{$\begin{array}{c}\text { Cumulative } \\
\text { Percent }\end{array}$} \\
\hline Valid & 1.00 & 1 & .5 & .5 & .5 \\
& 2.00 & 7 & 3.4 & 3.4 & 3.8 \\
& Frequency & Percent & Valid Percent \\
& 53 & 25.5 & 25.5 & 29.3 \\
& 4.00 & 147 & 70.7 & 70.7 & 100.0 \\
& Total & 208 & 100.0 & 100.0 & \\
\hline
\end{tabular}

\section{TOQ10}

\begin{tabular}{|rr|r|r|r|r|}
\hline & & & & \multicolumn{2}{c|}{$\begin{array}{c}\text { Cumulative } \\
\text { Percent }\end{array}$} \\
\hline Valid & 1.00 & 1 & .5 & .5 & .5 \\
& 2.00 & 1 & .5 & .5 & 1.0 \\
& Frequency & Percent & Valid Percent & 8.7 \\
& 16 & 7.7 & 7.7 & 100.0 \\
& 4.00 & 190 & 91.3 & 91.3 & \\
\hline & Total & 208 & 100.0 & 100.0 & \\
\hline
\end{tabular}


TOQ16

\begin{tabular}{|rl|r|r|r|r|}
\hline & & & & & Cumulative \\
& & Frequency & Percent & Valid Percent & Percent \\
\hline Valid & 3.00 & 54 & 26.0 & 26.0 & 26.0 \\
& 4.00 & 154 & 74.0 & 74.0 & 100.0 \\
& Total & 208 & 100.0 & 100.0 & \\
\hline
\end{tabular}

TOQ22

\begin{tabular}{|rr|r|r|r|r|}
\hline & & & & & $\begin{array}{c}\text { Cumulative } \\
\text { Percent }\end{array}$ \\
\hline Valid & 1.00 & 2 & 1.0 & 1.0 & 1.0 \\
& 2.00 & 11 & 5.3 & 5.3 & 6.3 \\
& Frequency & Percent & Valid Percent & 20.7 \\
& 3.00 & 14.4 & 14.4 & 100.0 \\
& 4.00 & 165 & 79.3 & 79.3 & \\
\hline & Total & 208 & 100.0 & 100.0 & \\
\hline
\end{tabular}

TOQ28

\begin{tabular}{|rr|r|r|r|r|}
\hline & & & & & Cumulative \\
& & Frequency & Percent & Valid Percent & Percent \\
\hline Valid & 1.00 & 6 & 2.9 & 2.9 & 2.9 \\
& 2.00 & 6 & 2.9 & 2.9 & 5.8 \\
& 4.00 & 19.2 & 19.2 & 25.0 \\
& 4.00 & 156 & 75.0 & 75.0 & 100.0 \\
& Total & 208 & 100.0 & 100.0 & \\
\hline
\end{tabular}

TOQ34

\begin{tabular}{|ll|r|r|r|r|}
\hline & & & & & \multicolumn{2}{c|}{ Cumulative } \\
& & Frequency & Percent & Valid Percent & \multicolumn{1}{c|}{ Percent } \\
\hline Valid & 2.00 & 4 & 1.9 & 1.9 & 1.9 \\
& 3.00 & 53 & 25.5 & 25.5 & 27.4 \\
& 4.00 & 151 & 72.6 & 72.6 & 100.0 \\
& Total & 208 & 100.0 & 100.0 & \\
\hline
\end{tabular}

EOQ5

\begin{tabular}{|rr|r|r|r|r|}
\hline & & & & & Cumulative \\
& & Frequency & Percent & Valid Percent & Percent \\
\hline Valid & 1.00 & 99 & 47.6 & 47.6 & 47.6 \\
& 2.00 & 49 & 23.6 & 23.6 & 71.2 \\
& 4.00 & 42 & 20.2 & 20.2 & 91.3 \\
& 4.00 & 18 & 8.7 & 8.7 & 100.0 \\
& Total & 208 & 100.0 & 100.0 & \\
\hline
\end{tabular}


EOQ11

\begin{tabular}{|rr|r|r|r|r|}
\hline & & & & & Cumulative \\
& & Frequency & Percent & Valid Percent & Percent \\
\hline Valid & 1.00 & 84 & 40.4 & 40.4 & 40.4 \\
& 2.00 & 81 & 38.9 & 38.9 & 79.3 \\
& 3.00 & 34 & 16.3 & 16.3 & 95.7 \\
& 4.00 & 9 & 4.3 & 4.3 & 100.0 \\
& Total & 208 & 100.0 & 100.0 & \\
\hline
\end{tabular}

\section{EOQ17}

\begin{tabular}{|rr|r|r|r|r|}
\hline & & & & & Cumulative \\
& & Frequency & Percent & Valid Percent & Percent \\
\hline Valid & 1.00 & 95 & 45.7 & 45.7 & 45.7 \\
& 2.00 & 61 & 29.3 & 29.3 & 75.0 \\
& 3.00 & 37 & 17.8 & 17.8 & 92.8 \\
& 4.00 & 15 & 7.2 & 7.2 & 100.0 \\
& Total & 208 & 100.0 & 100.0 & \\
\hline
\end{tabular}

EOQ23

\begin{tabular}{|rr|r|r|r|r|}
\hline & & & & & Cumulative \\
& & Frequency & Percent & Valid Percent & Percent \\
\hline Valid & 1.00 & 95 & 45.7 & 45.7 & 45.7 \\
& 2.00 & 51 & 24.5 & 24.5 & 70.2 \\
& 4.00 & 40 & 19.2 & 19.2 & 89.4 \\
& 4.00 & 22 & 10.6 & 10.6 & 100.0 \\
& Total & 208 & 100.0 & 100.0 & \\
\hline
\end{tabular}

EOQ29

\begin{tabular}{|rr|r|r|r|r|}
\hline & & Frequency & Percent & Valid Percent & $\begin{array}{c}\text { Cumulative } \\
\text { Percent }\end{array}$ \\
\hline Valid & 1.00 & 28 & 13.5 & 13.5 & 13.5 \\
& 2.00 & 46 & 22.1 & 22.1 & 35.6 \\
& 8.00 & 42.8 & 42.8 & 78.4 \\
& 4.00 & 45 & 21.6 & 21.6 & 100.0 \\
& Total & 208 & 100.0 & 100.0 & \\
\hline
\end{tabular}

\section{EOQ35}

\begin{tabular}{|rr|r|r|r|r|}
\hline & & & & & Cumulative \\
& & Frequency & Percent & Valid Percent & Percent \\
\hline Valid & 1.00 & 89 & 42.8 & 42.8 & 42.8 \\
& 2.00 & 82 & 39.4 & 39.4 & 82.2 \\
& 3.00 & 14.9 & 14.9 & 97.1 \\
4.00 & 6 & 2.9 & 2.9 & 100.0 \\
& Total & 208 & 100.0 & 100.0 & \\
\hline
\end{tabular}


ORCQ6

\begin{tabular}{|rr|r|r|r|r|}
\hline & & & & & Cumulative \\
& & Frequency & Percent & Valid Percent & Percent \\
\hline Valid & 1.00 & 8 & 3.8 & 3.8 & 3.8 \\
& 2.00 & 11 & 5.3 & 5.3 & 9.1 \\
& 4.00 & 48 & 23.1 & 23.1 & 32.2 \\
& 4.00 & 141 & 67.8 & 67.8 & 100.0 \\
& Total & 208 & 100.0 & 100.0 & \\
\hline
\end{tabular}

ORCQ12

\begin{tabular}{|rr|r|r|r|r|}
\hline & & & & & \multicolumn{2}{c|}{$\begin{array}{c}\text { Cumulative } \\
\text { Percent }\end{array}$} \\
\hline Valid & 1.00 & 1 & .5 & .5 & .5 \\
& 2.00 & 11 & 5.3 & 5.3 & 5.8 \\
& Frequency & Percent & Valid Percent & 30.8 \\
& 4.00 & 52 & 25.0 & 25.0 & 100.0 \\
& 4.00 & 144 & 69.2 & 69.2 & \\
\hline & Total & 208 & 100.0 & 100.0 & \\
\hline
\end{tabular}

ORCQ18

\begin{tabular}{|ll|r|r|r|r|}
\hline & & & & & Cumulative \\
& & Frequency & Percent & Valid Percent & \multicolumn{1}{|c|}{ Percent } \\
\hline Valid & 1.00 & 5 & 2.4 & 2.4 & 2.4 \\
& 2.00 & 26 & 12.5 & 12.5 & 14.9 \\
& 75 & 36.1 & 36.1 & 51.0 \\
& 4.00 & 102 & 49.0 & 49.0 & 100.0 \\
& Total & 208 & 100.0 & 100.0 & \\
\hline
\end{tabular}

ORCQ24

\begin{tabular}{|rr|r|r|r|r|}
\hline & & Frequency & Percent & Valid Percent & $\begin{array}{c}\text { Cumulative } \\
\text { Percent }\end{array}$ \\
\hline Valid & 1.00 & 11 & 5.3 & 5.3 & 5.3 \\
& 2.00 & 48 & 23.1 & 23.1 & 28.4 \\
& 95 & 45.7 & 45.7 & 74.0 \\
& 4.00 & 54 & 26.0 & 26.0 & 100.0 \\
& Total & 208 & 100.0 & 100.0 & \\
\hline
\end{tabular}

ORCQ30

\begin{tabular}{|rr|r|r|r|r|}
\hline & & & & & Cumulative \\
& & Frequency & Percent & Valid Percent & \multicolumn{1}{c|}{ Percent } \\
\hline Valid & 1.00 & 14 & 6.7 & 6.7 & 6.7 \\
& 2.00 & 27 & 13.0 & 13.0 & 19.7 \\
& 7.00 & 72 & 34.6 & 34.6 & 54.3 \\
& 4.00 & 95 & 45.7 & 45.7 & 100.0 \\
& Total & 208 & 100.0 & 100.0 & \\
\hline
\end{tabular}




\begin{tabular}{|c|c|c|c|c|c|}
\hline \multicolumn{6}{|c|}{ ORCQ36 } \\
\hline & & Frequency & Percent & Valid Percent & $\begin{array}{c}\text { Cumulative } \\
\text { Percent }\end{array}$ \\
\hline \multirow[t]{5}{*}{ Valid } & 1.00 & 3 & 1.4 & 1.4 & 1.4 \\
\hline & 2.00 & 32 & 15.4 & 15.4 & 16.8 \\
\hline & 3.00 & 61 & 29.3 & 29.3 & 46.2 \\
\hline & 4.00 & 112 & 53.8 & 53.8 & 100.0 \\
\hline & Total & 208 & 100.0 & 100.0 & \\
\hline
\end{tabular}


APPENDIX 11- Factor analysis of second draft SCES scale

KMO and Bartlett's Test

\begin{tabular}{|ll|l|}
\hline $\begin{array}{l}\text { Kaiser-Meyer-Olkin } \\
\text { Adequacy. }\end{array}$ & & .816 \\
Bartlett's Test of & Approx. Chi-Square & 1698.267 \\
Sphericity & df & 528 \\
& Sig. & .000 \\
\hline
\end{tabular}

\section{Communalities}

\begin{tabular}{|l|l|l|}
\hline & Initial & Extraction \\
\hline InvQ1 & 1.000 & .592 \\
\hline InvQ7 & 1.000 & .569 \\
\hline InvQ13 & 1.000 & .627 \\
\hline InvQ19 & 1.000 & .632 \\
\hline InvQ25 & 1.000 & .504 \\
\hline InvQ31 & 1.000 & .656 \\
\hline AffQ8 & 1.000 & .636 \\
\hline AffQ14 & 1.000 & .648 \\
\hline Aff20 & 1.000 & .618 \\
\hline AffQ26 & 1.000 & .517 \\
\hline AffQ32 & 1.000 & .571 \\
\hline CSQ3 & 1.000 & .546 \\
\hline CSQ15 & 1.000 & .566 \\
\hline CSQ21 & 1.000 & .547 \\
\hline CSQ27 & 1.000 & .429 \\
\hline CSQ33 & 1.000 & .486 \\
\hline TOQ4 & 1.000 & .506 \\
\hline TOQ16 & 1.000 & .551 \\
\hline TOQ22 & 1.000 & .543 \\
\hline TOQ28 & 1.000 & .636 \\
\hline TOQ34 & 1.000 & .565 \\
\hline EOQ5 & 1.000 & .509 \\
\hline EOQ11 & 1.000 & .493 \\
\hline EOQ17 & 1.000 & .700 \\
\hline EOQ23 & 1.000 & .648 \\
\hline EOQ29 & 1.000 & .709 \\
\hline EOQ35 & 1.000 & .545 \\
\hline ORCQ6 & 1.000 & .579 \\
\hline ORCQ12 & 1.000 & .591 \\
\hline ORCQ18 & 1.000 & .580 \\
\hline ORCQ24 & 1.000 & .718 \\
\hline ORCQ30 & 1.000 & .671 \\
\hline ORCQ36 & 1.000 & .680 \\
\hline ExI01 & 100 \\
\hline
\end{tabular}

Extraction Method: Principal Component Analysis. 
Total Variance Explained

\begin{tabular}{|l|l|l|l|l|l|l|l|l|l|}
\hline $\begin{array}{l}\text { Compon } \\
\text { ent }\end{array}$ & \multicolumn{3}{|l|}{ Initial Eigenvalues } & \multicolumn{3}{l|}{$\begin{array}{l}\text { Extraction Sums of Squared } \\
\text { Loadings }\end{array}$} & \multicolumn{3}{l|}{$\begin{array}{l}\text { Rotation Sums of Squared } \\
\text { Loadings }\end{array}$} \\
\hline & Total & $\begin{array}{l}\% \text { of } \\
\text { Variance }\end{array}$ & $\begin{array}{l}\text { Cumulative } \\
\%\end{array}$ & Total & $\begin{array}{l}\text { \% of } \\
\text { Variance }\end{array}$ & $\begin{array}{l}\text { Cumulative } \\
\%\end{array}$ & Total & $\begin{array}{l}\text { \% of } \\
\text { Variance }\end{array}$ & $\begin{array}{l}\text { Cumulative } \\
\%\end{array}$ \\
\hline 1 & 6.493 & 19.677 & 19.677 & 6.493 & 19.677 & 19.677 & 2.810 & 8.516 & 8.516 \\
\hline 2 & 2.072 & 6.278 & 25.955 & 2.072 & 6.278 & 25.955 & 2.375 & 7.197 & 15.713 \\
\hline 3 & 1.865 & 5.652 & 31.607 & 1.865 & 5.652 & 31.607 & 2.337 & 7.083 & 22.796 \\
\hline 4 & 1.593 & 4.827 & 36.434 & 1.593 & 4.827 & 36.434 & 2.068 & 6.267 & 29.063 \\
\hline 5 & 1.424 & 4.317 & 40.750 & 1.424 & 4.317 & 40.750 & 1.842 & 5.581 & 34.644 \\
\hline 6 & 1.332 & 4.037 & 44.788 & 1.332 & 4.037 & 44.788 & 1.826 & 5.535 & 40.179 \\
\hline 7 & 1.245 & 3.771 & 48.559 & 1.245 & 3.771 & 48.559 & 1.814 & 5.497 & 45.676 \\
\hline 8 & 1.159 & 3.512 & 52.071 & 1.159 & 3.512 & 52.071 & 1.537 & 4.656 & 50.332 \\
\hline 9 & 1.114 & 3.375 & 55.446 & 1.114 & 3.375 & 55.446 & 1.454 & 4.405 & 54.737 \\
\hline 10 & 1.069 & 3.239 & 58.686 & 1.069 & 3.239 & 58.686 & 1.303 & 3.949 & 58.686 \\
\hline 11 & .950 & 2.878 & 61.564 & & & & & & \\
\hline 12 & .943 & 2.858 & 64.421 & & & & & & \\
\hline 13 & .937 & 2.839 & 67.260 & & & & & & \\
\hline 14 & .863 & 2.614 & 69.874 & & & & & & \\
\hline
\end{tabular}

Extraction Method: Principal Component Analysis

\section{Scree Plot}

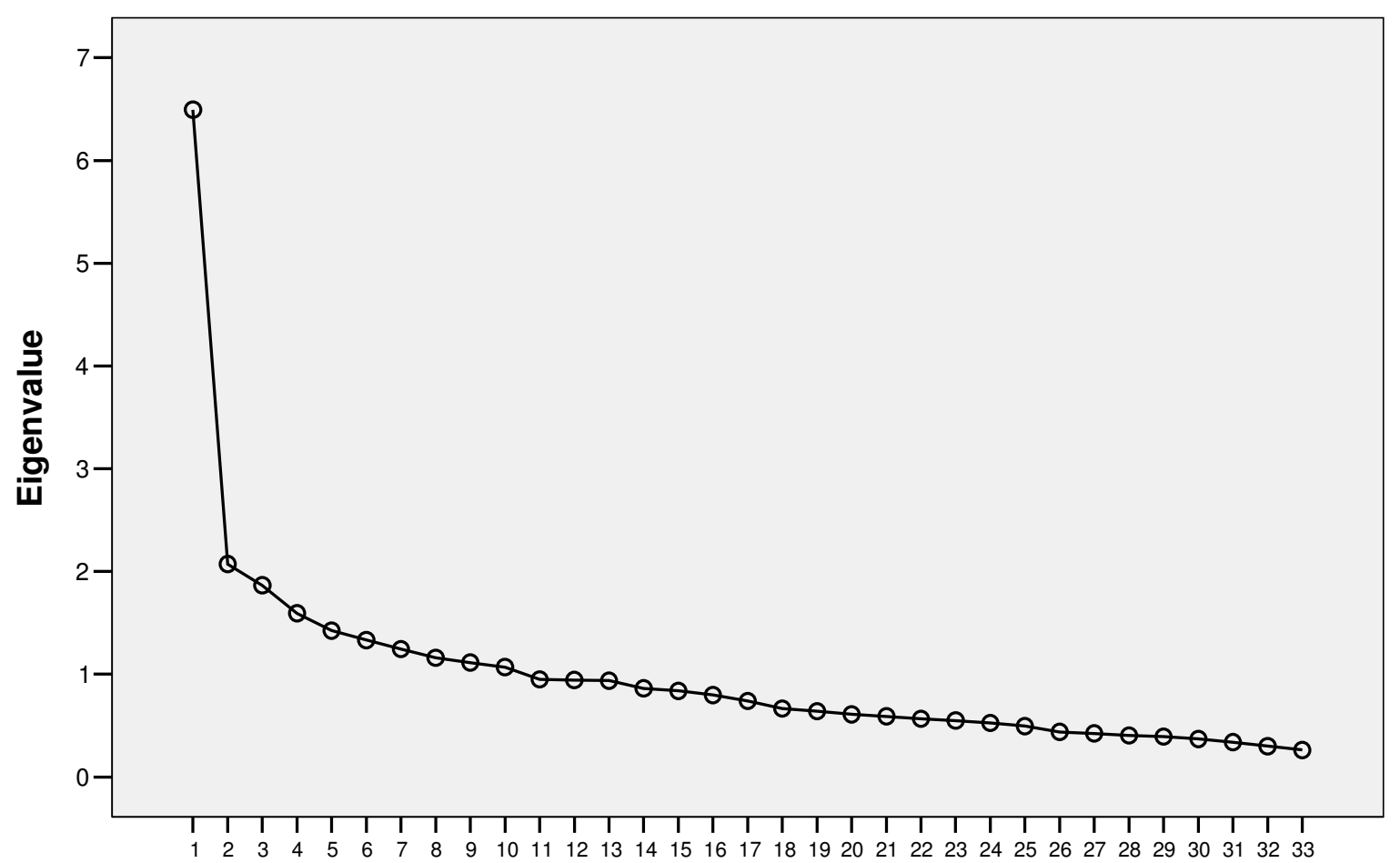

Component Number 


\begin{tabular}{|c|c|c|c|c|c|c|c|c|c|c|}
\hline & \multicolumn{10}{|c|}{ Rotated Component Matrix (Rotation converged in 18 iterations) } \\
\hline & 1 & 2 & 3 & 4 & 5 & 6 & 7 & 8 & 9 & 10 \\
\hline EOQ17 & -.729 & -.163 & -.029 & -.005 & -.093 & -.203 & -.064 & -.036 & -.172 & .240 \\
\hline EOQ23 & -.710 & -.165 & -.079 & -.136 & -.173 & -.203 & -.056 & .063 & -.114 & .021 \\
\hline EOQ5 & -.608 & .022 & -.063 & -.077 & .156 & .009 & -.037 & .049 & -.317 & .003 \\
\hline EOQ35 & -.544 & -.316 & -.062 & .111 & -.105 & -.164 & -.105 & .166 & .236 & .031 \\
\hline ORCQ18 & .474 & .111 & .062 & .151 & .348 & -.156 & .271 & .229 & -.207 & -.056 \\
\hline ORCQ24 & .173 & .774 & .231 & .038 & .119 & .104 & -.034 & .041 & .075 & -.022 \\
\hline InvQ7 & .102 & .690 & .178 & .104 & .106 & -.043 & .131 & -.013 & .080 & .056 \\
\hline InvQ13 & .360 & .520 & -.071 & .050 & .010 & -.072 & .291 & -.209 & -.279 & .088 \\
\hline InvQ25 & .030 & .452 & .405 & .068 & .157 & .233 & .021 & -.182 & .128 & -.022 \\
\hline ORCQ6 & .043 & .422 & -.016 & -.094 & .191 & .369 & .158 & .336 & .020 & -.280 \\
\hline InvQ31 & .001 & .164 & .759 & .061 & -.080 & .049 & .181 & .031 & .039 & -.075 \\
\hline InvQ1 & .071 & .259 & .657 & .122 & .093 & -.223 & .082 & .062 & .035 & -.046 \\
\hline AffQ14 & .312 & .145 & .507 & -.112 & .299 & .017 & -.077 & -.367 & .160 & .068 \\
\hline TOQ22 & .204 & -.096 & .434 & .025 & .180 & .218 & .375 & -.099 & -.196 & .187 \\
\hline TOQ34 & .001 & .078 & .378 & .291 & -.049 & .354 & .205 & .050 & -.151 & .369 \\
\hline ORCQ30 & .054 & .110 & .090 & .783 & -.076 & .060 & -.144 & .035 & -.024 & .053 \\
\hline ORCQ36 & .048 & -.003 & .129 & .774 & .063 & .059 & .201 & -.006 & -.021 & -.119 \\
\hline CSQ33 & .032 & .066 & -.095 & .477 & .231 & .337 & .221 & -.034 & .142 & .088 \\
\hline AffQ32 & .361 & -.050 & .335 & .384 & .182 & .331 & .063 & -.096 & .101 & .110 \\
\hline AffQ8 & .021 & .095 & .020 & .124 & .766 & .018 & .002 & -.003 & -.029 & -.149 \\
\hline AffQ20 & .210 & .210 & .093 & -.115 & .648 & .101 & .121 & .048 & .191 & .158 \\
\hline AffQ26 & -.002 & .108 & .365 & .145 & .422 & .250 & .054 & -.270 & .176 & .060 \\
\hline TOQ28 & .218 & -.003 & .078 & .130 & -.001 & .735 & -.044 & .025 & -.127 & -.076 \\
\hline CSQ15 & .150 & .158 & -.117 & .114 & .115 & .569 & .279 & .012 & .258 & .100 \\
\hline ORCQ12 & -.007 & .115 & .171 & -.014 & .109 & .076 & .669 & -.035 & .128 & -.254 \\
\hline TOQ16 & .286 & .091 & .256 & .138 & .001 & .087 & .585 & .053 & .039 & .150 \\
\hline CSQ3 & .012 & .274 & .031 & .171 & -.280 & .233 & .396 & -.362 & .133 & -.053 \\
\hline CSQ27 & .176 & .131 & -.056 & .274 & .138 & -.132 & .316 & -.270 & .136 & .274 \\
\hline CSQ21 & -.124 & -.077 & -.078 & .024 & -.026 & .038 & -.100 & .706 & -.047 & .084 \\
\hline InvQ19 & .292 & .335 & .163 & .027 & .065 & -.004 & .234 & .522 & .172 & .215 \\
\hline TOQ4 & .076 & .084 & .148 & -.120 & .106 & -.023 & .016 & -.115 & .656 & -.013 \\
\hline EOQ11 & -.251 & -.025 & .079 & -.238 & -.023 & -.061 & -.188 & -.091 &. .561 & -.062 \\
\hline EOQ29 & -.189 & .012 & -.033 & -.043 & -.026 & -.002 & -.081 & .138 & .046 & .802 \\
\hline
\end{tabular}

Extraction Method: Principal Component Analysis. Rotation Method: Varimax with Kaiser Normalization.

\section{Component Transformation Matrix}

\begin{tabular}{|l|l|l|l|l|l|l|l|l|l|l|}
\hline Component & 1 & 2 & 3 & 4 & 5 & 6 & 7 & 8 & 9 & 10 \\
\hline 1 & .501 & .435 & .392 & .272 & .297 & .293 & .352 & -.085 & .160 & .026 \\
\hline 2 & -.257 & -.342 & .006 & .747 & -.238 & .329 & .143 & .038 & -.047 & .264 \\
\hline 3 & -.546 & .178 & .712 & -.057 & .013 & -.260 & -.005 & -.208 & -.105 & .193 \\
\hline 4 & -.198 & .340 & -.066 & -.004 & .191 & .036 & .018 & .849 & -.180 & .225 \\
\hline 5 & -.177 & -.330 & .024 & -.046 & .697 & .203 & -.311 & -.011 & .457 & .158 \\
\hline 6 & -.113 & -.039 & .072 & .045 & .310 & .387 & -.175 & -.095 & -.663 & -.503 \\
\hline 7 & -.458 & .368 & -.206 & -.259 & -.222 & .563 & .173 & -.139 & .328 & -.149 \\
\hline 8 & -.261 & .358 & -.358 & .493 & .270 & -.458 & .021 & -.155 & .141 & -.326 \\
\hline 9 & -.036 & .093 & -.394 & -.150 & .280 & .007 & .288 & -.386 & -.388 & .593 \\
\hline 10 & -.151 & -.405 & .054 & -.168 & .191 & -.142 & .784 & .162 & .040 & -.290 \\
\hline
\end{tabular}

Measuring Sports Class Learning Climates: the development of the SCES 
APPENDIX 12 - Reliability analysis of modified SCES subscales

1. Reliability Analysis - Task Involvement \& improvement Scale - all Clubs

Reliability Statistics

\begin{tabular}{|c|c|r|}
\hline $\begin{array}{c}\text { Cronbach's } \\
\text { Alpha }\end{array}$ & $\begin{array}{c}\text { Cronbach's } \\
\text { Alpha Based } \\
\text { on } \\
\text { Ondandardized } \\
\text { Items }\end{array}$ & N of Items \\
\hline .489 & .495 & 4 \\
\hline
\end{tabular}

Item Statistics

\begin{tabular}{|l|c|r|r|}
\hline & Mean & $\begin{array}{c}\text { Std. } \\
\text { Deviation }\end{array}$ & \multicolumn{1}{c|}{$\mathrm{N}$} \\
\hline InvQ31 & 3.5048 & .64454 & 208 \\
InvQ1 & 3.4111 & .61032 & 208 \\
TOQ22 & 3.7236 & .59933 & 208 \\
TOQ28 & 3.6731 & .67305 & 208 \\
\hline
\end{tabular}

Inter-Item Correlation Matrix

\begin{tabular}{|l|r|r|r|r|}
\hline & \multicolumn{1}{|c|}{ InvQ31 } & \multicolumn{1}{|c|}{ InvQ1 } & \multicolumn{1}{c|}{ TOQ22 } & \multicolumn{1}{c|}{ TOQ28 } \\
\hline InvQ31 & 1.000 & .440 & .288 & .082 \\
InvQ1 & .440 & 1.000 & .180 & .023 \\
TOQ22 & .288 & .180 & 1.000 & .170 \\
TOQ28 & .082 & .023 & .170 & 1.000 \\
\hline
\end{tabular}

The covariance matrix is calculated and used in the analysis.

Summary Item Statistics

\begin{tabular}{|l|r|r|r|r|r|r|r|}
\hline & Mean & Minimum & Maximum & Range & $\begin{array}{c}\text { Maximum / } \\
\text { Minimum }\end{array}$ & Variance & N of Items \\
\hline Inter-Item Correlations & .197 & .023 & .440 & .417 & 19.173 & .020 & 4 \\
\hline
\end{tabular}

The covariance matrix is calculated and used in the analysis.

Item-Total Statistics

\begin{tabular}{|l|r|r|r|r|r|}
\hline & $\begin{array}{c}\text { Scale Mean if } \\
\text { Item Deleted }\end{array}$ & $\begin{array}{c}\text { Scale } \\
\text { Variance if } \\
\text { Item Deleted }\end{array}$ & $\begin{array}{c}\text { Corrected } \\
\text { Item-Total } \\
\text { Correlation }\end{array}$ & $\begin{array}{c}\text { Squared } \\
\text { Multiple } \\
\text { Correlation }\end{array}$ & $\begin{array}{c}\text { Cronbach's } \\
\text { Alpha if Item } \\
\text { Deleted }\end{array}$ \\
\hline InvQ31 & 10.8077 & 1.473 & .409 & .240 & .293 \\
InvQ1 & 10.9014 & 1.658 & .316 & .197 & .389 \\
TOQ22 & 10.5889 & 1.677 & .317 & .108 & .390 \\
TOQ28 & 10.6394 & 1.848 & .124 & .031 & .569 \\
\hline
\end{tabular}


2. Reliability Analysis - Ego Orientation \& Mistakes Scale - all Clubs

Reliability Statistics

\begin{tabular}{|c|c|c|}
\hline $\begin{array}{c}\text { Cronbach's } \\
\text { Alpha }\end{array}$ & $\begin{array}{c}\text { Cronbach's } \\
\text { Alpha Based } \\
\text { on } \\
\text { Standardized } \\
\text { Items }\end{array}$ & $\mathrm{N}$ of Items \\
\hline .712 & .710 & 4 \\
\hline
\end{tabular}

\section{Item Statistics}

\begin{tabular}{|l|c|r|r|}
\hline & Mean & \multicolumn{1}{|c|}{$\begin{array}{c}\text { Std. } \\
\text { Deviation }\end{array}$} & $\mathrm{N}$ \\
\hline EOQ5 & 1.8942 & 1.01122 & 208 \\
EOQ17 & 1.8606 & .95542 & 208 \\
EOQ23 & 1.9471 & 1.04122 & 208 \\
EOQ35 & 1.7788 & .81004 & 208 \\
\hline
\end{tabular}

Inter-Item Correlation Matrix

\begin{tabular}{|l|r|r|r|r|}
\hline & \multicolumn{1}{|c|}{ EOQ5 } & \multicolumn{1}{|c|}{ EOQ17 } & \multicolumn{1}{c|}{ EOQ23 } & \multicolumn{1}{c|}{ EOQ35 } \\
\hline EOQ5 & 1.000 & .370 & .366 & .154 \\
EOQ17 & .370 & 1.000 & .638 & .416 \\
EOQ23 & .366 & .638 & 1.000 & .335 \\
EOQ35 & .154 & .416 & .335 & 1.000 \\
\hline
\end{tabular}

The covariance matrix is calculated and used in the analysis.

Summary Item Statistics

\begin{tabular}{|l|r|r|r|r|r|r|r|}
\hline & Mean & Minimum & Maximum & Range & $\begin{array}{c}\text { Maximum / } \\
\text { Minimum }\end{array}$ & Variance & N of Items \\
\hline Inter-Item Correlations & .380 & .154 & .638 & .484 & 4.142 & .022 & 4 \\
\hline
\end{tabular}

The covariance matrix is calculated and used in the analysis.

Item-Total Statistics

\begin{tabular}{|l|r|r|r|r|r|}
\hline & $\begin{array}{c}\text { Scale Mean if } \\
\text { Item Deleted }\end{array}$ & $\begin{array}{c}\text { Scale } \\
\text { Variance if } \\
\text { Item Deleted }\end{array}$ & $\begin{array}{c}\text { Corrected } \\
\text { Item-Total } \\
\text { Correlation }\end{array}$ & $\begin{array}{c}\text { Squared } \\
\text { Multiple } \\
\text { Correlation }\end{array}$ & $\begin{array}{c}\text { Cronbach's } \\
\text { Alpha if Item } \\
\text { Deleted }\end{array}$ \\
\hline EOQ5 & 5.5865 & 5.133 & .379 & .166 & .725 \\
EOQ17 & 5.6202 & 4.353 & .659 & .472 & .548 \\
EOQ23 & 5.5337 & 4.202 & .611 & .433 & .575 \\
EOQ35 & 5.7019 & 5.775 & .375 & .181 & .716 \\
\hline
\end{tabular}


3. Reliability Analysis - Coach-Athlete Communication Scale - all Clubs

Reliability Statistics

\begin{tabular}{|c|c|c|}
\hline $\begin{array}{c}\text { Cronbach's } \\
\text { Alpha }\end{array}$ & $\begin{array}{c}\text { Cronbach's } \\
\text { Alpha Based } \\
\text { on } \\
\text { Standardized } \\
\text { Items }\end{array}$ & $\mathrm{N}$ of Items \\
\hline .555 & .554 & 4 \\
\hline
\end{tabular}

Item Statistics

\begin{tabular}{|l|c|r|r|}
\hline & Mean & $\begin{array}{c}\text { Std. } \\
\text { Deviation }\end{array}$ & $\mathrm{N}$ \\
\hline CSQ33 & 3.3413 & .88127 & 208 \\
ORCQ18 & 3.3125 & .78847 & 208 \\
ORCQ30 & 3.1923 & .90705 & 208 \\
ORCQ36 & 3.3558 & .79148 & 208 \\
\hline
\end{tabular}

Inter-Item Correlation Matrix

\begin{tabular}{|l|r|r|r|r|}
\hline & \multicolumn{1}{|c|}{ CSQ33 } & ORCQ18 & \multicolumn{1}{c|}{ ORCQ30 } & \multicolumn{1}{|c|}{ ORCQ36 } \\
\hline CSQ33 & 1.000 & .124 & .238 & .345 \\
ORCQ18 & .124 & 1.000 & .071 & .169 \\
ORCQ30 & .238 & .071 & 1.000 & .476 \\
ORCQ36 & .345 & .169 & .476 & 1.000 \\
\hline
\end{tabular}

The covariance matrix is calculated and used in the analysis.

Summary Item Statistics

\begin{tabular}{|l|r|r|r|r|r|r|r|}
\hline & Mean & Minimum & Maximum & Range & $\begin{array}{c}\text { Maximum / } \\
\text { Minimum }\end{array}$ & Variance & N of Items \\
\hline Inter-Item Correlations & .237 & .071 & .476 & .405 & 6.714 & .021 & 4 \\
\hline
\end{tabular}

The covariance matrix is calculated and used in the analysis.

Item-Total Statistics

\begin{tabular}{|l|r|r|r|r|r|}
\hline & $\begin{array}{c}\text { Scale Mean if } \\
\text { Item Deleted }\end{array}$ & $\begin{array}{c}\text { Scale } \\
\text { Variance if } \\
\text { Item Deleted }\end{array}$ & $\begin{array}{c}\text { Corrected } \\
\text { Item-Total } \\
\text { Correlation }\end{array}$ & $\begin{array}{c}\text { Squared } \\
\text { Multiple } \\
\text { Correlation }\end{array}$ & $\begin{array}{c}\text { Cronbach's } \\
\text { Alpha if Item } \\
\text { Deleted }\end{array}$ \\
\hline CSQ33 & 9.8606 & 3.067 & .335 & .130 & .487 \\
ORCQ18 & 9.8894 & 3.770 & .158 & .034 & .614 \\
ORCQ30 & 10.0096 & 2.889 & .378 & .233 & .449 \\
ORCQ36 & 9.8462 & 2.875 & .513 & .296 & .341 \\
\hline
\end{tabular}


4. Reliability Analysis - Effort, Order \& Organization Scale - all Clubs

Reliability Statistics

\begin{tabular}{|c|c|c|}
\hline $\begin{array}{l}\text { Cronbach's } \\
\text { Alpha }\end{array}$ & $\begin{array}{c}\text { Cronbach's } \\
\text { Alpha Based } \\
\text { on } \\
\text { Standardized } \\
\text { Items }\end{array}$ & $\mathrm{N}$ of Items \\
\hline .627 & .627 & 4 \\
\hline
\end{tabular}

Item Statistics

\begin{tabular}{|l|c|r|r|}
\hline & Mean & $\begin{array}{c}\text { Std. } \\
\text { Deviation }\end{array}$ & $\mathrm{N}$ \\
\hline InvQ7 & 2.9423 & .80250 & 208 \\
InvQ13 & 2.9399 & .91022 & 208 \\
ORCQ6 & 3.5529 & .76587 & 208 \\
ORCQ24 & 2.9135 & .83534 & 208 \\
\hline
\end{tabular}

Inter-Item Correlation Matrix

\begin{tabular}{|l|r|r|r|r|}
\hline & \multicolumn{1}{|c|}{ InvQ7 } & \multicolumn{1}{|c|}{ InvQ13 } & \multicolumn{1}{c|}{ ORCQ6 } & ORCQ24 \\
\hline InvQ7 & 1.000 & .290 & .178 & .526 \\
InvQ13 & .290 & 1.000 & .128 & .352 \\
ORCQ6 & .178 & .128 & 1.000 & .302 \\
ORCQ24 & .526 & .352 & .302 & 1.000 \\
\hline
\end{tabular}

The covariance matrix is calculated and used in the analysis.

Summary Item Statistics

\begin{tabular}{|l|r|r|r|r|r|r|r|}
\hline & Mean & Minimum & Maximum & Range & $\begin{array}{c}\text { Maximum / } \\
\text { Minimum }\end{array}$ & Variance & N of Items \\
\hline Inter-Item Correlations & .296 & .128 & .526 & .398 & 4.121 & .018 & 4 \\
\hline
\end{tabular}

The covariance matrix is calculated and used in the analysis.

Item-Total Statistics

\begin{tabular}{|l|r|r|r|r|r|}
\hline & $\begin{array}{c}\text { Scale Mean if } \\
\text { Item Deleted }\end{array}$ & $\begin{array}{c}\text { Scale } \\
\text { Variance if } \\
\text { Item Deleted }\end{array}$ & $\begin{array}{c}\text { Corrected } \\
\text { Item-Total } \\
\text { Correlation }\end{array}$ & $\begin{array}{c}\text { Squared } \\
\text { Multiple } \\
\text { Correlation }\end{array}$ & $\begin{array}{c}\text { Cronbach's } \\
\text { Alpha if Item } \\
\text { Deleted }\end{array}$ \\
\hline InvQ7 & 9.4063 & 3.212 & .468 & .289 & .513 \\
InvQ13 & 9.4087 & 3.238 & .347 & .139 & .607 \\
ORCQ6 & 8.7957 & 3.834 & .261 & .092 & .651 \\
ORCQ24 & 9.4351 & 2.879 & .574 & .358 & .427 \\
\hline
\end{tabular}


5. Reliability Analysis - Clubs Affiliation Scale - all Clubs

Reliability Statistics

\begin{tabular}{|c|c|r|}
\hline & $\begin{array}{c}\text { Cronbach's } \\
\text { Alpha Based } \\
\text { on } \\
\begin{array}{c}\text { Oronbach's } \\
\text { Alpha }\end{array}\end{array}$ & \\
\hline .626 & $\begin{array}{c}\text { Standardized } \\
\text { Items }\end{array}$ & N of Items \\
\hline
\end{tabular}

\section{Item Statistics}

\begin{tabular}{|l|c|r|r|}
\hline & Mean & \multicolumn{1}{|c|}{$\begin{array}{c}\text { Std. } \\
\text { Deviation }\end{array}$} & \multicolumn{1}{c|}{$\mathrm{N}$} \\
\hline AffQ8 & 3.7404 & .60585 & 208 \\
AffQ14 & 3.7260 & .48842 & 208 \\
AffQ20 & 3.7067 & .64122 & 208 \\
AffQ26 & 3.4856 & .63686 & 208 \\
\hline
\end{tabular}

Inter-Item Correlation Matrix

\begin{tabular}{|l|r|r|r|r|}
\hline & \multicolumn{1}{|c|}{ AffQ8 } & \multicolumn{1}{c|}{ AffQ14 } & \multicolumn{1}{c|}{ AffQ20 } & \multicolumn{1}{c|}{ AffQ26 } \\
\hline AffQ8 & 1.000 & .167 & .338 & .291 \\
AffQ14 & .167 & 1.000 & .390 & .306 \\
AffQ20 & .338 & .390 & 1.000 & .291 \\
AffQ26 & .291 & .306 & .291 & 1.000 \\
\hline
\end{tabular}

The covariance matrix is calculated and used in the analysis.

Summary Item Statistics

\begin{tabular}{|l|r|r|r|r|r|r|r|}
\hline & Mean & Minimum & Maximum & Range & $\begin{array}{c}\text { Maximum / } \\
\text { Minimum }\end{array}$ & Variance & N of Items \\
\hline Inter-Item Correlations & .297 & .167 & .390 & .223 & 2.342 & .005 & 4 \\
\hline
\end{tabular}

The covariance matrix is calculated and used in the analysis.

Item-Total Statistics

\begin{tabular}{|l|r|r|r|r|r|}
\hline & $\begin{array}{c}\text { Scale Mean if } \\
\text { Item Deleted }\end{array}$ & $\begin{array}{c}\text { Scale } \\
\text { Variance if } \\
\text { Item Deleted }\end{array}$ & $\begin{array}{c}\text { Corrected } \\
\text { Item-Total } \\
\text { Correlation }\end{array}$ & $\begin{array}{c}\text { Squared } \\
\text { Multiple } \\
\text { Correlation }\end{array}$ & $\begin{array}{c}\text { Cronbach's } \\
\text { Alpha if Item } \\
\text { Deleted }\end{array}$ \\
\hline AffQ8 & 10.9183 & 1.728 & .368 & .155 & .584 \\
AffQ14 & 10.9327 & 1.908 & .395 & .192 & .570 \\
AffQ20 & 10.9519 & 1.524 & .470 & .242 & .505 \\
AffQ26 & 11.1731 & 1.622 & .402 & .167 & .560 \\
\hline
\end{tabular}


APPENDIX 13- MANOVA - Club Type (Low [Jnr] Training hours \& High [Snr] Training hours) and competitive gymnastics Level

\begin{tabular}{|ll|l|r|}
\hline Type of club & 1 & & \\
\hline gps) & 2 & Sha & N \\
1=L3-5, 2=L6- & 1 & L3-5 & 150 \\
& 2 & L6-9 & 58 \\
& & & \\
\hline
\end{tabular}

Descriptive Statistics

\begin{tabular}{|c|c|c|c|c|c|}
\hline & Type of club (2 gps) & $1=\mathrm{L} 3-5,2=\mathrm{L} 6-10$ & Mean & $\begin{array}{c}\text { Std. } \\
\text { Deviation }\end{array}$ & $\mathrm{N}$ \\
\hline \multirow[t]{9}{*}{ TaskMean } & \multirow[t]{3}{*}{ JnrHrs } & L3-5 & 3.6008 & .39927 & 121 \\
\hline & & L6-9 & 3.5919 & .33861 & 37 \\
\hline & & Total & 3.5987 & .38490 & 158 \\
\hline & \multirow[t]{3}{*}{ SnrHrs } & L3-5 & 3.6690 & .30367 & 29 \\
\hline & & L6-9 & 3.5524 & .34003 & 21 \\
\hline & & Total & 3.6200 & .32135 & 50 \\
\hline & \multirow[t]{3}{*}{ Total } & L3-5 & 3.6140 & .38268 & 150 \\
\hline & & L6-9 & 3.5776 & .33667 & 58 \\
\hline & & Total & 3.6038 & .36999 & 208 \\
\hline \multirow[t]{9}{*}{ EgoMean } & \multirow[t]{3}{*}{ JnrHrs } & L3-5 & 1.7636 & .56804 & 121 \\
\hline & & L6-9 & 1.7405 & .60528 & 37 \\
\hline & & Total & 1.7582 & .57509 & 158 \\
\hline & \multirow[t]{3}{*}{ SnrHrs } & L3-5 & 2.3517 & .68171 & 29 \\
\hline & & L6-9 & 2.0095 & .62121 & 21 \\
\hline & & Total & 2.2080 & .67244 & 50 \\
\hline & \multirow[t]{3}{*}{ Total } & L3-5 & 1.8773 & .63364 & 150 \\
\hline & & L6-9 & 1.8379 & .61952 & 58 \\
\hline & & Total & 1.8663 & .62849 & 208 \\
\hline \multirow[t]{9}{*}{ CommMean } & \multirow[t]{3}{*}{ JnrHrs } & L3-5 & 3.3430 & .58375 & 121 \\
\hline & & L6-9 & 3.3176 & .51251 & 37 \\
\hline & & Total & 3.3370 & .56639 & 158 \\
\hline & \multirow[t]{3}{*}{ SnrHrs } & L3-5 & 3.4224 & .62715 & 29 \\
\hline & & L6-9 & 3.2024 & .70984 & 21 \\
\hline & & Total & 3.3300 & .66517 & 50 \\
\hline & \multirow[t]{3}{*}{ Total } & L3-5 & 3.3583 & .59105 & 150 \\
\hline & & L6-9 & 3.2759 & .58806 & 58 \\
\hline & & Total & 3.3353 & .58996 & 208 \\
\hline \multirow[t]{9}{*}{ EOOMean } & \multirow[t]{3}{*}{ JnrHrs } & L3-5 & 3.1843 & .51494 & 121 \\
\hline & & L6-9 & 3.0324 & .56865 & 37 \\
\hline & & Total & 3.1487 & .53008 & 158 \\
\hline & \multirow[t]{3}{*}{ SnrHrs } & L3-5 & 3.0897 & .53073 & 29 \\
\hline & & L6-9 & 3.2286 & .52644 & 21 \\
\hline & & Total & 3.1480 & .52808 & 50 \\
\hline & \multirow[t]{3}{*}{ Total } & L3-5 & 3.1660 & .51759 & 150 \\
\hline & & L6-9 & 3.1034 & .55724 & 58 \\
\hline & & Total & 3.1486 & .52833 & 208 \\
\hline \multirow[t]{9}{*}{ AffMean } & \multirow[t]{3}{*}{ JnrHrs } & L3-5 & 3.6570 & .40328 & 121 \\
\hline & & L6-9 & 3.6014 & .50847 & 37 \\
\hline & & Total & 3.6440 & .42913 & 158 \\
\hline & \multirow[t]{3}{*}{ SnrHrs } & L3-5 & 3.7414 & 34384 & 29 \\
\hline & & L6-9 & 3.7143 & .32869 & 21 \\
\hline & & Total & 3.7300 & .33442 & 50 \\
\hline & \multirow[t]{3}{*}{ Total } & L3-5 & 3.6733 & 39283 & 150 \\
\hline & & L6-9 & 3.6422 & .45188 & 58 \\
\hline & & Total & 3.6647 & .40927 & 208 \\
\hline
\end{tabular}




\section{Box's Test of Equality of Covariance Matrices ${ }^{a}$}

\begin{tabular}{|l|r|}
\hline Box's M & 62.191 \\
$\mathrm{~F}$ & 1.283 \\
$\mathrm{df1}$ & 45 \\
$\mathrm{df2}$ & 20058.77 \\
Sig. & .097 \\
\hline
\end{tabular}

Tests the null hypothesis that the observed covariance matrices of the dependent variables are equal across groups.

a. Design: Intercept+Clubtype+Level+Clubtype * Level

Multivariate Tests ${ }^{b}$

\begin{tabular}{|ll|r|r|r|r|r|}
\hline Effect & & \multicolumn{1}{c|}{ Value } & \multicolumn{1}{c|}{ F } & Hypothesis df & Error df & Sig. \\
\hline Intercept & Pillai's Trace & .994 & $6305.028^{\mathrm{a}}$ & 5.000 & 200.000 & .000 \\
& Wilks' Lambda & .006 & $6305.028^{\mathrm{a}}$ & 5.000 & 200.000 & .000 \\
& Hotelling's Trace & 157.626 & $6305.028^{\mathrm{a}}$ & 5.000 & 200.000 & .000 \\
& Roy's Largest Root & 157.626 & $6305.028^{\mathrm{a}}$ & 5.000 & 200.000 & .000 \\
\hline Clubtype & Pillai's Trace & .142 & $6.617^{\mathrm{a}}$ & 5.000 & 200.000 & .000 \\
& Wilks' Lambda & .858 & $6.617^{\mathrm{a}}$ & 5.000 & 200.000 & .000 \\
& Hotelling's Trace & .165 & $6.617^{\mathrm{a}}$ & 5.000 & 200.000 & .000 \\
& Roy's Largest Root & .165 & $6.617^{\mathrm{a}}$ & 5.000 & 200.000 & .000 \\
\hline Level & Pillai's Trace & .043 & $1.817^{\mathrm{a}}$ & 5.000 & 200.000 & .111 \\
& Wilks' Lambda & .957 & $1.817^{\mathrm{a}}$ & 5.000 & 200.000 & .111 \\
& Hotelling's Trace & .045 & $1.817^{\mathrm{a}}$ & 5.000 & 200.000 & .111 \\
& Roy's Largest Root & .045 & $1.817^{\mathrm{a}}$ & 5.000 & 200.000 & .111 \\
\hline Clubtype * Level & Pillai's Trace & .041 & $1.691^{\mathrm{a}}$ & 5.000 & 200.000 & .138 \\
& Wilks' Lambda & .959 & $1.691^{\mathrm{a}}$ & 5.000 & 200.000 & .138 \\
& Hotelling's Trace & .042 & $1.691^{\mathrm{a}}$ & 5.000 & 200.000 & .138 \\
& Roy's Largest Root & .042 & $1.691^{\mathrm{a}}$ & 5.000 & 200.000 \\
& & & & .138 \\
\hline
\end{tabular}

a. Exact statistic

b. Design: Intercept+Clubtype+Level+Clubtype * Level

\section{Levene's Test of Equality of Error Variances ${ }^{a}$}

\begin{tabular}{|l|r|r|r|r|}
\hline & \multicolumn{1}{|c|}{$\mathrm{F}$} & $\mathrm{df1}$ & $\mathrm{d}$ df2 & \multicolumn{1}{c|}{ Sig. } \\
\hline TaskMean & .662 & 3 & 204 & .576 \\
EgoMean & .595 & 3 & 204 & .619 \\
CommMean & .764 & 3 & 204 & .515 \\
EOOMean & .437 & 3 & 204 & .727 \\
AffMean & 2.435 & 3 & 204 & .066 \\
\hline
\end{tabular}

Tests the null hypothesis that the error variance of the dependent variable is equal across groups.

a. Design: Intercept+Clubtype+Level+Clubtype * Level 
Tests of Between-Subjects Effects

\begin{tabular}{|c|c|c|c|c|c|c|}
\hline Source & Dependent Variable & $\begin{array}{l}\text { Type III Sum } \\
\text { of Squares }\end{array}$ & df & Mean Square & $\mathrm{F}$ & Sig. \\
\hline \multirow[t]{5}{*}{ Corrected Model } & TaskMean & $.185^{a}$ & 3 & .062 & .447 & .720 \\
\hline & EgoMean & $9.125^{b}$ & 3 & 3.042 & 8.542 & .000 \\
\hline & CommMean & $.610^{\mathrm{c}}$ & 3 & .203 & .581 & .628 \\
\hline & EOOMean & $.889^{d}$ & 3 & .296 & 1.062 & .366 \\
\hline & AffMean & $.378^{\mathrm{e}}$ & 3 & .126 & .749 & .524 \\
\hline \multirow[t]{5}{*}{ Intercept } & TaskMean & 1769.822 & 1 & 1769.822 & 12824.83 & .000 \\
\hline & EgoMean & 526.988 & 1 & 526.988 & 1479.985 & .000 \\
\hline & CommMean & 1503.495 & 1 & 1503.495 & 4293.419 & .000 \\
\hline & EOOMean & 1338.451 & 1 & 1338.451 & 4799.422 & .000 \\
\hline & AffMean & 1844.254 & 1 & 1844.254 & 10970.33 & .000 \\
\hline \multirow[t]{5}{*}{ Clubtype } & TaskMean & .007 & 1 & .007 & .051 & .822 \\
\hline & EgoMean & 6.257 & 1 & 6.257 & 17.573 & .000 \\
\hline & CommMean & .011 & 1 & .011 & .031 & .860 \\
\hline & EOOMean & .088 & 1 & .088 & .315 & .575 \\
\hline & AffMean & .332 & 1 & .332 & 1.972 & .162 \\
\hline \multirow[t]{5}{*}{ Level } & TaskMean & .134 & 1 & .134 & .973 & .325 \\
\hline & EgoMean & 1.137 & 1 & 1.137 & 3.192 & .075 \\
\hline & CommMean & .513 & 1 & .513 & 1.465 & .227 \\
\hline & EOOMean & .001 & 1 & .001 & .005 & .943 \\
\hline & AffMean & .058 & 1 & .058 & .347 & .556 \\
\hline \multirow[t]{5}{*}{ Clubtype * Level } & TaskMean & .099 & 1 & .099 & .715 & .399 \\
\hline & EgoMean & .867 & 1 & .867 & 2.436 & .120 \\
\hline & CommMean & .323 & 1 & .323 & .921 & .338 \\
\hline & EOOMean & .720 & 1 & .720 & 2.583 & .110 \\
\hline & AffMean & .007 & 1 & .007 & .041 & .839 \\
\hline \multirow[t]{5}{*}{ Error } & TaskMean & 28.152 & 204 & .138 & & \\
\hline & EgoMean & 72.640 & 204 & .356 & & \\
\hline & CommMean & 71.438 & 204 & .350 & & \\
\hline & EOOMean & 56.891 & 204 & .279 & & \\
\hline & AffMean & 34.295 & 204 & .168 & & \\
\hline \multirow[t]{5}{*}{ Total } & TaskMean & 2729.780 & 208 & & & \\
\hline & EgoMean & 806.280 & 208 & & & \\
\hline & CommMean & 2385.938 & 208 & & & \\
\hline & EOOMean & 2119.770 & 208 & & & \\
\hline & AffMean & 2828.063 & 208 & & & \\
\hline \multirow[t]{5}{*}{ Corrected Total } & TaskMean & 28.337 & 207 & & & \\
\hline & EgoMean & 81.764 & 207 & & & \\
\hline & CommMean & 72.048 & 207 & & & \\
\hline & EOOMean & 57.780 & 207 & & & \\
\hline & AffMean & 34.673 & 207 & & & \\
\hline
\end{tabular}

a. $\mathrm{R}$ Squared $=.007$ (Adjusted R Squared $=-.008$ )

b. $\mathrm{R}$ Squared $=.112$ (Adjusted R Squared $=.099)$

c. R Squared $=.008$ (Adjusted R Squared $=-.006$ )

d. $\mathrm{R}$ Squared $=.015$ (Adjusted R Squared $=.001$ )

e. R Squared $=.011$ (Adjusted R Squared $=-.004$ ) 
Between-Subjects SSCP Matrix

\begin{tabular}{|c|c|c|c|c|c|c|c|}
\hline & & & TaskMean & EgoMean & CommMean & EOOMean & AffMean \\
\hline \multirow[t]{20}{*}{ Hypothesis } & \multirow[t]{5}{*}{ Intercept } & TaskMean & 1769.822 & 965.751 & 1631.232 & 1539.097 & 1806.655 \\
\hline & & EgoMean & 965.751 & 526.988 & 890.126 & 839.850 & 985.850 \\
\hline & & CommMean & 1631.232 & 890.126 & 1503.495 & 1418.574 & 1665.180 \\
\hline & & EOOMean & 1539.097 & 839.850 & 1418.574 & 1338.451 & 1571.128 \\
\hline & & AffMean & 1806.655 & 985.850 & 1665.180 & 1571.128 & 1844.254 \\
\hline & \multirow[t]{5}{*}{ Clubtype } & TaskMean & .007 & .209 & -.009 & .025 & .048 \\
\hline & & EgoMean & .209 & 6.257 & -.261 & .741 & 1.440 \\
\hline & & CommMean & -.009 & -.261 & .011 & -.031 & -.060 \\
\hline & & EOOMean & .025 & .741 & -.031 & .088 & .171 \\
\hline & & AffMean & .048 & 1.440 & -.060 & .171 & .332 \\
\hline & \multirow[t]{5}{*}{ Level } & TaskMean & .134 & .391 & .262 & .014 & .088 \\
\hline & & EgoMean & .391 & 1.137 & .764 & .040 & .258 \\
\hline & & CommMean & .262 & .764 & .513 & .027 & .173 \\
\hline & & EOOMean & .014 & .040 & .027 & .001 & .009 \\
\hline & & AffMean & .088 & .258 & .173 & .009 & .058 \\
\hline & \multirow[t]{5}{*}{ Clubtype * Level } & TaskMean & .099 & .293 & .178 & -.267 & -.026 \\
\hline & & EgoMean & .293 & .867 & .529 & -.790 & -.078 \\
\hline & & CommMean & .178 & .529 & .323 & -.482 & -.047 \\
\hline & & EOOMean & -.267 & -.790 & -.482 & .720 & .071 \\
\hline & & AffMean & -.026 & -.078 & -.047 & .071 & .007 \\
\hline \multirow[t]{5}{*}{ Error } & & TaskMean & 28.152 & -15.628 & 17.869 & 16.961 & 12.221 \\
\hline & & EgoMean & -15.628 & 72.640 & -24.791 & -29.498 & -20.991 \\
\hline & & CommMean & 17.869 & -24.791 & 71.438 & 16.126 & 13.050 \\
\hline & & EOOMean & 16.961 & -29.498 & 16.126 & 56.891 & 18.971 \\
\hline & & AffMean & 12.221 & -20.991 & 13.050 & 18.971 & 34.295 \\
\hline
\end{tabular}

Based on Type III Sum of Squares

\section{Estimated Marginal Means}

\section{Grand Mean}

\begin{tabular}{|l|r|r|r|r|}
\hline & & & \multicolumn{2}{|c|}{$95 \%$ Confidence Interval } \\
\cline { 4 - 5 } Dependent Variable & Mean & Std. Error & Lower Bound & Upper Bound \\
\hline TaskMean & 3.604 & .032 & 3.541 & 3.666 \\
EgoMean & 1.966 & .051 & 1.866 & 2.067 \\
CommMean & 3.321 & .051 & 3.221 & 3.421 \\
EOOMean & 3.134 & .045 & 3.045 & 3.223 \\
AffMean & 3.679 & .035 & 3.609 & 3.748 \\
\hline
\end{tabular}




\section{Type of club (2 gps)}

Estimates

\begin{tabular}{|ll|r|r|r|r|}
\hline & & & & \multicolumn{2}{|c|}{$95 \%$ Confidence Interval } \\
\cline { 5 - 6 } Dependent Variable & Type of club (2 gps) & Mean & Std. Error & Lower Bound & Upper Bound \\
\hline TaskMean & JnrHrs & 3.596 & .035 & 3.528 & 3.665 \\
& SnrHrs & 3.611 & .053 & 3.506 & 3.716 \\
\hline EgoMean & JnrHrs & 1.752 & .056 & 1.642 & 1.863 \\
& SnrHrs & 2.181 & .085 & 2.012 & 2.349 \\
\hline CommMean & JnrHrs & 3.330 & .056 & 3.221 & 3.440 \\
& SnrHrs & 3.312 & .085 & 3.145 & 3.480 \\
\hline EOOMean & JnrHrs & 3.108 & .050 & 3.011 & 3.206 \\
& SnrHrs & 3.159 & .076 & 3.010 & 3.308 \\
\hline AffMean & JnrHrs & 3.629 & .039 & 3.553 & 3.705 \\
& SnrHrs & 3.728 & .059 & 3.612 & 3.844 \\
\hline
\end{tabular}

Pairwise Comparisons

\begin{tabular}{|c|c|c|c|c|c|c|c|}
\hline \multirow{2}{*}{\multicolumn{3}{|c|}{ Dependent Varia (I) Type of club (2 (J) Type of club (2 }} & \multirow{2}{*}{$\begin{array}{c}\text { Mean } \\
\text { Difference } \\
(\mathrm{I}-\mathrm{J})\end{array}$} & \multirow[b]{2}{*}{ Std. Error } & \multirow[b]{2}{*}{ Sig. $^{\mathrm{a}}$} & \multicolumn{2}{|c|}{$\begin{array}{c}5 \% \text { Confidence Interval fd } \\
\text { Differencê }\end{array}$} \\
\hline & & & & & & -ower Boun & Jpper Bouno \\
\hline \multirow[t]{2}{*}{ TaskMean } & JnrHrs & SnrHrs & -.014 & .064 & .822 & -.140 & .111 \\
\hline & SnrHrs & JnrHrs & .014 & .064 & .822 & -.111 & .140 \\
\hline \multirow[t]{2}{*}{ EgoMean } & JnrHrs & SnrHrs & $-.429^{*}$ & .102 & .000 & -.630 & -.227 \\
\hline & SnrHrs & JnrHrs & $.429^{*}$ & .102 & .000 & .227 & .630 \\
\hline \multirow[t]{2}{*}{ CommMean } & JnrHrs & SnrHrs & .018 & .101 & .860 & -.182 & .218 \\
\hline & SnrHrs & JnrHrs & -.018 & .101 & .860 & -.218 & .182 \\
\hline \multirow[t]{2}{*}{ EOOMean } & JnrHrs & SnrHrs & -.051 & .090 & .575 & -.229 & .128 \\
\hline & SnrHrs & JnrHrs & .051 & .090 & .575 & -.128 & .229 \\
\hline \multirow[t]{2}{*}{ AffMean } & JnrHrs & SnrHrs & -.099 & .070 & .162 & -.237 & .040 \\
\hline & SnrHrs & JnrHrs & .099 & .070 & .162 & -.040 & .237 \\
\hline
\end{tabular}

Based on estimated marginal means

${ }^{*}$. The mean difference is significant at the .05 level.

a.Adjustment for multiple comparisons: Least Significant Difference (equivalent to no adjustments).

Multivariate Tests

\begin{tabular}{|l|r|r|r|r|r|}
\hline & \multicolumn{1}{|c|}{ Value } & F & Hypothesis df & Error df & \multicolumn{1}{c|}{ Sig. } \\
\hline Pillai's trace & .142 & $6.617^{\mathrm{a}}$ & 5.000 & 200.000 & .000 \\
Wilks' lambda & .858 & $6.617^{\mathrm{a}}$ & 5.000 & 200.000 & .000 \\
Hotelling's trace & .165 & $6.617^{\mathrm{a}}$ & 5.000 & 200.000 & .000 \\
Roy's largest root & .165 & $6.617^{\mathrm{a}}$ & 5.000 & 200.000 & .000 \\
\hline
\end{tabular}

Each $\mathrm{F}$ tests the multivariate effect of Type of club (2 gps). These tests are based on the linearly independent pairwise comparisons among the estimated marginal means.

a. Exact statistic 
Univariate Tests

\begin{tabular}{|c|c|c|c|c|c|c|}
\hline Dependent Variable & & $\begin{array}{l}\text { Sum of } \\
\text { Squares }\end{array}$ & df & Mean Square & $\mathrm{F}$ & Sig. \\
\hline \multirow[t]{2}{*}{ TaskMean } & Contrast & .007 & 1 & .007 & \multirow[t]{2}{*}{.051} & \multirow[t]{2}{*}{.822} \\
\hline & Error & 28.152 & 204 & .138 & & \\
\hline \multirow[t]{2}{*}{ EgoMean } & Contrast & 6.257 & 1 & 6.257 & \multirow[t]{2}{*}{17.573} & \multirow[t]{2}{*}{.000} \\
\hline & Error & 72.640 & 204 & .356 & & \\
\hline \multirow[t]{2}{*}{ CommMean } & Contrast & .011 & 1 & .011 & \multirow[t]{2}{*}{.031} & \multirow[t]{2}{*}{.860} \\
\hline & Error & 71.438 & 204 & .350 & & \\
\hline \multirow[t]{2}{*}{ EOOMean } & Contrast & .088 & 1 & .088 & \multirow[t]{2}{*}{.315} & \multirow[t]{2}{*}{.575} \\
\hline & Error & 56.891 & 204 & .279 & & \\
\hline \multirow[t]{2}{*}{ AffMean } & Contrast & .332 & 1 & .332 & \multirow[t]{2}{*}{1.972} & \multirow[t]{2}{*}{.162} \\
\hline & Error & 34.295 & 204 & .168 & & \\
\hline
\end{tabular}

The $\mathrm{F}$ tests the effect of Type of club (2 gps). This test is based on the linearly independent pairwise comparisons among the estimated marginal means.

\section{3. $1=\mathrm{L} 3-5,2=\mathrm{L} 6-10$}

Estimates

\begin{tabular}{|ll|r|r|r|r|}
\hline & & & & \multicolumn{3}{|c|}{ 95\% Confidence Interval } \\
\cline { 5 - 6 } Dependent Variable & 1=L3-5, 2=L6-10 & Mean & Std. Error & Lower Bound & Upper Bound \\
\hline TaskMean & L3-5 & 3.635 & .038 & 3.559 & 3.711 \\
& L6-9 & 3.572 & .051 & 3.472 & 3.672 \\
\hline EgoMean & L3-5 & 2.058 & .062 & 1.936 & 2.179 \\
& L6-9 & 1.875 & .082 & 1.714 & 2.036 \\
\hline CommMean & L3-5 & 3.383 & .061 & 3.262 & 3.503 \\
& L6-9 & 3.260 & .081 & 3.101 & 3.419 \\
\hline EOOMean & L3-5 & 3.137 & .055 & 3.029 & 3.245 \\
& L6-9 & 3.131 & .072 & 2.988 & 3.273 \\
\hline AffMean & L3-5 & 3.699 & .042 & 3.616 & 3.783 \\
& L6-9 & 3.658 & .056 & 3.547 & 3.768 \\
\hline
\end{tabular}

Pairwise Comparisons

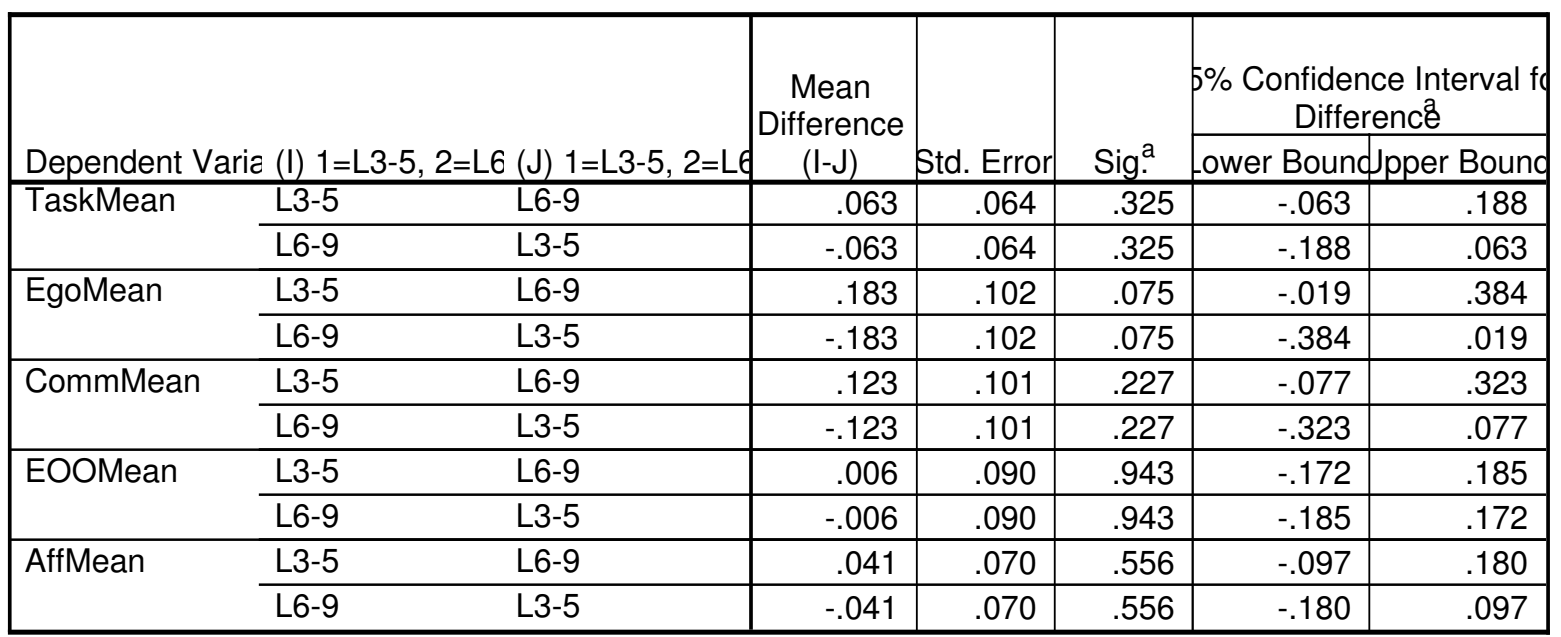

Based on estimated marginal means

a.Adjustment for multiple comparisons: Least Significant Difference (equivalent to no adjustments). 
Multivariate Tests

\begin{tabular}{|l|r|r|r|r|r|}
\hline & Value & \multicolumn{1}{|c|}{$\mathrm{F}$} & Hypothesis df & Error df & \multicolumn{1}{c|}{ Sig. } \\
\hline Pillai's trace & .043 & $1.817^{\mathrm{a}}$ & 5.000 & 200.000 & .111 \\
Wilks' lambda & .957 & $1.817^{\mathrm{a}}$ & 5.000 & 200.000 & .111 \\
Hotelling's trace & .045 & $1.817^{\mathrm{a}}$ & 5.000 & 200.000 & .111 \\
Roy's largest root & .045 & $1.817^{\mathrm{a}}$ & 5.000 & 200.000 & .111 \\
\hline
\end{tabular}

Each $\mathrm{F}$ tests the multivariate effect of $1=\mathrm{L} 3-5,2=\mathrm{L} 6-10$. These tests are based on the linearly independent pairwise comparisons among the estimated marginal means.

a. Exact statistic

Univariate Tests

\begin{tabular}{|ll|r|r|r|r|r|}
\hline \multirow{2}{*}{ Dependent Variable } & & \multicolumn{1}{c|}{$\begin{array}{c}\text { Sum of } \\
\text { Squares }\end{array}$} & df & Mean Square & \multicolumn{1}{c|}{$\mathrm{F}$} & Sig. \\
\hline TaskMean & Contrast & .134 & 1 & .134 & .973 & .325 \\
& Error & 28.152 & 204 & .138 & & \\
\hline EgoMean & Contrast & 1.137 & 1 & 1.137 & 3.192 & .075 \\
& Error & 72.640 & 204 & .356 & & \\
\hline CommMean & Contrast & .513 & 1 & .513 & 1.465 & .227 \\
& Error & 71.438 & 204 & .350 & & \\
\hline EOOMean & Contrast & .001 & 1 & .001 & .005 & .943 \\
& Error & 56.891 & 204 & .279 & & \\
\hline AffMean & Contrast & .058 & 1 & .058 & .347 & .556 \\
& Error & 34.295 & 204 & .168 & & \\
\hline
\end{tabular}

The $F$ tests the effect of $1=\mathrm{L} 3-5,2=\mathrm{L} 6-10$. This test is based on the linearly independent pairwise comparisons among the estimated marginal means.

\section{Type of club $(2 \mathrm{gps}){ }^{*} 1=\mathrm{L} 3-5,2=\mathrm{L} 6-10$}

\begin{tabular}{|c|c|c|c|c|c|c|}
\hline \multirow[b]{2}{*}{ Dependent Variable } & \multirow[b]{2}{*}{ Type of club (2 gps) } & \multirow[b]{2}{*}{$1=\mathrm{L} 3-5,2=\mathrm{L} 6-10$} & \multirow[b]{2}{*}{ Mean } & \multirow[b]{2}{*}{ Std. Error } & \multicolumn{2}{|c|}{ 95\% Confidence Interval } \\
\hline & & & & & Lower Bound & Upper Bound \\
\hline \multirow[t]{4}{*}{ TaskMean } & JnrHrs & L3-5 & 3.601 & .034 & 3.534 & 3.667 \\
\hline & & L6-9 & 3.592 & .061 & 3.471 & 3.712 \\
\hline & SnrHrs & L3-5 & 3.669 & .069 & 3.533 & 3.805 \\
\hline & & L6-9 & 3.552 & .081 & 3.393 & 3.712 \\
\hline \multirow[t]{4}{*}{ EgoMean } & JnrHrs & L3-5 & 1.764 & .054 & 1.657 & 1.871 \\
\hline & & L6-9 & 1.741 & .098 & 1.547 & 1.934 \\
\hline & SnrHrs & L3-5 & 2.352 & .111 & 2.133 & 2.570 \\
\hline & & L6-9 & 2.010 & .130 & 1.753 & 2.266 \\
\hline \multirow[t]{4}{*}{ CommMean } & JnrHrs & L3-5 & 3.343 & .054 & 3.237 & 3.449 \\
\hline & & L6-9 & 3.318 & .097 & 3.126 & 3.509 \\
\hline & SnrHrs & L3-5 & 3.422 & .110 & 3.206 & 3.639 \\
\hline & & L6-9 & 3.202 & .129 & 2.948 & 3.457 \\
\hline \multirow[t]{4}{*}{ EOOMean } & JnrHrs & L3-5 & 3.184 & .048 & 3.090 & 3.279 \\
\hline & & L6-9 & 3.032 & .087 & 2.861 & 3.204 \\
\hline & SnrHrs & L3-5 & 3.090 & .098 & 2.896 & 3.283 \\
\hline & & L6-9 & 3.229 & .115 & 3.001 & 3.456 \\
\hline \multirow[t]{4}{*}{ AffMean } & JnrHrs & L3-5 & 3.657 & .037 & 3.584 & 3.731 \\
\hline & & L6-9 & 3.601 & .067 & 3.468 & 3.734 \\
\hline & SnrHrs & L3-5 & 3.741 & .076 & 3.591 & 3.891 \\
\hline & & L6-9 & 3.714 & .089 & 3.538 & 3.891 \\
\hline
\end{tabular}


APPENDIX 14- MANOVA - Low (Junior or Type 1) Training hours clubs and Gender JnrHrsClubs $\sim=2$ (FILTER) * male $=1$, female $=2$ Crosstabulation

Count

\begin{tabular}{|ll|r|r|r|}
\hline \multirow{2}{*}{} & & \multicolumn{2}{|c|}{ male $=1$, female $=2$} & \multirow{2}{*}{ Total } \\
\cline { 3 - 4 } & \multicolumn{2}{|c|}{ male } & \multicolumn{1}{c|}{ female } & \multicolumn{1}{c|}{ Tom } \\
\hline JnrHrsClubs $\sim=$ & Not Selected & 0 & 50 & 50 \\
2 (FILTER) & Selected & 27 & 131 & 158 \\
Total & & 27 & 181 & 208 \\
\hline
\end{tabular}

JnrHrsClubs = 2 (FILTER) * 1=L3-5, 2=L6-10 Crosstabulation

Count
\begin{tabular}{|ll|r|r|r|}
\hline \multicolumn{2}{|c|}{} & \multicolumn{2}{|c|}{$1=$ L3-5, 2=L6-10 } & \multirow{2}{*}{ Total } \\
\cline { 2 - 4 } & \multicolumn{1}{|c|}{ L3-5 } & \multicolumn{1}{c|}{ L6-9 } & \multicolumn{1}{c|}{50} \\
\hline JnrHrsClubs $\sim=$ & Not Selected & 29 & 21 & 50 \\
2 (FILTER) & Selected & 121 & 37 & 158 \\
Total & 150 & 58 & 208 \\
\hline
\end{tabular}

\section{Between-Subjects Factors}

\begin{tabular}{|ll|l|r|}
\hline & & Value Label & \multicolumn{1}{|c|}{$\mathrm{N}$} \\
\hline JnrHrsClubs $=2$ & 0 & Not & 50 \\
(FILTER) & & Selected & Selected \\
& 1 & male & 27 \\
male=1, female=2 & 1 & female & 181 \\
& 2 & L3-5 & 150 \\
1=L3-5, 2=L6-10 & 1 & L6-9 & 58 \\
& 2 &
\end{tabular}

\section{Box's Test of Equality of Covariance Matrices ${ }^{\text {a }}$}

\begin{tabular}{|l|r|}
\hline Box's M & 142.465 \\
F & 1.655 \\
df1 & 75 \\
df2 & 5756.922 \\
Sig. & .000 \\
\hline
\end{tabular}

Tests the null hypothesis that the observed covariance matrices of the dependent variables are equal across groups.

a. Design:

Intercept+JnrHrsClubs+Gender+Level+JnrHrsClubs *

Gender+JnrHrsClubs * Level+Gender *

Level+JnrHrsClubs * Gender * Level 
Multivariate Tests ${ }^{b}$

\begin{tabular}{|c|c|c|c|c|c|c|}
\hline Effect & & Value & $F$ & Hypothesis df & Error df & Sig. \\
\hline \multirow[t]{4}{*}{ Intercept } & Pillai's Trace & .991 & $4260.375^{a}$ & 5.000 & 198.000 & .000 \\
\hline & Wilks' Lambda & .009 & $4260.375^{a}$ & 5.000 & 198.000 & .000 \\
\hline & Hotelling's Trace & 107.585 & $4260.375^{a}$ & 5.000 & 198.000 & .000 \\
\hline & Roy's Largest Root & 107.585 & $4260.375^{a}$ & 5.000 & 198.000 & .000 \\
\hline \multirow[t]{4}{*}{ JnrHrsClubs } & Pillai's Trace & .143 & $6.621^{a}$ & 5.000 & 198.000 & .000 \\
\hline & Wilks' Lambda & .857 & $6.621^{a}$ & 5.000 & 198.000 & .000 \\
\hline & Hotelling's Trace & .167 & $6.621^{a}$ & 5.000 & 198.000 & .000 \\
\hline & Roy's Largest Root & .167 & $6.621^{a}$ & 5.000 & 198.000 & .000 \\
\hline \multirow[t]{4}{*}{ Gender } & Pillai's Trace & .171 & $8.182^{\mathrm{a}}$ & 5.000 & 198.000 & .000 \\
\hline & Wilks' Lambda & .829 & $8.182^{\mathrm{a}}$ & 5.000 & 198.000 & .000 \\
\hline & Hotelling's Trace & .207 & $8.182^{a}$ & 5.000 & 198.000 & .000 \\
\hline & Roy's Largest Root & .207 & $8.182^{a}$ & 5.000 & 198.000 & .000 \\
\hline \multirow[t]{4}{*}{ Level } & Pillai's Trace & .037 & $1.522^{\mathrm{a}}$ & 5.000 & 198.000 & .185 \\
\hline & Wilks' Lambda & .963 & $1.522^{\mathrm{a}}$ & 5.000 & 198.000 & .185 \\
\hline & Hotelling's Trace & .038 & $1.522^{\mathrm{a}}$ & 5.000 & 198.000 & .185 \\
\hline & Roy's Largest Root & .038 & $1.522^{\mathrm{a}}$ & 5.000 & 198.000 & .185 \\
\hline \multirow[t]{4}{*}{ JnrHrsClubs * Gender } & Pillai's Trace & .000 &.$^{a}$ & .000 & .000 & \\
\hline & Wilks' Lambda & 1.000 & a & .000 & 200.000 & \\
\hline & Hotelling's Trace & .000 &.$^{a}$ & .000 & 2.000 & \\
\hline & Roy's Largest Root & .000 & $.000^{\mathrm{a}}$ & 5.000 & 197.000 & 1.000 \\
\hline \multirow[t]{4}{*}{ JnrHrsClubs * Level } & Pillai's Trace & .025 & $1.006^{a}$ & 5.000 & 198.000 & .415 \\
\hline & Wilks' Lambda & .975 & $1.006^{\mathrm{a}}$ & 5.000 & 198.000 & .415 \\
\hline & Hotelling's Trace & .025 & $1.006^{\mathrm{a}}$ & 5.000 & 198.000 & .415 \\
\hline & Roy's Largest Root & .025 & $1.006^{a}$ & 5.000 & 198.000 & .415 \\
\hline \multirow[t]{4}{*}{ Gender * Level } & Pillai's Trace & .051 & $2.123^{a}$ & 5.000 & 198.000 & .064 \\
\hline & Wilks' Lambda & .949 & $2.123^{a}$ & 5.000 & 198.000 & .064 \\
\hline & Hotelling's Trace & .054 & $2.123^{a}$ & 5.000 & 198.000 & .064 \\
\hline & Roy's Largest Root & .054 & $2.123^{a}$ & 5.000 & 198.000 & .064 \\
\hline \multirow{4}{*}{$\begin{array}{l}\text { JnrHrsClubs * Gender } \\
{ }^{*} \text { Level }\end{array}$} & Pillai's Trace & .000 &.$^{a}$ & .000 & .000 & \\
\hline & Wilks' Lambda & 1.000 & $a^{a}$ & .000 & 200.000 & \\
\hline & Hotelling's Trace & .000 & a & .000 & 2.000 & \\
\hline & Roy's Largest Root & .000 & $.000^{\mathrm{a}}$ & 5.000 & 197.000 & 1.000 \\
\hline
\end{tabular}

a. Exact statistic

b. Design: Intercept+JnrHrsClubs+Gender+Level+JnrHrsClubs * Gender+JnrHrsClubs * Level+Gender * Level+JnrHrsClubs * Gender * Level

Levene's Test of Equality of Error Variances a

\begin{tabular}{|l|r|r|r|r|}
\hline & \multicolumn{1}{|c|}{$\mathrm{F}$} & \multicolumn{1}{|c|}{$\mathrm{df1}$} & $\mathrm{df2}$ & \multicolumn{1}{c|}{ Sig. } \\
\hline TaskMean & 2.618 & 5 & 202 & .026 \\
EgoMean & 2.514 & 5 & 202 & .031 \\
CommMean & .578 & 5 & 202 & .717 \\
EOOMean & 1.010 & 5 & 202 & .413 \\
AffMean & 2.210 & 5 & 202 & .055 \\
\hline
\end{tabular}

Tests the null hypothesis that the error variance of the dependent variable is equal across groups.

a. Design:

Intercept+JnrHrsClubs+Gender+Level+JnrHrsClubs *

Gender+JnrHrsClubs * Level+Gender *

Level+JnrHrsClubs * Gender * Level 
Tests of Between-Subjects Effects

\begin{tabular}{|c|c|c|c|c|c|c|}
\hline Source & Dependent Variable & $\begin{array}{l}\text { Type III Sum } \\
\text { of Squares }\end{array}$ & $\mathrm{df}$ & Mean Square & $\mathrm{F}$ & Sig. \\
\hline \multirow[t]{5}{*}{ Corrected Model } & TaskMean & $2.164^{\mathrm{a}}$ & 5 & .433 & 3.341 & .006 \\
\hline & EgoMean & $13.656^{b}$ & 5 & 2.731 & 8.101 & .000 \\
\hline & CommMean & $.787^{\mathrm{C}}$ & 5 & .157 & .446 & .816 \\
\hline & EOOMean & $8.239^{d}$ & 5 & 1.648 & 6.719 & .000 \\
\hline & AffMean & $3.381^{\mathrm{e}}$ & 5 & .676 & 4.365 & .001 \\
\hline \multirow[t]{5}{*}{ Intercept } & TaskMean & 1138.341 & 1 & 1138.341 & 8785.684 & .000 \\
\hline & EgoMean & 393.023 & 1 & 393.023 & 1165.654 & .000 \\
\hline & CommMean & 1004.210 & 1 & 1004.210 & 2846.592 & .000 \\
\hline & EOOMean & 805.383 & 1 & 805.383 & 3283.952 & .000 \\
\hline & AffMean & 1166.376 & 1 & 1166.376 & 7529.383 & .000 \\
\hline \multirow[t]{5}{*}{ JnrHrsClubs } & TaskMean & .069 & 1 & .069 & .531 & .467 \\
\hline & EgoMean & 8.863 & 1 & 8.863 & 26.288 & .000 \\
\hline & CommMean & .044 & 1 & .044 & .124 & .726 \\
\hline & EOOMean & .191 & 1 & .191 & .780 & .378 \\
\hline & AffMean & .012 & 1 & .012 & .078 & .780 \\
\hline \multirow{5}{*}{ Gender } & TaskMean & 1.821 & 1 & 1.821 & 14.051 & .000 \\
\hline & EgoMean & 4.516 & 1 & 4.516 & 13.394 & .000 \\
\hline & CommMean & .150 & 1 & .150 & .426 & .515 \\
\hline & EOOMean & 7.161 & 1 & 7.161 & 29.199 & .000 \\
\hline & AffMean & 2.942 & 1 & 2.942 & 18.989 & .000 \\
\hline \multirow[t]{5}{*}{ Level } & TaskMean & .120 & 1 & .120 & .928 & .337 \\
\hline & EgoMean & .017 & 1 & .017 & .051 & .822 \\
\hline & CommMean & .472 & 1 & .472 & 1.338 & .249 \\
\hline & EOOMean & 1.170 & 1 & 1.170 & 4.770 & .030 \\
\hline & AffMean & .237 & 1 & .237 & 1.530 & .217 \\
\hline \multirow[t]{5}{*}{ JnrHrsClubs * Gender } & TaskMean & .000 & 0 & . & . & \\
\hline & EgoMean & .000 & 0 & . & . & \\
\hline & CommMean & .000 & 0 & . & . & . \\
\hline & EOOMean & .000 & 0 & & . & . \\
\hline & AffMean & .000 & 0 & . & & \\
\hline \multirow[t]{5}{*}{ JnrHrsClubs * Level } & TaskMean & .171 & 1 & .171 & 1.317 & .253 \\
\hline & EgoMean & .310 & 1 & .310 & .920 & .339 \\
\hline & CommMean & .411 & 1 & .411 & 1.165 & .282 \\
\hline & EOOMean & .107 & 1 & .107 & .435 & .510 \\
\hline & AffMean & .014 & 1 & .014 & .089 & .766 \\
\hline \multirow[t]{5}{*}{ Gender * Level } & TaskMean & .054 & 1 & .054 & .415 & .520 \\
\hline & EgoMean & 1.083 & 1 & 1.083 & 3.212 & .075 \\
\hline & CommMean & .100 & 1 & .100 & .285 & .594 \\
\hline & EOOMean & 2.441 & 1 & 2.441 & 9.952 & .002 \\
\hline & AffMean & .277 & 1 & .277 & 1.790 & .182 \\
\hline \multirow{5}{*}{$\begin{array}{l}\text { JnrHrsClubs * Gender } \\
\text { * Level }\end{array}$} & TaskMean & .000 & 0 & . & . & \\
\hline & EgoMean & .000 & 0 & . & . & \\
\hline & CommMean & .000 & 0 & . & . & . \\
\hline & EOOMean & .000 & 0 & . & . & \\
\hline & AffMean & .000 & 0 & & . & \\
\hline \multirow[t]{5}{*}{ Error } & TaskMean & 26.173 & 202 & .130 & & \\
\hline & EgoMean & 68.108 & 202 & .337 & & \\
\hline & CommMean & 71.261 & 202 & .353 & & \\
\hline & EOOMean & 49.540 & 202 & .245 & & \\
\hline & AffMean & 31.292 & 202 & .155 & & \\
\hline \multirow[t]{5}{*}{ Total } & TaskMean & 2729.780 & 208 & & & \\
\hline & EgoMean & 806.280 & 208 & & & \\
\hline & CommMean & 2385.938 & 208 & & & \\
\hline & EOOMean & 2119.770 & 208 & & & \\
\hline & AffMean & 2828.063 & 208 & & & \\
\hline \multirow[t]{5}{*}{ Corrected Total } & TaskMean & 28.337 & 207 & & & \\
\hline & EgoMean & 81.764 & 207 & & & \\
\hline & CommMean & 72.048 & 207 & & & \\
\hline & EOOMean & 57.780 & 207 & & & \\
\hline & AffMean & 34.673 & 207 & & & \\
\hline
\end{tabular}
a. R Squared $=.076$ (Adjusted R Squared $=.054$ )
b. $R$ Squared $=.167$ (Adjusted R Squared $=.146$ )
c. R Squared $=.011$ (Adjusted R Squared $=-.014$ )
d. R Squared $=.143$ (Adjusted R Squared $=.121$ )
e. R Squared $=.098$ (Adjusted R Squared $=.075$ ) 
Between-Subjects SSCP Matrix

\begin{tabular}{|c|c|c|c|c|c|c|c|}
\hline & & & TaskMean & EgoMean & CommMean & EOOMean & AffMean \\
\hline \multirow[t]{40}{*}{ Hypothesis } & \multirow[t]{5}{*}{ Intercept } & TaskMean & 1138.341 & 668.875 & 1069.174 & 957.497 & 1152.273 \\
\hline & & EgoMean & 668.875 & 393.023 & 628.234 & 562.613 & 677.062 \\
\hline & & CommMean & 1069.174 & 628.234 & 1004.210 & 899.318 & 1082.260 \\
\hline & & EOOMean & 957.497 & 562.613 & 899.318 & 805.383 & 969.216 \\
\hline & & AffMean & 1152.273 & 677.062 & 1082.260 & 969.216 & 1166.376 \\
\hline & \multirow[t]{5}{*}{ JnrHrsClubs } & TaskMean & .069 & -.781 & .055 & .115 & -.029 \\
\hline & & EgoMean & -.781 & 8.863 & -.622 & -1.303 & .328 \\
\hline & & CommMean & .055 & -.622 & .044 & .091 & -.023 \\
\hline & & EOOMean & .115 & -1.303 & .091 & .191 & -.048 \\
\hline & & AffMean & -.029 & .328 & -.023 & -.048 & .012 \\
\hline & \multirow[t]{5}{*}{ Gender } & TaskMean & 1.821 & -2.867 & .523 & 3.611 & 2.314 \\
\hline & & EgoMean & -2.867 & 4.516 & -.824 & -5.687 & -3.645 \\
\hline & & CommMean & .523 & -.824 & .150 & 1.037 & .665 \\
\hline & & EOOMean & 3.611 & -5.687 & 1.037 & 7.161 & 4.590 \\
\hline & & AffMean & 2.314 & -3.645 & .665 & 4.590 & 2.942 \\
\hline & \multirow[t]{5}{*}{ Level } & TaskMean & .120 & .045 & .238 & .375 & .169 \\
\hline & & EgoMean & .045 & .017 & .090 & .142 & .064 \\
\hline & & CommMean & .238 & .090 & .472 & .743 & .335 \\
\hline & & EOOMean & .375 & .142 & .743 & 1.170 & .527 \\
\hline & & AffMean & .169 & .064 & .335 & .527 & .237 \\
\hline & \multirow[t]{5}{*}{ JnrHrsClubs * Gender } & TaskMean & .000 & .000 & .000 & .000 & .000 \\
\hline & & EgoMean & .000 & .000 & .000 & .000 & .000 \\
\hline & & CommMean & .000 & .000 & .000 & .000 & .000 \\
\hline & & EOOMean & .000 & .000 & .000 & .000 & .000 \\
\hline & & AffMean & .000 & .000 & .000 & .000 & .000 \\
\hline & \multirow[t]{5}{*}{ JnrHrsClubs * Level } & TaskMean & .171 & .230 & .265 & -.135 & .048 \\
\hline & & EgoMean & .230 & .310 & .357 & -.182 & .065 \\
\hline & & CommMean & .265 & .357 & .411 & -.209 & .075 \\
\hline & & EOOMean & -.135 & -.182 & -.209 & .107 & -.038 \\
\hline & & AffMean & .048 & .065 & .075 & -.038 & .014 \\
\hline & \multirow[t]{5}{*}{ Gender * Level } & TaskMean & .054 & -.241 & .073 & .362 & .122 \\
\hline & & EgoMean & -.241 & 1.083 & -.330 & -1.626 & -.548 \\
\hline & & CommMean & .073 & -.330 & .100 & .495 & .167 \\
\hline & & EOOMean & .362 & -1.626 & .495 & 2.441 & .823 \\
\hline & & AffMean & .122 & -.548 & .167 & .823 & .277 \\
\hline & \multirow{5}{*}{$\begin{array}{l}\text { JnrHrsClubs * Gender } \\
\text { * Level }\end{array}$} & TaskMean & .000 & .000 & .000 & .000 & .000 \\
\hline & & EgoMean & .000 & .000 & .000 & .000 & .000 \\
\hline & & CommMean & .000 & .000 & .000 & .000 & .000 \\
\hline & & EOOMean & .000 & .000 & .000 & .000 & .000 \\
\hline & & AffMean & .000 & .000 & .000 & .000 & .000 \\
\hline \multirow{5}{*}{\multicolumn{2}{|c|}{ Error }} & TaskMean & 26.173 & -12.810 & 17.411 & 13.524 & 9.808 \\
\hline & & EgoMean & -12.810 & 68.108 & -23.947 & -23.757 & -17.377 \\
\hline & & CommMean & 17.411 & -23.947 & 71.261 & 15.017 & 12.426 \\
\hline & & EOOMean & 13.524 & -23.757 & 15.017 & 49.540 & 14.489 \\
\hline & & AffMean & 9.808 & -17.377 & 12.426 & 14.489 & 31.292 \\
\hline
\end{tabular}

Based on Type III Sum of Squares 


\section{JnrHrsClubs}

\section{Estimates}

\begin{tabular}{|ll|c|r|r|r|}
\hline & JnrHrsClubs & & & \multicolumn{2}{|c|}{$95 \%$ Confidence Interval } \\
\cline { 5 - 6 } Dependent Variable & $\sim=2$ (FILTER) & Mean & Std. Error & Lower Bound & Upper Bound \\
\hline TaskMean & Not Selected & $3.611^{\mathrm{a}}$ & .052 & 3.509 & 3.712 \\
& Selected & 3.498 & .042 & 3.415 & 3.582 \\
\hline EgoMean & Not Selected & $2.181^{\mathrm{a}}$ & .083 & 2.017 & 2.345 \\
& Selected & 1.902 & .068 & 1.767 & 2.037 \\
\hline CommMean & Not Selected & $3.312^{\mathrm{a}}$ & .085 & 3.145 & 3.480 \\
& Selected & 3.304 & .070 & 3.166 & 3.442 \\
\hline EOOMean & Not Selected & $3.159^{\mathrm{a}}$ & .071 & 3.019 & 3.299 \\
& Selected & 2.922 & .058 & 2.807 & 3.037 \\
\hline AffMean & Not Selected & $3.728^{\mathrm{a}}$ & .056 & 3.617 & 3.839 \\
& Selected & 3.506 & .046 & 3.415 & 3.598 \\
\hline
\end{tabular}

a. Based on modified population marginal mean.

\section{Pairwise Comparisons}

\begin{tabular}{|c|c|c|c|c|c|c|c|}
\hline \multirow[b]{2}{*}{ Dependent Variable } & \multirow{2}{*}{$\begin{array}{l}\text { (I) JnrHrsClubs } \\
\sim=2 \text { (FILTER) }\end{array}$} & \multirow{2}{*}{$\begin{array}{l}\text { (J) JnrHrsClubs } \\
\sim=2 \text { (FILTER) }\end{array}$} & \multirow{2}{*}{$\begin{array}{c}\text { Mean } \\
\text { Difference } \\
(I-J)\end{array}$} & \multirow[b]{2}{*}{ Std. Error } & \multirow[b]{2}{*}{ Sig. ${ }^{a}$} & \multicolumn{2}{|c|}{$\begin{array}{c}95 \% \text { Confidence Interval for } \\
\text { Difference }\end{array}$} \\
\hline & & & & & & Lower Bound & Upper Bound \\
\hline \multirow[t]{2}{*}{ TaskMean } & Not Selected & Selected & $.112^{b}$ & .067 & .094 & -.019 & .244 \\
\hline & Selected & Not Selected & $-.112^{c}$ & .067 & .094 & -.244 & .019 \\
\hline \multirow[t]{2}{*}{ EgoMean } & Not Selected & Selected & $.279^{*}, \mathrm{~b}$ & .108 & .010 & .067 & .491 \\
\hline & Selected & Not Selected & $-.279^{*}, \mathrm{C}$ & .108 & .010 & -.491 & -.067 \\
\hline \multirow[t]{2}{*}{ CommMean } & Not Selected & Selected & $.009^{b}$ & .110 & .938 & -.209 & .226 \\
\hline & Selected & Not Selected & $-.009^{c}$ & .110 & .938 & -.226 & .209 \\
\hline \multirow[t]{2}{*}{ EOOMean } & Not Selected & Selected & $.237^{*}, \mathrm{~b}$ & .092 & .010 & .056 & .418 \\
\hline & Selected & Not Selected & $-.237^{*}, \mathrm{C}$ & .092 & .010 & -.418 & -.056 \\
\hline \multirow[t]{2}{*}{ AffMean } & Not Selected & Selected & $.222^{*}, \mathrm{~b}$ & .073 & .003 & .078 & .365 \\
\hline & Selected & Not Selected & $-.222^{*}, \mathrm{C}$ & .073 & .003 & -.365 & -.078 \\
\hline
\end{tabular}

Based on estimated marginal means

*. The mean difference is significant at the .05 level.

a. Adjustment for multiple comparisons: Least Significant Difference (equivalent to no adjustments).

b. An estimate of the modified population marginal mean (I).

c. An estimate of the modified population marginal mean $(\mathrm{J})$.

Multivariate Tests

\begin{tabular}{|l|r|r|r|r|r|}
\hline & \multicolumn{1}{|c|}{ Value } & \multicolumn{1}{|c|}{$\mathrm{F}$} & Hypothesis df & Error df & \multicolumn{1}{c|}{ Sig. } \\
\hline Pillai's trace & .148 & $6.887^{\mathrm{a}}$ & 5.000 & 198.000 & .000 \\
Wilks' lambda & .852 & $6.887^{\mathrm{a}}$ & 5.000 & 198.000 & .000 \\
Hotelling's trace & .174 & $6.887^{\mathrm{a}}$ & 5.000 & 198.000 & .000 \\
Roy's largest root & .174 & $6.887^{\mathrm{a}}$ & 5.000 & 198.000 & .000 \\
\hline
\end{tabular}

Each $\mathrm{F}$ tests the multivariate effect of JnrHrsClubs $\sim=2$ (FILTER). These tests are based on the linearly independent pairwise comparisons among the estimated marginal means.

a. Exact statistic 
Univariate Tests

\begin{tabular}{|c|c|c|c|c|c|c|}
\hline Dependent Variable & & $\begin{array}{l}\text { Sum of } \\
\text { Squares }\end{array}$ & df & Mean Square & $\mathrm{F}$ & Sig. \\
\hline \multirow[t]{2}{*}{ TaskMean } & Contrast & .367 & 1 & .367 & 2.830 & .094 \\
\hline & Error & 26.173 & 202 & .130 & & \\
\hline \multirow[t]{2}{*}{ EgoMean } & Contrast & 2.262 & 1 & 2.262 & 6.709 & .010 \\
\hline & Error & 68.108 & 202 & .337 & & \\
\hline \multirow[t]{2}{*}{ CommMean } & Contrast & .002 & 1 & .002 & .006 & .938 \\
\hline & Error & 71.261 & 202 & .353 & & \\
\hline \multirow[t]{2}{*}{ EOOMean } & Contrast & 1.638 & 1 & 1.638 & 6.680 & .010 \\
\hline & Error & 49.540 & 202 & .245 & & \\
\hline \multirow[t]{2}{*}{ AffMean } & Contrast & 1.427 & 1 & 1.427 & 9.214 & .003 \\
\hline & Error & 31.292 & 202 & .155 & & \\
\hline
\end{tabular}

The $\mathrm{F}$ tests the effect of JnrHrsClubs $\sim=2$ (FILTER). This test is based on the linearly independent pairwise comparisons among the estimated marginal means.

\section{Gender: male $=1$, female $=2$}

\section{Estimates}

\begin{tabular}{|ll|c|r|r|r|}
\hline & & & & \multicolumn{2}{|c|}{$95 \%$ Confidence Interval } \\
\cline { 5 - 6 } Dependent Variable & male=1, female=2 & Mean & Std. Error & Lower Bound & Upper Bound \\
\hline TaskMean & male & $3.339^{\mathrm{a}}$ & .076 & 3.190 & 3.489 \\
& female & 3.634 & .032 & 3.571 & 3.697 \\
\hline EgoMean & male & $2.152^{\mathrm{a}}$ & .122 & 1.911 & 2.393 \\
& female & 1.916 & .052 & 1.814 & 2.018 \\
\hline CommMean & male & $3.258^{\mathrm{a}}$ & .125 & 3.011 & 3.505 \\
& female & 3.331 & .053 & 3.227 & 3.435 \\
\hline EOOMean & male & $2.607^{\mathrm{a}}$ & .104 & 2.401 & 2.812 \\
& female & 3.198 & .044 & 3.111 & 3.285 \\
\hline AffMean & male & $3.304^{\mathrm{a}}$ & .083 & 3.141 & 3.468 \\
& female & 3.718 & .035 & 3.649 & 3.787 \\
\hline
\end{tabular}

a. Based on modified population marginal mean. 
Pairwise Comparisons

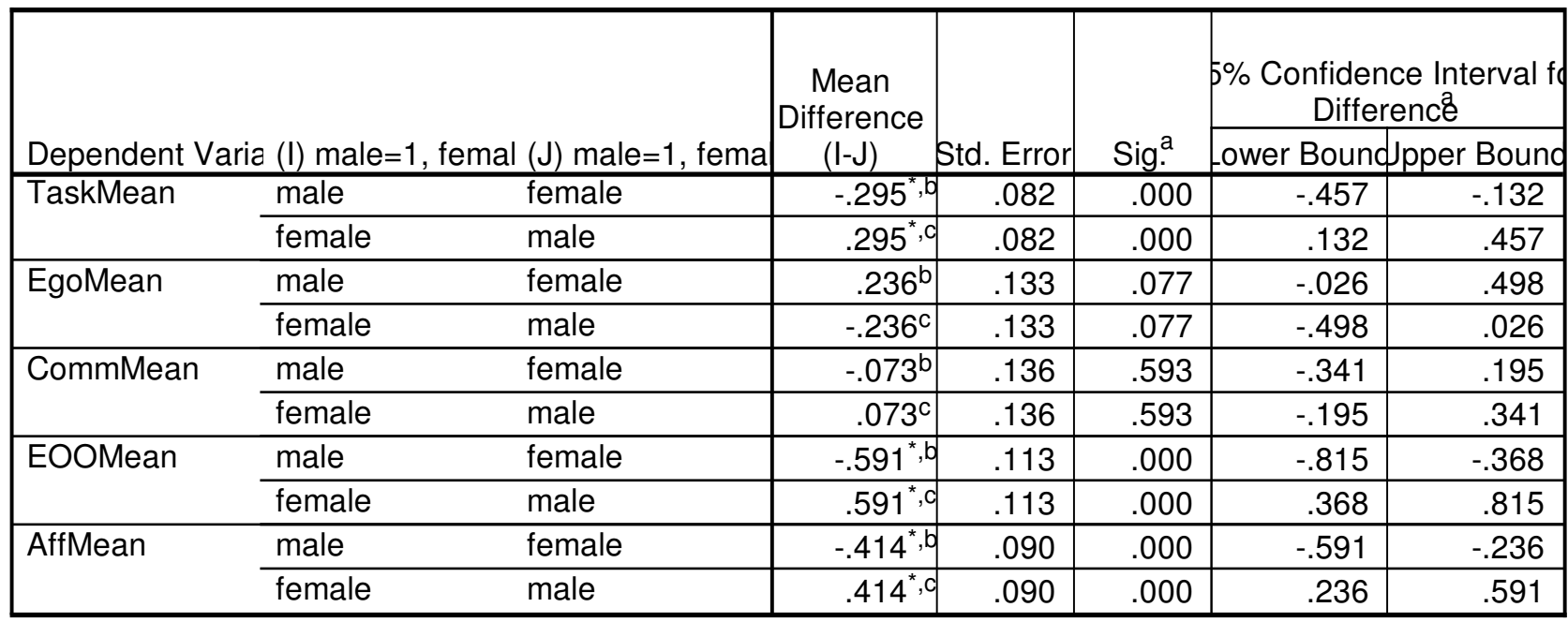

Based on estimated marginal means

${ }^{*}$. The mean difference is significant at the .05 level.

a. Adjustment for multiple comparisons: Least Significant Difference (equivalent to no adjustments).

b. An estimate of the modified population marginal mean (I).

c. An estimate of the modified population marginal mean (J).

Multivariate Tests

\begin{tabular}{|l|r|r|r|r|r|}
\hline & \multicolumn{1}{|c|}{ Value } & \multicolumn{1}{|c|}{$\mathrm{F}$} & Hypothesis df & Error df & \multicolumn{1}{c|}{ Sig. } \\
\hline Pillai's trace & .169 & $8.038^{\mathrm{a}}$ & 5.000 & 198.000 & .000 \\
Wilks' lambda & .831 & $8.038^{\mathrm{a}}$ & 5.000 & 198.000 & .000 \\
Hotelling's trace & .203 & $8.038^{\mathrm{a}}$ & 5.000 & 198.000 & .000 \\
Roy's largest root & .203 & $8.038^{\mathrm{a}}$ & 5.000 & 198.000 & .000 \\
\hline
\end{tabular}

Each $\mathrm{F}$ tests the multivariate effect of male $=1$, female $=2$. These tests are based on the linearly independent pairwise comparisons among the estimated marginal means.

a. Exact statistic

Univariate Tests

\begin{tabular}{|ll|r|r|r|r|r|}
\hline Dependent Variable & & \multicolumn{1}{c}{$\begin{array}{c}\text { Sum of } \\
\text { Squares }\end{array}$} & df & Mean Square & \multicolumn{1}{c|}{$\mathrm{F}$} & Sig. \\
\hline TaskMean & Contrast & 1.658 & 1 & 1.658 & 12.798 & .000 \\
& Error & 26.173 & 202 & .130 & & \\
\hline EgoMean & Contrast & 1.064 & 1 & 1.064 & 3.157 & .077 \\
& Error & 68.108 & 202 & .337 & & .101 \\
\hline CommMean & Contrast & .101 & 1 & .107 & .593 \\
& Error & 71.261 & 202 & .353 & & .000 \\
\hline EOOMean & Contrast & 6.687 & 1 & 6.687 & 27.266 & .245 \\
& Error & 49.540 & 202 & & .000 \\
\hline AffMean & Contrast & 3.273 & 1 & 3.273 & 21.128 & \\
& Error & 31.292 & 202 & .155 & & \\
\hline
\end{tabular}

The $F$ tests the effect of male $=1$, female $=2$. This test is based on the linearly independent pairwise comparisons among the estimated marginal means. 


\section{Gymnastics Level: 1=L3-5, 2=L6-10}

\section{Estimates}

\begin{tabular}{|ll|r|r|r|r|}
\hline & & & & \multicolumn{2}{|c|}{ 95\% Confidence Interval } \\
\cline { 5 - 6 } Dependent Variable & $1=\mathrm{L} 3-5,2=$ L6-10 & Mean & Std. Error & Lower Bound & Upper Bound \\
\hline TaskMean & L3-5 & $3.563^{\mathrm{a}}$ & .037 & 3.490 & 3.637 \\
& L6-9 & $3.508^{\mathrm{a}}$ & .055 & 3.401 & 3.616 \\
\hline EgoMean & L3-5 & $2.018^{\mathrm{a}}$ & .060 & 1.899 & 2.137 \\
& L6-9 & $1.971^{\mathrm{a}}$ & .088 & 1.798 & 2.145 \\
\hline CommMean & L3-5 & $3.366^{\mathrm{a}}$ & .062 & 3.244 & 3.487 \\
& L6-9 & $3.248^{\mathrm{a}}$ & .090 & 3.070 & 3.425 \\
\hline EOOMean & L3-5 & $3.093^{\mathrm{a}}$ & .051 & 2.991 & 3.194 \\
& L6-9 & $2.909^{\mathrm{a}}$ & .075 & 2.761 & 3.057 \\
\hline AffMean & L3-5 & $3.621^{\mathrm{a}}$ & .041 & 3.541 & 3.702 \\
& L6-9 & $3.539^{\mathrm{a}}$ & .060 & 3.421 & 3.657 \\
\hline
\end{tabular}

a. Based on modified population marginal mean.

Pairwise Comparisons

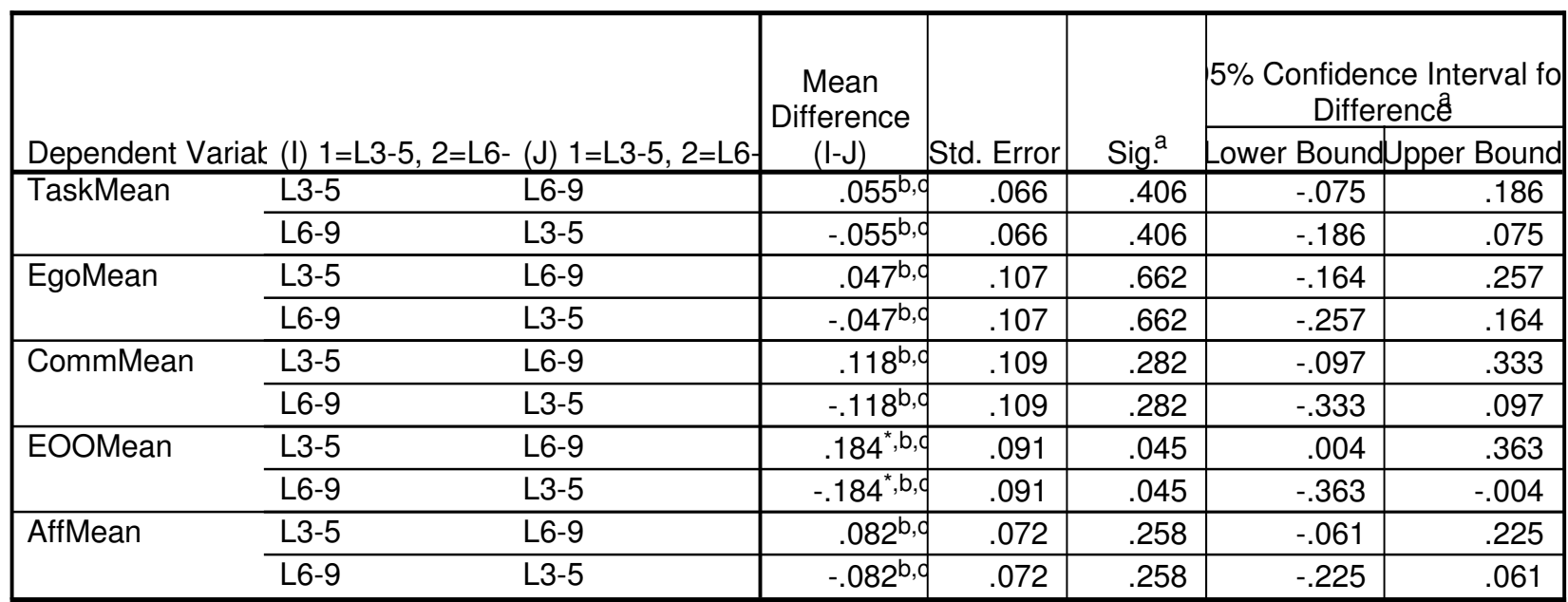

Based on estimated marginal means

*. The mean difference is significant at the .05 level.

a. Adjustment for multiple comparisons: Least Significant Difference (equivalent to no adjustments).

b. An estimate of the modified population marginal mean (I).

C. An estimate of the modified population marginal mean $(\mathrm{J})$.

Multivariate Tests

\begin{tabular}{|l|r|r|r|r|r|}
\hline & Value & \multicolumn{1}{|c|}{ F } & Hypothesis df & Error df & \multicolumn{1}{c|}{ Sig. } \\
\hline Pillai's trace & .036 & $1.471^{\mathrm{a}}$ & 5.000 & 198.000 & .201 \\
Wilks' lambda & .964 & $1.471^{\mathrm{a}}$ & 5.000 & 198.000 & .201 \\
Hotelling's trace & .037 & $1.471^{\mathrm{a}}$ & 5.000 & 198.000 & .201 \\
Roy's largest root & .037 & $1.471^{\mathrm{a}}$ & 5.000 & 198.000 & .201 \\
\hline
\end{tabular}

Each $\mathrm{F}$ tests the multivariate effect of $1=\mathrm{L} 3-5,2=\mathrm{L} 6-10$. These tests are based on the linearly independent pairwise comparisons among the estimated marginal means.

a. Exact statistic 
Univariate Tests

\begin{tabular}{|c|c|c|c|c|c|c|}
\hline Dependent Variable & & $\begin{array}{l}\text { Sum of } \\
\text { Squares }\end{array}$ & df & Mean Square & $\mathrm{F}$ & Sig. \\
\hline TaskMean & $\begin{array}{l}\text { Contrast } \\
\text { Error }\end{array}$ & $\begin{array}{r}.090 \\
26.173\end{array}$ & $\begin{array}{r}1 \\
202\end{array}$ & $\begin{array}{l}.090 \\
.130\end{array}$ & .693 & .406 \\
\hline EgoMean & $\begin{array}{l}\text { Contrast } \\
\text { Error }\end{array}$ & $\begin{array}{r}.065 \\
68.108 \\
\end{array}$ & $\begin{array}{r}1 \\
202 \\
\end{array}$ & $\begin{array}{l}.065 \\
.337 \\
\end{array}$ & .192 & .662 \\
\hline CommMean & $\begin{array}{l}\text { Contrast } \\
\text { Error }\end{array}$ & $\begin{array}{r}.411 \\
71.261 \\
\end{array}$ & $\begin{array}{r}1 \\
202 \\
\end{array}$ & $\begin{array}{l}.411 \\
.353 \\
\end{array}$ & 1.166 & .282 \\
\hline EOOMean & $\begin{array}{l}\text { Contrast } \\
\text { Error }\end{array}$ & $\begin{array}{r}1.000 \\
49.540 \\
\end{array}$ & $\begin{array}{r}1 \\
202 \\
\end{array}$ & $\begin{array}{r}1.000 \\
.245 \\
\end{array}$ & 4.079 & .045 \\
\hline AffMean & $\begin{array}{l}\text { Contrast } \\
\text { Error }\end{array}$ & $\begin{array}{r}.199 \\
31.292\end{array}$ & $\begin{array}{r}1 \\
202\end{array}$ & $\begin{array}{l}.199 \\
.155\end{array}$ & 1.286 & .258 \\
\hline
\end{tabular}

The $\mathrm{F}$ tests the effect of $1=\mathrm{L} 3-5,2=\mathrm{L} 6-10$. This test is based on the linearly independent pairwise comparisons among the estimated marginal means.

\section{JnrHrsClubs $\sim=2$ (FILTER) * male $=1$, female $=2$}

\begin{tabular}{|c|c|c|c|c|c|c|}
\hline \multirow[b]{2}{*}{ Dependent Variable } & \multirow{2}{*}{$\begin{array}{l}\text { JnrHrsClubs } \\
\sim=2 \text { (FILTER) }\end{array}$} & \multirow[b]{2}{*}{ male $=1$, female $=2$} & \multirow[b]{2}{*}{ Mean } & \multirow[b]{2}{*}{ Std. Error } & \multicolumn{2}{|c|}{ 95\% Confidence Interval } \\
\hline & & & & & Lower Bound & Upper Bound \\
\hline \multirow[t]{3}{*}{ TaskMean } & Not Selected & $\begin{array}{l}\text { male } \\
\text { female }\end{array}$ & $3.611^{a}$ & .052 & 3.509 & 3.712 \\
\hline & Selected & male & 3.339 & .076 & 3.190 & 3.489 \\
\hline & & female & 3.657 & .038 & 3.583 & 3.732 \\
\hline \multirow[t]{3}{*}{ EgoMean } & Not Selected & $\begin{array}{l}\text { male } \\
\text { female }\end{array}$ & $2.181^{a}$ & .083 & 2.017 & 2.345 \\
\hline & Selected & male & 2.152 & .122 & 1.911 & 2.393 \\
\hline & & female & 1.651 & .061 & 1.531 & 1.772 \\
\hline \multirow[t]{3}{*}{ CommMean } & Not Selected & $\begin{array}{l}\text { male } \\
\text { female }\end{array}$ & $3.312^{a}$ & .085 & 3.145 & 3.480 \\
\hline & Selected & male & 3.258 & .125 & 3.011 & 3.505 \\
\hline & & female & 3.350 & .062 & 3.226 & 3.473 \\
\hline \multirow[t]{3}{*}{ EOOMean } & Not Selected & $\begin{array}{l}\text { male } \\
\text { female }\end{array}$ & $3.159^{a}$ & .071 & 3.019 & 3.299 \\
\hline & Selected & male & 2.607 & .104 & 2.401 & 2.812 \\
\hline & & female & 3.237 & .052 & 3.134 & 3.340 \\
\hline \multirow[t]{3}{*}{ AffMean } & Not Selected & $\begin{array}{l}\text { male } \\
\text { female }\end{array}$ & $3.728^{a}$ & .056 & 3.617 & 3.839 \\
\hline & Selected & male & 3.304 & .083 & 3.141 & 3.468 \\
\hline & & female & 3.708 & .041 & 3.627 & 3.790 \\
\hline
\end{tabular}

a. This level combination of factors is not observed, thus the corresponding population marginal mean is not estimable. 
5. JnrHrsClubs $\sim=2$ (FILTER) * 1=L3-5, 2=L6-10

\begin{tabular}{|c|c|c|c|c|c|c|}
\hline \multirow[b]{2}{*}{ Dependent Variable } & \multirow{2}{*}{$\begin{array}{l}\text { JnrHrsClubs } \\
\sim=2 \text { (FILTER) }\end{array}$} & \multirow[b]{2}{*}{$1=\mathrm{L} 3-5,2=\mathrm{L} 6-10$} & \multirow[b]{2}{*}{ Mean } & \multirow[b]{2}{*}{ Std. Error } & \multicolumn{2}{|c|}{ 95\% Confidence Interval } \\
\hline & & & & & Lower Bound & Upper Bound \\
\hline \multirow[t]{4}{*}{ TaskMean } & Not Selected & L3-5 & $3.669^{a}$ & .067 & 3.537 & 3.801 \\
\hline & & L6-9 & $3.552^{\mathrm{a}}$ & .079 & 3.398 & 3.707 \\
\hline & Selected & L3-5 & 3.511 & .045 & 3.422 & 3.599 \\
\hline & & L6-9 & 3.486 & .072 & 3.344 & 3.628 \\
\hline \multirow[t]{4}{*}{ EgoMean } & Not Selected & L3-5 & $2.352^{\mathrm{a}}$ & .108 & 2.139 & 2.564 \\
\hline & & L6-9 & $2.010^{\mathrm{a}}$ & .127 & 1.760 & 2.259 \\
\hline & Selected & L3-5 & 1.851 & .073 & 1.708 & 1.994 \\
\hline & & L6-9 & 1.952 & .116 & 1.724 & 2.181 \\
\hline \multirow[t]{4}{*}{ CommMean } & Not Selected & L3-5 & $3.422^{\mathrm{a}}$ & .110 & 3.205 & 3.640 \\
\hline & & L6-9 & $3.202^{\mathrm{a}}$ & .130 & 2.947 & 3.458 \\
\hline & Selected & L3-5 & 3.337 & .074 & 3.191 & 3.484 \\
\hline & & L6-9 & 3.270 & .119 & 3.037 & 3.504 \\
\hline \multirow[t]{4}{*}{ EOOMean } & Not Selected & L3-5 & $3.090^{\mathrm{a}}$ & .092 & 2.908 & 3.271 \\
\hline & & L6-9 & $3.229^{a}$ & .108 & 3.015 & 3.442 \\
\hline & Selected & L3-5 & 3.094 & .062 & 2.972 & 3.216 \\
\hline & & L6-9 & 2.749 & .099 & 2.554 & 2.944 \\
\hline \multirow[t]{4}{*}{ AffMean } & Not Selected & L3-5 & $3.741^{a}$ & .073 & 3.597 & 3.885 \\
\hline & & L6-9 & $3.714^{\mathrm{a}}$ & .086 & 3.545 & 3.884 \\
\hline & Selected & L3-5 & 3.561 & .049 & 3.464 & 3.658 \\
\hline & & L6-9 & 3.452 & .079 & 3.297 & 3.606 \\
\hline
\end{tabular}

a. Based on modified population marginal mean.

6. male $=1$, female $=2 * 1=\mathrm{L} 3-5,2=\mathrm{L} 6-10$

\begin{tabular}{|c|c|c|c|c|c|c|}
\hline \multirow[b]{2}{*}{ Dependent Variable } & \multirow[b]{2}{*}{ male $=1$, female $=2$} & \multirow[b]{2}{*}{$1=\mathrm{L} 3-5,2=\mathrm{L} 6-10$} & \multirow[b]{2}{*}{ Mean } & \multirow[b]{2}{*}{ Std. Error } & \multicolumn{2}{|c|}{ 95\% Confidence Interval } \\
\hline & & & & & Lower Bound & Upper Bound \\
\hline \multirow[t]{4}{*}{ TaskMean } & male & L3-5 & $3.379^{a}$ & .083 & 3.216 & 3.542 \\
\hline & & L6-9 & $3.300^{\mathrm{a}}$ & .127 & 3.049 & 3.551 \\
\hline & female & L3-5 & 3.656 & .038 & 3.581 & 3.730 \\
\hline & & L6-9 & 3.612 & .052 & 3.511 & 3.714 \\
\hline \multirow[t]{4}{*}{ EgoMean } & male & L3-5 & $1.979^{\mathrm{a}}$ & .133 & 1.716 & 2.242 \\
\hline & & L6-9 & $2.325^{\mathrm{a}}$ & .205 & 1.920 & 2.730 \\
\hline & female & L3-5 & 2.038 & .061 & 1.917 & 2.158 \\
\hline & & L6-9 & 1.794 & .083 & 1.630 & 1.958 \\
\hline \multirow[t]{4}{*}{ CommMean } & male & L3-5 & $3.329^{a}$ & .136 & 3.060 & 3.598 \\
\hline & & L6-9 & $3.188^{\mathrm{a}}$ & .210 & 2.773 & 3.602 \\
\hline & female & L3-5 & 3.384 & .062 & 3.261 & 3.507 \\
\hline & & L6-9 & 3.278 & .085 & 3.110 & 3.446 \\
\hline \multirow[t]{4}{*}{ EOOMean } & male & L3-5 & $2.963^{\mathrm{a}}$ & .114 & 2.739 & 3.187 \\
\hline & & L6-9 & $2.250^{\mathrm{a}}$ & .175 & 1.905 & 2.595 \\
\hline & female & L3-5 & 3.158 & .052 & 3.055 & 3.260 \\
\hline & & L6-9 & 3.238 & .071 & 3.099 & 3.378 \\
\hline \multirow[t]{4}{*}{ AffMean } & male & L3-5 & $3.421^{a}$ & .090 & 3.243 & 3.599 \\
\hline & & L6-9 & $3.188^{\mathrm{a}}$ & .139 & 2.913 & 3.462 \\
\hline & female & L3-5 & 3.721 & .041 & 3.640 & 3.803 \\
\hline & & L6-9 & 3.715 & .056 & 3.604 & 3.826 \\
\hline
\end{tabular}

a. Based on modified population marginal mean. 
7. JnrHrsClubs $\sim=2$ (FILTER) * male $=1$, female $=2$ * $1=$ L3-5, 2=L6-10

\begin{tabular}{|c|c|c|c|c|c|c|c|}
\hline \multirow{2}{*}{ Dependent Variak } & \multirow{2}{*}{$\begin{array}{l}\text { JnrHrsClubs } \\
\sim=2 \text { (FILTEF }\end{array}$} & \multirow{2}{*}{\multicolumn{2}{|c|}{ male $=1$, female $=1=L 3-5,2=L 6-1$}} & \multirow[b]{2}{*}{ Mean } & \multirow[b]{2}{*}{ Std. Error } & \multicolumn{2}{|c|}{ 95\% Confidence Interval } \\
\hline & & & & & & Lower Bound & Upper Bound \\
\hline \multirow[t]{8}{*}{ TaskMean } & Not Selected & male & L3-5 & ${ }^{a}$ & & & \\
\hline & & & L6-9 &.$^{\mathrm{a}}$ & & & \\
\hline & & female & L3-5 & 3.669 & .067 & 3.537 & 3.801 \\
\hline & & & L6-9 & 3.552 & .079 & 3.398 & 3.707 \\
\hline & Selected & male & L3-5 & 3.379 & .083 & 3.216 & 3.542 \\
\hline & & & L6-9 & 3.300 & .127 & 3.049 & 3.551 \\
\hline & & female & L3-5 & 3.642 & .036 & 3.572 & 3.712 \\
\hline & & & L6-9 & 3.672 & .067 & 3.541 & 3.804 \\
\hline \multirow[t]{8}{*}{ EgoMean } & Not Selected & male & L3-5 & $a^{a}$ & & & \\
\hline & & & L6-9 &.$^{\mathrm{a}}$ & & & \\
\hline & & female & L3-5 & 2.352 & .108 & 2.139 & 2.564 \\
\hline & & & L6-9 & 2.010 & .127 & 1.760 & 2.259 \\
\hline & Selected & male & L3-5 & 1.979 & .133 & 1.716 & 2.242 \\
\hline & & & L6-9 & 2.325 & .205 & 1.920 & 2.730 \\
\hline & & female & L3-5 & 1.724 & .057 & 1.610 & 1.837 \\
\hline & & & L6-9 & 1.579 & .108 & 1.367 & 1.792 \\
\hline \multirow[t]{8}{*}{ CommMean } & Not Selected & male & L3-5 & $\bar{a}$ & & & \\
\hline & & & L6-9 &.$^{\mathrm{a}} \quad$ & & & \\
\hline & & female & L3-5 & 3.422 & .110 & 3.205 & 3.640 \\
\hline & & & L6-9 & 3.202 & .130 & 2.947 & 3.458 \\
\hline & Selected & male & L3-5 & 3.329 & .136 & 3.060 & 3.598 \\
\hline & & & L6-9 & 3.188 & .210 & 2.773 & 3.602 \\
\hline & & female & L3-5 & 3.346 & .059 & 3.230 & 3.462 \\
\hline & & & L6-9 & 3.353 & .110 & 3.136 & 3.571 \\
\hline \multirow[t]{8}{*}{ EOOMean } & Not Selected & male & L3-5 &.$^{\mathrm{a}}$ & & & \\
\hline & & & L6-9 &.$^{\mathrm{a}}$ & & & \\
\hline & & female & L3-5 & 3.090 & .092 & 2.908 & 3.271 \\
\hline & & & L6-9 & 3.229 & .108 & 3.015 & 3.442 \\
\hline & Selected & male & L3-5 & 2.963 & .114 & 2.739 & 3.187 \\
\hline & & & L6-9 & 2.250 & .175 & 1.905 & 2.595 \\
\hline & & female & L3-5 & 3.225 & .049 & 3.129 & 3.322 \\
\hline & & & L6-9 & 3.248 & .092 & 3.067 & 3.430 \\
\hline \multirow[t]{8}{*}{ AffMean } & Not Selected & male & $\bar{L} 3-5$ & $a^{a}$ & & & \\
\hline & & & L6-9 &.$^{\mathrm{a}}$ & & & \\
\hline & & female & L3-5 & 3.741 & .073 & 3.597 & 3.885 \\
\hline & & & L6-9 & 3.714 & .086 & 3.545 & 3.884 \\
\hline & Selected & male & L3-5 & 3.421 & .090 & 3.243 & 3.599 \\
\hline & & & L6-9 & 3.188 & .139 & 2.913 & 3.462 \\
\hline & & female & $\bar{L} 3-5$ & 3.701 & .039 & 3.624 & 3.778 \\
\hline & & & L6-9 & 3.716 & .073 & 3.571 & 3.860 \\
\hline
\end{tabular}

a. This level combination of factors is not observed, thus the corresponding population marginal mean is not estin 
APPENDIX 15 -Sports Class Environment Scale - Student Actual Short form

DIRECTIONS for survey administration

2. Sit the students in a private (uninterrupted) and comfortable area where they can complete the survey forms. Have them sit separately, so that they may complete the forms privately and in silence.

2. Read the following direction to the students:

This survey has questions about things that generally take place in your gymnastics class. You will be asked how well each statement describes what your class is actually like. There are no "right" or 'wrong" answers. It's not a test - it's just what you think - your opinion.

We have some statements here, and l'm going to explain how to answer each of these. There is a sample statement at the top of the survey page. (see below). I'll read this out aloud and you follow along with me. Think about how well the statement describes what your actual gymnastics class is like. Place a tick in one box.

For each statement you will only check one box. Sometimes this box will be on one side of the page, and other times it might be on the other side of the page.

\begin{tabular}{|l|l|l|l|l|l|l|l|}
\cline { 2 - 7 } \multicolumn{1}{c|}{} & QUESTION & Always & $\begin{array}{l}\text { Nearly } \\
\text { always }\end{array}$ & Often & $\begin{array}{l}\text { Some- } \\
\text { times }\end{array}$ & Seldom & Never \\
\hline early for class & $\begin{array}{l}\text { Gymnasts often arrive } \\
\text { eame }\end{array}$ & & & & & \\
\hline
\end{tabular}

Be sure to give an answer for all questions. If you change your mind about an answer, just cross it out and check another. Some statements in this survey are similar to other statements. Don't worry about this. Simply give your opinion about all statements.

Your responses will be coded and confidential, and will never be seen by your coaches or any one else at your club. DO NOT write your name on the questionnaire

When you finish your survey form, place it back in the small envelope and SEAL the envelope.

3. Give each student an open envelope (with a questionnaire form and pen/pencil inside)

4. Give all students up to 20 mins to complete the questionnaire

5. Collect all envelopes and check that they are sealed. Place then in the large envelope and seal carefully.

Thanks for your help. 
SPORTS CLASS ENVIRONMENT SCALE -Student Actual Short form

CLASS:

DATE:

\section{DIRECTIONS:}

This survey asks questions about things that take place in your gymnastics class. You are being asked how well each statement describes what your class is actually like. It is not a test. There are no right or wrong answers. Think about how well each statement describes what your actual gymnastics class is like and put a tick underneath that box. If you change your mind, just cross it out and tick another. Your answers will be coded and private and will never be seen by your coaches or anyone else at your club.

\begin{tabular}{|c|c|c|c|c|c|c|c|}
\hline & QUESTION & Always & $\begin{array}{l}\text { Nearly } \\
\text { always }\end{array}$ & Often & Seldom & $\begin{array}{c}\text { Almost } \\
\text { never }\end{array}$ & Never \\
\hline Ex. & $\begin{array}{l}\text { Gymnasts often arrive early } \\
\text { for class }\end{array}$ & & & & & & \\
\hline 1 & $\begin{array}{l}\text { Gymnasts in this class put a } \\
\text { lot of energy into what they } \\
\text { do here }\end{array}$ & & & & & & \\
\hline 2 & $\begin{array}{l}\text { In this class, gymnasts get } \\
\text { picked on when they make } \\
\text { a mistake }\end{array}$ & & & & & & \\
\hline 3 & $\begin{array}{l}\text { The coach explains what } \\
\text { will happen if a gymnast } \\
\text { breaks a rule }\end{array}$ & & & & & & \\
\hline$\underline{4}$ & $\begin{array}{l}\text { Gymnasts day-dream in this } \\
\text { class }\end{array}$ & & & & & & \\
\hline 5 & $\begin{array}{l}\text { Gymnasts in this class are } \\
\text { very interested in getting to } \\
\text { know other }\end{array}$ & & & & & & \\
\hline 6 & $\begin{array}{l}\text { In this class we try to } \\
\text { improve those things we } \\
\text { don't do well }\end{array}$ & & & & & & \\
\hline 7 & $\begin{array}{l}\text { In this class, only the best } \\
\text { gymnasts get noticed' by } \\
\text { the coach. }\end{array}$ & & & & & & \\
\hline$\underline{8}$ & $\begin{array}{l}\text { Rules in this class seem to } \\
\text { change a lot }\end{array}$ & & & & & & \\
\hline$\underline{9}$ & $\begin{array}{l}\text { Gymnasts often get bored } \\
\text { and check how soon their } \\
\text { class finishes }\end{array}$ & & & & & & \\
\hline 10 & $\begin{array}{l}\text { Gymnasts in this class are } \\
\text { friendly towards each other }\end{array}$ & & & & & & \\
\hline
\end{tabular}




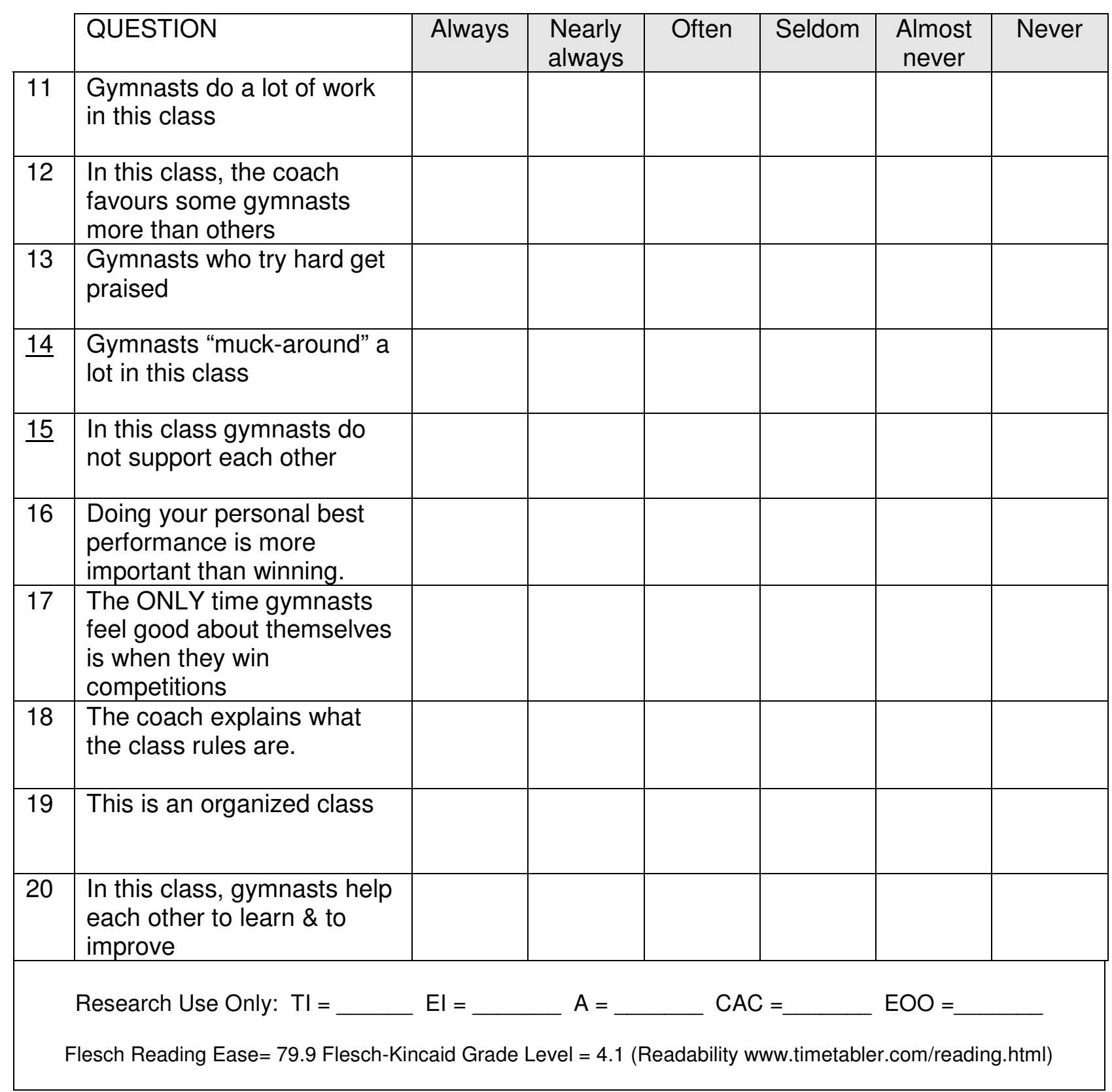

Thank you for completing this survey 


\section{REFERENCES}

Alberto, P. A. \& Troutman, A. C. (1991). Applied behaviour analysis for teachers, (3 ${ }^{\text {rd }}$ ed.). New York: Merrill Pub. Co.

Aldridge, J., Fraser, B., Fisher, D., Trinidad, S. \& Wood, D. (2003). Monitoring the success of an outcomes-based, technology-rich learning environment. Paper presented at the Annual meeting of the American Educational Research Association, April, Chicago, IL.

Ames, C. (1984). Competitive, cooperative, and individualist goal structures: A motivational analysis. In R. Ames \& C. Ames (Eds.), Research on motivation in education: Student motivation (pp.177-207). New York: Academic Press.

Ames, C. (1988). Achievement goals in the classroom: Student's learning strategies and motivational processes. Journal of Educational Psychology, 80(3), 260-267.

Ames, C. (1992). Classrooms: Goals, structures, and student motivation. Journal of Educational Psychology, 84, 261-271.

Ames, C. (1995). Achievement goals, motivational climate and motivational Processes. In G. C. Roberts (Ed.), Motivation in sport and exercise (pp.161176), Champaign, IL: Human Kinetics.

Anderson, G. J. \& Walberg, H. J. (1974). Learning environments. In H. J. Walberg (Ed.), Evaluating educational performance: $A$ source book of methods, instruments and Examples (pp. 81-98). Berkeley, CA: McCutchan.

Barker, R. (1968). Ecological psychology: Concepts and methods for studying the environment of human behaviour. Stanford, CA: Stanford University Press.

Baric, R. (2001). Verification of a motivational climate inventory in a sports setting. Kinesiology, 32(2), 106-116.

Booth, M. L., Macaskill, P., \& McLellan, L. (1997). NSW schools fitness and physical activity survey 1997. Sydney: NSW Department of School Education.

Booth, M. L., Okely, A., Denney-Wilson, E., Dobbins, T. \& Yang., B. (2004). NSW schools fitness and physical activity survey (SPANS) 2006. Sydney: NSW Dept of Health.

Boixad'os, M., Cruz, J., Torregrosa, M., \& Valiente, L. (2004). Relationships among motivational climate, satisfaction, perceived ability, and fair play attitudes in young soccer players. Journal of Applied Sport Psychology, 16, 301-317.

Bompa, T. (1983). Theory and methodology of training. Dubuque, IA: Kendall Hunt.

Byra, M., \& Karp, G. (2000). Data collection techniques employed in qualitative research in physical education teacher education. Journal of Teaching in Physical Education, 19, 246-266.

Carron, A. V. (1980). Social psychology of sport. Ithaca, NY: Mouvement Pub. 
Chi, L. (1993). Predication of achievement-related cognition and behaviours in the physical Domain: A test of the theories of goal perspectives and self-efficacy. Unpublished doctoral dissertation, Purdue University.

Chie-der, D., Chen, S., Hung-yu, C., \& Li-kang, C. (2003). Male and female basketball players' goal orientation, perceived motivational climate, perceived ability and the sources of sport confidence. Sport Journal, 6(3), 1-6. Retrieved 4-1-2005, from http://www.thesportjournal.org/2003Journal/Vol6-No3/confidence.asp

Cooke, N. J. (1999). Knowledge elicitation. In F. Durso, R. Nickerson, S. Schvaneveldt, D. Dumas, D. Lindsay and M. Chi (Eds.), Handbook of applied cognition, New York: John Wiley and Sons.

Creemers, B. P. M. (1994). The effective classroom. London: Cassell.

Cury, F., Biddle, S. H.,Sarrazin, P., \& Famose, J. P. (1997). Achievement goals and perceived ability predict investment in learning a sport task. British Journal of Educational Psychology, 67(3), 293-309.

DeYoung, A. J. (1977). Classroom climate and class success: A case study at the university level. Journal of Educational Research, 70(5), 252-257.

Dorman J. P., Fraser, B., \& McRobbie, C. J. (1997). Relationship between school-level and classroom-level environments in secondary schools, Journal of Educational Administration, 35(1), 91.

Dowdell, T. (1981). The environmental press in a sports class: A pilot study. Unpublished manuscript, University of Queensland, Brisbane, Australia.

Dowdell, T. (2002a). Effective sport coaching -part 1: A literature review. Unpublished manuscript, Griffith University, Brisbane, Australia.

Dowdell, T. (2002b). Effective sport coaching - part 2: A project using conversational analysis methodology. Unpublished manuscript, Griffith University, Brisbane, Australia.

Dowdell, T. (2002c). Effective sport coaching - part 3: A report of discursive analytical methodology. Unpublished manuscript, Griffith University, Brisbane, Australia.

Duda, J. L. (1989) The relationship between task and ego orientation and the percieved purpose of sport among male and female high school athletes. Journal of Sport and Exercise Psychology, 11, 318-335.

Duda, J. L. (2001). Achievement goal research in sport: Pushing the boundaries and clarifying some misunderstandings. In G. C. Roberts (Ed.), Advances in Motivation in Sport and Exercise (pp.129-182). Champaign, ILL: Human Kinetics.

Duda, J. L., Chi, L., Newton, M. L., Walling, M. D., \& Catley, D. (1995). Task and ego orientation and intrinsic motivation in sport. International Journal of Sport Psychology, 26, 40-63.

Duda, J. L., \& Nicholls, J. G. (1992). Dimensions of achievement motivation in schoolwork and sport, Journal of Educational Psychology, 84(3):290-299. 
Duda, J. L., \& Whitehead, J. (1998). Measurement of goal perspectives in the physical domain. In J. L. Duda (Ed.), Advances in sport and exercise psychology measurement: fitness (pp. 21-48). Morgantown, WV: Fitness Information Technology

Dweck, C. S., \& Leggett, E. L. (1988). A social-cognitive approach to motivation and personality. Psychological Review, 95, 256-273.

Epstein, J. L. (1989). Family structures and student motivation: A developmental perspective. In C. Ames \& R. Ames (Eds.), Research on motivation in education, (Vol. 3, pp.259-295), San Diego CA: Academic Press.

Fisher, D. \& Fraser, B. (1981). Validity and the use of My Class Inventory. Science Education, 65, 145-156.

Fraser, B. (1986). Classroom environment. London: CroonHelm.

Fraser, B. (1991). Two decades of classroom research, In B. Fraser \& H. Walberg (Eds.), Educational environments: Evaluation, antecedents, consequences (pp. 3-27). Oxford: Pergamon Press.

Fraser, B. (1994). Research on classroom climate. In D. L. Gabel (Ed.), Handbook on science teaching and learning (pp.493-541). New York: Macmillan.

Fraser, B. (1998). Science learning environments: Assessment, effects and determinants. In B.J. Fraser \& K.G. Tobin (Eds.), International handbook of science education (pp. 527-564). Dordrecht, The Netherlands: Kluwer.

Fraser, B. (2001). Twenty thousand hours: Editor's introduction, Learning Environment. Research, 4,1-5.

Fraser, B. (2002). Learning environments research: Yesterday, today and tomorrow. In S. C. Goh \& M. S. Khine (Eds.), Studies in educational learning environments: An international perspective (pp. 1-25). New Jersey: World Scientific

Fraser, B., Anderson, G. J., \& Walberg, H. J. (1982). Assessment of learning environments: Manual for the Learning Environment Inventory (LEI) and My Class Inventory (MCl). Perth, WA: Western Australian Institute of Technology.

Fraser, B. \& Fisher, D. L. (1982). Predicting students' outcomes from their perceptions of classroom psychosocial environment. American Educational Research Journal 19, 498-518.

Fraser, B., \& Fisher, D. L. (1983). Development and validation of short forms of some instruments measuring student perceptions of actual and preferred classroom learning environment. Science Education, 67(1),115-131.

Fraser, B., \& Fisher, D. L. (1986). Using short forms of classroom climate instruments to assess and improve classroom psychosocial environment. Journal of Research in Science Teaching, 5, 387-413. 
Fraser, B., Fisher, D., \& McRobbie, C. J.. (1996, April). Development, validation and use of personal and class forms of a new classroom environment instrument. Paper presented at the Annual meeting of the American educational research association, New York.

Fraser, B. J., Giddings, G. J., \& McRobbie, C. J. (1995). Evolution, validation and application of a personal form of an instrument for assessing science laboratory classroom environments. Journal of Research in Science Teaching, 32, 399-422.

Fraser, B., \& Rentoul, A. J. (1982). Relationships between school-level and classroom level environment. The Alberta Journal of Educational Research, 28(3), 212-225.

Fraser, B., \& Sinclair, B. (2001). Assessing and changing classroom environments in urban middle schools in Texas, presented at The Annual Conference of the Australian Association for Research in Education - AARE 2001 Conference, 'Crossing Borders: New Frontiers for Education Research', 2-6 December 2001, Fremantle, Australia.

Fraser, B. \& Tobin, K. (1991). Combining qualitative and quantitative methods in classroom environment research. In B. Fraser \& H.J. Walberg (Eds.), Educational environments: Evaluation, antecedents and consequences, (pp.271292). London: Pergamon.

Fraser, B., \& Treagust, D. F. (1986). Validity and use of an instrument for assessing classroom psychosocial environment in higher education. Higher Education, 15, 37-57.

Fry, M. D., \& Duda, J. L. (1997). A developmental examination of children's understanding of effort and ability. Research Quarterly for Exercise and Sport, 68(4), 331-344.

Genn, J. M. (1972). Measurement of schools, colleges and universities: Progress, problems, prospects. The Australian Journal of Education, 16(3), 301-315.

Genn, J. M. (1975). Students perceptions of their actual and ideal diploma in education learning environments. The Australian University, 13(1), 64-81.

Goudas, M., \& Biddle, S. (1994). Perceived motivational climate and intrinsic motivation in school physical education classes. European Journal of Psychology of Education, 9, 241-250.

Goudas, M., Biddle, S., \& Fox, K. (1994). Perceived locus of causality, goal orientations, and perceived competence in school physical education classes. British Journal of Educational Psychology, 64(3),453-463.

Hall, H. K. (1990). A social-cognitive approach to goal setting: The mediating effects of achievement goals and perceived ability. Unpublished doctoral dissertation, University of Illinois at Urbana-Champaign.

Halpin, A. W., \& Croft, D. B. (1963). Organizational climate of schools. Midwest Administration Centre of the University of Chicago. 
Halliburton, A. L., \& Weiss, M. R. (2002). Sources of competence information and perceived motivational climate among adolescent female gymnasts varying in skill level. Journal of Sport \& Exercise Psychology, 24(4), 396-419.

Hite, B. C. \& Arnold, A. (2007). Lighting the fire: Enhancing and maintaining your athlete's Motivation. Technique, 27(6), 14-19

Horn,T. S. (2002). Coaching effectiveness in the sport domain. In T. S. Horn (Ed.), Advances in sport psychology (pp. 309-348). Champaign, IL: Human Kinetics.

Hoy, W., Tarter, R., \& Kottkamp, R. B. (1991). Open schools-healthy schools: Measuring organizational climate. Newbury Park, CA: Corwin Press.

Hunt, D. E. (1975). Person - environment interaction: A challenge found wanting before it was tried. Review of Educational Research, 45(2), 209-230.

Jegede, O., Fraser, B., \& Fisher, D. (1995). The development and validation of a distance and open learning environment scale. Educational Technology Research and Development, 43, 90-93.

Johnson, B. (2002). Extending the study of learning environments: Connecting the field to other literatures. Queensland Journal of Educational Research, 18(2),183-206.

Johnson, K. (1998). Readability. Retrieved $17^{\text {th }}$ February, 2007, from http://www.timetabler.com/reading.html

Johnson, R. B., \& Onwuegbuzie, A. J. (2004). Mixed methods research: A research paradigm whose time has come. Educational Researcher, 33(7), 14-26.

Jourdan, J. G., Bandura, A., \& Banfield, J. (1991).The impact of conceptions of ability on self-regulatory factors and motor skill acquisition. Journal of Sport and Exercise Psychology, 8, 213-226.

Kavussanu, M., \& Roberts, G. C. (1996). Motivation in physical activity contexts: The relationship of perceived motivational climate to intrinsic motivation and selfefficacy. Journal of Sport and Exercise Psychology, 18, 264-281.

Kiley,T., \& Jensen, R. (1998). Cooperating and student teacher's actual and preferred learning environments: A matched pair analysis. Learning Environments Research, 1,181-197.

Lattimore, D. L. (2000). Motivational perspectives of female gymnasts and their coaches. Microform Publications Bulletin: Health, Physical Education and Recreation, Exercise and Sport Sciences, 13(1), University of Memphis.

Langsley, E. (1996) Gymnastics: The art of sport. Switzerland: FIG

Lewin, K. (1936). Principles of topological psychology. New York: McGraw-Hill.

Lewin, K. (1951). Field theory in social science: Selected theoretical papers. London: Routledge \& Kegan Paul. 
Maor, D., \& Fraser, B. (1996). Use of classroom environment perceptions in evaluating inquiry-based computer assisted learning. International Journal of Science Education 18, 401-421.

Mageau, G. V. A. \& Vallerand, R. J. (2003). The coach-athlete relationship: A motivational model, Journal of Sports Sciences, 21, 883-904.

McRobbie, C. J., \& Fraser, B. (1993). Associations between student outcomes and psychosocial science environment. Journal of Educational Research, 87, 78-85.

Michell, J. (1997a). Reply to Kline, Laming, Lovie, Luce and Morgan. British Journal of Psychology, 88(3), 401-407.

Michell, J. (1997b). Quantitative science and the definition of measurement in psychology. British Journal of Psychology, 88(3), 355-384.

Moos, R. H. (1974). Evaluating treatment environments: A social ecological approach. New York: John Wiley \& Sons.

Moos, R. H. (1976). The human context: Environmental determinants of behaviour. New York: John Wiley \& Sons.

Moos, R. H. (1979). Educational climates. In H. J. Walberg (Ed.), Educational environments and effects (pp.79-99). Berkeley, CA: MrCutchen Publishers.

Moos, R.H. (2002). The mystery of human context and coping: An unraveling of clues. American Journal of Community Psychology. 30(1), 67-89.

Moos, R. H., \& Trickett, E.J. (1974). Classroom environment scale manual. Palo Alto. CA: Consulting Psychologists Press.

Moos, R. H., \& Trickett, E.J. (1987). Classroom environment scale manual (2 ${ }^{\text {nd }}$ ed.). Palo Alto. CA: Consulting Psychologists Press.

Murray, H. A. (1938). Explorations in personality. New York: Oxford Uni. Press.

Neuman, W. L. (1997). Social research methods: Qualitative and quantitative approaches ( $3^{\text {rd }}$ ed.). Needham Heights, MA: Allyn \& Bacon.

Newby, M., \& Fisher, D. (1997). Development and use of the computer laboratory environment inventory. Paper presented at the 1997 Conference of Australian Society for Computers in Learning in Tertiary Education (ASCILITE). Curtin University of Technology, Perth.

Newton, M., \& Duda, J. L. (1993). The perceived motivational climate in sport questionnaire-2: Construct and predictive validity. Journal of Sport and Exercise Psychology, 15(suppl.), S59.

Newton, M., Duda, J. L., \& Yin, Z. (2000). Examination of the psychometric properties of the perceived motivational climate in sport questionnaire-2 in a sample of female athletes. Journal of Sport Sciences, 18(4), 275-290. 
Nicholls, J. (1984). Achievement motivation: Conceptions of ability, subjective experience, task choice and performance. Psychological Review, 91, 328-346.

Nicholls J. (1992). The general and the specific in the development and expression of achievement motivation. In G. C. Roberts (Ed.), Motivation in sport and exercise (pp161-176). Champaign, IL: Human Kinetics.

Norton, K., Dollman, J., Klanarong, S., \& Robertson, I. (2001). Kids' sport: Who's playing what? Sport Health, 19(3), 12-14.

Ntoumanis, N., \& Biddle. S. (1998). The relationship between competitive anxiety, achievement goals, and motivational climates. Research Quarterly for Exercise and Sport. Washington, 69(2), 176-188.

Ntoumanis, N., \& Biddle, S. (1999). A review of motivational climate in physical activity. Journal of Sports Science, 17, 643-665.

Nyheim, M., Kavussanu, M., Roberts, G. C., \& Treasure, D. C. (1996, June). Goal orientations, beliefs about success, and satisfaction in summer sports camp participation. Paper presented at the annual conference of the North American society for the Psychology of Sport and Physical Exercise, Ontario, Canada.

Owens, R. G. (1991). Organizational behaviour in education. London: Prentice-Hall Int.

Pace, C. R., \& Stern, G. G. (1958). An approach to the measurement of psychological characteristics of college environments. Journal of Educational Psychology, 49(5), 269-277.

Pace, C. R. (1964). The influence of academic and student subcultures in college and university enrolments. Cooperative Research Project, No.1083, University of California- Los Angeles.

Pallant, J. (2004). SPSS Survival Manual (2nd ed.). Sydney, Allen \& Unwin.

Papaioannou, A. (1994). Development of a questionnaire to measure achievement orientations in physical education. Research Quarterly for Exercise and Sport, 65(1), 11-20.

Papaioannou, A., Marsh, H. W., \& Theodorakis, Y. (2004). A multilevel approach to motivational climate in physical education and sport settings: An individual or a group level construct? Journal of Sport \& Exercise Psychology, 26(1), 90-118.

Paulson, R. (1999). A comparison of the goal orientations and perceived motivational climate of NCAA division 2 basketball players and cross-country runners. Unpublished master's thesis, Sonoma State University, Rohnert Park, CA.

Polgar, S., \& Thomas, S. A. (1995) Introduction to research in the health sciences (3rd.ed.). Melbourne: Churchill Livingstone.

Potrac, P., Brewer, C., Jones, R., Armour, K., \& Hoff, J. (2000). Toward an holistic understanding of the coaching process. Quest, 52,186-199. 
Pensgaard, A. M., \& Roberts, G. C. (2000). The relationship between motivational climate, perceived ability and sources of distress among elite athletes. Journal of Sport Sciences, 18(3), 191-200.

Reinboth, M., \& Duda, J. L. (2004). The motivational climate, perceived ability, and athletes' psychological and physical well-being. Sport Psychologist, 18(3), 237251.

Rickards, T., Bull, E., \& Fisher, D. (2001). Application of the WIHIC in a study of school racial diversity and socio-economic status. In Proceedings of the Western Australian Institute for Educational Research Forum 2001. Retrieved March $20^{\text {th }}$, 2006, from http://education.curtin.edu.au/waier/forums/2001/contents.html

Roberts, G. C. (1992). Motivation in sport and exercise: Conceptual constraints and convergence. In G. C. Roberts (Ed.), Motivation in Sport and Exercise (pp. 161176) Champaign, ILL: Human Kinetics.

Roberts, G. C. (2001). Understanding the dynamics of motivation in physical activity: The influence of achievement goals and motivational processes. In G. C. Roberts (Ed.), Advances in Motivation in Sport and Exercise (pp.1-49). Champaign, ILL: Human Kinetics.

Roberts, G. C., \& Ommundsen, Y. (1996). Effect of goal orientations on achievement beliefs, cognition, and strategies in team sport. Scandinavian Journal of Medicine an Science in Sport, 6, 46-56.

Roberts, G. C., Treasure, D. C., \& Kavussanu, M. (1997). Motivation in physical activity contexts: An achievement goal perspective. In P.Pintrich \& M. Maehr (Eds.), Advances in motivation and achievement (Vol.10, pp.413-447). Stamford, CT: JAI Press.

Rushall, B. S. (1978). Environment specific behaviour inventories: Developmental procedures. International Journal of Sports Psychology, 9, 97-110.

Sanders, L., \& Kidman, L. (1998). Can primary school children perform fundamental motor skills? Journal of Physical Education New Zealand, 31(4),11-13.

Sarrazin, P., Roberts, G. C., Cury, F., Biddle, S., \& Famose J. P. (2002). Exerted effort and performance in climbing among boys: The influence of achievement goals, perceived ability, and task difficulty. Research Quarterly for Exercise and Sport, 73(4), 425-36.

Schmidt, R. A (1991). Motor learning and performance: From principles to practice, Champaign. ILL: Human Kinetics.

Seifriz, J. J., Duda, J. L., \& Chi, L.. (1992). The relationship of perceived motivational climate to intrinsic motivation and beliefs about success in basketball. Journal of Sport and Exercise Psychology, 14, 375-391.

Solmon, M. A. (1996). Impact of motivational climate on students' behaviours and perceptions in a physical education setting. Journal of Educational Psychology, 88, $731-738$. 
Stern, G. G. (1964). B=F (P.E.). Journal of Projective Techniques, 28, 161-168.

Stern, G. G. (1970). The need-press model and its implementation. In G. G. Stern, People in context (pp.6-9). New York: John Wiley \& Sons.

Strauss A., \& Corbin, J. (1998). Basics of qualitative research: Techniques and processes for developing grounded theory. Thousand Oaks, CA, SAGE.

Taylor, P., Dawson, V., \& Fraser, B. (1995, April). Classroom learning environments under transformation: A constructivist perspective. Paper presented at the Annual meeting of the American Educational Research Association, San Francisco, CA.

Teh G. P. L., \& Fraser, B. (1994). An evaluation of computer assisted learning in geography in Singapore. Australian Journal of Educational Technology, 10(1), 55-68.

Theeboom, M., De Knop, P., \& Weiss, M. R. (1995). Motivational climate, psychological response, and motor skill development in children's sport: A field-based intervention study. Journal of Sport and Exercise Psychology, 17, 294 - 311.

Thomas, J. R., Nelson J. K., \& Silverman S. J. (2005). Research methods in physical activity $\left(5^{\text {th }}\right.$ ed.). Champaign, IL: Human Kinetics.

Tobin, K., \& Fraser, B. (1998). Qualitative and quantitative landscapes of classroom learning environments. In B. Fraser \& K. G. Tobin (Eds.), International handbook of science education (pp 623-640). Dordrecht, The Netherlands: Kluwer.

Tomkinson, G. R., Olds, T. S., \& Gulbin, J. (2003). Evolution of the fitness of Australian children: Evidence from the talent search program. Journal of Sports Medicine and Physical Fitness, 43(1), 90-98.

Treasure, D. C., \& Roberts, G. C. (1994). Cognitive and affective concomitants of task and ego goal orientations during the middle school years. Journal of Sport and Exercise Psychology, 16(1), 15-28.

Tremayne, P., \& Tremayne, B. (2004). Children and sport psychology. In T. Morris \& J. Summers (Eds.), Sport Psychology: Theory, applications and issues $\left(2^{\text {nd }} \mathrm{ed}\right.$., pp.529-546). Milton, Austalia: John Wiley \& Sons.

Trickett E. J., \& Moos R. H. (1973). Social environment of junior high and high school classrooms. Journal of Educational Psychology, 65, 93-102.

Trinidad, S., Aldridge, J., \& Fraser, B. (2005). Development, validation and use of the online learning environment Survey. Australasian Journal of Educational Technology, $1(1), 60-81$.

Vlachopoulas, S., \& Biddle, S. J. (1997). Modeling the relation of goal orientation to achievement-related affect in physical education: Does perceived ability matter? Journal of Sport and Exercise Psychology, 19(2), 169-187.

Wald, J. (2003). Parental motivations for enrolling their children in a private gymnastic program. The Sport Journal, 6(3). Retrieved January $2^{\text {nd }}, 2007$, from http://www.thesportjournal.org/2003Journal/Vol6-No3/motivations.asp 
Walkley, J., Holland, B., Treloar, R. \& Probyn-Smith, H. (1993). Fundamental motor skill proficiency of children. Australian Council for Health, Physical Education and Recreation National Journal, 40(3),11-14.

Walberg, H. J. (1981). A psychological theory of educational productivity. In F. Farley \& N. J. Gordon (Eds.), Psychology and education: The state of the union (pp.81108). Berkeley, CA: McCutchan.

Wayne, S. J. \& Liden, R. C. (1995). Effects of impression management on performance ratings: A longitudinal study. Academy of Management Journal, 38(1), 232-260.

White, S. A. (1996). Goal orientation and perceptions of the motivational climate initiated by parents. Pediatric Exercise Science, 8, 122-129.

White, S. A., Duda, J. L., \& Hart, S. (1992). An exploratory examination of the parentinitiated motivational climate questionnaire. Perceptual and Motor Skills, 75, 870880.

Whitehead, J., Andree, K. V., \& Lee, M. J. (1997). Longitudinal interactions between dispositional and situational goals, perceived ability and intrinsic motivation. In $\mathrm{R}$. Lidor \& M. Bar-Eli (Eds.), Innovations in sport psychology: linking theory and practice. Proceedings of the IX World Congress in Sport Psychology: Part II (pp. 750-752). Netanya, Israel: Ministry of Education, Culture and Sport.

Yarrow, A., Millwater, J., \& Fraser, B. (1997). Improving university and primary school classroom environments through pre-service teachers' action research. International Journal of Practical Experience in Professional Education, 1(1), 6893. 
This page left intentionally blank 